\title{
Gravity constraints on structure of the East-West Antarctic lithospheric transition zone
}

\author{
By \\ Sam Treweek
}

\begin{abstract}
A thesis
submitted to Victoria University of Wellington in fulfilment of requirements for the degree of Master of Science in Geophysics
\end{abstract}

School of Geography, Environment and Earth Sciences

Victoria University of Wellington 


\section{Abstract}

The differing structural evolution of cratonic East Antarctica and younger West Antarctica has resulted in contrasting lithospheric and asthenospheric mantle viscosities between the two regions. Combined with poor constraints on the upper mantle viscosity structure of the continent, estimates of surface uplift in Antarctica predicted from models of glacial isostatic adjustment (GIA) and observed by Global Satellite Navigation System (GNSS) contain large misfits. This thesis presents a gravity study of the lithospheric transition zone beneath the Taylor Valley, Antarctica, conducted to constrain the variation in lithological parameters such as viscosity and density of the upper mantle across this region.

During this study 119 new gravity observations were collected in the ice-free regions of the Taylor Valley and amalgamated with 154 existing land-based gravity observations, analysed alongside aerogravity measurements of southern Victoria Land. Gravity data are used to construct 2D gravity models of the subsurface beneath this region. An eastward gradient in Bouguer anomalies of $\sim-1.6 \mathrm{mGal} / \mathrm{km}$ is observed within the Taylor Valley. Models reveal thickening of the Moho from $23 \pm 5 \mathrm{~km}$ beneath the Ross Sea to $35 \pm 5 \mathrm{~km}$ in the Polar Plateau (dipping at $24.5 \pm 7.2^{\circ}$ ), and lithospheric mantle $100 \mathrm{~km}$ thicker in East Antarctica $(\sim 200 \pm 30 \mathrm{~km})$ than West Antarctica $(\sim 90 \pm 30 \mathrm{~km})$.

Models of predicted surface uplift history are used to estimate an asthenospheric mantle viscosity of $2.1 \times 10^{20}$ Pa.s at full surface recovery beneath the Ross Embayment, differing by $\sim 14 \%$ from the viscosity at $50 \%$ recovery. The temperature contrast between lithospheric and asthenospheric mantle is estimated as $\sim 400{ }^{\circ} \mathrm{C}$, equivalent to a viscosity that decreases by a factor of about 30 over the mantle boundary.

Results demonstrate that the history of surface uplift in the study area may be com- 
plicated, resulting in observations of uplift, or subsidence, at GNSS stations. Future work should incorporate additional geophysical methods, such as seismicity and electrical resistivity, improving constraints on gravity models. A better understanding of the surface uplift (or subsidence) history in the Transantarctic Mountains is critical, with implications in reducing uncertainty in GIA models. 


\section{Acknowledgements}

Firstly I would like to thank my supervisor Tim Stern for providing guidance and years of valuable experience towards this project. Without your knowledge on gravity methods and the Transantarctic Mountains this study would not have been possible. A huge thanks also to Simon Lamb, whose enthusiasm, positivity, and fascinating discussion facilitated development of this study. Also, thanks to Steven Kesler for working alongside me on this project.

Special thanks to my friends Josh Lee, Brenton Tozer, Emily Moore, Alistair Stronach, and everyone else in CO421. Without you this year would have been infinitely more difficult and nowhere near as fun! The biggest thanks goes to my family for providing endless kindness, understanding, and emotional support over the past five years, it is your encouragement that has motivated me to be where I am today.

Thank you to all staff at Victoria University of Wellington who provided computational and technical support with a smiling face every day. It has been a pleasure to be a part of SGEES with you all.

Finally I would like to thank Antarctica New Zealand and the New Zealand Marsden Fund for providing the funding and field support that made this project possible. 


\section{Contents}

List of Figures ix

List of Tables $\quad$ xiii

$\begin{array}{lll}1 & \text { Introduction } & 1\end{array}$

\begin{tabular}{lll}
\hline 2 & Background & 5
\end{tabular}

$2.1 \quad$ Study Area $\ldots \ldots \ldots \ldots \ldots$

2.1 .1 The Taylor Valley . . . . . . . . . . . . . . . . . . . 5

2.1 .2 Tectonic setting of the Transantarctic Mountains . . . . . . . . 7

$2.1 .3 \quad$ Geological setting of southern Victoria Land . . . . . . . . . . . 11

$2.1 .4 \quad$ Glacial history of the Taylor Valley . . . . . . . . . . . . . . . . 18

2.2 Previous Studies . . . . . . . . . . . . . . . . . . . . . . 20

$2.2 .1 \quad$ Drilling projects . . . . . . . . . . . . . . . . . 20

2.2 .2 Gravity studies . . . . . . . . . . . . . . . . . 23

$2.2 .3 \quad$ Seismic constraints on lithospheric structure . . . . . . . . 26

2.3 Gravity model constraints . . . . . . . . . . . . . . . . . . . . . . . . . 29

2.3 .1 Seismic studies . . . . . . . . . . . . . . . . . . . . . . . . . 29

2.3 .2 Gravity data and models . . . . . . . . . . . . . . . . . 34

2.3 .3 Rock density estimates . . . . . . . . . . . . . . . . . . 35

$\begin{array}{lll}3 & \text { Methods } & 37\end{array}$

3.0 .1 Instrumentation . . . . . . . . . . . . . . . . . . . . 37

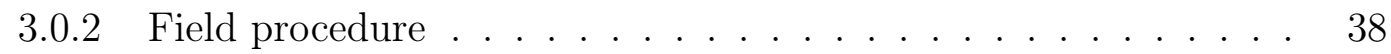

3.1 Gravity data processing $\ldots \ldots \ldots$. . . . . . . . . . . . . . . . . . . . . . 38

$3.1 .1 \quad$ Background . . . . . . . . . . . . . . . . . . . . . . . 38

3.1 .2 Gravity anomaly reduction . . . . . . . . . . . . . . . . . . . 40

3.1 .3 The Bouguer anomaly . . . . . . . . . . . . . . . . . . . 51

3.1 .4 Separation of regional and residual gravity anomalies . . . . . . 51

3.2 Uncertainty in gravity data $\ldots \ldots \ldots \ldots$. . . . . . . . . . . . 53 
3.2 .1 Instrument error and drift . . . . . . . . . . . . . . . . . 53

3.2 .2 GNSS uncertainty . . . . . . . . . . . . . . . . 54

3.2 .3 Terrain correction uncertainty . . . . . . . . . . . . . . 54

3.2 .4 Total uncertainty . . . . . . . . . . . . . . . . 56

3.3 Gravity modelling . . . . . . . . . . . . . . . . . . . . . 57

3.3 .1 Two-dimensional gravity modelling . . . . . . . . . . . . . 57

$\begin{array}{lll}4 & \text { Results } & 59\end{array}$

4.1 Gravity data . . . . . . . . . . . . . . . . . . . . 59

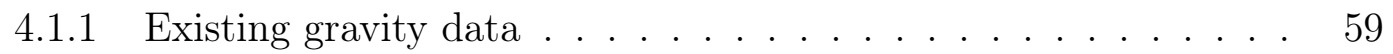

4.1 .2 New gravity data in this study . . . . . . . . . . . . . . . 59

4.1 .3 Amalgamation of gravity observations . . . . . . . . . . . . . 60

4.2 Gravity Models . . . . . . . . . . . . . . . . . . . . 63

4.2 .1 Introduction . . . . . . . . . . . . . . . . . 63

4.3 Local gravity models . . . . . . . . . . . . . . . . . . . . 63

4.3 .1 New Harbour gravity models . . . . . . . . . . . . . . . . 64

4.3 .2 Gravity models from previous studies . . . . . . . . . . . . . . 66

4.4 Regional gravity models $\ldots \ldots \ldots$. . . . . . . . . . . . . . . . 69

4.4 .1 Gravity models of Profiles 1, 2, and 3 . . . . . . . . . . . . . 69

4.5 Moho shape and depth beneath the TAM . . . . . . . . . . . . . . 89

$\begin{array}{lll}5 & \text { Discussion } & 93\end{array}$

5.1 Introduction $\ldots \ldots \ldots \ldots$

5.2 Isostatic balance of gravity models and uplift of the TAM . . . . . . . . 93

5.3 Estimates of viscosity $\ldots \ldots \ldots$. . . . . . . . . . . . . . . . 96

$5.3 .1 \quad$ Asthenospheric mantle viscosity in the Ross Embayment . . . . 99

5.3 .2 Viscosity contrast in the upper mantle . . . . . . . . . . . . . . 104

5.4 Convective removal of the lithosphere . . . . . . . . . . . . . . 106

5.5 Study uncertainties and future recommendations . . . . . . . . . . . . . 109

$\begin{array}{lll}6 & \text { Conclusions } & 111\end{array}$

\begin{tabular}{ll}
\hline A Appendix & 113
\end{tabular}

A.1 GNSS and DEM elevation differences . . . . . . . . . . . . . . . . . 113

A.2 Observed gravity anomalies . . . . . . . . . . . . . . . 115

A.3 Gravity data . . . . . . . . . . . . . . . . . . 117 


\section{List of Figures}

1.1 GIA-model predicted contribution of the Antarctic Ice Sheet to future GMSL. . . . . . . . . . . . . ..... 3

2.1 Map of the Taylor Valley, Antarctica . . . . . . . . . . . . . . . 6

2.2 Map of the tectonic setting of Antarctica . . . . . . . . . . . . . . 8

2.3 Schematic gravity model of flexure across the TAM . . . . . . . . . . . 10

2.4 Distribution of Skelton Group units in southern Victoria Land . . . . . 12

2.5 Distribution of Beacon Supergroup units in Southern Victoria Land . . 14

2.6 Ferrar Dolerite intrusions on an unnamed peak east of the Taylor Glacier 15

2.7 Annotated aerial image of lithological units at the head of the Taylor Valley . . . . . . . . . . . . . . . . . . . . . . . . 17

2.8 Map of DVDP borehole locations in McMurdo Sound and the Dry Valleys 22

2.9 Topographic map of ETV and DVDP boreholes in the Taylor Valley . . 23

2.10 Bouguer gravity anomaly map of the McMurdo Dry Valleys. . . . . . . 24

2.11 Map of existing gravity survey lines. . . . . . . . . . . . . . . 25

2.12 Tomography models of relative velocity perturbations in Southern Victoria Land . . . . . . . . . . . . . . . . . . . . . . . . . 28

2.13 S-wave velocity variations of the subsurface below the Ross Sea and TAM 31

2.14 Subsurface Moho topography across the TAM front . . . . . . . . . . . 32

2.15 Free-air gravity anomalies, surface topography, and Moho and bedrock depths across the TAM front. . . . . . . . . . . . . . 33

2.16 Existing gravity model of the central Taylor Valley. . . . . . . . . . . . 35

$3.1 \quad$ Map of new and existing gravity stations in the Taylor Valley . . . . . 39

3.2 Gravity measurement drift over two days . . . . . . . . . . . . . . . . 42

3.3 Linear and non-drift in gravity observations . . . . . . . . . . . . . . 42

3.4 Earth's topographic, ellipsoidal, and geoidal surfaces . . . . . . . . . 45

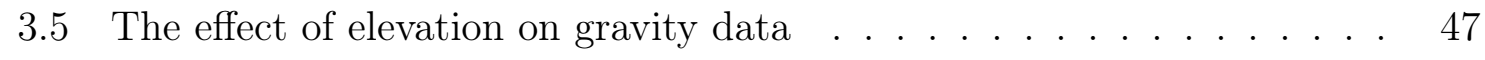

3.6 The effect of rock mass below an observation point on gravity data . . 47 
3.7 The effect of topography on gravity data . . . . . . . . . . . . . . . 48

3.8 The Hammer (1939) graticule used in terrain corrections . . . . . . . . 49

3.9 Terrain correction grid used in Oasis Montaj . . . . . . . . . . . . . . . 50

3.10 Separation of regional and residual gravity anomalies . . . . . . . . . . 52

3.11 Comparison of GNSS and DEM elevations measured in the Taylor Valley 55

3.12 Schematic of a two-dimensional gravity model . . . . . . . . . . . 57

4.1 Comparison of existing observed and DEM-measured elevations along Line B . . . . . . . . . . . . . . . . . . . 62

4.2 Gravity Model Version 1 of New Harbour. . . . . . . . . . . . . . . . . 64

4.3 Gravity Model Version 2 of New Harbour . . . . . . . . . . . . . . . . . 65

4.4 Existing gravity model of Line C in the Taylor Valley . . . . . . . . . . 67

4.5 Existing gravity model of Line D in the Taylor Valley . . . . . . . . . . 68

4.6 Gravity effect of a vertical fault in a two-layer subsurface structure . . 72

4.7 Basic three-layer subsurface structure assumed in this study . . . . . . 73

4.8 Gravity edge effect for two mass anomalies in Profile 1 . . . . . . . . 75

4.9 Gravity edge effect for two mass anomalies in Profile 3 . . . . . . . . . 76

4.10 Overview map of profiles used in regional gravity modelling. . . . . . . 78

4.11 Gravity model of Profile 1 with a uniform mantle density . . . . . . . . 80

4.12 Model 1A of Profile 1 . . . . . . . . . . . . . . . . . 81

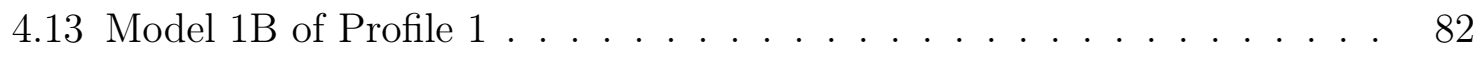

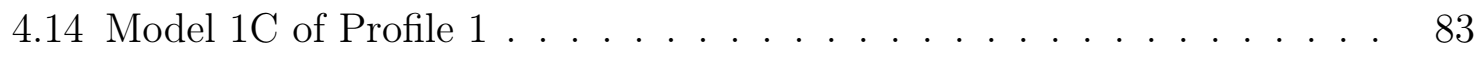

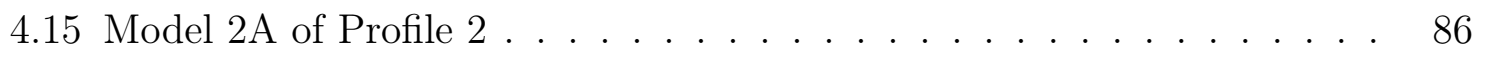

4.16 Overview map of Profile 3 . . . . . . . . . . . . . . . . . . . 87

4.17 Model 3A of Profile 3 . . . . . . . . . . . . . . . . . . 88

4.18 Confidence region of the bottom crustal step point in gravity models. . 90

4.19 Confidence region of the top crustal step point in gravity models . . . . 91

$5.1 \quad$ GIA-model-calculated and GNSS-observed surface uplift in Antarctica. 97

5.2 GNSS-observed versus model-predicted surface uplift-rates in Antarctica 98

5.3 Theoretical uplift history for central regions of two subsurface geometries 100

5.4 Theoretical uplift history of a square-edged, cylindrical depression. . . . 103

5.5 Vertical $\mathrm{v}_{\mathrm{s}}$ cross-section across the TAM . . . . . . . . . . . . . 108

A.1 Comparison of existing observed and DEM-measured elevations along Line A . . . . . . . . . . . . . . . . . . . . . 113

A.2 Comparison of existing observed and DEM-measured elevations along Line C . . . . . . . . . . . . . . . . . . . . . . . . 114 
A.3 Comparison of existing observed and DEM-measured elevations along Line D . . . . . . . . . . . . . . . . . . . . . . . . . . 114

A.4 Residual gravity anomalies along Line Y . . . . . . . . . . . . . . . . . 115

A.5 Bouguer gravity anomalies along Line $\mathrm{X}$. . . . . . . . . . . . . . . . . 116 


\section{List of Tables}

$2.1 \quad$ Crustal depths and velocity perturbations in East and West Antarctica 30

3.1 Uncertainties in Bouguer anomalies . . . . . . . . . . . . . . . . 56

4.1 Parameters of the crustal step from gravity models . . . . . . . . . . . 89

4.2 Confidence region of the crustal step in Model 1C . . . . . . . . . . . . 92

5.1 Pressure at the base of three columns in Model 1C . . . . . . . . . . 95

5.2 Asthenospheric mantle viscosities in the Ross Embayment assuming no lithosphere . . . . . . . . . . . . . . . . . 102

5.3 Asthenospheric mantle viscosities in the Ross Embayment with a lithosphere ........................... 104

A.1 Details of existing and new gravity measurements modelled in this study. 118 


\section{Chapter 1}

\section{Introduction}

The transition between East and West Antarctica is unusual for an intra-continental region in that it displays strong geophysical signals that are suggestive of geologically young tectonics. These include a strong horizontal gradient in upper mantle shear-wave $\left(\mathrm{v}_{\mathrm{s}}\right)$ velocities (Ritzwoller et al., 2001), a steep gradient in gravity anomalies (Smithson, 1972), and uplift of one of the longest and highest (in terms of relief) mountain ranges in the world (Stern \& ten Brink, 1989), forming the Transantarctic Mountains (TAM). Defining the detailed deep structure in this region is challenging with the existing regional-scale seismic tomography because of the sparse distribution of observations that gives rise to limited resolution in both depth and lateral position.

Gravity studies are useful in defining the structure of the East-West Antarctic transition, because the gradient of the long-wavelength gravity anomalies is a direct measure of the depth of the transition, and the amplitude of the change in gravity is a measure of the anomalous mass distribution within the transition zone. Gravity analysis is particularly useful where observations can be made in ice free regions like the Dry Valleys as the presence of low density ice introduces a large unknown into the modelling process. Past gravity studies (ten Brink et al., 1997; ten Brink et al., 1993; Stern \& ten Brink, 1989) have modelled crustal and mantle structure across the East-West Antarctic transition in terms of simple first-order processes, but were limited by the lack of seismic constraints at the time. New seismic studies (Priestley et al., 2018; Shen et al., 2018a Priestley \& McKenzie, 2013) are now available that bear on lithospheric structure, but even these are tomography based and necessarily smoothed results. Note 
that the lithosphere in this study is defined as the thermally conductive and cooler lid resting on the underlying convective mantle interior, and hence the base of the lithosphere marks a density contrast in the mantle - see Lamb et al. (2020), Priestley et al. (2018) and Priestley and McKenzie (2013).

Antarctica is a major contributor to climate and sea level change, containing $90 \%$ of the world's ice and potentially contributing up to $15 \mathrm{~m}$ of sea level rise by 2500 (DeConto \& Pollard, 2016). An understanding of how these ice sheets have changed over the last $\sim 20,000$ years is critical to global models of glacial isostatic adjustment (GIA) (Whitehouse et al., 2019), but remains poorly constrained. Present-day land-sea-level changes are still influenced by ice removed following the Last Glacial Maximum (LGM) as a result of the ongoing viscous Earth's response to the relatively rapid removal of the surface load. Hence, knowledge of how much ice was shed from Antarctica in the past is vital for quantifying present day land-sea-level changes in GIA models. Global positioning system (GNSS) monitoring at solid rock sites provides one method of measuring the post-glacial response to past ice removal. GNSS stations in the ice-free Dry Valleys of the TAM are an important part of this monitoring.

The observed uplift rates in the TAM are $\sim 5 \mathrm{~mm} / \mathrm{yr}$ less than what is predicted in models of glacial isostatic adjustment that use a fixed and standard viscosity for the upper mantle. This reflects uncertainty in the two key parameters controlling GIA models: the viscosity of the upper mantle and the past changes in surface ice cover and topography in Antarctica. East Antarctica (EANT) is an old, stable craton with predicted high mantle viscosities (Whitehouse et al., 2019; van der Wal et al., 2015) compared to younger West Antarctica (WANT) which underwent significant extension and subsidence in the Late Cretaceous (O'Donnell et al., 2017), resulting in different rates of post-glacial rebound (PGR) for the two regions.

Whitehouse et al. (2019) modelled the contribution from the Antarctic Ice Sheet (AIS) to Global Mean Sea Level (GMSL) relative to modern under future climate warming in which $\mathrm{CO} 2$ is doubled and the oceans are warmed by $\sim 2{ }^{\circ} \mathrm{C}$ (Figure 1.1). Three simulations with differing lithospheric thicknesses and viscosities were modelled. GMSL relative to modern sea level decreases proportionally with viscosity in the models, demonstrating the importance of constraining the contrast in Antarctic upper and 


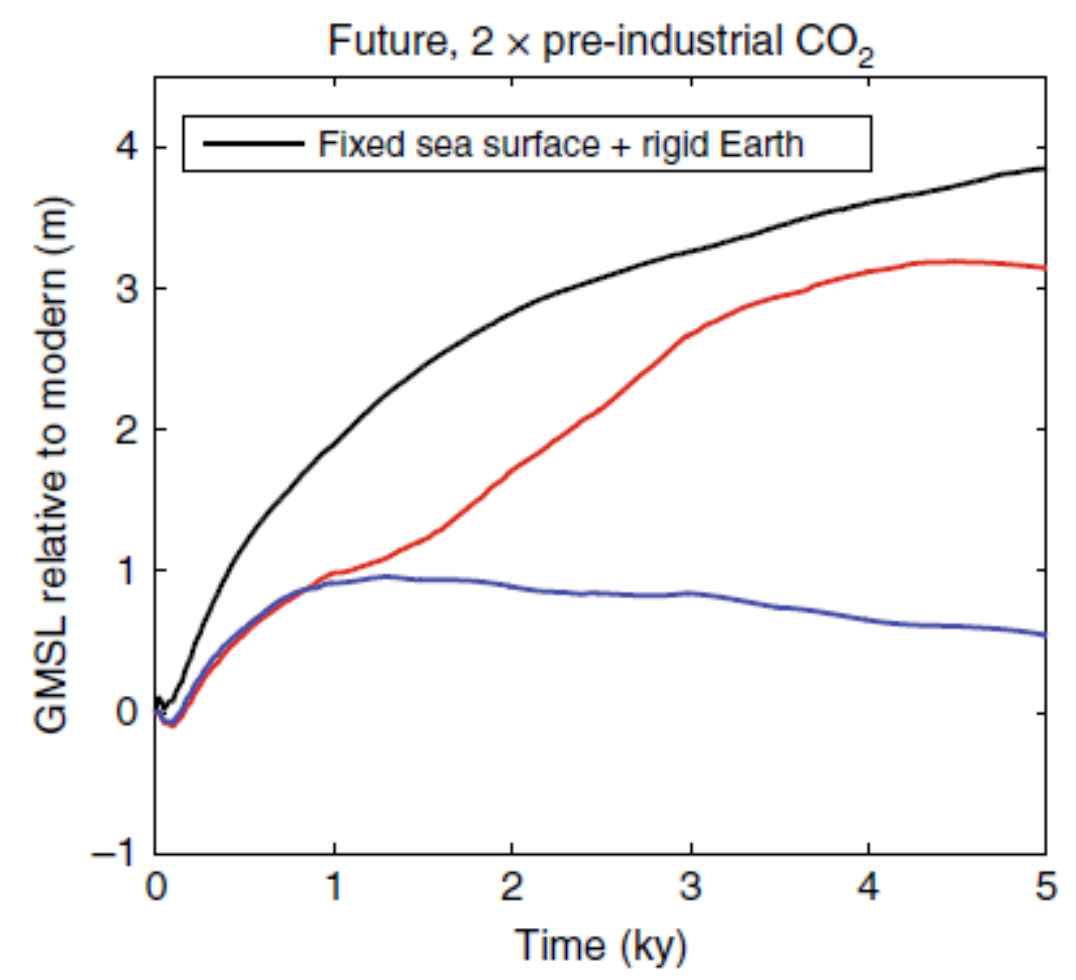

Figure 1.1: The glacial isostatic model-predicted contribution from the Antarctic Ice Sheet (AIS) to future global mean sea level (GMSL) relative to modern under future climate warming. $\mathrm{CO} 2$ is doubled and the oceans are warmed by $\sim 2{ }^{\circ} \mathrm{C}$ at the start of the simulations. Three simulations are modelled: An Elastic Lithosphere Relaxing Asthenosphere (ELRA) bedrock deformation model with relaxation time of $3 \mathrm{ka}$ (black line); an Earth model with $120 \mathrm{~km}$ thick lithosphere and upper and lower mantle viscosities of 0.5 and $5 \times 10^{21}$ Pa.s respectively (red line); an Earth model with $50 \mathrm{~km}$ thick lithosphere, upper and lower mantle viscosities of 0.2 and $3 \times 10^{21}$ Pa.s respectively, and a low viscosity zone of $10^{19}$ Pa.s down to a depth of $200 \mathrm{~km}$ (blue line). Figure from Whitehouse et al. (2019).

lower mantle viscosity and thickness of the lithosphere in models of GIA.

This study aims to: i) improve understanding of the crustal and lithospheric structure beneath the TAM, ii) and further constrain lateral variations in density and viscosity in the mantle across the East-West Antarctica transition zone.

To achieve these aims, new gravity data have been collected in the $\sim 80 \mathrm{~km}$ long icefree Taylor Valley of the McMurdo Dry Valleys, southern Victoria Land over a seven day period in the 2018/19 Austral Summer season. This is one of few regions with extensive bedrock exposure on the continent, where there is a reasonable dataset of existing land-based and aero gravity observations (Scheinert et al., 2016; Hicks \& Bennett, 1981; Smithson, 1972) which can be incorporated into the study. Gravity measurements were made at spaced intervals along the valley and combined with more 
regional aerogravity measurements (Scheinert et al., 2016) to develop a regional-scale understanding of the transition zone. These were used to refine the shape and density contrasts across the Moho and base of the lithosphere, already constrained by seismic data (Priestley et al., 2018, Shen et al., 2018a Finotello et al., 2011; Hansen et al., 2009: Bannister et al., 2003). Converting modelled density contrasts to temperatures helps to define mantle viscosity (using the well known relation between temperature and viscosity) and how it varies between East and West Antarctica.

This research is not only important from a geological perspective, but also has implications in developing our understanding of post-glacial rebound using modern GNSS data. Revision of GIA models will help to improve predictions of future ice mass loss and melt contribution to changes in global sea level, which is likely to be significant in the context of a warming climate. 


\section{Chapter 2}

\section{Background}

\subsection{Study Area}

\subsubsection{The Taylor Valley}

This study was carried out in the Taylor Valley, one of three major east-west "Dry Valleys" in southern Victoria Land, Antarctica (Figure 2.1) (Angino et al., 1962). The $85 \mathrm{~km}$-long Taylor Valley lies between the Polar Plateau and McMurdo Sound (Armstrong et al., 1968), bounded to the north by the Asgard Range and the south by the Kukri Hills, separating it from the Wright Valley and Ferrar Glacier respectively. The Taylor Glacier, which is an active outlet glacier draining down-valley from the Polar Ice Cap, occupies the upper $50 \mathrm{~km}$ of the valley (Angino et al., 1962). The remaining $35 \mathrm{~km}$ is ice-free, with surface cover composed of glacial till and exposed basement rock (Cox et al., 2012). Precipitation in the Dry Valleys is low, averaging less than $10 \mathrm{~cm}$ annually and reaching as low as $0.6 \mathrm{~cm}$ in the Wright Valley (Fountain et al., 1999; Bromley, 1985). Small alpine glaciers on the valley walls flow from the surrounding Asgard Range and Kukri Hills (Armstrong et al., 1968).

The cross profile of the Taylor Valley consists of a narrow, inner U-shaped valley carved by multiple glacial advances (Armstrong et al., 1968). Filling the valley floor are glacial lakes, many of which were formed during the Taylor Glaciation $(\sim 40,000$ years ago) as a result of an extensive glacial advance that blocked the Dry Valleys from McMurdo Sound (Denton et al., 1989, Péwé, 1960). The mean annual temperature is $\sim-16$ to 


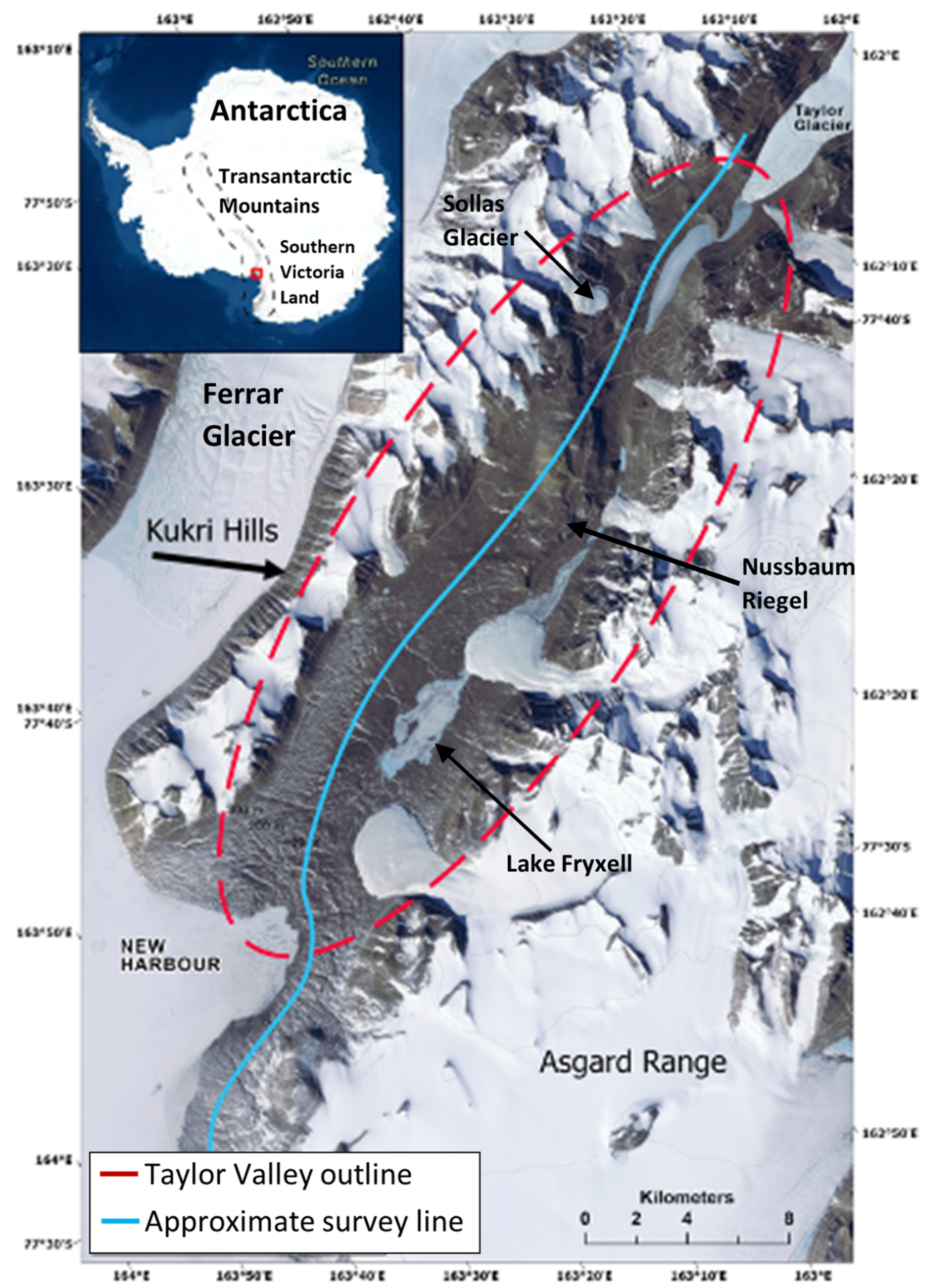

Figure 2.1: Map of the Taylor Valley, southern Victoria Land. The approximate extent of the ice-free zone in the Taylor Valley (dotted red line) and new and existing gravity observations (blue line) are displayed. The inset map (top left) shows the position of the study area with respect to the Antarctic Continent (red box) and the approximate extent of the Transantarctic Mountains (dotted black line). 
$-21^{\circ} \mathrm{C}$ (Fountain et al., 1999), so that lakes have perennial frozen ice cover 3- $6 \mathrm{~m}$ thick (Obryk et al., 2014). During the warm periods of the austral summers, meltwater flows into the lakes from the surrounding glaciers (Conovitz et al., 1998; Chinn, 1993).

\subsubsection{Tectonic setting of the Transantarctic Mountains}

The Antarctic continent is broadly comprised of two domains: the stable craton of East Antarctica; and West Antarctica, a Cenozoic-Mesozoic amalgamation of younger crustal blocks which also make up the West Antarctic Rift System (WARS) (Cox et al., 2012). The Transantarctic Mountains are a major geologic boundary, separating East and West Antarctica and bounding the thick ice sheet of the Polar Plateau (Figure 2.2. (Studinger et al., 2004).

The West Antarctic Rift System formed $~ 85$ Ma as a result of crustal extension between East and West Antarctica during the break-up of part of Gondwana (Cox et al., 2012, Lawver \& Gahagan, 1994). The Transantarctic Mountains form the rift shoulder of the WARS (Figure 2.2), with boundary faults lying immediately offshore and following the coast (Henrys et al., 2008; Fitzgerald, 2002).

Southern Victoria Land is positioned between the Polar Plateau of East Antarctica and the Victoria Land Basin (VLB) of West Antarctica. The VLB is a fault-bounded sedimentary basin located offshore beneath McMurdo Sound within the West Antarctic Rift System (Cox et al., 2012). Since the Jurassic, southern Victoria Land has acted as a single tectonic block bounded on three sides by high angle normal faults. Two of these faults dip East-West, located between the Mackay and Ferrar Glaciers. The remaining fault is positioned east of the Nussbaum Riegel, and is orientated northsouth (Wrenn \& Webb, 1982; Gunn \& Warren, 1962). North-south trending faults, along with similar faults in the lower Wright Valley, compose a major frontal fault zone of the Transantarctic Mountains (Wilch et al., 1993).

Significant uplift of the TAM is inferred to have occurred between the early Eocene ( $55 \mathrm{Ma}$ ) and Oligocene ( 30 Ma) (Elliot, 2013; Fitzgerald et al., 1992), although some uplift and exhumation may have occurred in the Late Cretaceous (Fitzgerald, 2002 Fitzgerald, 1995). During this period, exhumation of the mountains is estimated to be $6 \mathrm{~km}$ (Cox et al., 2012). As a result of uplift, tilting, and erosion of the TAM, 


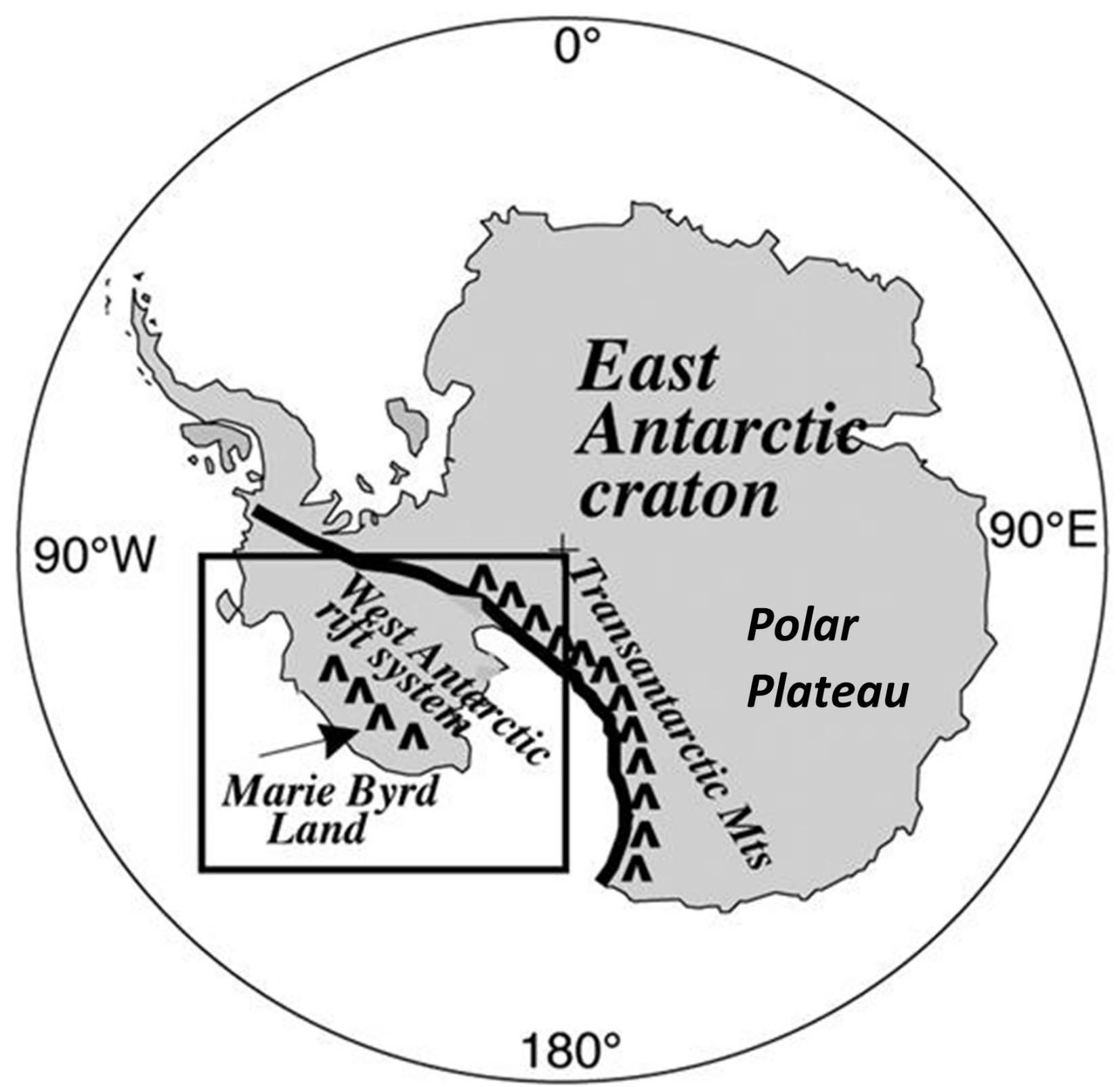

Figure 2.2: Map of Antarctica with positions of the West Antarctic Rift System (WARS) and Transantarctic Mountains (TAM) marked. The southern extent of the WARS is defined by the TAM (black triangles), outlined by the black line. The Victoria Land Basin is located within the WARS against the TAM. The black box defines the study area of Winberry and Anandakrishnan (2004). Figure from Winberry and Anandakrishnan (2004) 
basement rocks underlying southern Victoria Land are widely exposed near the Ross Sea. The age of the rock units decreases inland towards the Polar Plateau (Cox et al., 2012).

Various mechanisms of uplift have been proposed to explain the origin of the TAM. Fitzgerald et al. (1986) suggested that both uplift of the Transantarctic Mountains and subsidence of the Ross Embayment since the Early Cenozoic are a result of passive rifting. A westward dipping crustal detachment fault zone is the fundamental control in development of this extensional orogen, allowing translation of extensional strain from crustal to subcrustal levels beneath the TAM.

Stern and ten Brink (1989) and ten Brink et al. (1997) attributed uplift of the TAM to intrusion of hotter mantle in the WARS below the TAM and thicker crust of the Polar Plateau. This mantle intrusion provides a thermal load along the edge of East Antarctic lithosphere, leading to broad-scale flexure and uplift. Stern and ten Brink (1989) produced a simplified model of the lithospheric structure between East and West Antarctica across the TAM front (Figure 2.3) based on gravity anomalies. This had a vertical boundary between East and West Antarctic upper mantle, associated with a density contrast that lay beneath the Transantarctic Mountains. Lower density mantle provided buoyancy that supported uplift of the TAM and flexure beneath the Polar Plateau.

This model is supported by regional- (Shen et al., 2018b; Hansen et al., 2009, Lawrence et al., 2006) and continental-scale (Brenn et al., 2017; Hansen et al., 2014) seismic tomographic images which have revealed relatively low upper-mantle velocities in the Ross Embayment suggestive of higher mantle temperatures relative to the Polar Plateau, extending to depths of $\sim 300 \mathrm{~km}$ and up to $\sim 100 \mathrm{~km}$ horizontally beneath the TAM front. Brenn et al. (2017) indicated that thermal loading plays a critical role in observed uplift and elevations of the TAM, and is consistent with a flexural origin for the Mountains.

Studinger et al. (2004) attributed formation of the TAM to rift flank uplift and climateinduced erosional unloading, supported isostatically by a $\sim 5 \mathrm{~km}$ thick crustal root beneath the mountain range. Seismically-derived crustal and lithospheric thickness estimates (Priestley et al., 2018, Brenn et al., 2017) reveal minimal evidence for a 


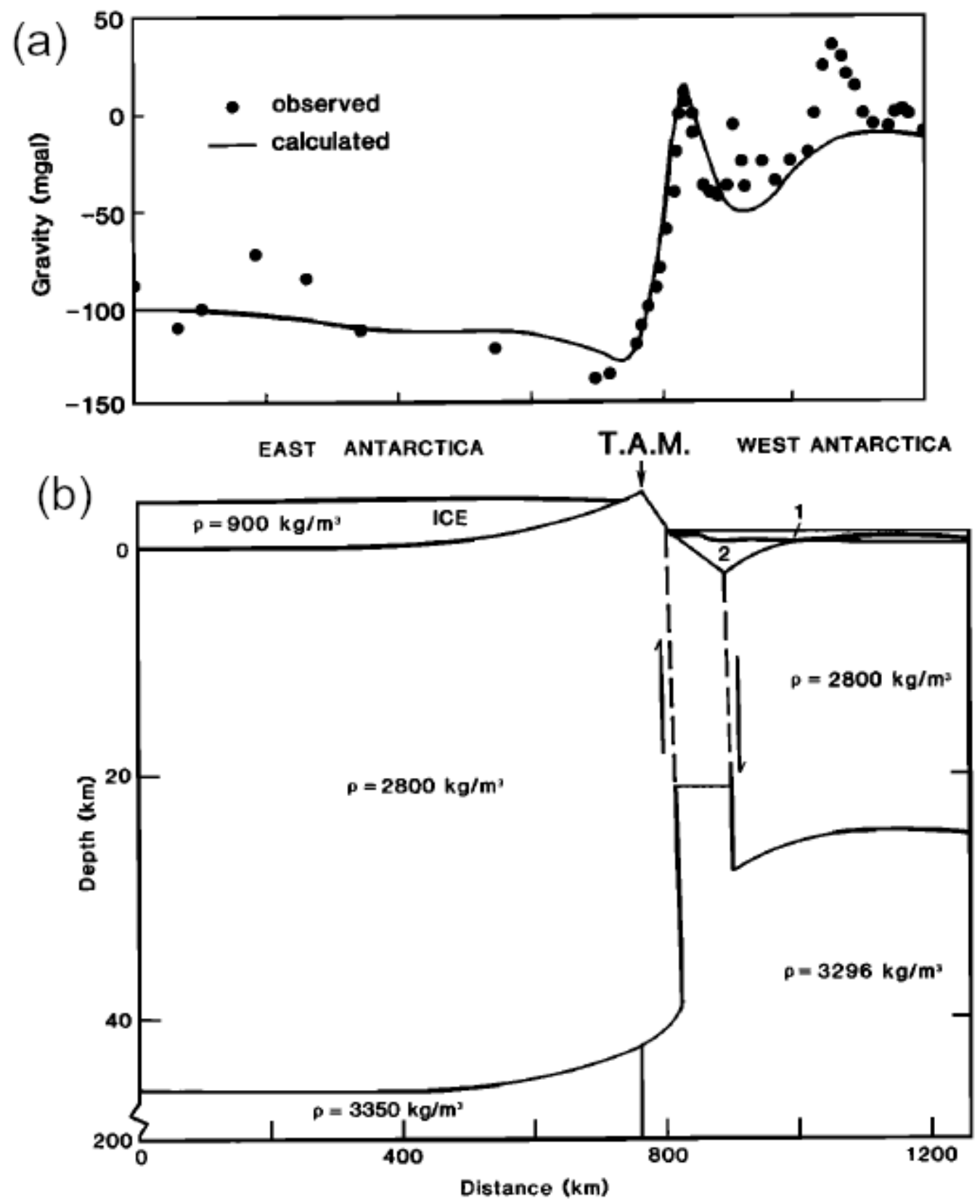

Figure 2.3: Gravity model of the subsurface structure beneath East and West Antarctica. (a) Observed (black circles) and calculated (solid line) gravity anomalies along a profile measured across the Ross Embayment (West Antarctica) and into the Transantarctic Mountains (T.A.M; see Stern and ten Brink, 1989) Bouguer anomalies are modelled on land, while free-air anomalies are used offshore. Bouguer corrections are made for ice above and below sea level. (b) Gravity model of the subsurface structure beneath the measured profile. Bodies labelled 1 and 2 are seawater and sediments of density 1000 and $2400 \mathrm{~kg} / \mathrm{m}^{3}$ respectively. The best fit between calculated and observed anomalies was achieved at a compensation depth of $200 \mathrm{~km}$ and by advancing the upper mantle density contrast between East and West Antarctica $50 \mathrm{~km}$ inland beneath the TAM. Figure from Stern and ten Brink (1989) 
root beneath the TAM, indicating a crustal thickness comparable to, or thinner than, that found below much of the Polar Plateau (Shen et al., 2018b; Hansen et al., 2015). However, the disagreement in these studies demonstrates the need for gravity models to resolve the question of the uplift mechanism of the TAM.

\subsubsection{Geological setting of southern Victoria Land}

\section{Basement rock}

In southern Victoria Land, metasedimentary rocks of the Skelton Group are the oldest rocks exposed. Mapped along the Ross Sea coast (Figure 2.4), this group was deposited in a Neoproterozoic rift setting post $650 \mathrm{Ma}$ (Cox et al., 2012 Cook, 2007). Intense deformation and metamorphism have destroyed sedimentary structures and stratigraphy (Cox et al., 2012), leaving only a general indication of the original lithological units.

The Skelton Group in the region surrounding the Taylor Valley consists of interlayered garnet schist, felsic gneiss, and amphibolite (Cox et al., 2012) intruded by plutons of the Granite Harbour Intrusive Complex (Gunn \& Warren, 1962), emplaced between 550 and $530 \mathrm{Ma}$. These are grouped into four petrogenetic suites (Cox et al., 2012):

- the Koettlitz Glacier Alkaline suite; predominately mafic rocks.

- the Dry Valleys 1a (DV1a) Suite; predominately hornblende-biotite granitoid rocks.

- the Dry Valleys 1b (DV1b) Suite; predominately biotite granitoid rocks.

- the younger Dry Valleys 2 Suite; predominately discordant granitoid plutons.

Pluton intrusions in the Asgard Range and Kukri Hills surrounding New Harbour are primarily the DV1b and Koettlitz Glacier Alkalines Suites. Up-valley, the DV1a Suite dominates, composed of the Bonney Pluton, which accounts for $15 \%$ of basement rocks in southern Victoria Land (Cox, 1993). In the vicinity of the Polar Plateau, all intrusions are of the DV2 Suite. 


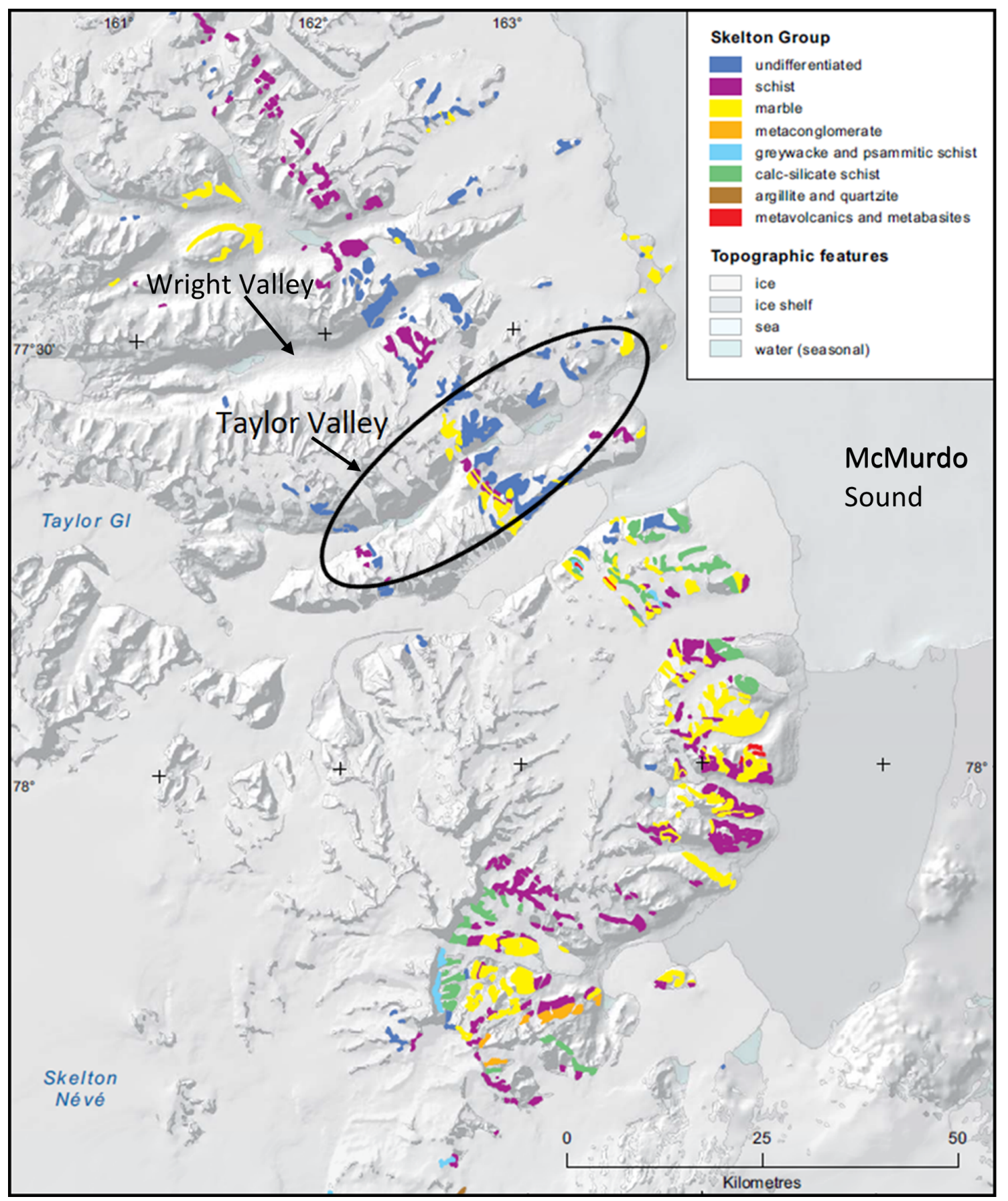

Figure 2.4: The distribution of Skelton Group lithologies in southern Victoria Land, Antarctica, differentiated by colour. The approximate location of the Taylor Valley is displayed (open circle). Figure from Cox et al. (2012). 


\section{The Kukri Erosion Surface}

Between the Cambrian and Ordovician periods (541 to $485.4 \mathrm{Ma}$ ), there was deformation and intrusion at the margin of the East Antarctic craton as part of the Ross Orogeny, followed by a prolonged period of uplift, erosion, weathering, and planation (Elliot, 1975). These processes led to the formation of the low-relief Kukri Peneplain, or Kukri Erosion Surface (Figure 2.1) (Fitzgerald, 2002; Gunn \& Warren, 1962). Lying near-horizontal, this surface uncomfortably overlies basement rock and represents a period of erosion that lasted $\sim 80$ to 100 million years (McKelvey et al., 1977).

The presence of shallow marine sediments overlying the erosion surface provide a reference for deformation since Mesozoic times. At present, the height of the Kukri Peneplain varies between 1000 and $3500 \mathrm{~m}$, with persistent dip of the surface across the TAM and beneath the Antarctic ice cap at an angle of $2-3^{\circ}$. These field observations are taken as evidence of a flexural uplift where the load is applied at the edge of the TAM, and the plate is weak at its end but gets progressively stronger toward the interior of East Antarctica (ten Brink et al., 1997; Forsyth, 1996 Stern \& ten Brink, 1989).

\section{The Beacon Supergroup}

The Beacon Supergroup underlies much of southern Victoria Land (Figure 2.5), composed primarily of Windy Gully and undifferentiated Taylor Group sandstones (Gunn \& Warren, 1962). The Windy Gully Sandstone is a thin, discontinuous basal conglomerate, with clasts of quartz and basement rocks, which is succeeded by trough cross-bedded quartzose sandstone (MacElroy \& Rose, 1987; Plume, 1978). Beacon Supergroup units overly the Kukri Erosion Surface, outcropping in the Kukri Hills and parts of the Asgard and Olympus ranges (Cox et al., 2012; Isaac et al., 1996).

\section{Ferrar Group}

The Ferrar large igneous province was emplaced during the initial stages of Gondawana breakup in the Early Jurassic, starting at 201.3 Ma (Elliot, 2013). Ferrar rocks are exposed in a $\sim 3500 \mathrm{~km}$ long belt that extends along the Transantarctic Mountains from the Weddell Sea to the Wilkes Land Coast (Elliot \& Fleming, 2008). In southern 


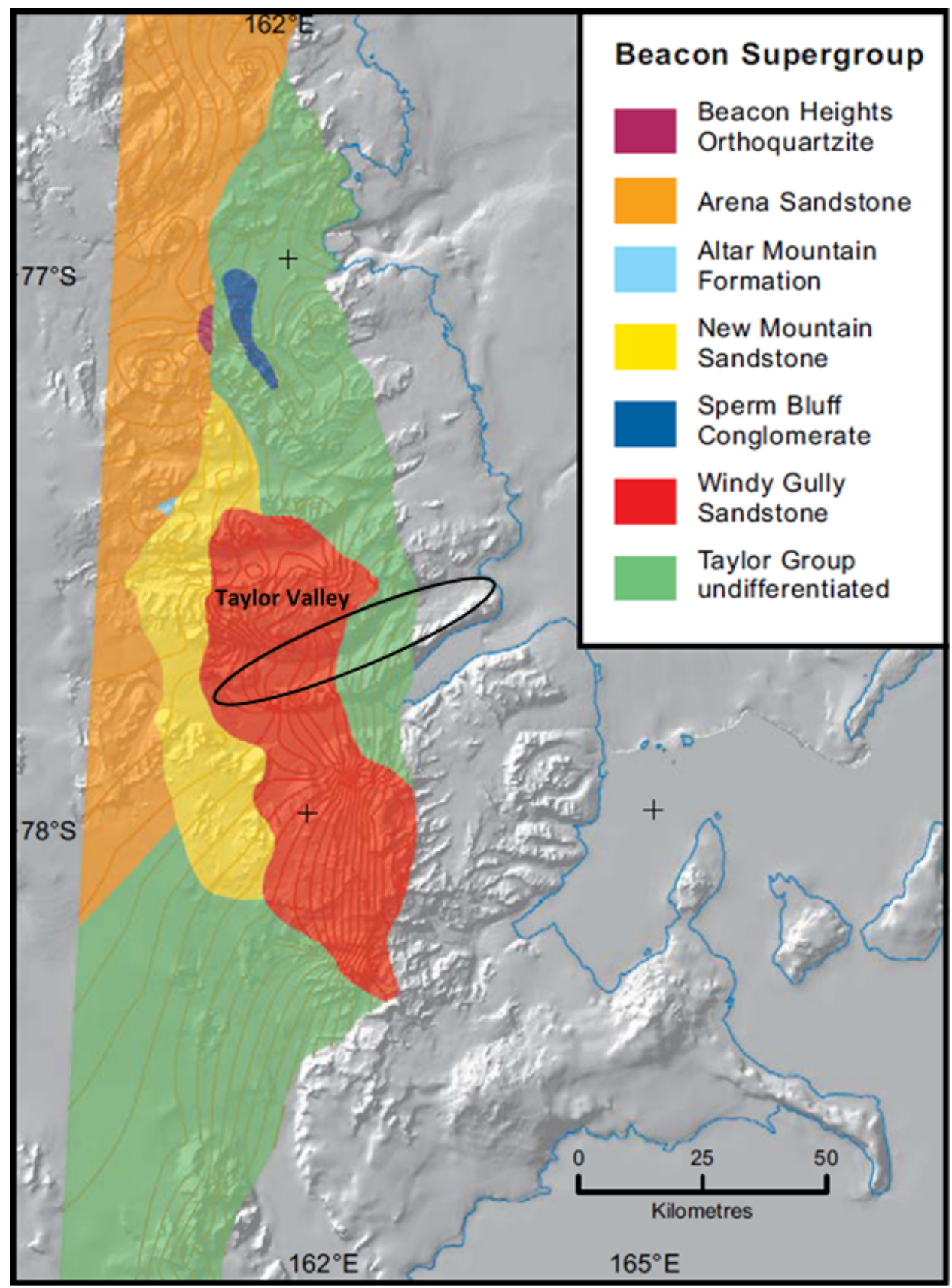

Figure 2.5: Distribution of Beacon Supergroup Units in southern Victoria Land, differentiated by colour. The approximate location of the Taylor Valley is displayed (open circle). Figure from Cox et al. (2012). 


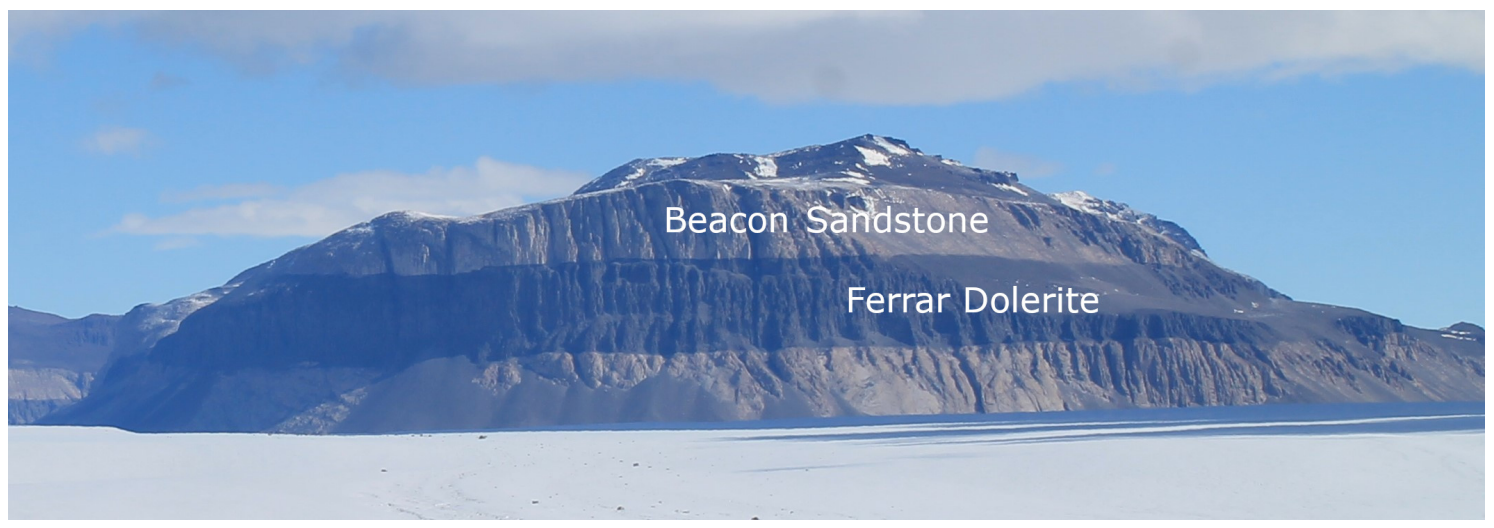

Figure 2.6: Ferrar Dolerite intrusions in Beacon Sandstone on an unnamed peak up-valley of the Taylor Glacier.

Victoria Land they are mainly volcaniclastic rocks, flood basalts and sills of the Ferrar Dolerite (Grindley, 1963, Gunn \& Warren, 1962, Ferrar, 1907).

\section{Ferrar Dolerite}

Ferrar dolerites were erupted and emplaced during an 8 Myr period of magmatic activity (Elliot et al., 1999) in the early Jurassic between $~ 176.2$ and 183.6 Ma (Fleming et al., 1997; Encarnación et al., 1996). This unit forms cliffs in the walls of the Dry Valleys, with numerous sills of varying thickness widely distributed throughout southern Victoria Land (Cox et al., 2012), intruding units such as Beacon Sandstones (Figure 2.6.).

\section{Glacial and surface sediments}

Much of the Dry Valleys is covered by Eocene to Holocene age surficial sediments deposited by fluvial and glacial processes. Mapping of deposits is based on findings from drill cores (Talalay \& Pyne, 2017), lithologic information gained from exposures, and morphology of landforms as the deposits themselves are only exposed where meltwater was sufficient to cut into the sediment (Cox et al., 2012).

The distribution of glacial deposits within the valley, as well as the ice limits during successive past glaciations, have been mapped (Calkin, 1964 Péwé, 1960), revealing that multiple phases of glaciation have occurred in the Dry Valleys (Wright \& Priestley, 1922 David et al., 1914).

The presence of exposed basement rock and glacial tills in the Taylor Valley provides 
critical information needed to reconstruct the evolution of the East Antarctic Ice Sheet, Ross Ice Sheet, and local alpine glaciers. Multiple drifts are observed in the valley; here the term drift describes all sedimentary material transported and deposited by a glacier or from water originating from a glacier (Cox et al., 2012).

\section{Mid Taylor 4 Drift (MT4)}

Formed by southward incursions of the Taylor Glacier, Mid Taylor 4 Drift (MT4) is observed at high elevations $(\sim 900-1100 \mathrm{~m})$ on the valley walls (Figure 2.7). This unit is part of a well preserved sequence of tills, formed by down-valley advance of the Taylor Glacier (Denton et al., 1989). MT4 contains a combination of angular, unweathered gravel to cobble-sized clasts of Beacon Sandstone, Ferrar Dolerite and granite (Marchant et al., 1994). Cosmogenic nuclide dating give an age for the drift ranging from $400 \mathrm{ka}$ to $2.1 \mathrm{Ma}$ (Brook et al., 1993).

The maximum thickening of Taylor Glacier ice is marked by the Thomson Drift, observed in patches along the Kukri Hills (Wilch et al., 1993). This till is typically included within the Mid Taylor 4 Drift given the similar elevation of the units. The Thomson Group is the oldest part of MT4, with an age of formation between 2.7 and $3 \mathrm{Ma}$ (Bockheim et al., 2008).

\section{Upper Taylor 3 Drift (UT3)}

The central Taylor Valley contains near-continuous tills of Upper Taylor 3 drift (UT3) along the valleys walls, 100 - $200 \mathrm{~m}$ above the present elevation of the Taylor Glacier (Figure 2.7). UT3 is younger and much more extensive than MT4, left by thickened glacier ice in the middle Pleistocene around $\sim 1.2 \pm 02 \mathrm{Ma}$ (Bockheim et al., 2008).

\section{Upper Taylor 2 Drift (UT2)}

The remainder of exposed valley floor and walls are covered in a near-continuous sheet of Upper Taylor 2 Drift (UT2; Figure 2.7) (Brook et al., 1993). This drift forms sets of hummocky moraines on the floor, modified by downslope movement (Swanger et al., 2010). Detailed studies of UT2 units, such as the Bonney Drift, suggest sediments originated as a combination of water-laid and melt-out tills deposited following downvalley advance of the Taylor Glacier into a proglacial lake (Cox et al., 2012).

\section{Undifferentiated local glacier till (ul)}




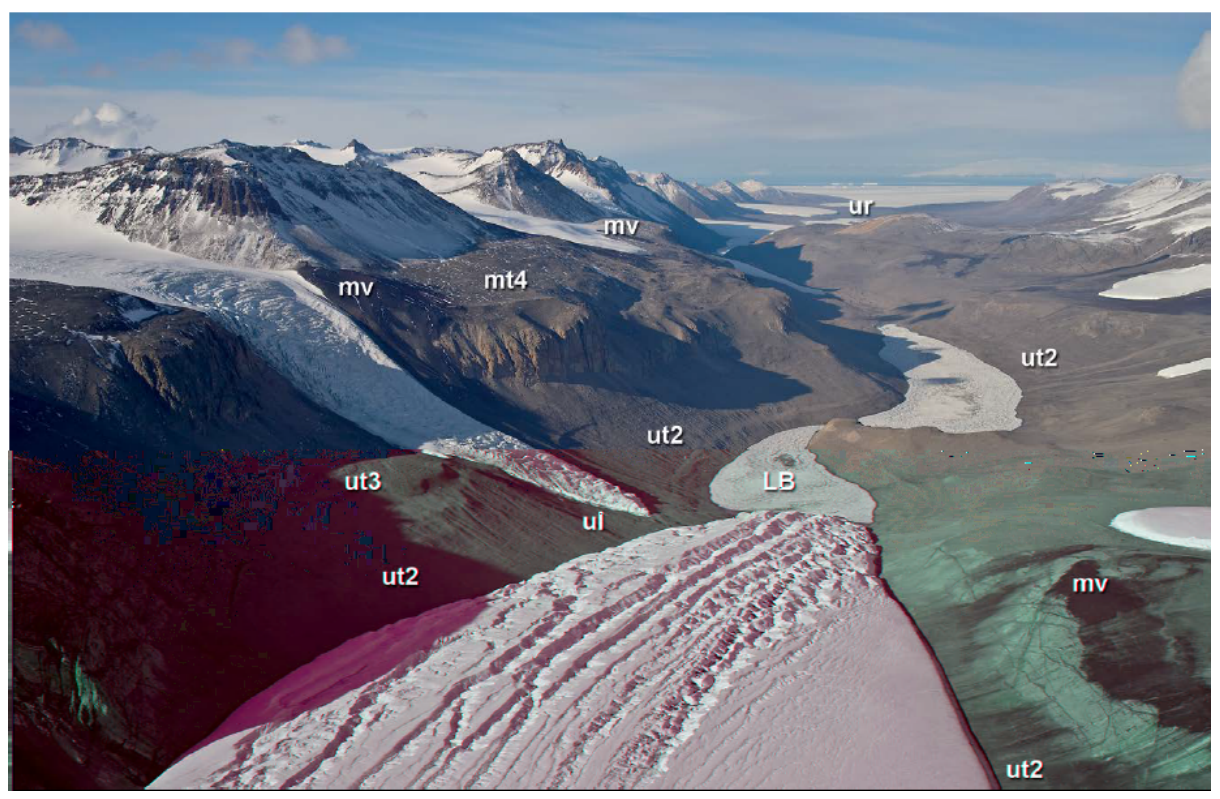

Figure 2.7: Annotated aerial image of lithological units at the head of the Taylor Valley, looking down-valley from above the Taylor Glacier. mv - Undifferentiated McMurdo Volcanic Group, mt4 - Mid Taylor 4 Drift, ut3 - Upper Taylor 3 Drift, ut2 - Upper Taylor 2 Drift, ul Moraine Ridges, ur - Coastal tills, LB - Lake Bonney. Figure from Cox et al. (2012)

Deposits of undifferentiated local glacier till (ul) are generally in close proximity to local glaciers, forming prominent moraine ridges. A lack of modification suggests deposits are relatively young (Cox et al., 2012), although their exact age is unclear (Hall et al., 1993).

\section{Coastal Tills (ur)}

Coastal Tills (ur) are located in New Harbour (Figure 2.1), actively forming along the margins of the McMurdo and Ross Ice Shelves (Wilson, 2000). These tills contain wellpreserved macrofossils, are ice-cored, and matrix-poor. Coastal tills record the most recent stages of deglaciation in the Holocene, with thinning of the Ross Ice Sheet, and retreat of the ice margin from coastal areas (Cox et al., 2012).

\section{McMurdo Volcanic Group}

Cenozoic volcanoes composed primarily of alkaline basaltic rocks are exposed along the flanks of the West Antarctic Rift System (LeMasurier et al., 1990). These are part of the McMurdo Volcanic Group of southern Victoria Land. McMurdo Volcanic Group rocks vary in composition from mafic basalts to felsic trachytes (Cole et al., 1971). 
Near the snout of the Taylor Glacier multiple Pliocene and Pleistocene age scoria cones are found on the floor and walls of the valley, and in the Kukri Hills (Figure 2.7) (Cox et al., 2012, Allibone et al., 1991, Haskell et al., 1965). Argon-argon (Ar-Ar) dating of flows in the valley indicate ages for these between 1.5 and $4.8 \mathrm{Ma}$ (Wilch et al., 1993).

\subsubsection{Glacial history of the Taylor Valley}

The presence of high elevation volcanic ash and rock surfaces in the Dry Valleys indicate little change in these landscapes since Middle Miocene times, supporting the theory that the East Antarctic ice sheet has remained relatively stable over the last $\sim 15 \mathrm{Myr}$ (Summerfield et al., 1999, Wilch et al., 1993). Ash-bearing moraines in the Olympus Range recorded the transition from warmer wet-based to cold-based ice in the Middle Miocene, indicating that the ice sheet became stable around this time (Lewis et al., 2007). During this climatic transition there were periods of minor retreat and advance of grounded ice, extending into the Ross Sea during large-scale ice sheet expansions (Bart et al., 2000).

Well-preserved glacial deposits in ice-free areas around McMurdo Sound indicate that there were at least four major Quaternary glacial fluctuations of the ice cap (Péwé, 1958a, 1958b). These deposits can be used to constrain the extent of ice cover and magnitude of each successive glaciation.

\section{McMurdo Glaciation}

The McMurdo Glaciation is the earliest and most extensively recorded Quaternary glacial advance, occurring sometime during the Pleistocene (Péwé, 1960). During this period, the Taylor Glacier advanced along the Taylor Valley, occupying elevations greater than $1000 \mathrm{~m}$ and coalescing with the Ross Ice Shelf and Koettlitz and Ferrar Glaciers in McMurdo Sound (Péwé, 1958b). Drift deposited by the glacier has been observed at $\sim 900$ masl (metres above sea level). 


\section{Taylor Glaciation}

The Taylor Glaciation, named after widespread deposits in the Taylor Valley, is the next recognised glacial advance in the McMurdo Sound (Péwé, 1960). Although less extensive than the McMurdo Glaciation, advance of the Taylor Glacier was significant, attaining altitudes of $\sim 300 \mathrm{~m}$ and coalescing with both the Koettlitz and Wilson Piedmont Glaciers in McMurdo Sound.

Many glacial lakes of the Taylor Valley were formed during this period as a result of ice from the Ross Sea and surrounding glaciers in McMurdo Sound damming the Dry Valleys, preventing drainage of melt water as the climate warmed (Péwé, 1958b). No age has been estimated for this event, other than that it occurred between the McMurdo and Fryxell Glaciations.

\section{Fryxell Glaciation}

A third glacial advance, the Fryxell Glaciation, is indicated by well-preserved moraines adjacent to Lake Fryxell in the lower Taylor Valley. Deposits suggest that ice cover during this period was less than in preceding advances, extending 100 $\mathrm{m}$ up the valley walls but not advancing as far into the Ross Sea (Péwé, 1960).

Alpine glaciers of the Asgard Range and Kukri Hills reached the valley floor during the glacial period, overriding till deposited in previous events. Glaciers in the lower valley spread into McMurdo Sound, coalescing with ice of the Ross Sea (Péwé, 1958b).

\section{Koettlitz Glaciation}

The Koettlitz Glaciation, named after moraine deposits surrounding the Koettlitz glacier, is the most recent recorded glaciation in the McMurdo Dry Valleys. This is the least extensive glaciation, when alpine glaciers advanced only 100s of meters horizontally and the Ross Ice Shelf extended $\sim 5 \mathrm{~km}$ up-valley (Taylor, 1922).

Deposits left by outlet glaciers are widespread, well-preserved, and easily distinguished from older drift filling moraines. Radiocarbon dating of algae buried in moraines show that glaciation initiated 26000 years ago (Péwé, 1960). 


\subsection{Previous Studies}

Previous studies of the Taylor Valley provide information on subsurface structure in the region. These are valuable constraints for gravity models and provide a starting point for structural and lithological parameters in these models.

\section{The British Antarctic expedition}

The Taylor Valley was first discovered during the British National Antarctic Expedition conducted between 1901 and 1904. This survey involved little study of the valley itself, which would be more fully explored between 1907-1909 and 1910-1913 by the British Antarctic Expedition (BrAE) led by Robert Scott. Both the Taylor Glacier and Valley were named after Thomas Taylor, an Australian geologist and member of the expedition. Objectives of the BrAE were various, involving geological, magnetic and meteorological studies conducted across Antarctica; this was some of the first work done on the continent in these sciences.

\subsubsection{Drilling projects}

\section{The Dry Valleys drilling project}

The Dry Valley Drilling Project (DVDP) was a New Zealand-USA-Japan collaborative study in the 1970's aimed at understanding the geological complexity of the McMurdo Dry Valleys (Smith, 1981). The goal was to examine subsurface sediments through core drilling programs and downhole measurements, which could extend the geologic record on land and in lakes of the McMurdo Dry Valleys. In doing this, many speculative and diverse theories on the origins of the valleys could be eliminated (Smith, 1981).

To provide geological and geophysical information about drill sites in the valley, a regional-scale aeromagnetic survey was conducted across the McMurdo Sound region (Pederson et al., 1981). East-west oriented lines were flown at $2 \mathrm{~km}$ intervals and altitudes of $300 \mathrm{~m}$, designed to build upon existing magnetic measurements made in the region (Robinson, 1964). Eleven land-based magnetic profiles were measured across volcanic cindercones in the Taylor and Wright Valleys to provide ground control for aerial observations. 
Residual magnetic profiles derived from the data do not show any obvious expression of a major fault between the Transantarctic Mountains and McMurdo Sound. Furthermore, the anomalies in the Dry Valley appear to be entirely due to the presence of sills and dikes of the Ferrar Dolerite Group (Pederson et al., 1981).

A seismic refraction survey (McGinnis, 1979), and drilling of boreholes, were carried out between 1975 and 1980 (McKelvey, 1981; Barrett et al., 1976, Chapman-Smith, 1975). Seismic data were collected to characterise lithological properties and thickness of the sediment underlying McMurdo Sound, providing information on basement lithology and buried bedrock topography. Three refraction profiles were shot on sea ice in water depths between $\sim 100$ and $200 \mathrm{~m}$. Resultant time-distance curves indicated an average basement rock depth of $480 \mathrm{~m}$ below the sea ice at the front of the Taylor Valley (McGinnis, 1979).

To quantify properties of glacial till within the Taylor Valley, 14 boreholes were drilled as part of the DVDP, located in McMurdo Sound, Ross Island, and the Taylor and Wright Valleys (Figure 2.8) (Torii, 1981). Of these, six were based in the Taylor Valley, drilled during the 1973-74 and 1974-75 austral summers (Talalay \& Pyne, 2017). Most of these boreholes are not of significance in this study, and are explained in more detail by Talalay and Pyne (2017).

DVDP - 8 and 9 were located along the shoreline of McMurdo Sound in New Harbour (Figure 2.9). A maximum depth of $157.06 \mathrm{~m}$ was drilled without reaching bedrock, with the entire section comprised of permafrost containing a highly varied sequence of ice-cemented sands, silts, gravels, and diamictites (Talalay \& Pyne, 2017). Succeeding geophysical studies (Hicks \& Bennett, 1981; McGinnis, 1980) estimate a sediment thickness of $\sim 500 \mathrm{~m}$ below the drill site.

DVDP - 10 and 12 were drilled during the 1974 - 1975 Antarctic field season. DVDP - 10 was located in New Harbour (Figure 2.9), $1 \mathrm{~km}$ inland from DVDP-8 and 9 (Treves \& McKelvey, 1974). As with previous boreholes, drilling was terminated before reaching bedrock at $185.5 \mathrm{~m}$ due to technical problems.

The only borehole to reach bedrock in the Dry Valleys Drilling Project was DVDP - 12, located near an unnamed lake west of Canada Glacier in the Taylor Valley (Figure 2.8. Basement rock was encountered at $166 \mathrm{~m}$, with drilling reaching a total depth of 


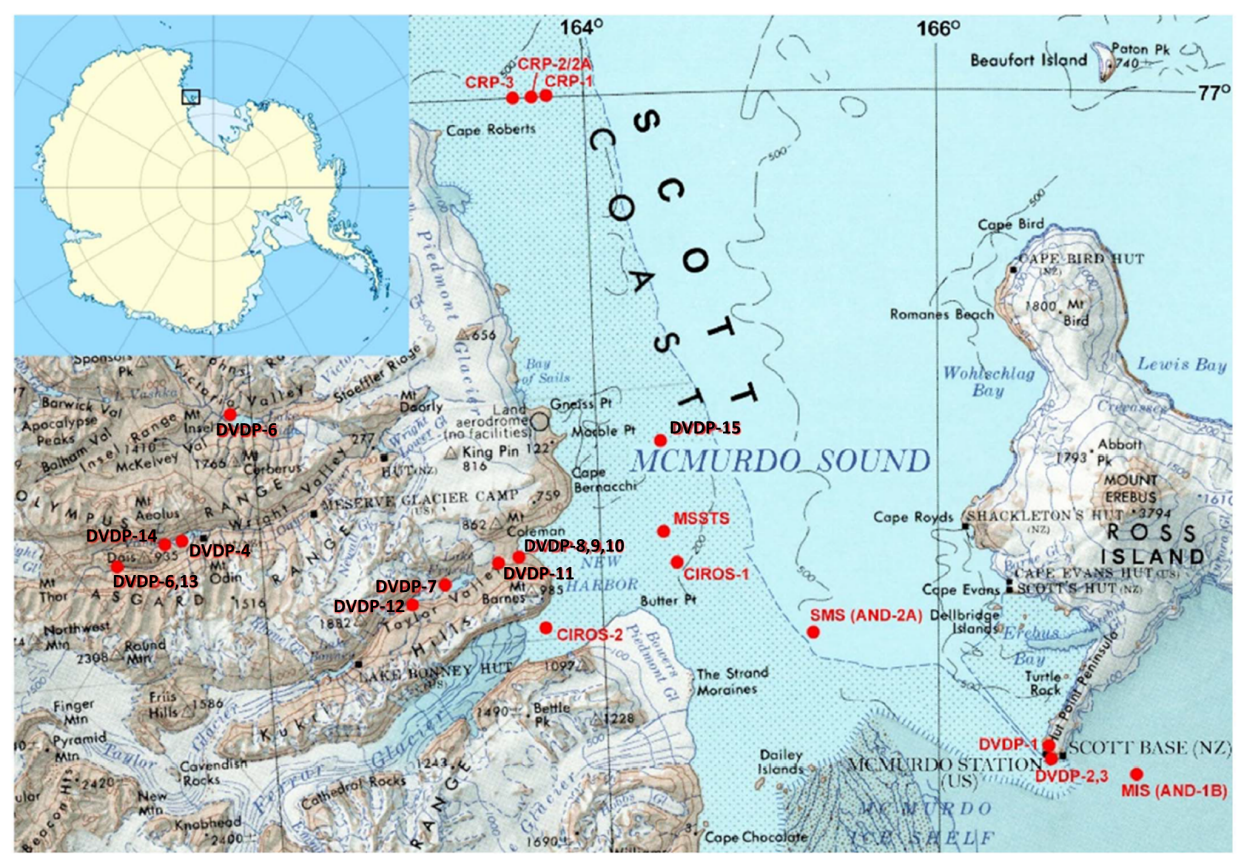

Figure 2.8: Location of drilled boreholes (red circles) as part of various drilling projects in the Dry Valleys and McMurdo Sound. DVDP - Dry Valleys Drilling Project, MSSTS - McMurdo Sound Science and Tectonic Studies, CRP - Cape Roberts Project, CIROS - Cenozoic Investigations in western Ross Sea, SMS - Southern McMurdo Sound, ANDRILL - Antarctic geological Drilling. Figure from Talalay and Pyne (2017).

$184.6 \mathrm{~m}$ and recovering $98.5 \%$ of the core. Interpretation of core revealed glacial till resting unconformably on 'rough, unweathered basement rock' (McGinnis \& Mudrey Jr, 1975).

\section{Eastern Taylor Valley drilling project}

The Eastern Taylor Valley Drilling Project (ETV) was a US-New Zealand collaborative paleomagnetic, stratigraphic, and sedimentologic study of the Taylor Valley. Thirteen cores were drilled in this study (Figure 2.9p, with locations selected to answer questions that arose during analysis of DVDP cores (Talalay \& Pyne, 2017).

ETV - 1 and 2, were located on a ridge $\sim 1 \mathrm{~km}$ down-valley of DVDP - 11 (Figure 2.9), drilled during the 1981-82 field season, reaching depths of $4.1 \mathrm{~m}$ and $44.9 \mathrm{~m}$ respectively (Elston et al., 1981). ETV-1 encountered solitary corals and bivalves that had been transported from the Ross Sea during the most recent glacial incursion. An incomplete section of ice-cemented sand was recovered by ETV-2, also found between depths of 2 to $16 \mathrm{~m}$ in DVDP - 11 .

The 1982 - 83 field season involved drilling of a further six boreholes between Explorers 


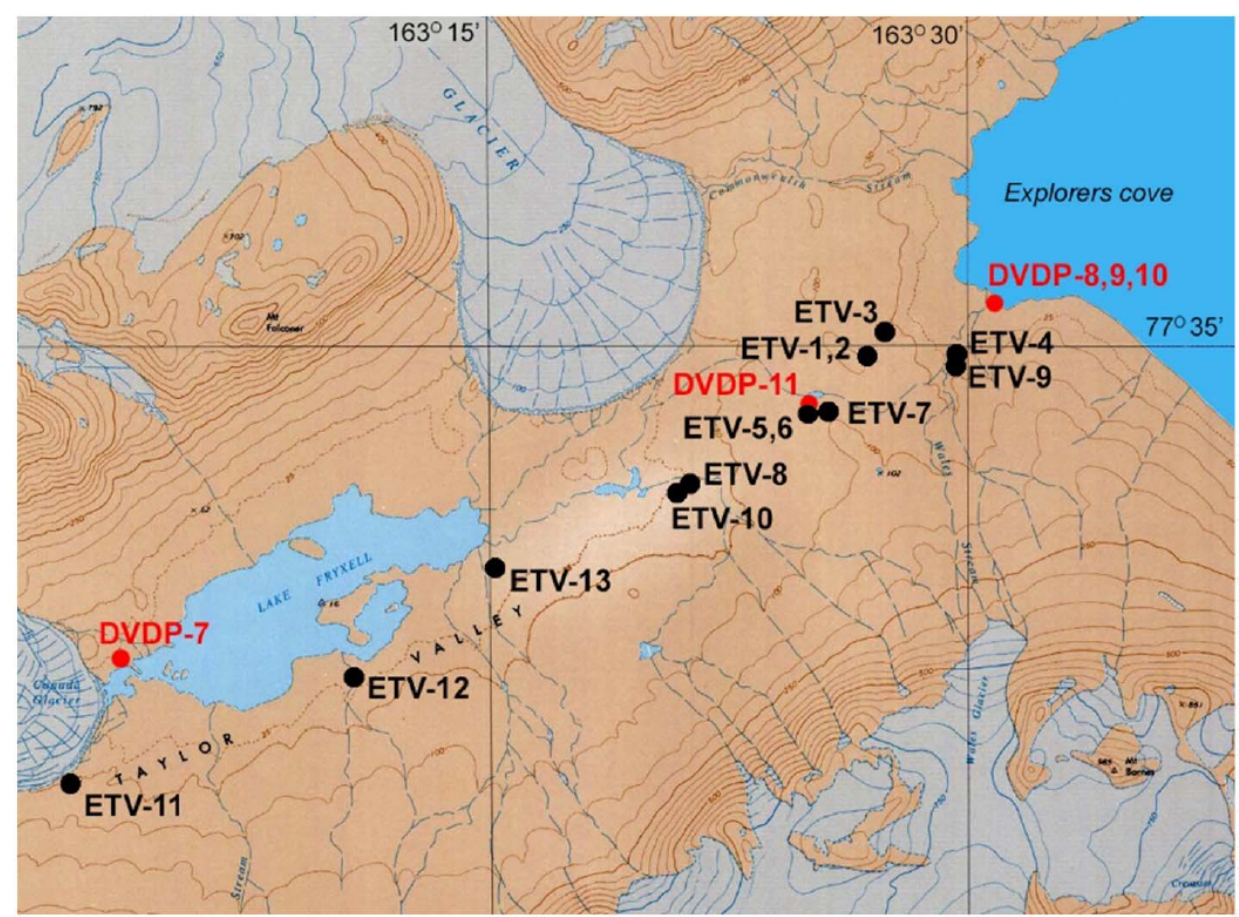

Figure 2.9: Locations of drilled boreholes in the Dry Valleys Drilling Project (DVDP; red circles) and Eastern Taylor Valley Drilling Project (ETV; black circles) in the Taylor Valley. $50 \mathrm{~m}$ contours on the valley floor (brown lines) and glaciers (blue lines) are plotted. Figure from Talalay and Pyne (2017).

Cove and Lake Fryxell (Figure 2.9) (Elston et al., 1985). Depths cored ranged between 10.5 and $58.5 \mathrm{~m}$, with a total of $151.7 \mathrm{~m}$ of sediment drilled (Talalay \& Pyne, 2017).

ETV - 9 to 13 (Figure 2.9) were drilled during the 1983 - 84 season, ranging in depths between 16.9 and $70.9 \mathrm{~m}$ (Elston et al., 1985). Lithologies observed included terrestrial deposits of Taylor Glacier-origin with marine bivalves identified in the lower $\sim 5 \mathrm{~m}$ (Elston et al., 1985). Presence of a terrestrial glacio-fluvial sequence directly under the surface indicates multiple Ross Ice Sheet incursions into the Taylor Valley.

\subsubsection{Gravity studies}

In research gravity is commonly expressed as an acceleration due to gravitational force. Acceleration has units of $\mathrm{m} / \mathrm{s}^{2}$, however, in geophysics gravity is expressed in Gals, where $1 \mathrm{Gal}$ is defined as $1 \mathrm{~cm} / \mathrm{s}^{2}$. Variations in Earth's gravity are small, commonly on the order of milliGals where $1 \mathrm{mGal}=0.001$ Gal (Lowrie, 1997; Keary \& Brooks, 1992). Previous studies, such as those referred to in this section, commonly expressed 


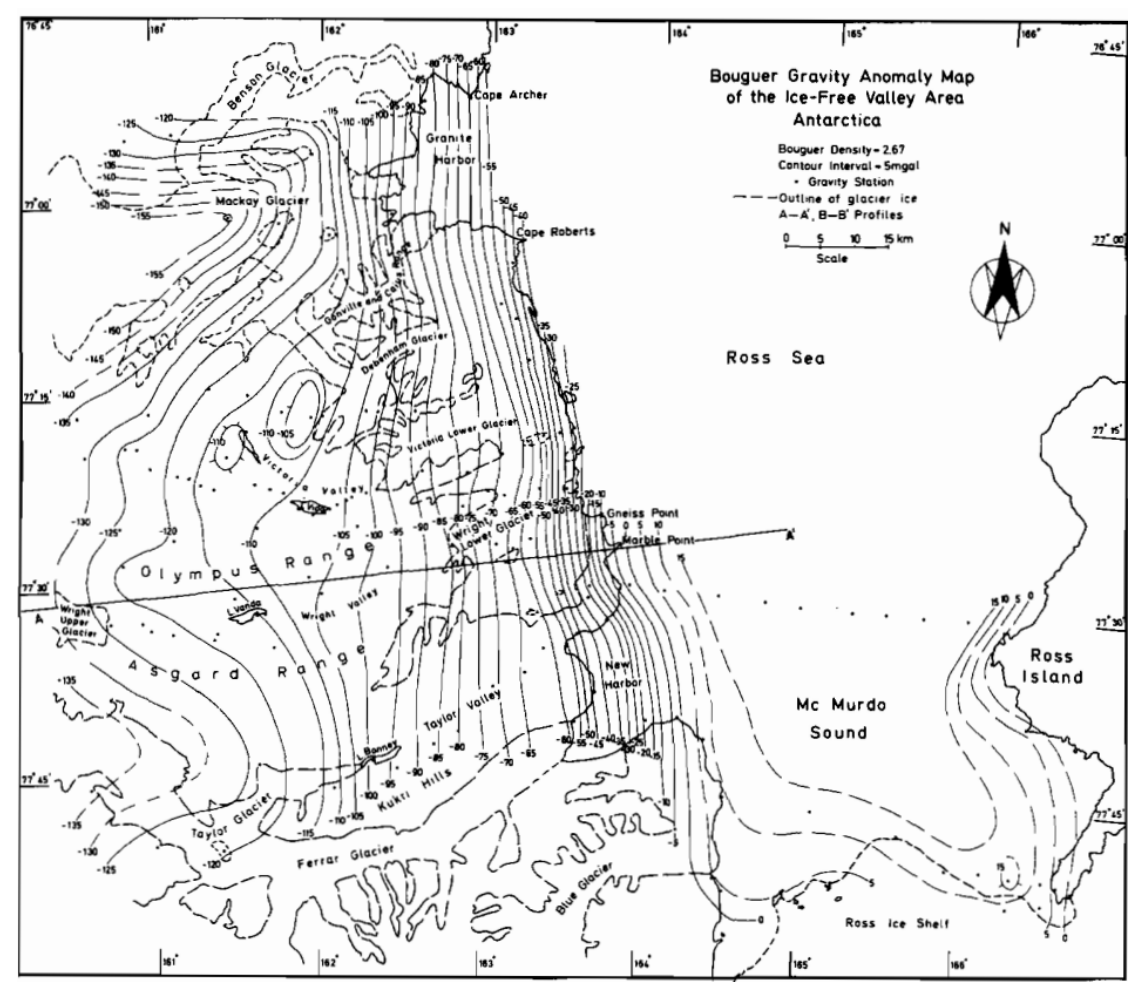

Figure 2.10: Bouguer gravity anomaly map of the McMurdo Dry Valleys and measured gravity survey line A-A' (solid line) by Smithson (1972). Bouguer anomalies are in 5 mGal contours. The outline of glacier ice (dotted line) and measured gravity stations (black circles) are displayed. Figure from Smithson (1972).

gravity in units of $\mu \mathrm{N} / \mathrm{kg}$, where $1 \mathrm{mGal}=10 \mu \mathrm{N} / \mathrm{kg}$.

Smithson (1972) collected gravity observations along a line from Marble Point to the Upper Wright Glacier (Figure 2.10). Data revealed a gravity gradient of $7 \mathrm{mGal} / \mathrm{km}$ in McMurdo Sound, culminating in a negative Bouguer anomaly of $-130 \mathrm{mGal}$ in the lower TAM. Smithson (1972) modelled this in terms of a thickening of the crust from $27 \mathrm{~km}$ in McMurdo Sound to $40 \mathrm{~km}$ near the Taylor Glacier with an $8 \mathrm{~km}$-thick slab of relatively dense basaltic material in the upper crust of McMurdo Sound, interpreted as representing an ancient subduction zone.

An initial estimate of glacial till thickness in the Taylor Valley was obtained from gravity observations made between Lake Fryxell and the Upper Taylor Glacier (Figure 2.11) (Stern, 1978). One hundred and eight gravity stations were established along six survey lines during the 1977-78 field season by Stern (1978), observing a maximum Bouguer anomaly of $-139 \mathrm{mGal}$, comparable to that found by Smithson (1972). This anomaly implies a maximum ice thickness of $\sim 1100 \mathrm{~m}$ at the time of the study, becoming progressively thinner towards the snout of the glacier, underlain by $\sim 600 \mathrm{~m}$ of 


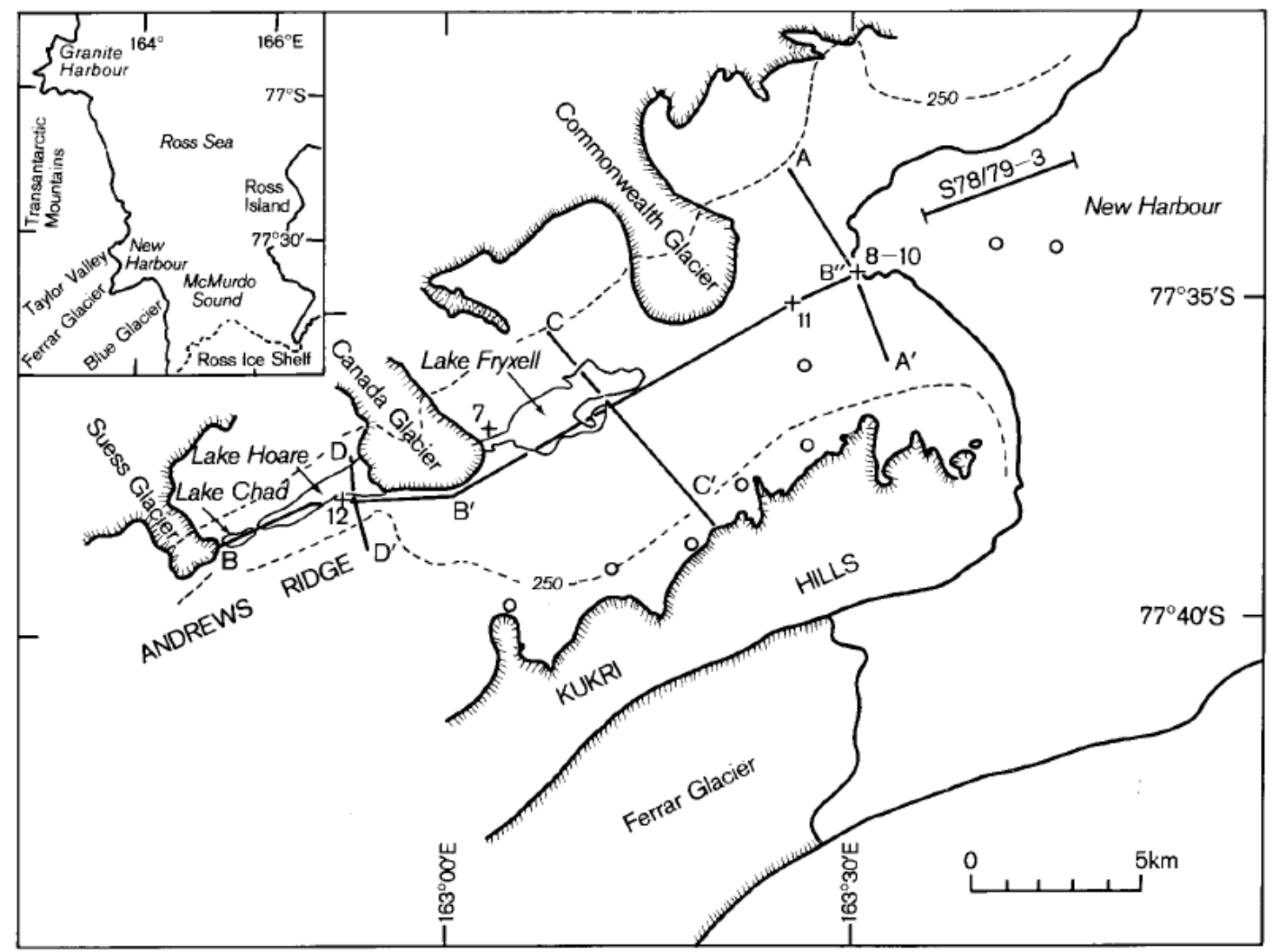

Figure 2.11: Map of the Taylor Valley, showing boreholes DVDP7-12 (numbered crosses), line S78/79-3 of the seismic refraction study by McGinnis (1980, 1979) (solid line offshore) and gravity survey lines measured by Hicks and Bennett (1981) (solid lines onshore) and Sissons (1980) (circles). The ground contour at 250 masl is displayed (dashed line). Hatched lines represent the limit of the ice-free regions in the valley. The inset map (top left) displays the location of the Taylor Valley within the Ross Embayment. Figure from Hicks and Bennett (1981).

sediment. Models were constrained by estimates of sub-ice topography from radar echo sounding (Calkin, 1974), showing the implications of combined geophysical techniques to constrain estimates of sediment thickness.

Both studies by Smithson (1972) and Stern (1978) calculated inner terrain corrections (170 $\mathrm{m})$ by eye in the field and outer terrain corrections $(20 \mathrm{~km})$ using a United States Geological Survey (USGS) map at a scale of 1:100,000. These methods introduce an error of $\pm 20 \%$ to corrections applied when calculating Bouguer anomalies, limiting the resolution of resultant gravity models.

Sissons (1980) conducted a gravity survey across the Ross Sea and Victoria Land Coast. Absolute gravity at Scott Base was linked to the site of DVDP-8/9, with an observed value of $982927.78 \mathrm{~N} / \mathrm{kg}$. A steep, positive eastward gradient in Bouguer anomalies 
was observed, similar to the results of Smithson (1972). Furthermore, Sissons (1980) observed a $15 \mathrm{mGal}$ anomaly, relative to the regional gravity signal, with a wavelength of $5 \mathrm{~km}$ and centred $10 \mathrm{~km}$ off the Victoria Land Coast - the anomaly was interpreted as due to a basement fault down-thrown eastward. The large uncertainties in terrain corrections were similar to previous studies (Stern, 1978, Smithson, 1972) stemming from the use of a barometric altimeter and topographic maps for the calculations.

The most recent land-based gravity observations in the Taylor Valley are those collected by Hicks and Bennett (1981). This study established 154 gravity stations between the Suess Glacier and New Harbour (Figure 2.11) to determine depth to basement rock throughout the valley. A roughly symmetrical basement profile is modelled.

Scheinert et al. (2016) created an Antarctic-wide gravity data compilation derived from a combination of ground-based, airborne, and shipborne datasets. Covering $73 \%$ of the continent with 13 million gravity observations, this study presents gridded free-air and Bouguer anomalies at $10 \mathrm{~km}$ lateral resolution. The lower-resolution aerial gravity measurements are used to extrapolate the survey lines measured in this study, revealing the long-wavelength $(\sim 1000 \mathrm{~km})$ trend in gravity anomalies. This makes possible a true regional-scale analysis of the gravity field in the Taylor Valley and surrounding Ross Sea and Polar Plateau regions.

\subsubsection{Seismic constraints on lithospheric structure}

Installation of seismograph stations across Antarctica during the International Geophysical Year (1957 - 1958) enabled the collection of seismic data throughout the continent. This led to the first major evaluation of crustal structure in Antarctica, based on the dispersion of earthquake-generated surface waves (Evison et al., 1960). At that time little was known about the nature of the Antarctic crust. Key findings of Evison et al. (1959) and Evison et al. (1960) were that the crust of East and West Antarctica are about 35 and $25 \mathrm{~km}$ thick, respectively.

Active-source seismic reflection and refraction data were collected as part of the Seismic Experiment Ross Ice Shelf (SERIS) experiment and compared to gravimetric observations (ten Brink et al., 1993). Key goals of this work were investigation of the boundary between the West Antarctic Rift System and East Antarctica, and possible causes for 
uplift of the TAM. Multichannel reflection data were used to image subsurface layers, while wide angle reflection and refraction data constrained the seismic velocity of subsurface lithologies. Primary findings of the study were:

- Glacial deposits beneath the ice shelf.

- A gradual increase in crustal thickness from $\sim 20-30 \mathrm{~km}$ under the Ross Ice Shelf to $40 \mathrm{~km}$ or more under the TAM.

- Different crustal velocity structures under the ice shelf and beneath the TAM.

- No obvious sedimentary trough adjacent to the mountain front.

ten Brink et al. (1993) used these data to infer lateral thermal conduction from the Ross Embayment to the Polar Plateau, with increased upper mantle buoyancy beneath the TAM.

Recently, seismic data from the Transantarctic Mountains Northern Network (TAMNET) (Hansen et al., 2015) were combined with three other regional networks to derive regional-scale body-wave tomographic images of the upper-mantle structure beneath the central and northern TAMs (Brenn et al., 2017). The study was aimed at investigating the mechanism of uplift of the TAM, suggesting that the thermal buoyancy in the mantle beneath the TAM front serves as a principle driver of their uplift and resultant elevations.

Seismic velocity models (Figure 2.12) reveal relatively high $\mathrm{P}$ and S-wave velocities $\left(\delta \mathrm{V}_{\mathrm{P}} \approx+1.25 \% ; \delta \mathrm{V}_{\mathrm{S}} \approx+2.75 \%\right)$ below the Polar Plateau to a depth of $\sim 300 \mathrm{~km}$. Two relatively low velocity anomalies are also observed: beneath Ross Island $\left(\delta \mathrm{V}_{\mathrm{P}} \approx-2.0 \%\right.$; $\left.\delta \mathrm{V}_{\mathrm{S}} \approx-2.75 \%\right)$ and Terra Nova Bay $\left(\delta \mathrm{V}_{\mathrm{P}} \approx-1.75 \% ; \delta \mathrm{V}_{\mathrm{S}} \approx-2.5 \%\right)$. The Ross Island anomaly extends laterally $\sim 100 \mathrm{~km}$ beneath the TAM, consistent with estimates in previous seismic studies (Lawrence et al., 2006; Watson et al., 2006).

Results of modelling indicate that low velocities along the TAM front are consistent with upwelling of high-temperature, low-density mantle associated with lithospheric extension along the Terror Rift. The thermal anomaly beneath the more-or-less uniform crustal structure of the TAM would exert a buoyancy force driving uplift of these mountains; consistent with models suggesting a flexural origin for the TAM (ten Brink et al., 1997; Stern \& ten Brink, 1989). The low-velocity anomaly can be related to 
(a)
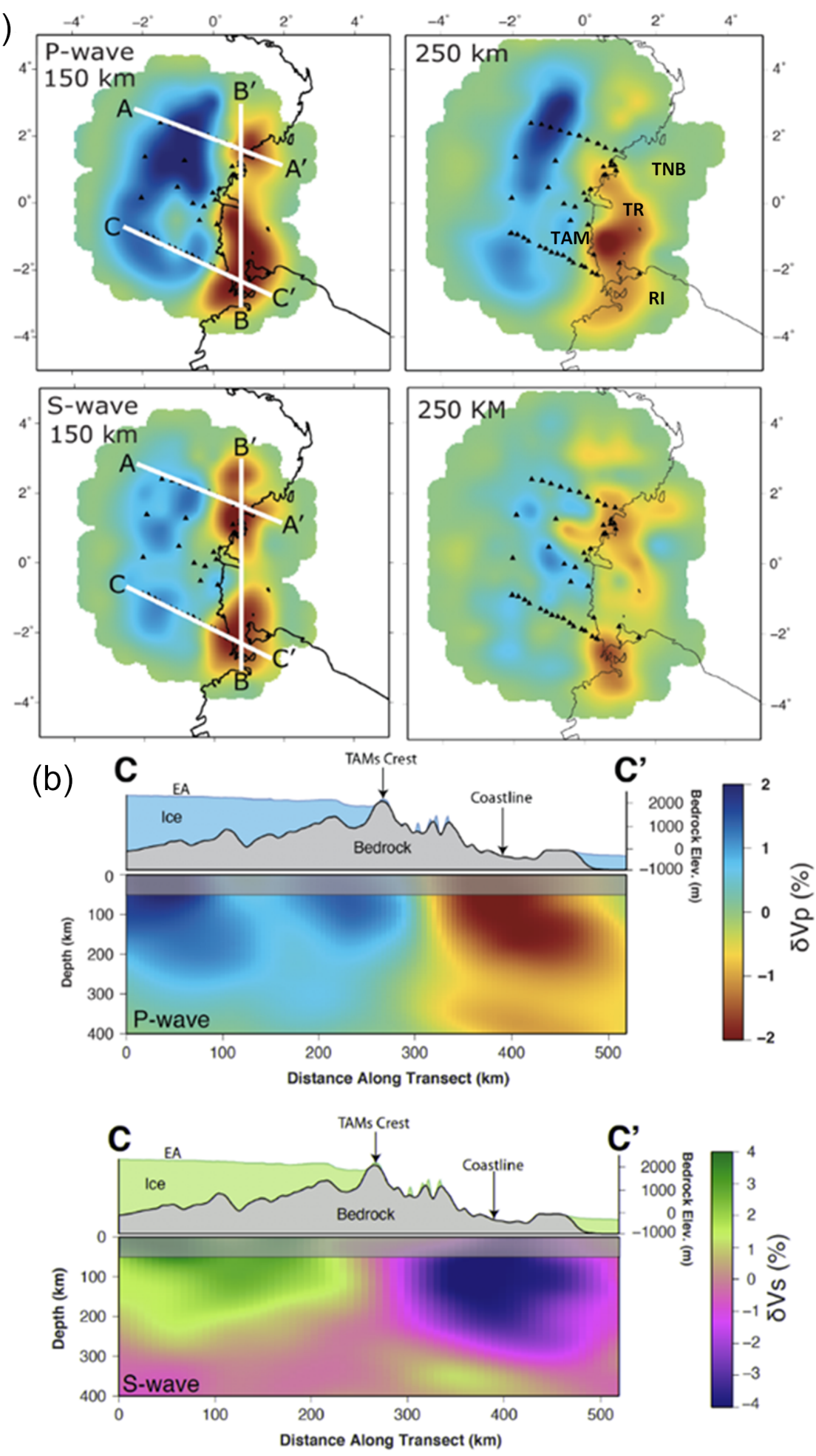

Figure 2.12: a: Map-view slices through $P$ and S-wave tomographic models of southern Victoria Land, showing relative velocity perturbations, differentiated by color scale, at depths of 150 and $250 \mathrm{~km}$. Terra Nova Bay (TNB), the Terror Rift (TR), the Transantarctic Mountains (TAM) and Ross Island (RI) are labelled. Black triangles denote seismic stations and white lines show the positions of vertical cross-sections. b: Vertical cross sections of Line C-C' showing $\delta \mathrm{V}_{\mathrm{P}}$ (top) and $\delta \mathrm{V}_{\mathrm{S}}$ (bottom) velocity perturbations with depth (in $\mathrm{km}$ ) beneath the RI, TAM, and East Antarctica (EA). The colour scale indicates the relative velocity perturbation to an average value. Figure from Brenn et al. (2017). 
surface elevation by using a velocity-temperature-density relationship and a bending model for a broken elastic plate. Analysis shows that present-day topography of the TAM can be fit by modelled flexural profiles, although these models require an elastic thickness for the East Antarctic lithosphere of up to $100 \mathrm{~km}$ (ten Brink et al., 1997).

\subsection{Gravity model constraints}

\subsubsection{Seismic studies}

Numerous seismic studies (Priestley et al., 2018, Shen et al., 2018a; Brenn et al., 2017, Priestley \& McKenzie, 2013, Lawrence et al., 2006, Watson et al., 2006, ten Brink et al., 1993) over the last two decades have constructed seismic tomographic images of the lithospheric transition between East and West Antarctica. These models provide estimates of the thicknesses of the crust and lithosphere (Table 2.1), and are used to infer mantle temperature differences across the TAM front from subsurface $\mathrm{P}$ and $\mathrm{S}$ wave velocity perturbations ( $\delta \mathrm{V}_{\mathrm{P}}$ and $\delta \mathrm{V}_{\mathrm{S}}$ respectively). This data constrains gravity models, estimating the crustal thickness as increasing from $20-\dot{2} 5 \mathrm{~km}$ in the Ross Embayment to $37-45 \mathrm{~km}$ beneath the Polar Plateau, thus reducing non-uniqueness in the modelling process.

Ambient noise tomography from more than 200 seismic stations has been used to construct Rayleigh wave phase and group velocity maps (Shen et al., 2018a). Joint Monte Carlo inversion with P-wave receiver functions (as described by Shen and Ritzwoller, 2016) allowed construction of a 3-D shear velocity model for the crust and upper mantle of the Ross Embayment and surrounding regions. Resultant maps of crustal thickness characterise the TAM with a large horizontal crustal thickness gradient varying from 20-30 km beneath WANT to 45-48 km in EANT (Shen et al., 2018a), consistent with results of localised receiver function studies across the TAM front and Ross Sea (Finotello et al., 2011; Hansen et al., 2009, Lawrence et al., 2006, Bannister et al., 2003, Stern \& ten Brink, 1989). Three-dimensional models of mantle S-wave $\left(\mathrm{V}_{\mathrm{S}}\right)$ structure depict a low-velocity $(\sim 3.6 \mathrm{~km} / \mathrm{s})$ belt based in WANT mantle along the WARS-TAM boundary, in contrast with the relatively higher velocities 


\begin{tabular}{lccc}
\hline Polar Plateau & Crustal thickness $(\mathrm{km})$ & $\delta \mathrm{V}_{\mathrm{P}}(\%)$ & $\delta \mathrm{V}_{\mathrm{S}}(\%)$ \\
\hline ten Brink et al. $(\overline{1993})$ & 37 & & \\
Lawrence et al. $(\overline{2006})$ & 40 & & 2.25 \\
Shen et al. (2018a) & 45 & 1.75 & 3.0 \\
Watson et al. (2006) & & 1.25 & 2.75 \\
Brenn et al. (2017) & & & \\
\hline Ross Embayment & 20 & & \\
\hline ten Brink et al. $(\overline{1993})$ & 23 & & -2.25 \\
Lawrence et al. $(\overline{2006})$ & 25 & -1.75 & -3.25 \\
Shen et al. (2018a) & & -2.0 & -2.75 \\
Watson et al. (2006) & & & \\
Brenn et al. (2017) & & & \\
\hline
\end{tabular}

Table 2.1: Crustal thickness and $\mathrm{P}\left(\delta \mathrm{V}_{\mathrm{P}}\right)$ and S-wave $\left(\delta \mathrm{V}_{\mathrm{S}}\right)$ velocity perturbations within the lithospheric mantle beneath the Ross Embayment and Polar Plateau in southern Victoria Land, calculated in tomographic models from five studies (Shen et al., 2018a Brenn et al., 2017; Lawrence et al., 2006, Watson et al., 2006; ten Brink et al., 1993). Velocity perturbations represent the percent deviation of observed velocity from an average value.

\section{$(\sim 3.8-4.2 \mathrm{~km} / \mathrm{s})$ in EANT.}

Bannister et al. (2003) used surface wave inversion in the western Ross Sea to obtain relative $\mathrm{V}_{\mathrm{S}}$ perturbations as a function of depth (Figure 2.13). Analysis of three broadband stations in the Ross Sea region provides interpreted depth sections that estimate Moho depth and crustal structure. Thickness of the crust beneath the Ross Sea and TAM is estimated as $20-22 \mathrm{~km}$ and $\sim 35 \mathrm{~km}$ respectively, consistent with other seismic studies of the region (Shen et al., 2018a Lawrence et al., 2006; ten Brink et al., 1993). Similarly, shear-wave velocities measured beneath the Terror Rift are $6 \%$ lower than in the PREM velocity model (Bannister et al., 2003), consistent with the results of Brenn et al. (2017).

Observations of P-to-S conversions (see Section 2.2.3) have revealed a thickening of the crust from 18-20 km beneath the Ross Sea to 30-33 km beneath the TAM $\sim 85 \mathrm{~km}$ from the coast (Figure 2.13) (Bannister et al., 2003). These observations are used to constrain gravity models of the Taylor Valley and surrounding region.

Estimation of Moho topography beneath ice sheets of the Polar Plateau and Transantarctic Mountains using S-wave receiver functions (Hansen et al., 2009) provides evidence for existence of a strong gradient in crustal thickness between East and West Antarctica. S-wave receiver functions are not as affected by ice multiples as P-to-S conversions 

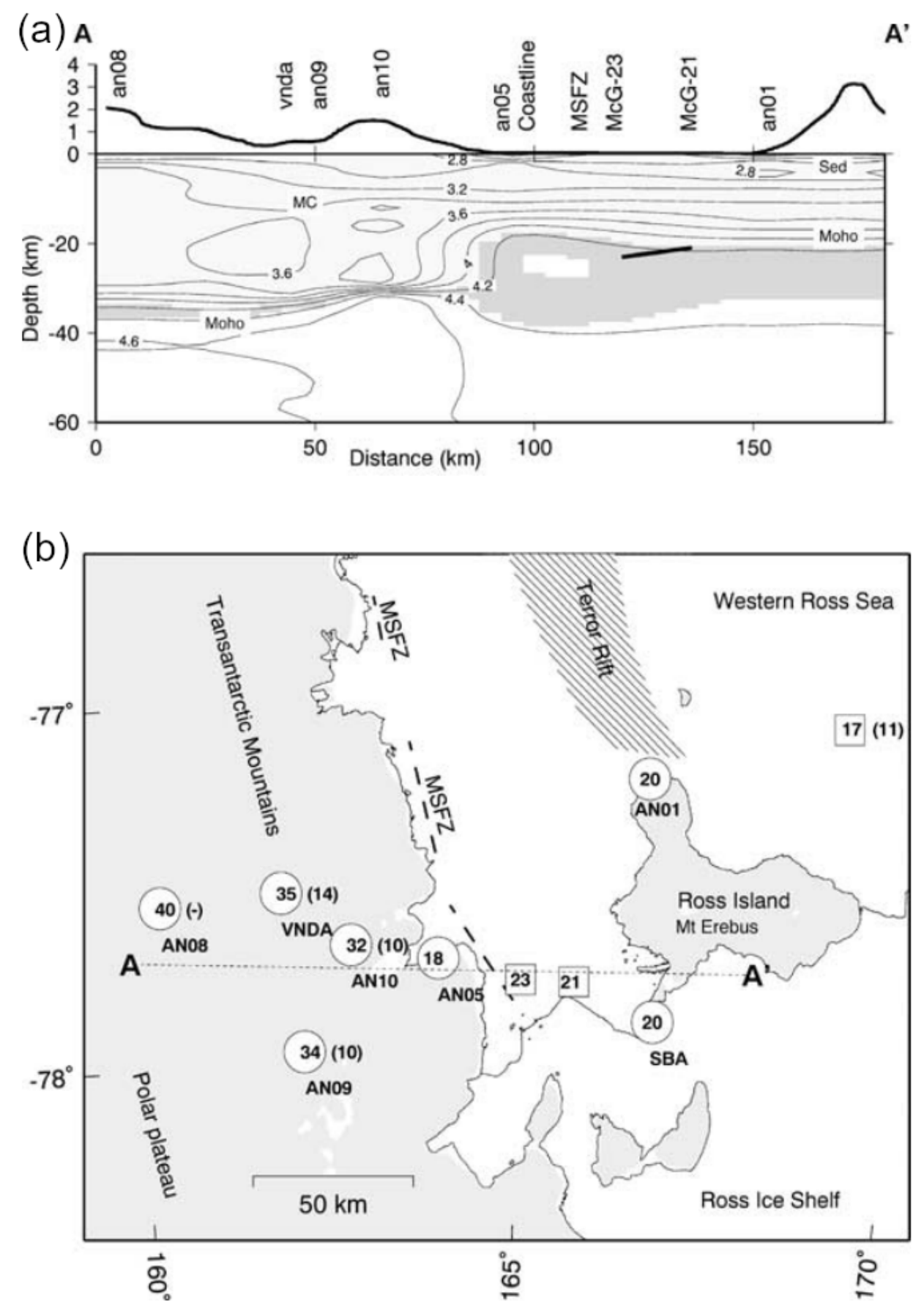

Figure 2.13: (a) Schematic cross-section beneath the Ross Sea and TAM in southern Victoria Land, showing smoothed S-wave velocity variation with depth in $0.2 \mathrm{~km} / \mathrm{s}$ contours. Vertically exaggerated surface topography (in $\mathrm{km}$ ) is shown. Seismic stations at the top constrain Moho depth. (b) Approximate inferred depth of the Moho (inside circles) and the mid-crustaldiscontinuity (inside brackets) estimated from receiver function data by Bannister et al. (2003). The position of survey line A-A' is shown (dashed line). Moho depths estimated from previous seismic reflection studies (Cooper et al., 1997; McGinnis et al., 1985) are displayed inside boxes. All depths are in km. VNDA, AN, and SBA are seismic stations. MSFZ - McMurdo Sound Fault Zone. Figure from Bannister et al. (2003). 

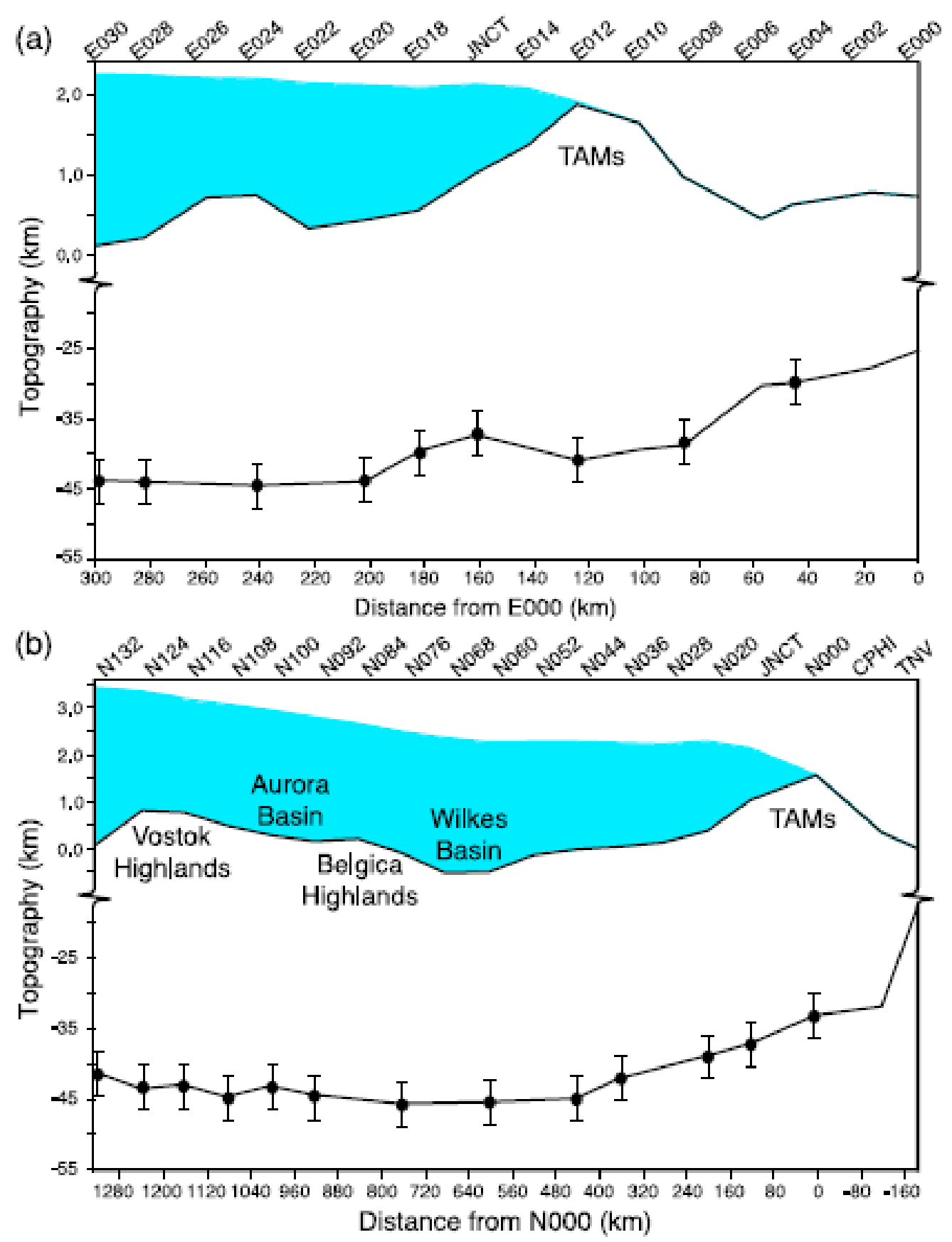

Figure 2.14: Subsurface Moho topography along two profiles across the TAM front (see Hansen et al., 2009), in relation to bedrock and surface topography. Note the break in surface topography and subsurface depths on the y-axis. Ice thickness is indicated by the blue shaded area. Moho depth estimates with $3 \mathrm{~km}$ error bars from S-wave receiver functions (Hansen et al., 2009) are shown (black circles). The solid line displays estimated subsurface Moho topography. TAMs- Transantarctic Mountains. Figure from Hansen et al. (2009). 


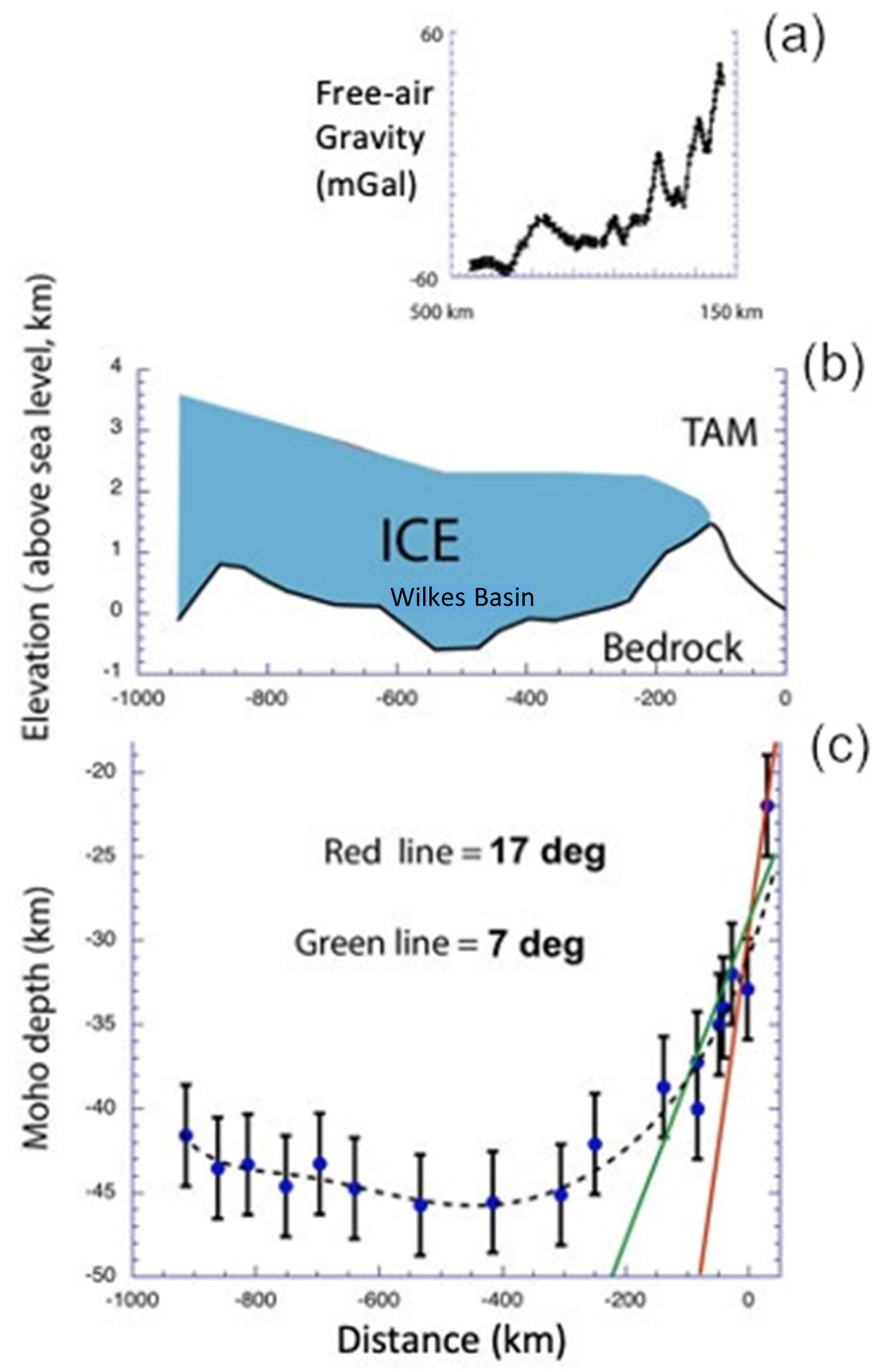

Figure 2.15: (a) Free-air gravity anomalies (mGal) from satellite observations across the Wilkes Subglacial Basin and TAM. (b) Surface topography and depth to bedrock in southern Victoria Land from Bedmap2 (Fretwell et al., 2013), plotted as elevation above sea level (in $\mathrm{km}$ ). Surface ice cover is represented by the blue area. (c) Estimates of Moho depth (blue circles) from S-wave receiver functions on-ice (Hansen et al., 2009) and P-wave receiver functions on land (Bannister et al., 2003). Depth estimates have $\pm 3 \mathrm{~km}$ error bars (black lines). The dashed line displays the assumed subsurface Moho topography from the best fit of seismic estimates. Maximum (red line) and minimum (green line) dips of the crustal step between East and West Antarctica are displayed. Figure from Tim Stern (personal comm.) 
are (Julià et al., 2004, Zelt \& Ellis, 1999), reducing uncertainty in estimates of Moho depth. Observations are focused on two profiles extending between the Ross Sea and Polar Plateau, coincident with the TAM front. Deepening of the crust from $\sim 25 \mathrm{~km}$ below West Antarctica to $\sim 45 \mathrm{~km}$ beneath Wilkes Subglacial Basin (Figure 2.14) is observed. Of this, a change in depth of $\sim 14 \mathrm{~km}$ occurs over a horizontal distance of $\sim 40 \mathrm{~km}$ beneath the TAM front.

Figure 2.15 displays estimates of crustal thickness from seismic studies, using S-wave receiver functions on ice (Hansen et al., 2009) and P-wave receiver functions on land (Bannister et al., 2003). Estimated depths vary between $18-25 \mathrm{~km}$ in the Ross Embayment to $40-45 \mathrm{~km}$ beneath the Polar Plateau (Figure 2.15). A dip of $7-17^{\circ}$ in the crust is estimated across the TAM.

Free-air gravity anomalies differ from Bouguer anomalies in that the attraction of landmass above the ellipsoid has not been corrected by a Bouguer plate correction (Lowrie, 1997). Thus, free-air anomalies are correlated to the depth of bedrock and the variations in this. Behind the TAM front and into the Polar Plateau, although surface elevations increase with ice thickness, free-air gravity anomalies (FAA) decrease by $\sim 120 \mathrm{mGal}$ over a distance of $\sim 600 \mathrm{~km}$ (Figure 2.15). These anomalies reflect the deepening of the Moho beneath the Polar Plateau and into East Antarctica, which increases in thickness by $\sim 20 \mathrm{~km}$ over the same distance. Note in Figure 2.15 that distances are projected, as seismic profiles were initially at $45^{\circ}$ to the gravity profiles and TAM front (Figure 2.14).

\subsubsection{Gravity data and models}

Residual gravity anomalies observed between New Harbour and Lake Hoare in the Taylor Valley (Figure 2.16) were modelled to demonstrate a thickening of glacial till from $\sim 300$ m near Lake Chad to $~ 500 \mathrm{~m}$ beneath the Suess Glacier in the Taylor Valley (see Section 2.2.2) (Hicks \& Bennett, 1981). Modelled depths agree with sediment and basement depths measured by the DVDP drill sites and results of a seismic refraction study conducted by McGinnis (1979), who estimated basement rock at $\sim 200 \mathrm{~m}$ below New Harbour. These data are amalgamated with gravity measurements collected in this study to extend coverage of gravity observations in the valley, increasing constraints 
when modelling gravity data.

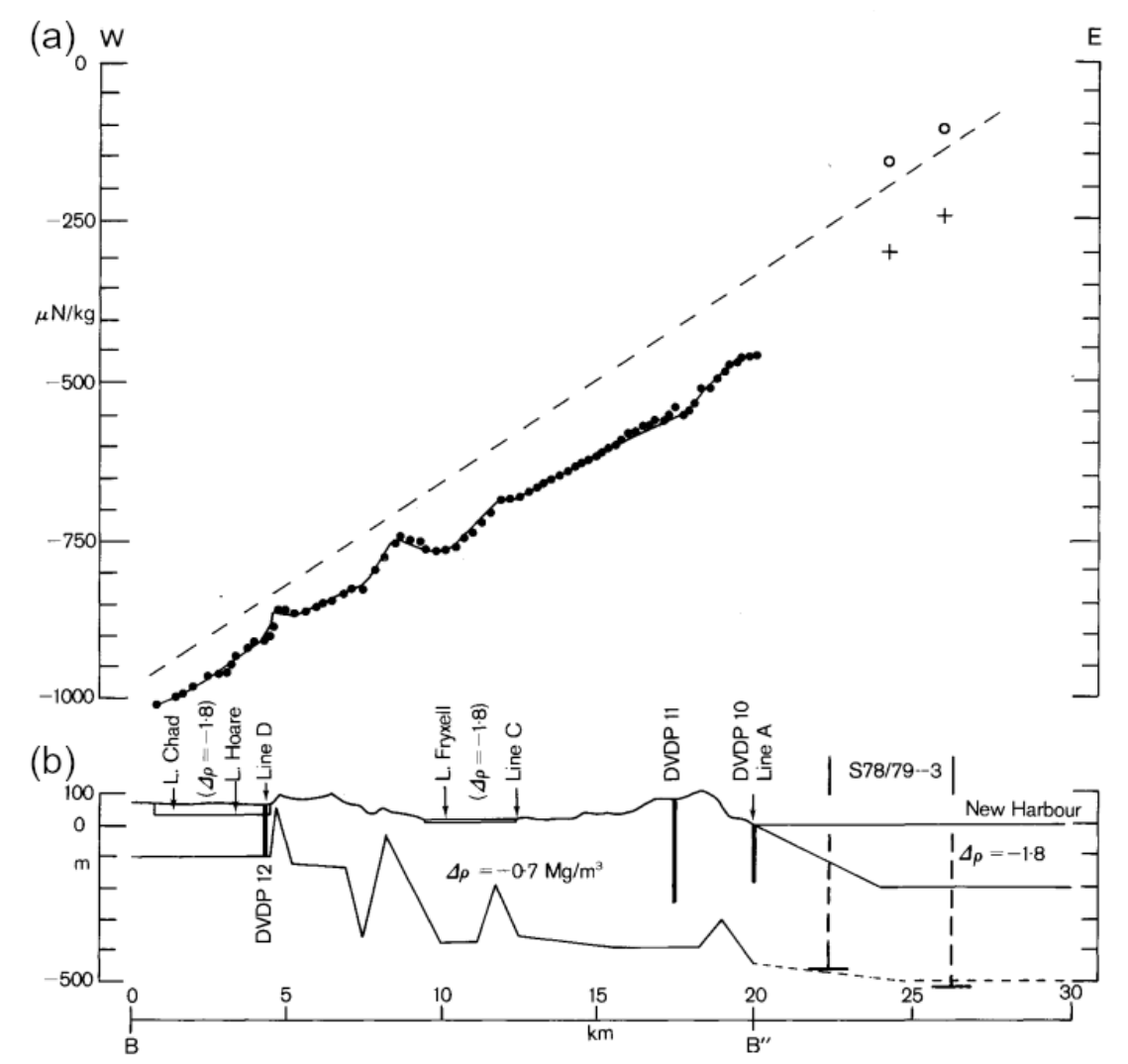

Figure 2.16: (a) Observed (solid circles) and calculated (solid line) Bouguer anomalies between New Harbour and Suess Glacier in the Taylor Valley (Hicks \& Bennett, 1981) against the assumed regional gradient (dashed line). Anomalies are in units of $\mu \mathrm{N} / \mathrm{kg}(1 \mathrm{mGal}=$ $10 \mu \mathrm{N} / \mathrm{kg}$ ). Also shown are gravity values at offshore sites, which have been Bouguer corrected for water depth only (crosses) and the thickness of sedimentary rock (open circles). (b) Twodimensional gravity model of glacial till thickness (in $\mathrm{m}$ ) in the Taylor Valley. Positions and depths of boreholes DVDP10-12 (Talalay \& Pyne, 2017) and seismic refraction line S78/793 (McGinnis, 1980) are projected onto the profile, with estimated and observed depth to bedrock marked below each (bars). Vertical to horizontal exaggeration is 10:1. L. = Lake

To combine existing gravity data (Hicks \& Bennett, 1981) with observations made in this study, corrections are made for uncertainty in elevation and terrain corrections of the previous measurements. Use of barometric altimeters in previous studies to estimate measurement elevation resulted in error up to $\pm 10 \mathrm{~m}$, equivalent to an uncertainty of $\sim 3 \mathrm{mGal}$ in Bouguer anomalies. The corrections applied are discussed in Section 4.1.3.

\subsubsection{Rock density estimates}

The density contrast between denser basement rock and overlying sediments produces a local gravity signal that can be modelled to estimate the thickness of the sediments 
(Keary \& Brooks, 1992). However, there is a trade-off between density contrast and sediment thickness - reducing the contrast results in a thicker modelled layer of sediment.

Mean densities of basement rock in the Taylor Valley range from 2630 to $2790 \mathrm{~kg} / \mathrm{m}^{3}$ between sedimentary and igneous lithologies (Hicks \& Bennett, 1981). Glacial till of the Taylor Valley is well-mixed and low-density, overlying denser basement rock (Haskell et al., 1965). Estimates of till densities from boreholes range between 1850 and $2190 \mathrm{~kg} / \mathrm{m}^{3}$, averaging $2100 \mathrm{~kg} / \mathrm{m}^{3}$ in the upper $300 \mathrm{~m}$ of valley fill (Hicks \& Bennett, 1981). In the northern valleys, basement outcrops are entirely granitic, averaging about $2700 \mathrm{~kg} / \mathrm{m}^{3}$ in density (Haskell et al., 1965).

Chetwin (1998) determined glacial till density in the Mackenzie Basin, New Zealand, using Nettleton's method. Gravity observations were made over a small area with local topographic highs. Data is then reduced using different density in terrain and Bouguer plate corrections. The density value that creates a Bouguer correction with the least correlation to topography is taken as representative of rock density in the area. A mean density of $2350 \pm 50 \mathrm{~kg} / \mathrm{m}^{3}$ is found for glacial tills (Chetwin, 1998). 


\section{Chapter 3}

\section{Methods}

\subsubsection{Instrumentation}

Gravity observations were made using a Scintrex CG-6 Autograv Gravimeter (CG6), which measures the acceleration due to gravity to a factory specified standard deviation of $0.005 \mathrm{mGal}$ (Geomatrix Earth Science Ltd., 2020). Measurements are of the difference in gravity between two survey locations, or at one location over time called relative gravity. Note that from here on in 'gravity' refers to the acceleration due to gravity rather than the force of attraction.

The location and elevation of each observation was recorded using a Septentrio Global Positioning System (GNSS) receiver. Precise point positioning (PPP) (Zumberge et al., 1997) was used to post-process data. PPP uses GNSS satellite clock and orbit corrections from a global network of reference stations to produce corrected coordinates at given survey locations to a constant accuracy with a single receiver, regardless of base station proximity (Natural Resources Canada, 2012). To achieve centimetre precision in horizontal and vertical positions, in-field GNSS measurements are made over a long enough period to resolve local biases such as atmospheric conditions and satellite geometry (NovAtel Inc., 2015). In this study measurements at each observation point were recorded every second for 15 minutes. The location and elevation of all positions were calculated relative to the World Geodetic System 1984 (WGS84) ellipsoid. To ensure consistency between data, existing gravity measurements (Hicks \& Bennett, 1981) are converted to the WGS84 datum. 


\subsubsection{Field procedure}

The gravity survey comprised two principal survey lines: Line $Y$ that traversed northsouth across the Taylor Valley; Line $\mathrm{X}$ that $\mathrm{ran} \sim 80 \mathrm{~km}$ along the valley axis from Marble Point to $\sim 4 \mathrm{~km}$ up glacier from the snout of the Taylor Glacier (Figure 3.1). Line $\mathrm{X}$ consists of new data that are reported here, combined with existing data collected by Hicks and Bennett (1981). In total 119 gravity stations were established, linked at the beginning and end of surveying to an absolute gravity reference station at Scott Base measured by Näränen and Amos, 2019 (personal comm.).

The location and spacing of survey lines were planned using a $2 \mathrm{~m}$ resolution digital elevation model (Howat et al., 2019). In addition, the digital elevation model was used to get improved heights for stations collected by Hicks and Bennett (1981). Line Y was orientated across valley to model the shallow glacial till-bedrock interface in New Harbour. Observations were made on exposed basement rock each side of the valley so that a classical regional-residual gravity field separation (e.g. Stern, 1979) could take place. This allowed an estimate of the thickness of sediments in the Taylor Valley. Sedimentary thickness estimates mean an effective back-strip of gravity values on Line $\mathrm{X}$, up the middle of the valley, to basement-based values can be conducted.

Three gravity measurements were made at each observation point, each with gravity recorded in $0.1 \mathrm{~s}$ intervals for $60 \mathrm{~s}$. The DVDP-8/9 drill (Figure 2.8) site was used as a reference point to previous observations (Hicks \& Bennett, 1981). During surveying observation points were re-occupied at the beginning and end of each day to monitor temporal drift in measurements due to tidal effects and instrument instabilities.

\subsection{Gravity data processing}

This section outlines the theory of acceleration due to gravity and the steps taken in the gravity data processing sequence.

\subsubsection{Background}

Newton's law of gravitation states that two point masses, $m_{1}$ and $m_{2}$, at a distance $r$ apart exert a gravitational force, $\mathrm{F}_{\mathrm{g}}$, upon each other, expressed in equation 3.1.(Fowler 


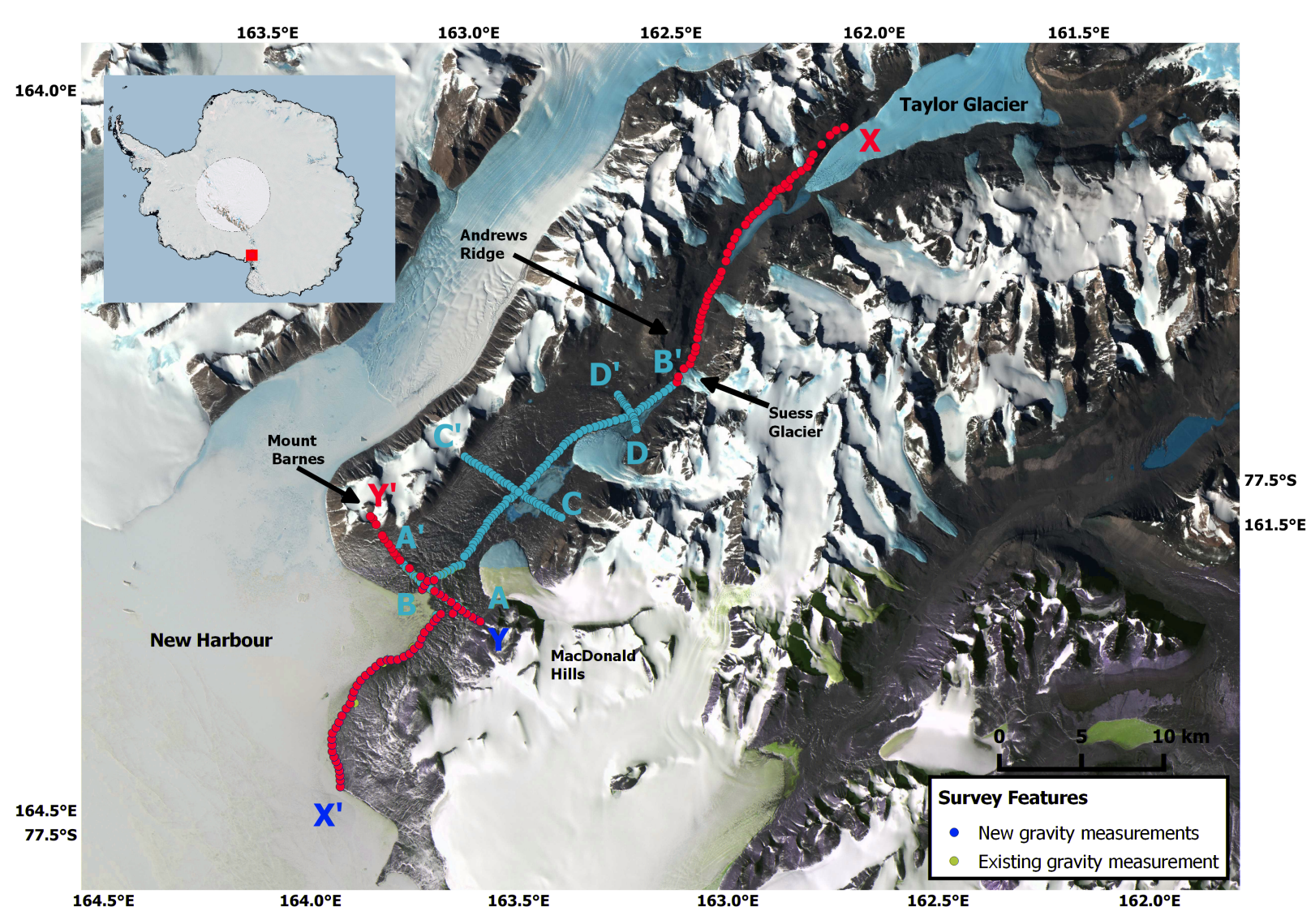

Figure 3.1: Geomorphic map of the Taylor Valley, showing positions of new gravity observations (red circles) collected during this study alongside existing gravity observations (blue circles). Notable landmarks are labelled. The inset map (top left) displays the location of the study area (red square). A-A' represents Survey Line A, B-B' represents Survey Line B, C-C' represents Survey Line C, X-X' represents Survey Line X, Y-Y' represents Survey Line Y. 
et al., 1990).

$$
F_{g}=G \frac{m_{1} m_{2}}{r^{2}}
$$

where $\mathrm{G}$ is the gravitational constant $\left(\mathrm{G}=6.674 \times 10^{-11} \mathrm{~m}^{3} \mathrm{~kg}^{-1} \mathrm{~s}^{-2}\right)$. Approximating the Earth as a uniform sphere of radius $\mathrm{R}_{\mathrm{E}}$ and mass $\mathrm{M}_{\mathrm{E}}$, the gravitational force acting on a mass on Earth's surface is given by equation 3.2 .

$$
F_{g}=G \frac{M_{E} m_{1}}{R_{E}^{2}}
$$

Newton's second law of motion states that a force $(F)$ acting on a constant mass produces an acceleration proportional in magnitude to and in the direction of the force (equation 3.3. Lowrie, 1997):

$$
F=m a
$$

Equating equations 3.2 and 3.3 gives the equation for the acceleration due to gravity (g) (Keary \& Brooks, 1992):

$$
g=-\frac{G M_{e}}{R_{e}^{2}}
$$

Gravitational acceleration is positive towards the centre of mass (Fowler et al., 1990). Equation 3.4 expresses that acceleration due to gravity depends on the distribution of mass within Earth and distance from Earth.

\subsubsection{Gravity anomaly reduction}

Earth is not a uniform sphere with a constant density distribution. Rather, the Earth's ellipsoidal shape, rotation, irregular surface topography, and heterogeneous internal mass distribution cause variation in the potential gravity field with position on Earth (Keary \& Brooks, 1992). The magnitude of gravity measured at any location is controlled by five properties: latitude, elevation, topography, tidal effects, and subsurface 
density variations (Telford et al., 1990).

Small changes in rock density, and thus rock mass, produce variations in the gravity field which are observed by gravimeters. These subsurface density variations are exploited to model the local and regional structure of the subsurface after the factors of latitude, elevation, topography, and tidal effects have been accounted for by a wellestablished set of corrections (Lowrie, 1997; Fowler et al., 1990). These make up the steps involved in the gravity data processing sequence.

\section{Tidal Variation}

Gravimeters are able to detect changes in the gravitational field caused by tidal effects i.e. the movement of the Sun and Moon with position and time relative to the Earth (Telford et al., 1990). The range of diurnal gravity variation can be significant $(\sim 0.3 \mathrm{mGal})$ in residual gravity anomalies $(\sim 5 \mathrm{mGal})$, changing at a rate of $0.05 \mathrm{mGal} /$ hour (Lowrie, 1997; Telford et al., 1990)).

Theory of tidal effects is well established, so the impact of these on gravity measurements can be accounted for at any position (Burger et al., 2006).

\section{Instrument drift}

Gravimeters have inherent instabilities that cause drift of gravity readings with time, unrelated to the effects of latitude, elevation, tidal effects, etc. Instrument drift is caused by variations in internal structure of the instrument that occur due to temperature changes (leading to thermal expansion of the beam within the instrument) and wear of the gravimeter with age.

The effect of instrument drift on gravity measurements is linear, compared to tidal effects which are periodic. Figure 3.2 displays instrument and tidal drift over a 2 day period with an observed linear drift rate of $0.01 \mathrm{mGal} /$ day. Periodicity in the signal is due to tidal effects, while the overall positive linear trend is a result of instrument drift.

In this study gravity stations were re-occupied at the start and end of each day to quantify drift in observations throughout each period of surveying (Figure 3.3). Linear drift is assumed between readings, allowing calculation of a drift rate by taking the 


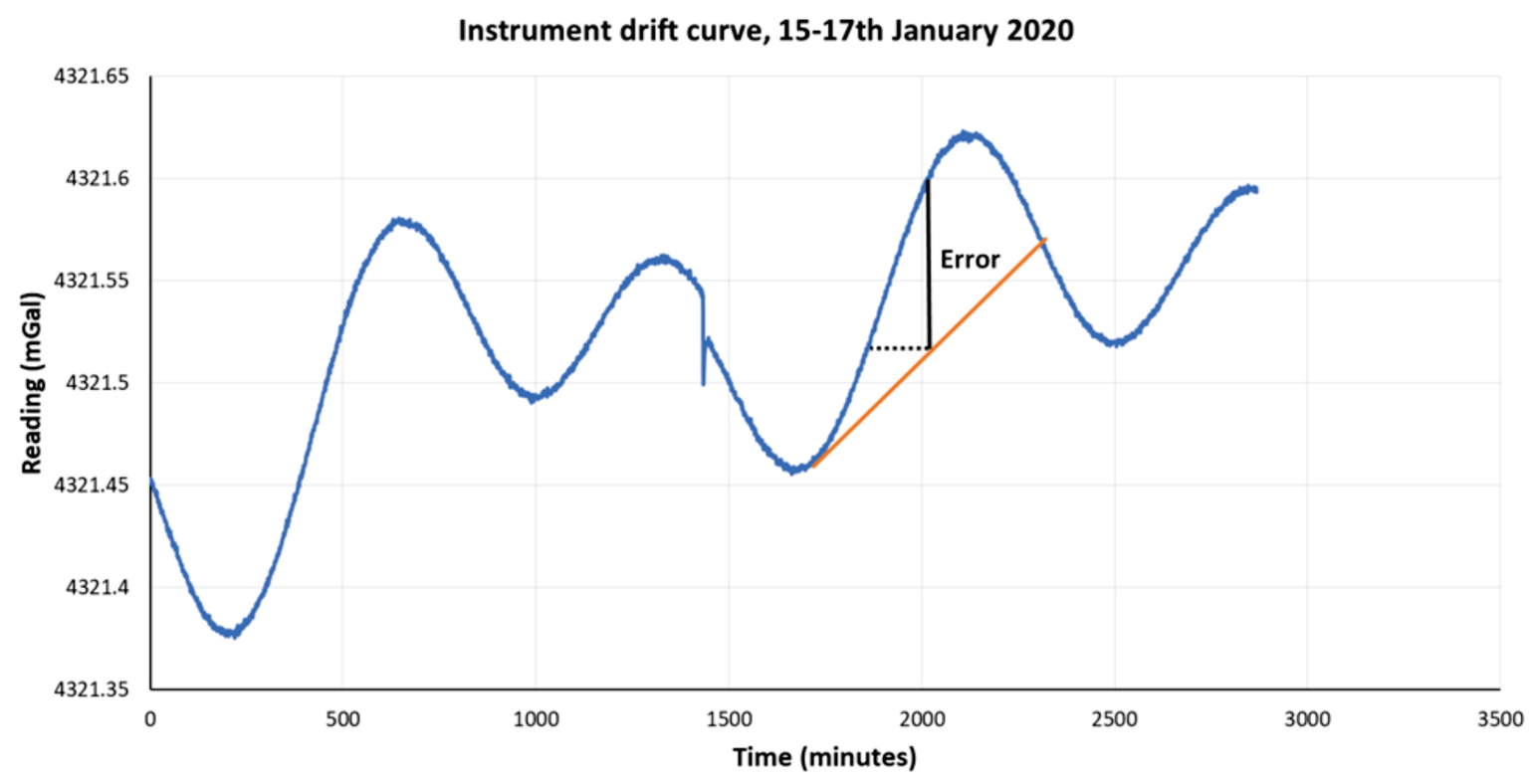

Figure 3.2: A plot of instrument readings at one location over two days in January 2020. Readings were made on the CG-6 Gravimeter every minute. The blue line is observed gravity readings with slow, varying, linear drift of up to $0.01 \mathrm{mGal} /$ day. The orange line represents linear drift between two points ( $\sim 12$ hours apart) that may have been before and after a day of surveying. The maximum error due to adopting a linear, compared to a higher order, approach is $\sim 0.07 \mathrm{mGal}$. The jump in anomalies before 1500 minutes is due to manual level adjustment of the instrument.

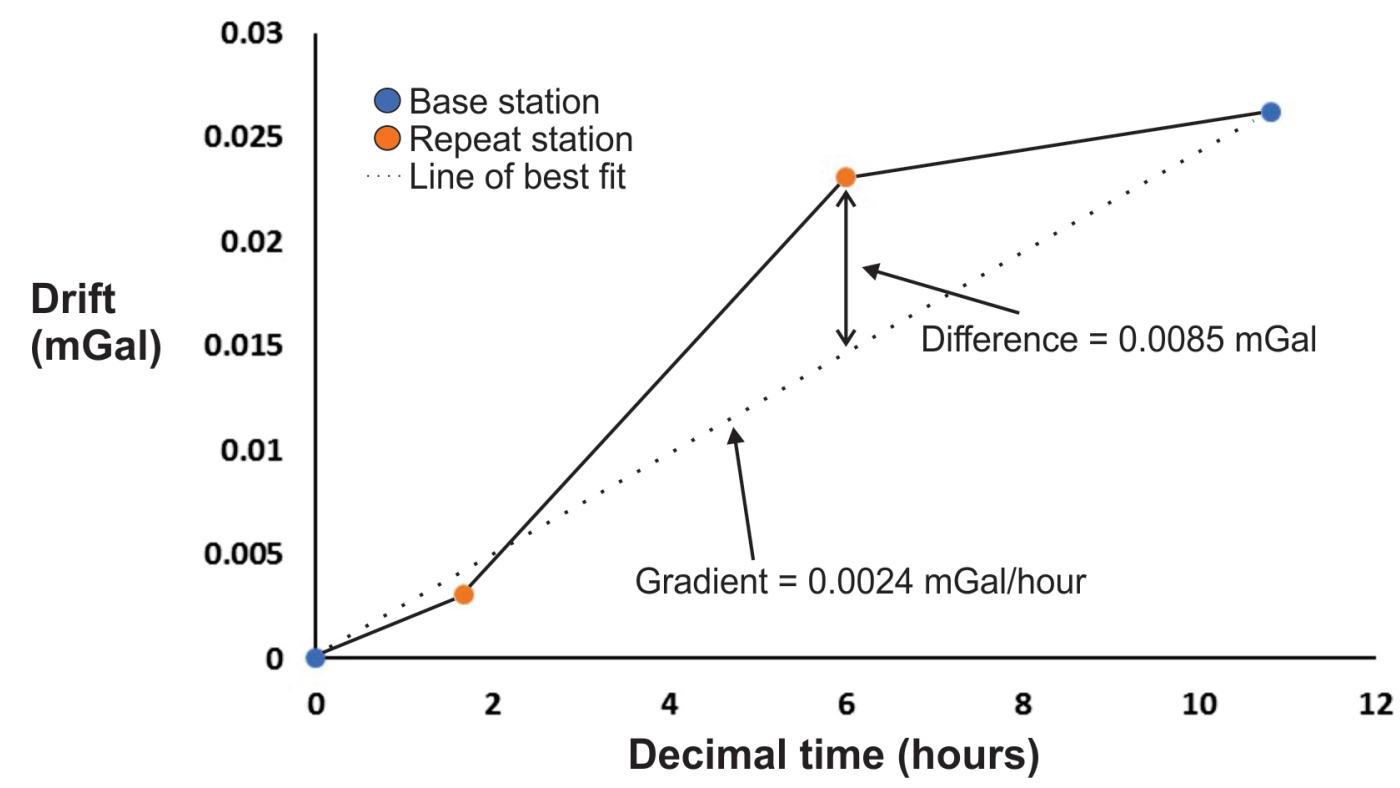

Figure 3.3: A linear drift curve (dashed line) calculated using measurements at base stations (blue circles) and an arbitrary station located along the survey line (orange circles) during a single day of surveying. The linear drift rate is $0.0024 \mathrm{mGal} /$ hour on this day of surveying. The solid black line displays non-linear drift between base and repeat measurements. Maximum error between linear and non-linear drift rates is $0.0085 \mathrm{mGal}$. 
difference in readings divided by the time between measurements, expressed in equation 3.5

$$
g_{\text {drift }}=\frac{g_{2}-g_{1}}{t_{2}-t_{1}}
$$

Where $g_{1}$ and $g_{2}$ are observed gravity at times $t_{1}$ and $t_{2}$ respectively. Figure 3.3 shows a drift curve calculated using a simple looping procedure. Gravity is measured at a base station at the start and end of the day, and twice at an arbitrary intermediate observation point during surveying. Measurements are shifted relative to measured gravity at the base station, and equation 3.5 is used to calculate the drift rate in measurements, equal to $0.0024 \mathrm{mGal} /$ hour over that specific day of surveying.

Assumption of linear drift between stations introduces error in to the calculated drift rate. In Figure 3.2, the difference between a linear drift rate calculated from two stations compared to a continuous drift rate is up to $0.07 \mathrm{mGal}$. This is partially accounted for through use of looping during surveying, displayed in Figure 3.3, where the maximum difference between linear and non-linear drift rates is $\sim 0.0085 \mathrm{mGal}$.

Individual gravity measurements $\left(\mathrm{g}_{\mathrm{obs}}\right)$ are corrected for drift using equation 3.6:

$$
g_{\text {shift }}=g_{\text {obs }}-t . g_{\text {drift }}
$$

where $\mathrm{g}_{\text {shift }}$ is relative gravity at a base station such as the DVDP-8/9 drill site, $\mathrm{t}$ is time the observation was made, and $g_{\text {drift }}$ is the drift rate in mgal/hour. Subtracting the drift rate from gravity observations corrects for the effects of both tidal variation and instrument drift.

\section{Absolute gravity calculation}

Absolute gravity is the absolute acceleration of gravity at a location on Earth's surface at any particular time (Burger et al., 2006). Converting observations to absolute gravity is beneficial as absolute gravity is comparable between studies, whereas relative gravity observations are not.

To calculate absolute gravity from relative gravity observations a site of measured ab- 
solute gravity must be occupied during surveying. In this study, the absolute gravity station at Scott Base observed by Näränen and Amos, 2019 (personal comm.) was occupied. Relative gravity observations are converted to absolute gravity using equation 3.7

$$
g_{a b s}(\text { site })=g_{\text {observed }}(\text { site })-g_{\text {shift }}+g_{a b s}(\text { base })
$$

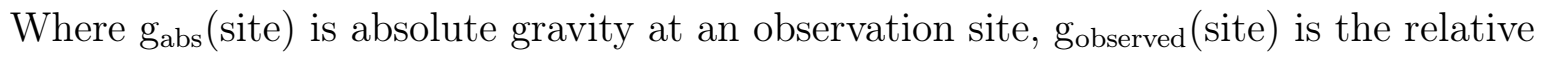
gravity measured at an observation site, $\mathrm{g}_{\text {shift }}$ is the relative gravity reading at Scott Base corrected for drift (equation 3.5), and $g_{\text {abs }}$ (base) is the measured absolute gravity at Scott Base.

\section{Latitude correction}

Gravity varies with latitude due to the rotation of Earth, which produces an outward centrifugal force at the equator that is larger than at the poles. This force acts in the opposite direction to the force of gravity (Telford et al., 1990), thus decreasing gravitational acceleration by up to $0.3 \%$ at equatorial latitudes (Keary \& Brooks, 1992).

Earth responds to the centrifugal force over long time scales by forming an equatorial bulge and flattening of the polar regions, causing a $21 \mathrm{~km}$ radial difference between the equator and poles (Telford et al., 1990). Given equation 3.4 the bulge results in greater gravitational acceleration at the poles than the equator. Conversely, the larger equatorial radius means more mass is present at the equator than at the poles, which acts to increase gravitational acceleration towards the equator. Combined, the effects of Earth's rotation, oblate shape, and increased equatorial mass cause observed gravity at the poles to be $\sim 5180 \mathrm{mGal}$ greater than at the equator.

To correct for variations in gravity with latitude a reference surface is defined that best fits Earth's gravity field; the reference ellipsoid (Telford et al., 1990). The reference ellipsoid is an equipotential surface that approximates the sea level surface of Earth (Keary \& Brooks, 1992). The ellipsoid is a simplification of the geoid, the equipotential surface of global mean sea level under the influence of gravity and rotation alone, 


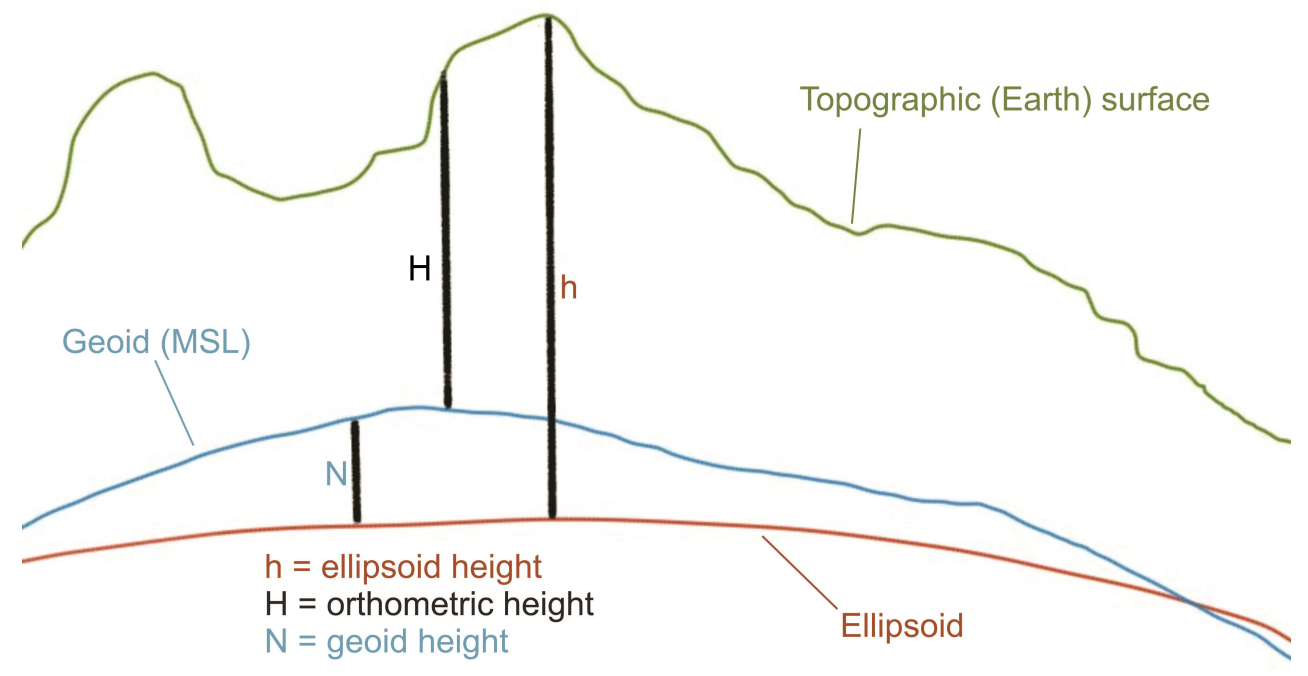

Figure 3.4: The topographic (green line), ellipsoidal (orange line), and geoidal (blue line) surfaces of Earth. N - elevation difference between ellipsoidal and geoidal surfaces; $\mathrm{H}$ - elevation difference between geoidal and topographic surfaces; $\mathrm{h}$ - elevation difference between ellipsoidal and topographic surfaces. Figure from Environmental Systems Research Institute (2013).

rarely varying by more than $100 \mathrm{~m}$ from the geoid. The geoid is characterised by broad undulations caused by Earth's heterogeneous mass distribution. In contrast, the shape of the reference ellipsoid is constant and therefore more suitable as a firstapproximation of gravity at a given latitude (Keary \& Brooks, 1992, Telford et al., 1990). Figure 3.4 is a schematic diagram of differences in the geoid, ellipsoid, and orthometric surfaces.

Three equations have been developed that approximate gravity on the ellipsoid. The first approximation was the 1930 International Gravity Formula, expressed in equation 3.9 ,

$$
g_{1930}=978049\left(1+0.0052884 \sin ^{2}(l)-0.0000059 \sin ^{2}(2 l)\right)
$$

where $\mathrm{g}_{1930}$ is approximate gravity on the ellipsoid normal to the survey site, and $l$ is latitude of the observation site. Improved accuracy of geodetic parameters with new satellite technology led to development of the Geodetic Reference System 1967 (GRS67), and the International Gravity Formula 1967 (Nagy, 1978): 


$$
g_{1967}=978031.846\left(1+0.005278895 \sin ^{2}(l)+0.000023462 \sin ^{4}(l)\right)
$$

The currently used formula exists due to an improvement in the reference ellipsoid, the Geodetic Reference System 1980 (GRS80). The World Geodetic System 1984 (WGS84) used in modern surveying is based on GRS80, and differences between the two are insignificant (Li \& Götze, 2001). The accompanying International Gravity Formula is expressed in equation 3.10 (Moritz, 1980):

$$
g_{1980}=978032.7\left(1+0.0053024 \sin ^{2}(l)-0.0000058 \sin ^{2}(2 l)\right)
$$

In this study GNSS-derived positions and elevations reference WGS84 and latitude corrections are calculated using equation 3.10 .

\section{Free-air correction}

Gravitational acceleration is inversely proportional to the square of distance from the centre of Earth (equation 3.4). The free-air correction (FAC) accounts for local change in gravity with elevation (Figure 3.5) (Lillie, 1999) by amending data for the height difference between the observation point and the reference ellipsoid (Figure 3.4) (Connor \& Connor, 2017). The free-air correction is calculated using equation 3.11 .

$$
g_{f a}=0.3086 h
$$

Where $\mathrm{h}$ is the orthometric elevation (elevation above sea level) of the observation point. The FAC is positive for observations above the reference ellipsoid as gravity decreases with elevation (Keary \& Brooks, 1992). The constant, 0.3086, is derived from equation 3.4 with respect to the radius $R_{E}$ of Earth. More detail on the derivation of the free-air constant is given by Lillie (1999). As gravity measurements typically have an accuracy on the order of $\sim 0.01 \mathrm{mGal}$ it is essential to measure station elevation to centimetrescale accuracy, minimising uncertainty in the FAC (Burger et al., 2006). 


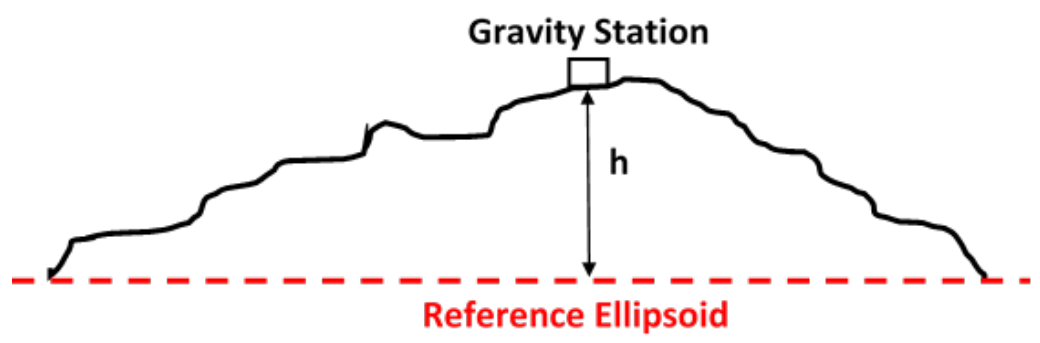

Figure 3.5: Schematic diagram of the free-air correction for an observation at a height $\mathrm{h}$ above the reference datum. Observed gravity is reduced by increasing elevation between the observation point (open box) and the reference ellipsoid (dashed red line).

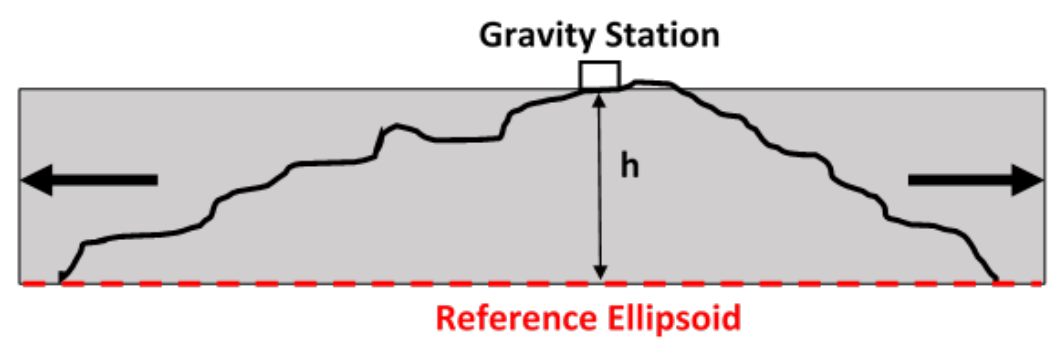

Figure 3.6: Schematic diagram of the Bouguer plate correction, accounting for rock mass between the observation point and the reference ellipsoid. The grey region corresponds to an infinite horizontal slab of density $2670 \mathrm{~kg} / \mathrm{m}^{3}$ and thickness equal to elevation (h) of the gravity observation (open box) above the reference datum (dashed red line).

\section{Bouguer plate correction}

A consequence of the elevation difference between an observation point and the reference ellipsoid is that excess mass between the surfaces contributes an additional gravitational effect. The Bouguer plate correction (BPC) amends data for the gravitational attraction of mass between the surfaces that is not accounted for in the free-air correction (Telford et al., 1990).

The BPC is calculated assuming an infinite horizontal slab of constant density exists between the observation point and the reference datum (Figure 3.6), given by equation 3.12 (Keary \& Brooks, 1992; Telford et al., 1990):

$$
g_{b c}=2 \pi \rho G h
$$

where $\mathrm{G}$ is the gravitational constant and $\mathrm{h}$ is the difference in elevation between the observation point and reference ellipsoid. Surface rock on the continents of Earth is primarily granitic in composition. Therefore, a density, $\rho$, of $2670 \mathrm{~kg} / \mathrm{m}^{3}$ is assumed 


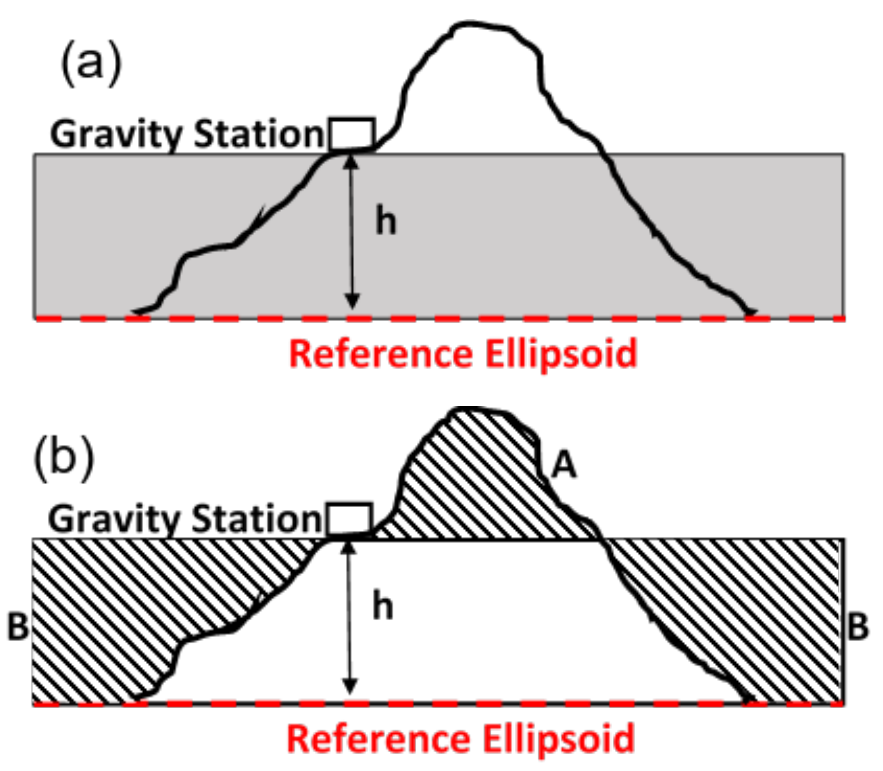

Figure 3.7: (a) The infinite slab (shaded area) applied during the Bouguer plate correction. The observation point (open box) is at height $h$ above the reference datum (dashed red line). (b) Excess (A) and deficit (B) mass resulting from topographic highs and lows in the Bouguer slab respectively, reducing observed gravity.

for the slab (LaFehr, 1991; Telford et al., 1990).

\section{Terrain correction}

The Bouguer correction is flawed in the assumption that the infinite horizontal slab represents topography above the geoid. (Keary \& Brooks, 1992). Excess (or deficit) mass caused by topographic highs (or lows) relative to the observation point cause the Bouguer correction to under-correct (or over-correct) the gravity data (Figure 3.7) (Telford et al., 1990).

Terrain effects due to this mass imbalance cause error on the order of 10's of milligals in gravity anomalies, and are corrected for by a terrain correction. The terrain correction accounts for the topographic difference in a circle of radius $\sim 22 \mathrm{~km}$ surrounding observation points (Telford et al., 1990). The correction is always positive and added to gravity data, as topography above and below the Bouguer slab acts to reduce the observed gravity (Telford et al., 1990).

Classically, terrain corrections were determined by estimating terrain variations in segments of differing radii in a circular graticule around the observation point (Figure 3.8) (Hammer, 1939). Estimates to $170 \mathrm{~m}$ were made in field, while those to $22 \mathrm{~km}$ are 


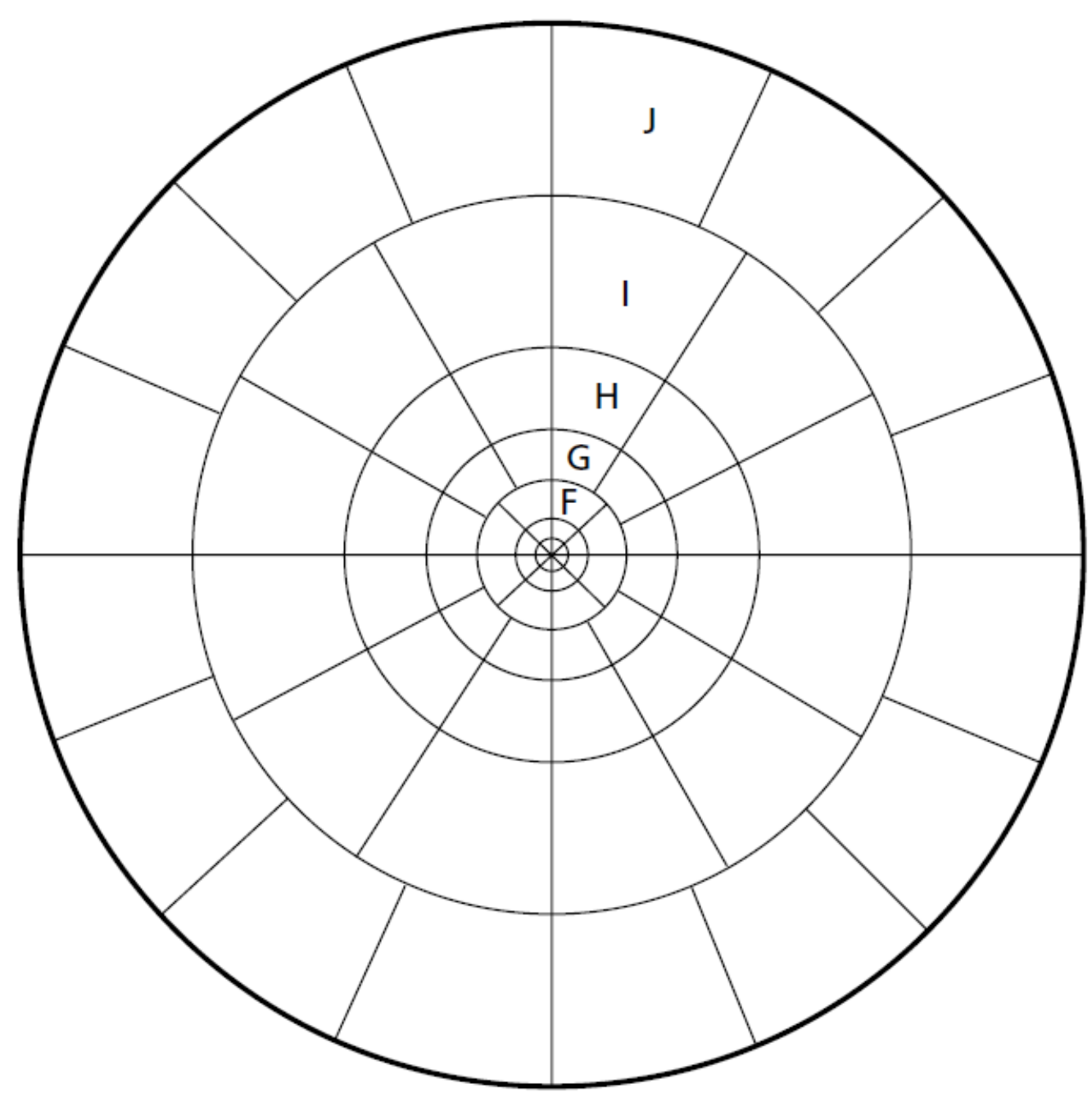

Figure 3.8: The circular graticule used in calculation of terrain corrections (Hammer, 1939). The gravity station is located in the centre, with zones extending out to a radius of $22 \mathrm{~km}$. Innermost zones (A to E) are not shown. Figure from Keary and Brooks (1992).

estimated with a graticule overlain on a topographic map. The total terrain correction is given by the sum of individual corrections in each segment (equation 3.13)

$$
g_{T C}=T_{\text {inner }}+T_{\text {outer }}
$$

Where $T_{\text {inner }}$ represents terrain corrections out to $170 \mathrm{~m}$, and $\mathrm{T}_{\text {outer }}$ represents terrain corrections to $22 \mathrm{~km}$.

The recent development of a 2 m resolution digital elevation model (DEM) of Antarctica (Howat et al., 2019) allows computational calculation of all terrain corrections in this study, removing error involved in estimations made by eye in-field and with topographic 


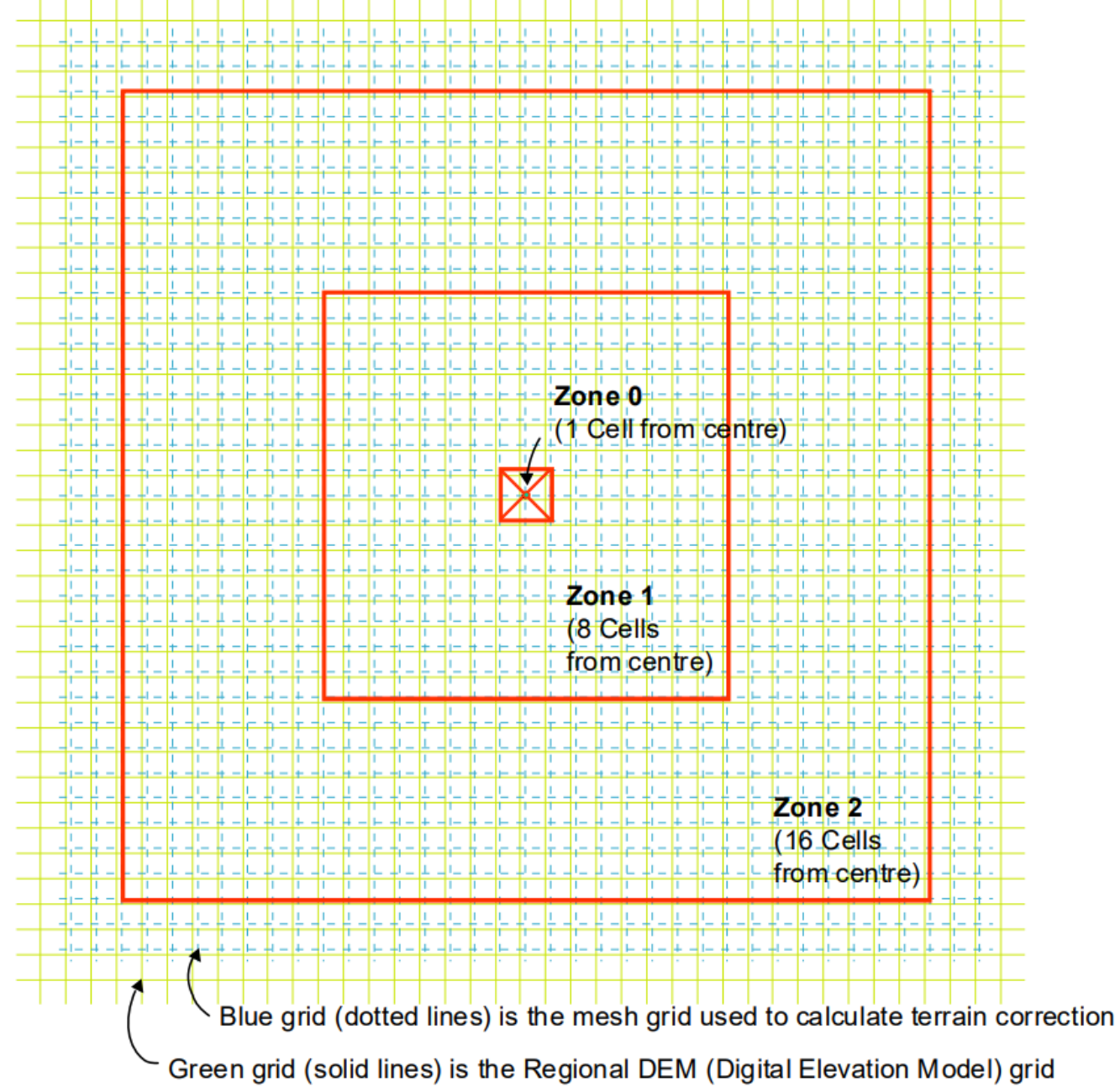

Figure 3.9: Correction grid applied to calculate terrain corrections in Oasis Montaj. The regional DEM (green grid) and mesh grid used to calculate terrain corrections (green grid) are displayed. Near, intermediate, and far zones are displayed (red boxes). Figure from Whitehead (2010).

maps. The program Oasis montaj developed by Geosoft was used to calculate inner $(5 \mathrm{~km})$ and outer $(22 \mathrm{~km})$ terrain corrections on land using $2 \mathrm{~m}$ and $8 \mathrm{~m}$ resolution DEMs respectively. Outer terrain corrections located offshore were calculated using a $1 \mathrm{~km}$ resolution bathymetric model (Fretwell et al., 2013).

Oasis montaj calculates terrain corrections by draping a lower resolution regionalscale $(\sim 20 \mathrm{~km})$ DEM over a higher resolution, local-scale $(\sim 5 \mathrm{~km})$ DEM, producing a regional terrain correction grid (Figure 3.9). A combination of methods developed by Kane $(1962)$ and Nagy $(1966)$ are used to calculate corrections. Full explanation of the methods involved in calculation of terrain corrections is available in the supporting documents of Oasis Montaj (Montaj, 2004). 


\subsubsection{The Bouguer anomaly}

Above, four of the five factors that determine the magnitude of gravitational acceleration at Earth's surface have been discussed. The Bouguer anomaly represents the difference between the measured and calculated gravity at an observation point. The calculated value of gravity at the observation point $\left(\mathrm{g}_{\mathrm{bp}}\right)$ is the combination of the gravitational effects of elevation, mass, terrain differences from the geoid, and latitude (Keary \& Brooks, 1992), expressed in equation 3.14 .

$$
g_{b p}=g_{1980}-g_{f a}+g_{b c}-g_{t c}
$$

where $\mathrm{g}_{1980}$ is gravity at latitude $l$ (the latitude correction), $\mathrm{g}_{\mathrm{fa}}$ is the free air correction, $\mathrm{g}_{\mathrm{bc}}$ is the Bouguer plate correction, and $\mathrm{g}_{\mathrm{tc}}$ is the terrain correction.

The difference in observed, $g_{a b s}\left(\right.$ site), and expected, $g_{b p}$, gravity at an observation point is due to density variations within the Earth's subsurface, called the Bouguer anomaly $\left(g_{b a}\right)$ :

$$
\begin{gathered}
g_{b a}=g_{a b s}(\text { site })-g_{b p} \\
g_{b a}=g_{a b s}(\text { site })-g_{1980}+g_{f a}-g_{b c}+g_{t c}
\end{gathered}
$$

The Bouguer anomaly can be interpreted in terms of lateral and vertical variations in density. A positive anomaly $\left(\mathrm{g}_{\mathrm{abs}}>\mathrm{g}_{\mathrm{bp}}\right.$ ) represents excess mass as gravitational attraction is greater than expected on the reference datum. The opposite is true for a negative anomaly (Lowrie, 1997).

\subsubsection{Separation of regional and residual gravity anomalies}

The Bouguer gravity anomaly is a combination of gravity signals of different wavelengths and is often simplified in to two effects: that of the shallow localised structure and deep-seated regional structure (Keary \& Brooks, 1992). In gravimetric analysis it is desirable to remove effects of the long-wavelength regional signal so that shortwavelength residual anomalies associated with the glacial till-bedrock density contrast can be interpreted (Burger et al., 2006). Figure 3.10 is a schematic diagram of the sep- 


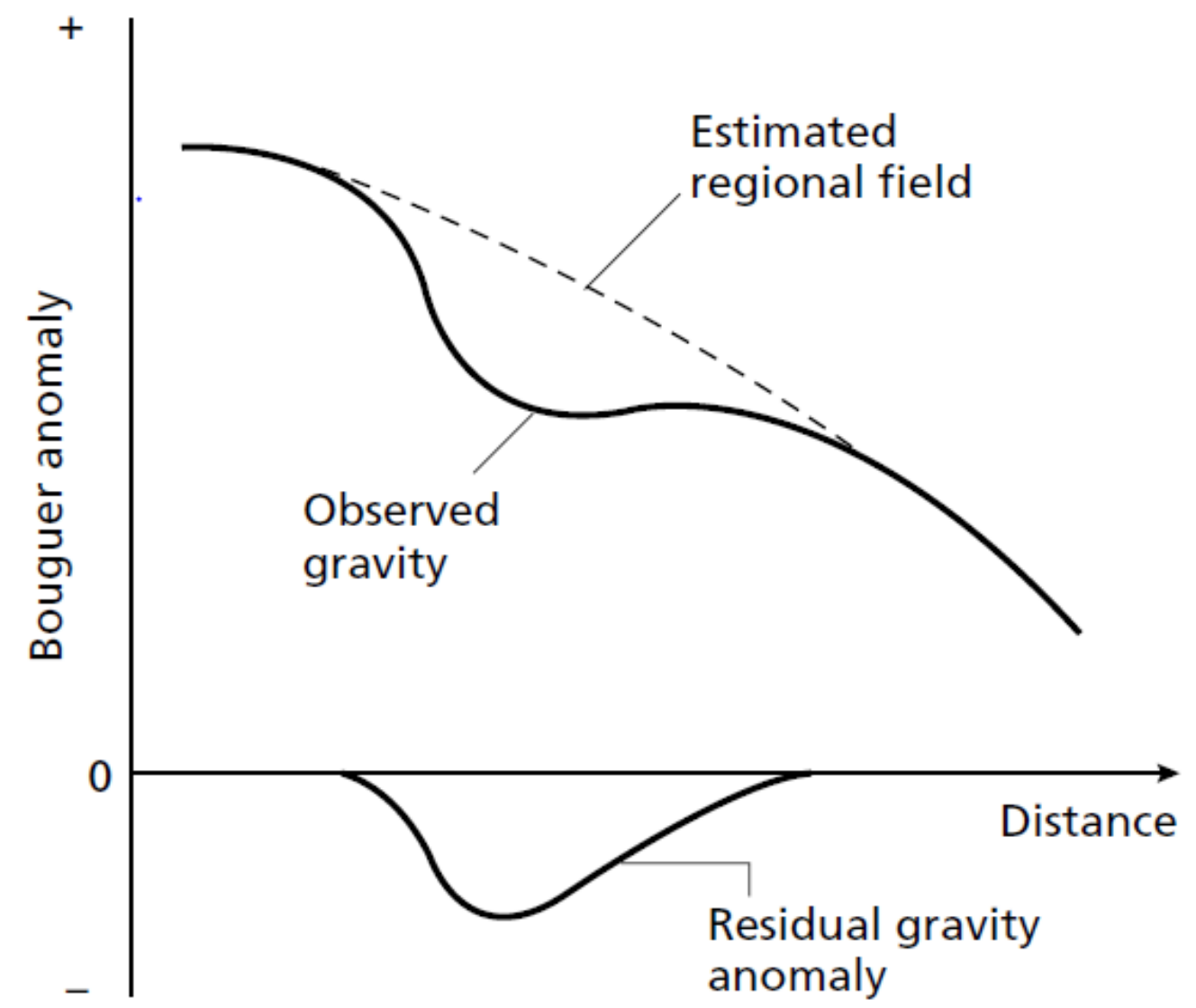

Figure 3.10: Separation of regional (dashed line) and residual anomalies (black line; bottom) from observed Bouguer anomalies (black line; top). Figure from Keary and Brooks (1992)

aration of regional and residual gravity anomalies from observed Bouguer anomalies. The depression in residual gravity anomalies represents only local the Bouguer anomalies, while the regional field represents the long-wavelength Bouguer anomalies.

The separation from long to short-wavelength anomalies is non-unique, making separation of the individual signals subjective and in some cases difficult (Keary \& Brooks, 1992). One method of separation is by using gravity observations made on basement rock only and fitting a mathematical surface to these values. This is then defined as a regional gravity field for that specific gravity survey. Line Y in this study (Section 3.0.2 was constrained by observations on bedrock at each end, allowing the north-south regional gradient in the direction of the line to be calculated using equation 3.17 .

$$
g_{\text {gradient }}=\frac{\Delta g_{b a}}{\Delta \text { distance }}
$$

The regional gradient is the linear change in Bouguer anomalies with distance where, in 
equation 3.17, $\Delta \mathrm{g}_{\mathrm{ba}}$ is difference in Bouguer anomalies between end points of the survey line, and $\Delta$ distance is the length of the survey line. By then calculating the regional gravity at each observation point using the regional gradient, and subtracting from observed Bouguer anomalies at each survey point, the remaining signal is theoretically the residual anomalies.

\subsection{Uncertainty in gravity data}

Three sources contribute to uncertainty in residual and Bouguer gravity anomalies: instrument error and drift. latitude and elevation error, and error in calculation of terrain corrections. This section quantifies the relative contribution of each uncertainty source to total uncertainty in residual and Bouguer anomalies.

\subsubsection{Instrument error and drift}

In field factors including unstable terrain, wind, and a faulty instrument can contribute to inconsistent meter readings. Unstable terrain and wind can imbalance the meter during measurements. Therefore, the CG-6 was placed on solid, stable ground at each observation point and readings were taken in sheltered locations wherever possible to reduce the uncertainty in measurements caused by these effects.

The impact of anomalous observations was reduced by averaging three gravity measurements at each position, with gravity in each measured in $0.1 \mathrm{~s}$ intervals for a total of $60 \mathrm{~s}$. Furthermore, the Scintrex CG-6 automatically assigns a standard error based on the standard deviation of observations, on the order of $\sim 0.002 \mathrm{mGal}$, to all measurements.

During surveying observation points were re-occupied to ensure consistency of the equipment. This accounts for both instrument drift and drift due to tidal variation, observed at a maximum of $0.006 \mathrm{mGal} /$ day over one day of surveying. The average difference in drift calculated by the gravimeter and that determined manually assuming linear drift each day is $\pm 0.035 \mathrm{mGal} /$ hour.

Similarly, when a looping procedure isn't applied in calculation of drift corrections due to a lack of intermediate repeat measurements, the calculated drift rate differs on aver- 
age by $-5.6 \times 10^{-5} \mathrm{mGal} /$ hour. This uncertainty is negligible, and has been disregarded in this study.

\subsubsection{GNSS uncertainty}

The elevation of all observation points was measured using a Septentrio GNSS and post-processed using precise point positioning. Positions at observations points were recorded in $1 \mathrm{~s}$ intervals for 15 minutes by the GNSS receiver, resulting in an average elevation uncertainty of $\pm 10 \mathrm{~cm}$, equivalent to an uncertainty of $\pm .019 \mathrm{mGal}$ in Bouguer anomalies.

Latitudinal positions have an average uncertainty of $\pm 3 \mathrm{~cm}$. As a $\pm 1 \mathrm{~m}$ uncertainty in latitude results in a $\pm 0.0008 \mathrm{mGal}$ uncertainty in Bouguer anomalies, these uncertainties have been disregarded in this study.

\subsubsection{Terrain correction uncertainty}

Uncertainty in terrain corrections depend on the resolution of DEMs used. A $2 \mathrm{~m}$ resolution DEM was used to calculate terrain corrections out to $5 \mathrm{~km}$, with outer corrections $(22 \mathrm{~km})$ calculated using an $8 \mathrm{~m}$ resolution DEM on land (Howat et al., 2019) and a $1 \mathrm{~km}$ resolution bathymetric model offshore (Fretwell et al., 2013). These DEMs are of sufficient resolution to minimise error in terrain corrections. Therefore, uncertainty in inner and outer terrain corrections are considered negligible.

Additional uncertainty is due to differences in elevation observed by the GNSS and that calculated in the DEM. Differences exist between the data because of artefacts in models or uncertainty in GNSS-derived elevations. Correlation between DEM elevations and those observed by GNSS in this study is quantified with a linear fit; a $\mathrm{R}^{2}$ value of zero indicates no correlation between datasets while $\mathrm{R}^{2}=1$ represents perfect correlation.

Comparison of 91 gravity stations from this study show near-perfect correlation $\left(\mathrm{R}^{2}\right.$ $=0.99$ ) between DEM- and GNSS-derived elevations (Figure 3.11). The standard deviation of the difference in GNSS and DEM elevations is calculated using equation 3.18 


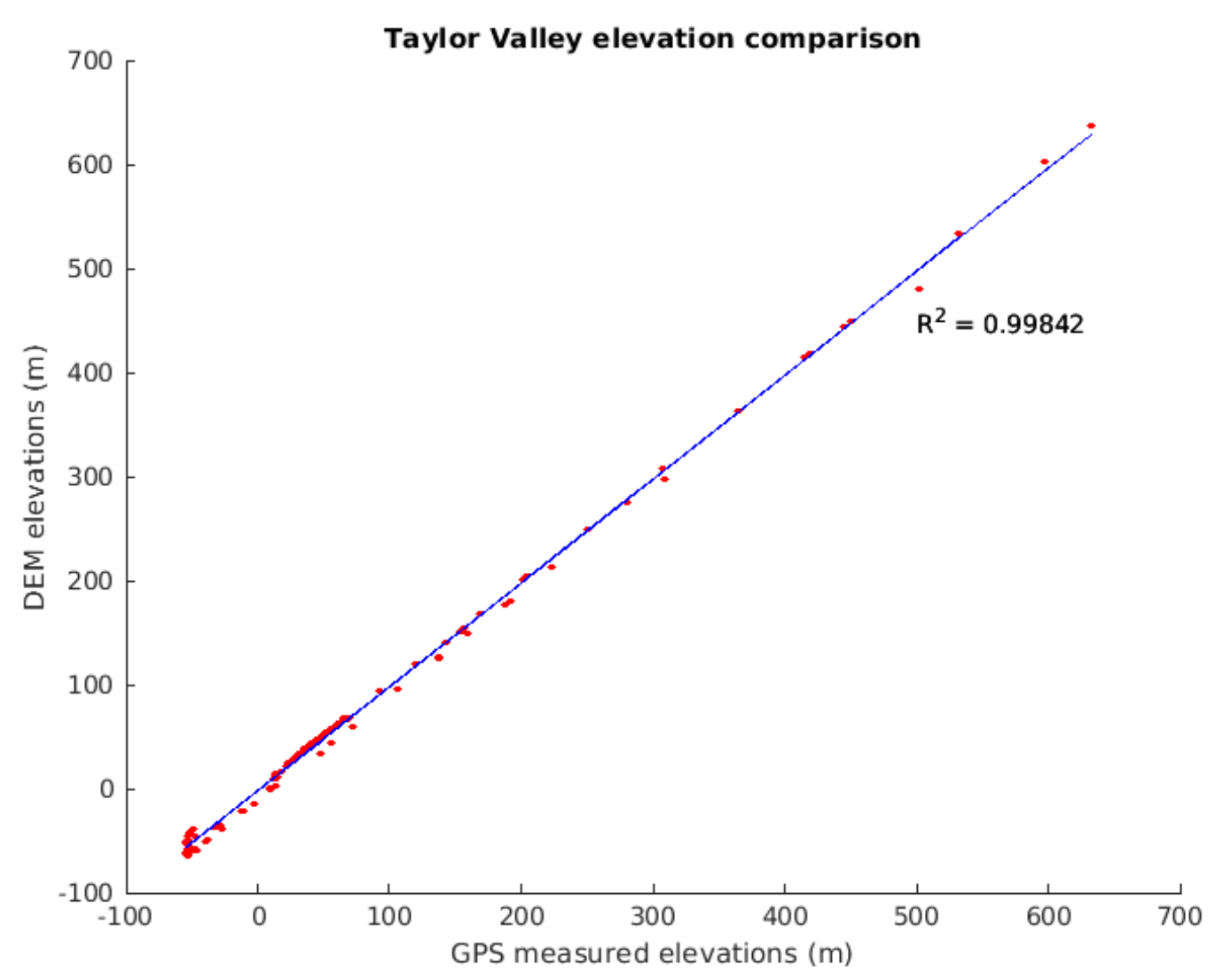

Figure 3.11: Comparison of GNSS measured elevations and those derived from LiDAR DEM (Howat et al., 2019) at all gravity observations (red circles) collected in the Taylor Valley during this study. The blue line is the position along which observations have perfect correlation $\left(R^{2}=1\right)$. The data sets have near perfect correlation $\left(R^{2}=0.99\right)$. 


\begin{tabular}{cccc}
\hline $\mathbf{E}_{\mathrm{tc}}(\mathrm{mGal})$ & $\mathrm{E}_{\mathrm{I}}(\mathbf{m G a l})$ & $\mathbf{E}_{\mathbf{H}}(\mathbf{m G a l})$ & $\mathbf{E}(\mathbf{m G a l})$ \\
\hline 0.003 & 0.035 & 0.019 & 0.04 \\
\hline
\end{tabular}

Table 3.1: The average individual contributions of uncertainties in terrain corrections $\left(\mathrm{E}_{\mathrm{tc}}\right)$, instrument error and drift $\left(\mathrm{E}_{\mathrm{I}}\right)$, and elevation $\left(\mathrm{E}_{\mathrm{H}}\right)$ to the total uncertainty (in mGal) in Bouguer anomalies.

$$
h_{\text {err }}=\sqrt{0.19^{2}+0.1^{2}}=0.19 m
$$

Where $0.1 \mathrm{~m}$ is the standard deviation of GNSS-derived elevations. The contribution of the difference in elevations between data sets to Bouguer anomalies is calculated using equation 3.2 .3

$$
E_{t c}=h^{e r r}(-0.3086+0.04191 \rho)=-0.19 h^{e r r}
$$

Resulting in an average standard error of $0.003 \mathrm{mGal}$.

\subsubsection{Total uncertainty}

The total uncertainty (in mGal) in Bouguer anomalies at each observation point (E) is the Root Mean Square (RMS) of each error source:

$$
E=\sqrt{E_{t c}^{2}+E_{I}^{2}+E_{H}^{2}}
$$

where $\mathrm{E}_{\mathrm{tc}}$ is the terrain correction uncertainty, $\mathrm{E}_{\mathrm{I}}$ is uncertainty from instrument error and drift, and $\mathrm{E}_{\mathrm{H}}$ is uncertainty in GNSS elevations, all of which are displayed in Table 3.1

The average uncertainty in the Bouguer anomaly is $\pm 0.04 \mathrm{mGal}$, The uncertainty in each gravity observation made in this study can be seen in Section A.3. 


\subsection{Gravity modelling}

Gravity models in this study were constructed using Geosoft ${ }^{\circledR}$ GM-SYS software. A simple two-dimensional modelling technique is applied, adopting parameters such as density to estimate the thickness of subsurface units (Montaj, 2004).

\subsubsection{Two-dimensional gravity modelling}

In 2-dimensional gravity modelling the Earth is assumed as 2.5-dimensional in nature; adopted densities vary with depth $(\mathrm{z})$ and in the direction of the profile $(\mathrm{x})$, but not in the strike direction (y) (Figure 3.12). All directions are assumed to extend to infinity.

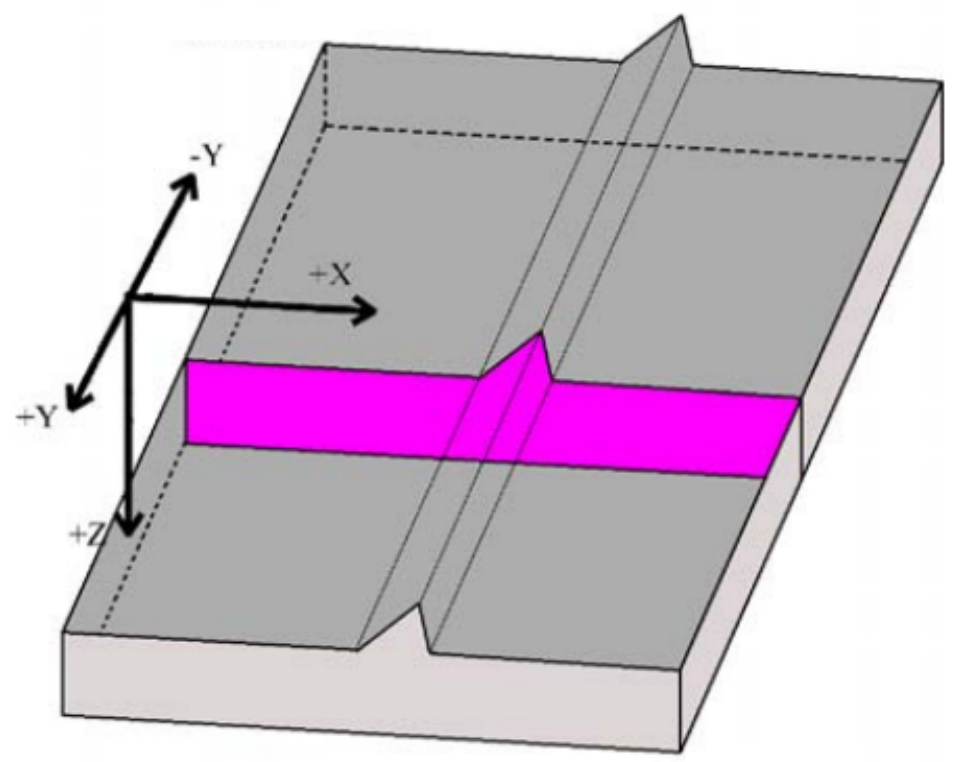

Figure 3.12: Schematic diagram of a two-dimensional gravity model (pink polygon) as modelled in GM-SYS. Distances extend to infinity in x- and y- directions. Densities vary with depth $(\mathrm{z})$ and in the direction of the profile $(\mathrm{x})$, but not in the strike direction $(\mathrm{y})$. Figure from Montaj (2004).

The pink cross section in Figure 3.12 is a schematic of a 2-D model. One layer of constant density is modelled, which extends to infinity in the y-direction. Generally, models are constructed using polygonal units of varying densities. The resultant gravity signal is calculated and compared to that observed to estimate the best fit of the model.

In this study, two-dimensional gravity models are used to define the shallow subsurface 
structure below New Harbour and estimate the deeper regional-scale structure of the Taylor Valley. Models were constructed using the GM-SYS package in Oasis Montaj following established methods (Talwani et al., 1959). The results of 2-D gravity modelling are presented in Chapter 4 


\section{Chapter 4}

\section{Results}

\subsection{Gravity data}

\subsubsection{Existing gravity data}

The prime objective of this study is to acquire from the Taylor Valley new gravity data, integrate these with older data (Hicks \& Bennett, 1981; Sissons, 1980; Smithson, 1972), and then interpret the merged data set.

Hicks and Bennett (1981) measured 154 gravity stations between New Harbour and the Suess Glacier in the Taylor Valley (Figure 3.1). This was a reconnaissance study, conducted to gain knowledge of depth to basement rock in the Taylor Valley. The major uncertainty in existing gravity data was in control of the regional gravity field (Hicks \& Bennett, 1981); however, no formal error estimates are given.

\subsubsection{New gravity data in this study}

In total, 119 new gravity observations were made in this study within the Taylor Valley (Figure 3.1). Measurements were linked to an absolute gravity value of $982977.939 \mathrm{mGal}$ observed at Scott Base by Näränen and Amos, 2019 (personal comm.). Both this and previous studies (Hicks \& Bennett, 1981) had a common observation point at the DVDP-8/9 drill site. In this study an average absolute gravity value of $982912.315 \mathrm{mGal}$ was measured at the drill site, which is $0.046 \mathrm{mGal}$ less than the value of $982912.361 \mathrm{mGal}$ measured by Hicks and Bennett (1981). This difference is not significant, and could 
be simply due to erosion of till at the drill site removing mass around the drill head, or non-linear drift of the meter when making the link between Scott Base and the drill site by either our party or Hicks and Bennett (1981).

Ninety-one new measurements were collected between McMurdo Sound and the Taylor Glacier along the centre of the valley (Figure 3.1), which in effect extended Survey Line B established by Hicks and Bennett (1981) to an $\sim 50 \mathrm{~km}$ long regional gravity line. This is referred to as Line $\mathrm{X}$ when combined with existing measurements. A typical measurement spacing along Line X was between 300 and $400 \mathrm{~m}$.

A further 28 gravity stations made in this study were collected along an 'across-valley' survey line in New Harbour, near the McMurdo Sound coast, in the lower Taylor Valley (Figure 3.1). Measurements were spaced between $\sim 600 \mathrm{~m}$ in the central valley to $300 \mathrm{~m}$ nearer the valley walls. Observations overlap and extend beyond survey Line A-A' measured by Hicks and Bennett (1981), and are referred to as Line Y (Figure 3.1 .

Existing gravity observations (Hicks \& Bennett, 1981) were not made on bedrock at each end of the survey lines, creating an incomplete profile that could not confidently be interpreted in terms of depth to basement rock. Measurements in this study were made on bedrock at the ends of Survey Line Y, reducing uncertainty in estimates of the north-south 'across-valley' regional gravity gradient previously calculated in New Harbour.

\subsubsection{Amalgamation of gravity observations}

Hicks and Bennett (1981) calculated Bouguer gravity anomalies with normal gravity relative to the International Gravity Formula (1930). These were converted to values relative to the WGS84 ellipsoid used in this study with equations 4.1 and 4.2 (Li \& Götze, 2001):

$$
\begin{gathered}
\gamma_{1967}-\gamma_{1930}=\left(19-136 \cdot \sin ^{2} \phi\right) / 10(m G a l) \\
\gamma_{1980}-\gamma_{1967}=0.8316+0.0782 \sin ^{2} \phi(m G a l)
\end{gathered}
$$

where $\gamma_{1930}, \gamma_{1967}$ and $\gamma_{1980}$ represent the 1930, 1967, and 1980 gravity formulas respec- 
tively, and $\phi$ is latitude of the observation point in radians. The 1967 formula (equation 4.1) gives values $\sim 10 \mathrm{mGal}$ less than the 1930 formula at $-72^{\circ}$ latitude, while those of the 1980 formula (equation 4.2 ) are $\sim 0.8 \mathrm{mGal}$ greater. Corrections are applied to absolute gravity measurements from Hicks and Bennett (1981).

Existing gravity measurements (Hicks \& Bennett, 1981) were collected before portable GNSS receivers were available. Instead, tacheometric surveying was the method used to calculate the position and elevation of each observation point. This technique calculates the horizontal distance and change in elevation between two points by observing the vertical angle between the two points and 'the angle at the instrument at one point subtended by a known short distance along a staff kept at another point' (Roy, 2010). Tacheometric surveying lacks accuracy compared to today's GNSS systems, and introduces potentially significant uncertainty in measured positions and elevations.

The correlation, $\mathrm{R}^{2}$, of 0.6535 between elevations of existing gravity observations along Line B (Hicks \& Bennett, 1981) and those from the $2 \mathrm{~m}$ DEM (Figure 4.1) (Howat et al., 2019) indicates relatively poor agreement between the datasets. This is likely to be a result of error in both vertical elevations and horizontal positions of existing data (Hicks \& Bennett, 1981) or error in the DEM as a result of aliasing. Similar analyses are performed for Lines A, C and D of Hicks and Bennett (1981) (Appendix A).

Terrain corrections applied to existing gravity observations were estimated in the field by eye to $390 \mathrm{~m}$ and to a lateral distance of $9900 \mathrm{~m}$ using the United States Geological Survey's Antarctica 1:50,000 Topographic Series S7730 maps which have a contour interval of $50 \mathrm{~m}$. In this study terrain corrections are calculated digitally, and therefore are more accurate as digital elevation models capture features less than $50 \mathrm{~m}$ in wavelength. Thus, an attempt is made to recalculate existing terrain corrections.

Recalculation of existing terrain corrections using Oasis Montaj and DEMs (Section 3.1 .2 is limited by the uncertainty in horizontal position of existing observation points (Hicks \& Bennett, 1981). Latitude and longitudes measured by Hicks and Bennett (1981) have a maximum uncertainty to the nearest $\sim 1 \mathrm{~km}$. Digital terrain corrections with an uncertainty of less than $0.5 \mathrm{mGal}$ require accurate positioning of gravity stations given the high topographic gradient in the valley. Therefore, gravity observations from Hicks and Bennett $(1981)$ are only merged into this study from locations in the 


\section{Line B elevation Comparison}

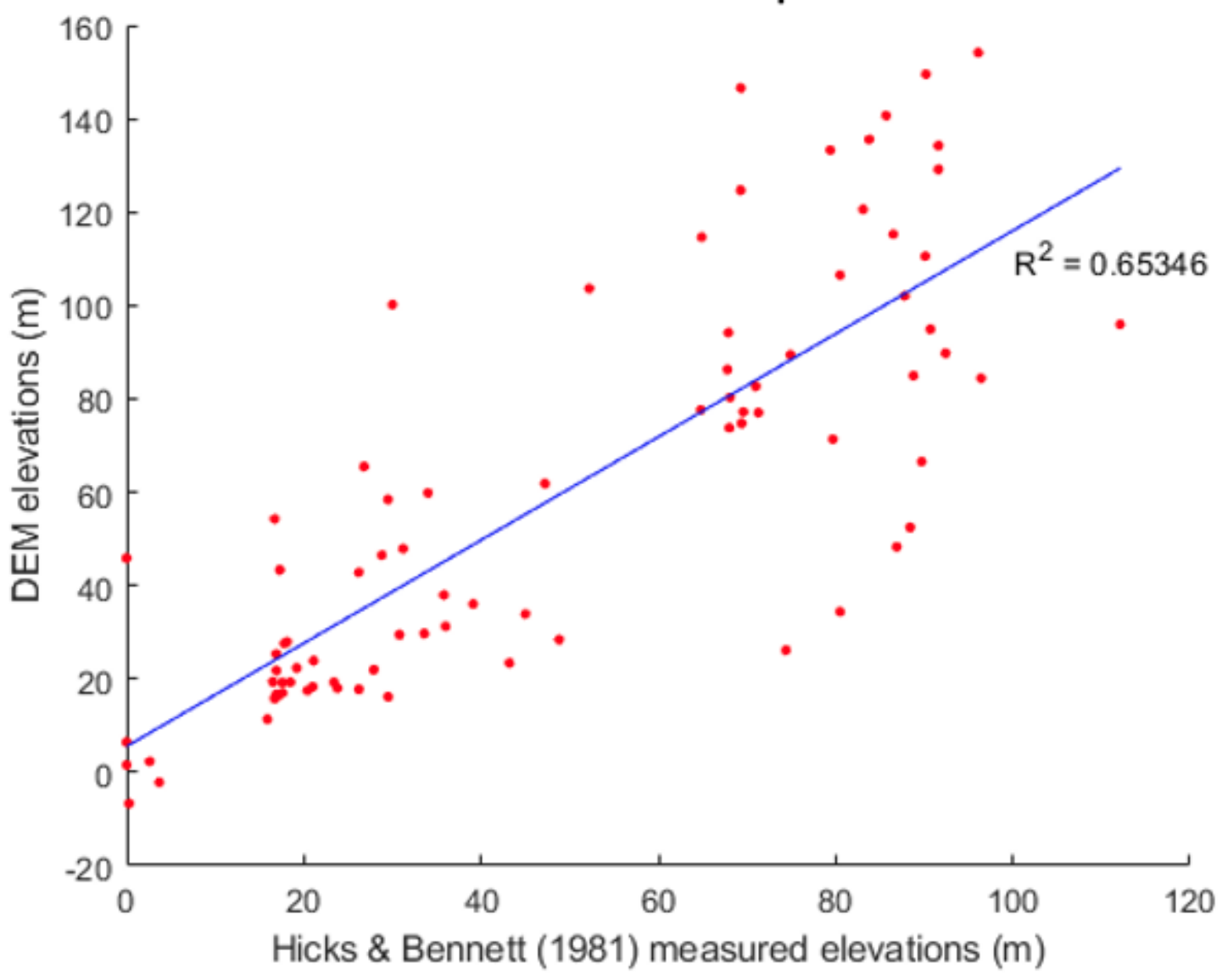

Figure 4.1: Comparison of elevations estimated by the $2 \mathrm{~m}$ resolution digital elevation model (Howat et al., 2019) and those estimated by Hicks and Bennett (1981) at gravity observations (red circles) along Survey Line B. The blue line is the position along which observations have perfect correlation $\left(\mathrm{R}^{2}=1\right)$. The correlation of 0.65 is relatively poor. 
middle of the valley where there is relatively low topographic gradient. Measurements in regions of high topographic gradient are included for comparison with new gravity observations, but neglected in error analysis of gravity models.

\subsection{Gravity Models}

\subsubsection{Introduction}

Forward gravity modelling involves building a theoretical model computationally and adjusting the geometry and density of 'layers' that represent underlying geologic units. The goal is then to minimise the difference between the calculated and observed gravity field (Lowrie, 1997; Telford et al., 1990). Models are typically simple and always nonunique i.e. multiple combinations of different density units can fit the same data-set. For example, the gravity effect of a deep confined mass anomaly can always be reproduced by a more broadly distributed, shallower mass distribution (Burger et al., 2006, Telford et al., 1990). Complementary geophysical studies, such as seismic or electrical resistivity, can help to constrain models, ruling out particular mass distributions.

This chapter presents local and regional 2-D gravity models of the subsurface within and beyond the Taylor Valley. The positions of observation points along Lines X and $\mathrm{Y}$ are projected onto a straight line for simple 2-D modelling. The fit of calculated gravity anomalies from models to the observed anomalies is quantified as the Root Mean Square Error (RMSE), which is the square root of the mean of the squared differences between observations and models.

\subsection{Local gravity models}

Local 'residual' gravity models of the Taylor Valley interpret short-wavelength perturbations in the gravity field in terms of local changes in the thickness of relatively low density glacial sediment resting on higher density bedrock. Models are two-dimensional, which is a good approximation for modelling shallow glacial till where the thickness is small compared to the dimensions of the valley. 


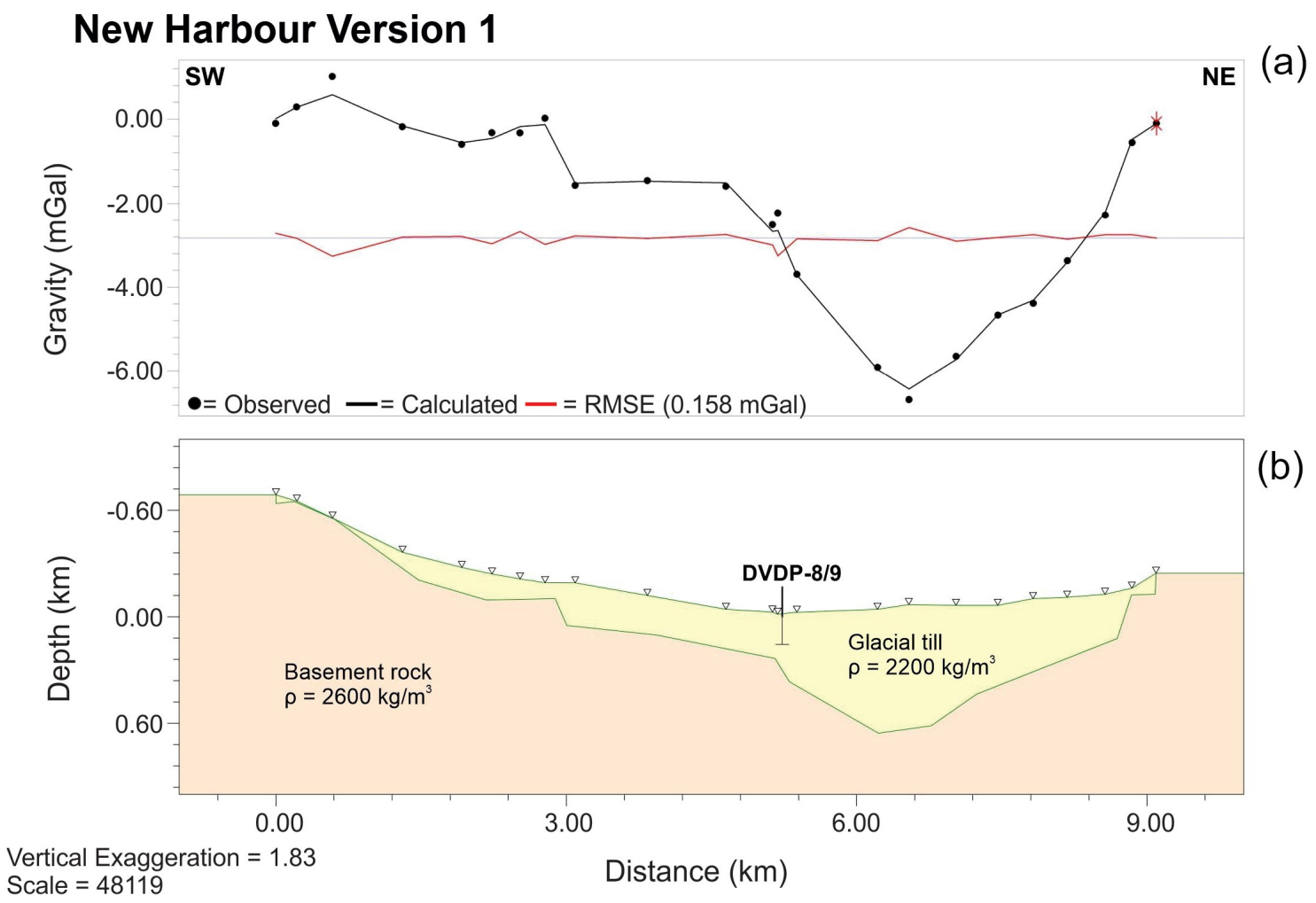

Figure 4.2: Gravity Model Version 1 of New Harbour. (a) Observed (black circles and calculated (black line) gravity anomalies are plotted against the Root Mean Square Error (RMSE) of the fit between calculated and observed anomalies (red line) in mGal. The model has been 'tied' to the furthest north-east station (red cross) where an observation was made on bedrock. (b) Model of the New Harbour subsurface. Measured gravity stations (inverted triangles) and the location of and depth drilled by the DVDP-8,9 drill site (vertical line) are displayed. Subsurface units are differentiated by colour.

\subsubsection{New Harbour gravity models}

New Harbour is located in the lower Taylor Valley, a region of low relief as a result of glacial erosion. New gravity measurements along Line Y (Figure 3.1), across the valley, extend from an elevated cirque on Mount Barnes in the north, to exposed bedrock at the foot of the southern MacDonald Hills (Figure 3.1). The gravity model for this line has a constraint from the DVDP-8,9 drill site (Figure 3.1), where the sediment reached a depth of $157 \mathrm{~m}$ (Mudrey Jr, 1974), giving a minimum glacial till depth in the model (Talalay \& Pyne, 2017).

Density of glacial till in the Taylor Valley is estimated to lie within the range of 1850 to $2190 \mathrm{~kg} / \mathrm{m}^{3}$ based on the analysis described in Section 2.2. Chetwin (1998) measured in situ density contrasts of -300 to $-400 \mathrm{~kg} / \mathrm{m}^{3}$ for glacial till in the South Island of New Zealand. These densities differ by $-400 \mathrm{~kg} / \mathrm{m}^{3}$ from that adopted for glacial till in 


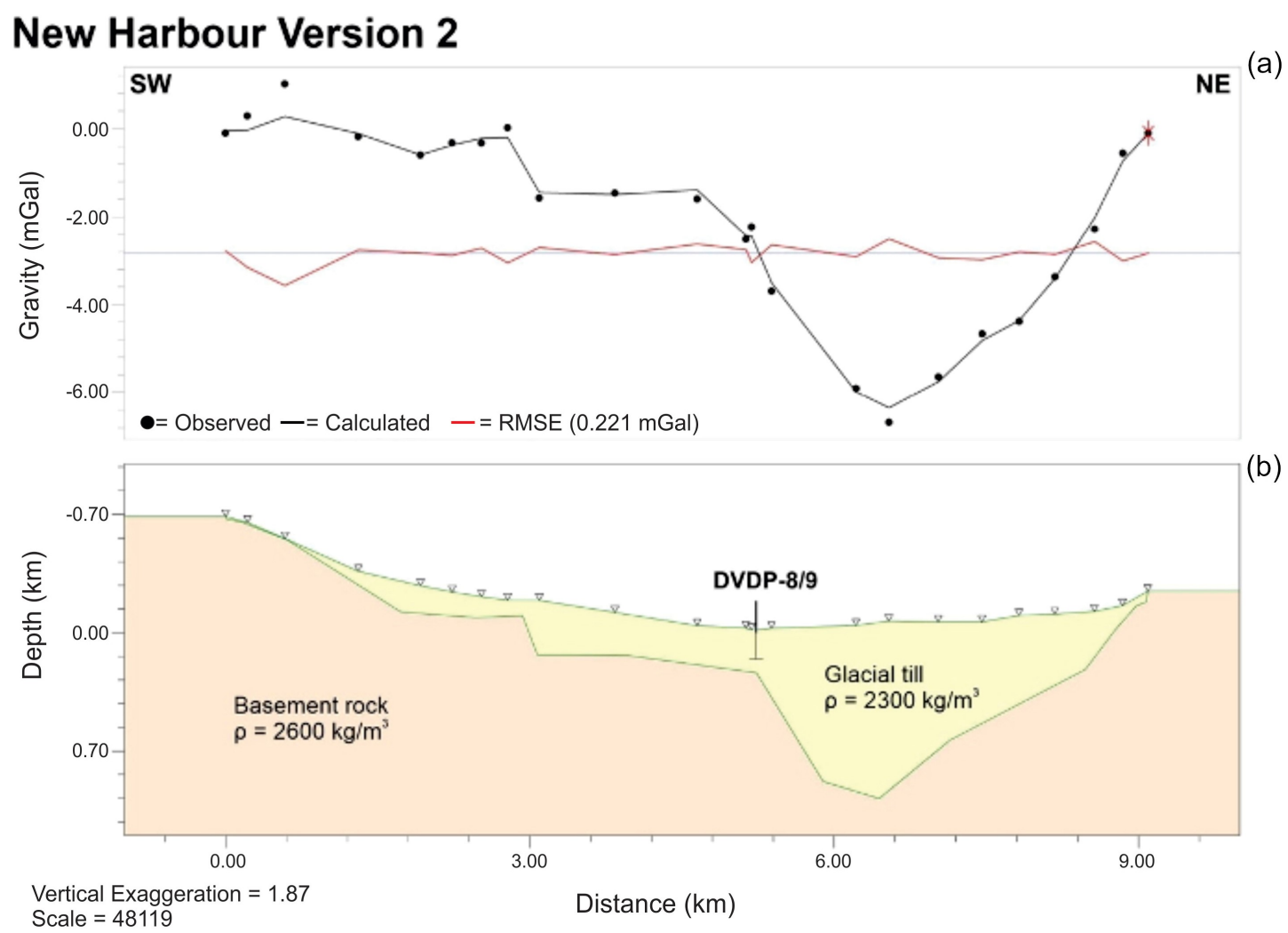

Figure 4.3: Gravity Model Version 2 of New Harbour. (a) Observed (black circles) and calculated (black line) gravity anomalies are plotted against the Root Mean Square Error (RMSE) of the fit between calculated and observed anomalies (red line) in mGal. The model has been 'tied' to the furthest north-east station (red cross) where an observation was made on bedrock. (b) Model of the New Harbour subsurface. Measured gravity stations (inverted triangles) and the location of and depth drilled by the DVDP-8,9 drill site (vertical line) are displayed. Subsurface units are differentiated by colour.

the Taylor Valley by Hicks and Bennett (1981). Resultant gravity models modelling density contrasts estimated by Chetwin (1998) in this study have better agreement between calculated and observed Bouguer anomalies (Figures 4.2 and 4.3 than when a $-700 \mathrm{~kg} / \mathrm{m}^{3}$ density contrast is adopted. Two models are created for New Harbour, using the density contrasts estimated by Chetwin (1998).

Bedrock densities are broadly constrained by the presence of bedrock lithologies such as metamorphic rock, Beacon Sandstone, and intrusive granite (Hicks \& Bennett, 1981), with densities varying between 2220 to $2790 \mathrm{~kg} / \mathrm{m}^{3}$ (Barrett \& Froggatt, 1978, Smithson, 1972). An absence of Beacon Sandstone and intrusive volcanics in the lower Taylor Valley suggests bedrock densities here in the range of $\sim 2600-2700 \mathrm{~kg} / \mathrm{m}^{3}$. From the standpoint of modelling residual gravity anomalies, what is important is the density 
contrast between glacial till and bedrock, not the absolute densities.

In Model Version 1 of Line Y (Figure 4.2), a till-bedrock density contrast of $-400 \mathrm{~kg} / \mathrm{m}^{3}$ is adopted. Sediments are modelled as being 300 $\mathrm{m}$ thick at the DVDP site, reaching a maximum of depth $\sim 650 \mathrm{~m}$ in the valley centre. The RMSE of $0.158 \mathrm{mGal}$ indicates a good fit between model and observations.

The till-bedrock density contrast is reduced to $-300 \mathrm{~kg} / \mathrm{m}^{3}$ in Model Version 2 (Figure 4.3), requiring a maximum sediment thickness of $\sim 980 \mathrm{~m}$, and a thickness of $\sim 250 \mathrm{~m}$ at the DVDP site. RMS error is higher than for Model Version 1 at $0.221 \mathrm{mGal}$.

\subsubsection{Gravity models from previous studies}

Due to uncertainties in elevation and position of observation points in previous studies, it was not possible to make more accurate terrain corrections for the existing gravity observations along Lines $\mathrm{C}$ and D (Figure 3.1); Section 4.1.3). Therefore, the mid (Figure 4.4) and upper-Taylor Valley (Figure 4.5 models published by Hicks and Bennett (1981) cannot be improved on.

Hicks and Bennett (1981) adopt a till-bedrock density contrast of $-700 \mathrm{~kg} / \mathrm{m}^{3}$ in their models. This gives a modelled sediment thickness of $\sim 300 \mathrm{~m}$ for the intersection of Line $\mathrm{C}$ with Line $\mathrm{B}$, reaching a maximum of $\sim 400 \mathrm{~m}$ (Figure 4.4 ). In the model for Line D (Figure 4.5 a maximum depth of $\sim 240 \mathrm{~m}$ is modelled. Note that Bouguer anomalies, rather than residual anomalies, are modelled by Hicks and Bennett (1981).

The till-bedrock density contrast modelled by Hicks and Bennett (1981) is up to $400 \mathrm{~kg} / \mathrm{m}^{3}$ higher than that used in this study. The 'across-valley' regional gradients assumed by Hicks and Bennett (1981) are 1, 1.7, and $0.1 \mathrm{mGal} / \mathrm{km}$ for Lines A, $\mathrm{C}$, and D respectively, compared to an across valley regional gradient of $0.86 \mathrm{mGal} / \mathrm{km}$ calculated for the New Harbour region in this study. This reflects the lack of control in the existing measurements because few observations were made on exposed bedrock; no measurements were made on bedrock in Lines $\mathrm{A}$ and $\mathrm{C}$, but bedrock was observed on Andrews Ridge in Line D of Hicks and Bennett (1981) (Figure 3.1).

Although the differences between model parameters in this and previous studies are significantly different (Hicks \& Bennett, 1981), their effects tended to counteract each 
(a)

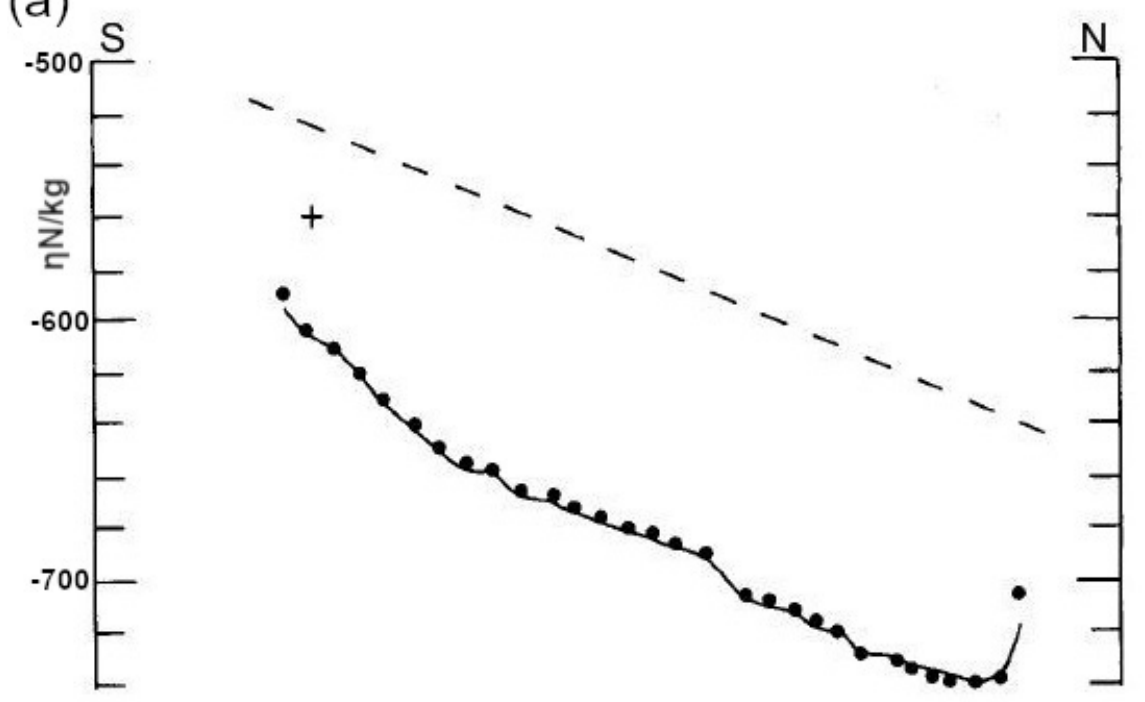

(b)

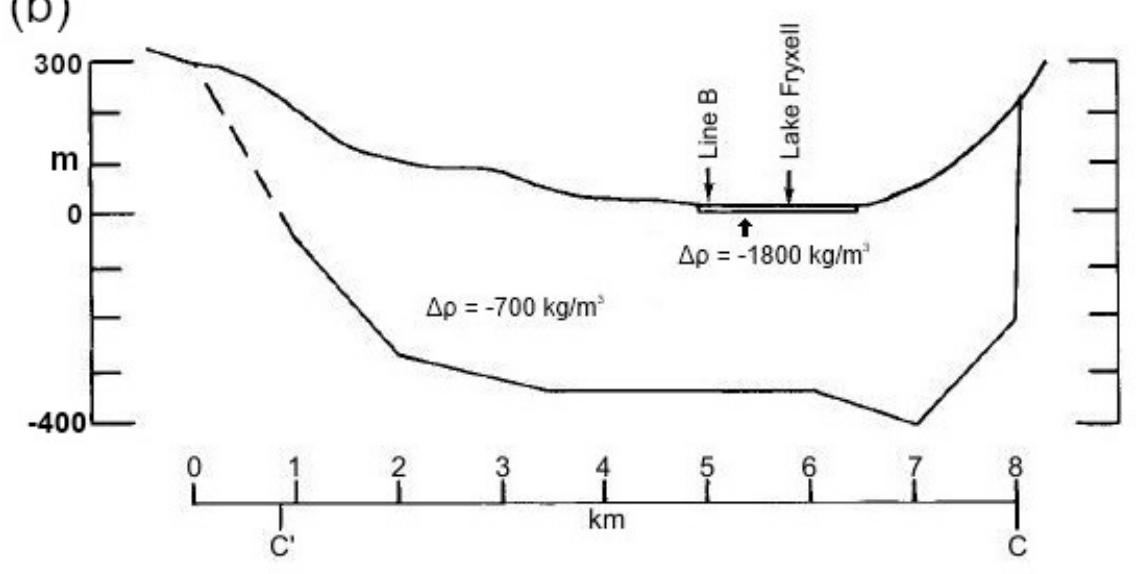

Figure 4.4: Gravity model of Line C by Hicks and Bennett (1981). (a) Comparison of observed (circles) and calculated (solid line) Bouguer gravity anomalies. The assumed regional gravity gradient (dashed line) across the survey line is displayed. The cross marks an interpolated Bouguer anomaly between near-basement stations of Sissons (1980). Anomalies are in units of $\mu \mathrm{N} / \mathrm{kg}(1 \mathrm{mGal}=10 \mu \mathrm{N} / \mathrm{kg})$. (b) Two-dimensional gravity model of Survey Line C by Hicks and Bennett (1981) with positions of the intersection with Line B and Lake Fryxell shown. Vertical to horizontal exaggeration is 5:1. $\Delta \rho$ is density contrast with bedrock (in $\left.\mathrm{kg} / \mathrm{m}^{3}\right)$. Figure from Hicks and Bennett (1981). 

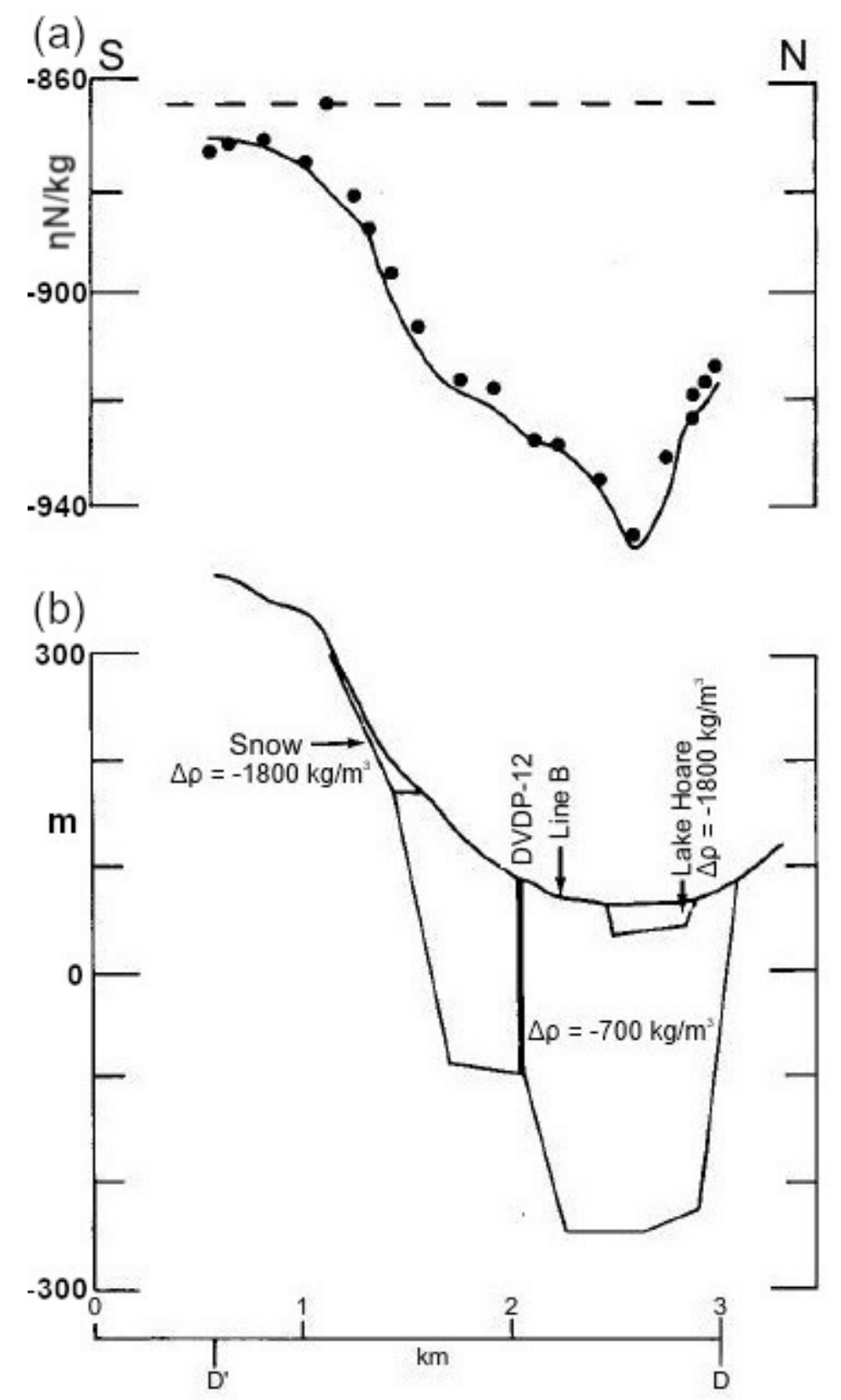

Figure 4.5: Gravity model of Line D by Hicks and Bennett (1981). (a) Comparison of observed (circles) and calculated (solid line) Bouguer gravity anomalies. The regional gravity gradient (dashed line) across the survey line is displayed. Anomalies are in units of $\mu \mathrm{N} / \mathrm{kg}$ $(1 \mathrm{mGal}=10 \mu \mathrm{N} / \mathrm{kg})$. (b) Two-dimensional gravity model of Survey Line D by Hicks and Bennett (1981) with positions of the intersection with Line B and Lake Hoare shown. DVDP12 is overlain as a black line extending to basement. Vertical to horizontal exaggeration is 5:1. $\Delta \rho$ is density contrast with bedrock (in $\mathrm{kg} / \mathrm{m}^{3}$ ). Figure from Hicks and Bennett $(1981)$.

other. Therefore, sediment depths modelled by Hicks and Bennett (1981) are comparable to those modelled in this study. 


\subsection{Regional gravity models}

The previous analysis has looked at local gravity models of the Taylor Valley that interpret short-wavelength perturbations in the gravity field. The following section now considers regional models of the gravity field, interpreted in terms of variation in crustal and lithospheric thicknesses. Here, the lithosphere is defined as the crust and the cooled 60 - $150 \mathrm{~km}$ of the upper mantle (Isacks et al., 1968). The latter is sometimes referred to as the mantle lid and is typically about $1 \%$ more dense than the underlying asthenospheric mantle (Shen et al., 2018b; Isacks et al., 1968).

The analyses in this study are two dimensional, assuming that variations in structure are small for directions at right angles to the chosen profile. Gravity profiles are, therefore, chosen to be at right angles to the trend in the regional gravity field as defined by Scheinert et al. (2016) from their continent-wide compilation of aero and land-based gravity data. Three profiles are considered here: (1) Profile 1, which runs most closely through the new gravity observations in this study; (2) Profile 2, slightly father north, where the along-strike change in the regional gravity field is minimal; (3) Profile 3, which straddles gravity data from both the Taylor Valley, acquired in this study, and the Wright Valley, analysed by Steven Kesler (Steven Kesler, unpublished MSc thesis, Victoria University of Wellington, 2021). All the profiles trend $\sim 77^{\circ}$, and gravity data are projected on to them in a swath $50 \mathrm{~km}$ either side of the profile (see Figures 4.10 and 4.16). It is clear from all the swaths that there is agreement between the regional gravity data from Scheinert et al. (2016) and that collected in this study, and the new data in this study better defines the abrupt 'step' in the gravity profile.

\subsubsection{Gravity models of Profiles 1, 2, and 3}

Gravity models of Profiles 1, 2, and 3 are constructed without upper crustal density contrasts to focus on the long-wavelength gravity anomalies associated with density variations between the crust, lithospheric mantle, and asthenospheric mantle. The approach taken here is to start with a simple model for the East-West Antarctic transition, then build incrementally more complex ones as the need arises. Our starting point is a simple edge-effect model where the variation in crustal and mantle lid thickness occurs 
on a vertical edge that corresponds to the coastline at Marble Point (Figure 4.12). This is a locally, isostatically-compensated model, although the topographic load is ignored at this juncture. We then build in seismic constraints on the Moho geometry and estimates of lithospheric thickness variations. Because the seismic constraints come from smoothed tomographic data, the implicit uncertainty is such that the model needs to be modified to fit the gravity data. Thus, the final model complies with the broad seismic constraints, is isostatically balanced at its far ends, and within the transition zone is out of balance with a net buoyancy, which can account for some of the observed topography.

The main features of the East-West Antarctic transition are a pronounced increase or 'step' in both crustal and lithospheric thickness across the boundary between West and East Antarctica in the vicinity of the Transantarctic Mountains. Thus, Priestley et al. (2018) image lithosphere up to $200 \mathrm{~km}$ thick beneath the Wilkes Basin in East Antarctica, compared to less than $100 \mathrm{~km}$ thick beneath the Ross Sea area of McMurdo Sound in West Antarctica. In the same region, Shen et al. (2018a), Hansen et al. (2009), and Bannister et al. (2003) suggest the crustal thickness beneath East Antarctica is up to $20 \mathrm{~km}$ thicker compared to that below the Ross Sea.

Previous gravity models (Pappa et al., 2019; ten Brink et al., 1997) have demonstrated that modelling an Antarctic crust, lithospheric mantle, and asthenospheric mantle with densities of 2850,3350 , and $\sim 3310 \mathrm{~kg} / \mathrm{m}^{3}$ respectively can give a satisfactory fit for calculated Bouguer anomalies across the Transantarctic Mountains. Therefore, these densities are used in this study. For simplicity, we assume constant crustal and lithospheric mantle density. As for residual anomaly analysis, the actual densities of the rock units are not that important, but the density contrasts between them are.

Aero and satellite-based gravity studies of Antarctica (Pappa et al., 2019, Scheinert et al., 2016) observe a steep gradient, or edge-effect, in Bouguer anomalies between East and West Antarctica in the Dry Valleys of southern Victoria Land. This gradient, caused by the different lithological structures of the two regions, is critical in capturing the variation in thickness and density properties between East and West Antarctica in gravity modelling. Thus, gravity observations in this study were made in the icefree areas of the Taylor Valley to accurately measure the gravity gradient where it 
is steepest and constrain the variation in lithological parameters. Observed Bouguer anomalies decrease by $-1.6 \mathrm{mGal} / \mathrm{km}$ between the Ross Embayment and Polar Plateau, and the wavelength of the observed anomaly curve (Figure 4.8) suggests that Bouguer gravity anomalies are a result of density contrasts in both the crust and lithospheric mantle.

\section{Simple Edge-effect model}

Griffiths and King (2013) derived a formula for the gravity effect expected due to a subsurface mass anomaly caused by a density contrast, $\Delta \rho$, across a vertical fault in a sequence consisting of two mediums (Figure 4.6). In this diagram, the step is defined by the thinner crust of West Antarctica.

Defining the system in Figure 4.6 as a horizontal slab, and assuming the slab is relatively thin compared to its depth, the expected gravity due to excess mass in the median plane of the slab where the edge is at horizontal distance zero is calculated using equation 4.3 (Griffiths \& King, 2013, Keary \& Brooks, 1992):

$$
g=2 G \Delta \rho t\left(\frac{\pi}{2}+\arctan \frac{x}{z}\right)
$$

Where $\mathrm{G}$ is the gravitational constant, $\mathrm{t}$ is layer thickness, $\mathrm{x}$ is horizontal distance from the edge of the step in anomalies, and $\mathrm{z}$ is depth to the centre of the layer. This equation gives a step function where the half width, or distance from the maximum gradient in anomalies, $\mathrm{x}_{\max }$, to where the gradient of observed Bouguer anomalies drops by a factor of two, $\mathrm{x}_{1 / 2}$, is equivalent to depth to the centre of the source layer, $\mathrm{Z}$ :

$$
Z=x_{1 / 2}
$$

Where the factor $\mathrm{x}_{\max }$ is always zero if the edge is at a horizontal distance of zero.

Another layer with an edge can be added such that the system in Figure 4.6 is isostatically balanced. This represents a simplified model of the lithospheric structure between the Ross Sea (West Antarctica) and Polar Plateau (East Antarctica; Figure 4.7) from previous seismic studies (Shen et al., 2018a; Brenn et al., 2017). We construct the 
(a)

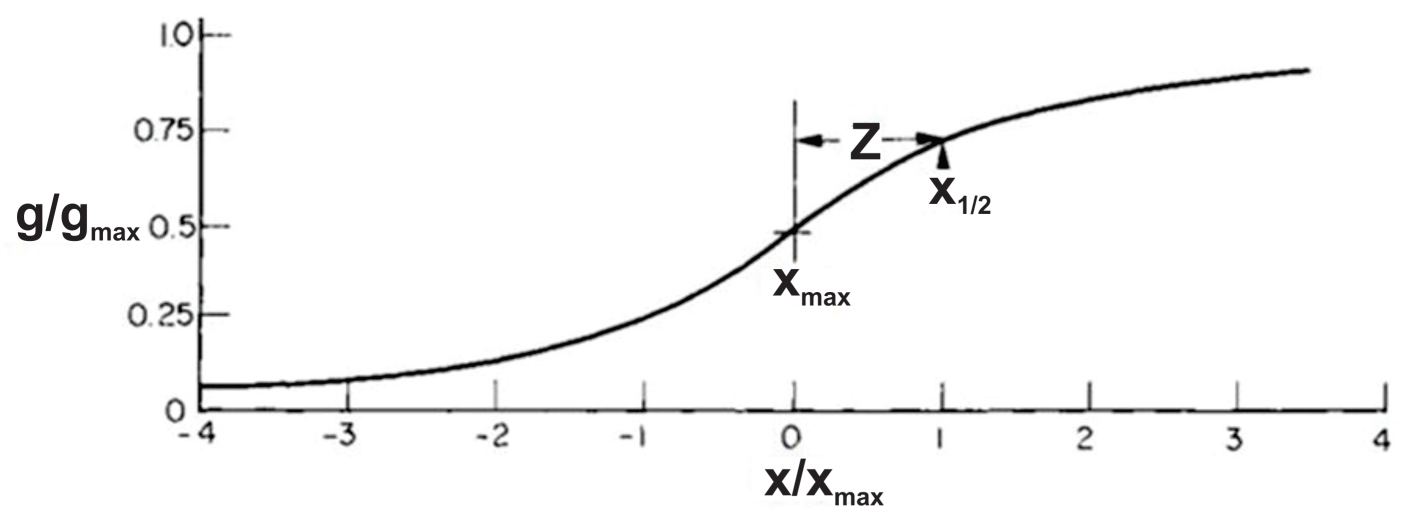

(b)

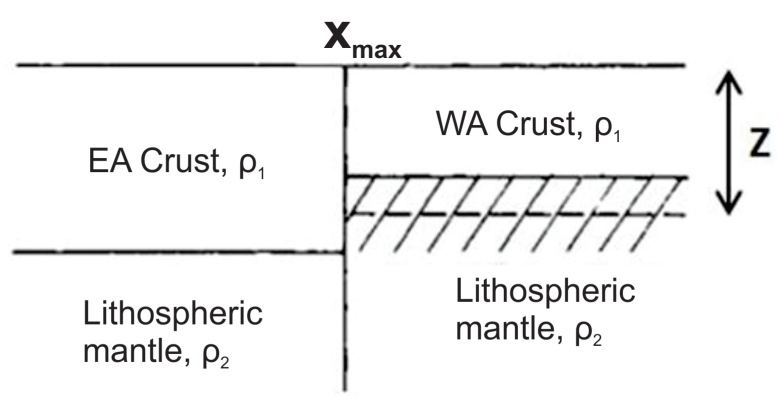

Figure 4.6: Gravity anomaly across a vertical fault, displacing a horizontal interface. (a) Observed gravity anomalies (bold black line), plotted as normalised gravity, g/gmax, against normalised distance, $\mathrm{x} / \mathrm{x}_{\max }$. Depth, $\mathrm{Z}$, to the source of the observed anomalies is equal to the distance between the maximum gradient of anomalies, $\mathrm{x}_{\max }$, to where the gradient of anomalies drops by a factor of two, $\mathrm{x}_{1 / 2}$ (equation 4.4). (b) Subsurface structure of a single mass anomaly causing the observed anomalies. A vertical fault displaces the horizontal interfaces. The dashed area highlights a mass anomaly due to juxtaposition of higher density lithospheric mantle $\left(\rho_{2}\right)$ against lower density crust $\left(\rho_{1}\right)$. Z is vertical distance to the centre of the mass anomaly i.e. depth to the source of observed anomalies. EA - East Antarctic; WA - West Antarctic. Figure from Griffiths and King (2013).

model by adopting the structure in East Antarctica of a $40 \mathrm{~km}$ thick crust underlain by a $160 \mathrm{~km}$ thick mantle lid as "normal". Then, this is juxtaposed to West Antarctica where the crustal thickness is taken as $20 \mathrm{~km}$ and we assume, for simplicity, there is no mantle lid. There are, therefore, two equal and opposite mass anomalies within West Antarctica (Figure 4.7): the $20 \mathrm{~km}$ of thinned crust of density contrast $-500 \mathrm{~kg} / \mathrm{m}^{3}$ with lithospheric mantle, and a $160 \mathrm{~km}$ thick layer of asthenospheric mantle that must have a density contrast with lithospheric mantle of $\Delta \rho$, where to achieve isostatic balance we need:

$$
400 \mathrm{~kg} / \mathrm{m}^{3} \times 20 \mathrm{~km}=160 \mathrm{~km} \times \Delta \rho
$$




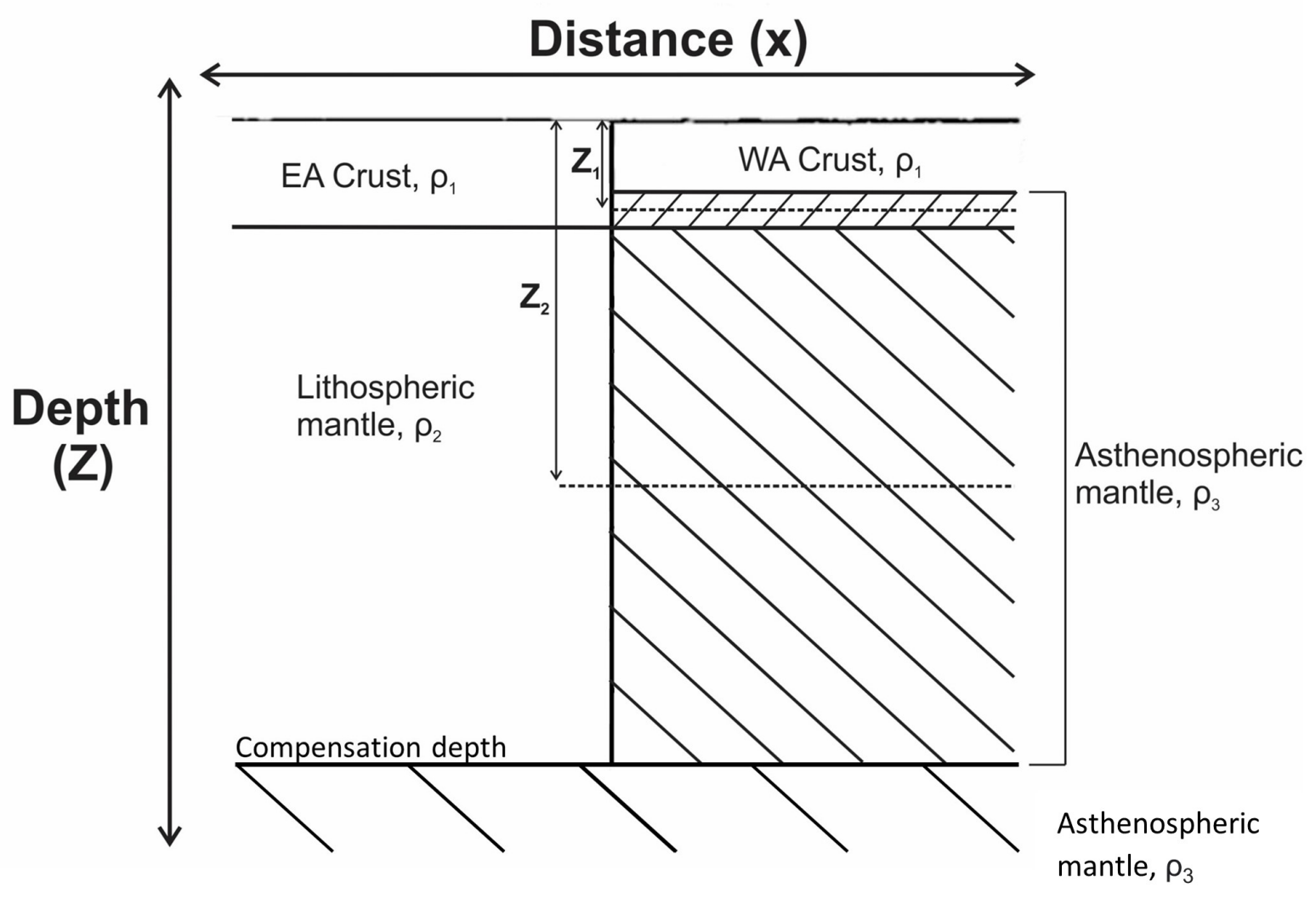

Figure 4.7: Basic three-layer structure of the subsurface assumed in this study. A vertical fault displaces the horizontal interfaces of East and West Antarctica. Densities of relative layers are on the order of $\rho_{2}>\rho_{3}>\rho_{1}$. The dashed areas highlight mass anomalies caused by juxtaposition of higher density asthenospheric mantle $\left(\rho_{3}\right)$ against lower density crust $\left(\rho_{1}\right)$ (top) and higher density lithospheric mantle $\left(\rho_{2}\right)$ against lower density asthenospheric mantle (bottom). $\mathrm{Z}_{1}$ and $\mathrm{Z}_{2}$ are depths to the crustal and mantle sources of anomalies (horizontal dashed lines) respectively. The compensation depth is the depth at which pressure is equal at the bottom of two vertical columns through the cross-section EA - East Antarctic; WA - West Antarctic. Figures 4.8 and 4.9 display calculated anomalies resulting from this subsurface structure. 
Therefore, $\Delta \rho$ is $50 \mathrm{~kg} / \mathrm{m}^{3}$.

Note that when using Figure 4.7 to represent the boundary between East and West Antarctica, the transition zone between the two regions is assumed to be vertical. Seismic studies (Shen et al., 2018a; Hansen et al., 2009; Bannister et al., 2003) show that this is not the case in reality, however, this assumption is satisfactory for our preliminary analysis.

Equation 4.3 can be used to define the expected gravity of each mass anomaly in Figure 4.7 individually, expressed in equations 4.6 and 4.7 .

$$
\begin{aligned}
& g_{1}=2 G \Delta \rho t\left(\frac{\pi}{2}+\arctan \frac{x}{z_{1}}\right) \\
& g_{2}=2 G \Delta \rho t\left(\frac{\pi}{2}+\arctan \frac{x}{z_{2}}\right)
\end{aligned}
$$

Where $\mathrm{g}$ is expected gravity, $\mathrm{z}$ is depth, and the subscripts 1 and 2 represent the first (crustal) and second (mantle) mass anomalies, respectively. Subtracting equation 4.7 from equation 4.6, the solution is simplified as the product of density contrast and layer thickness is the same, but of opposite sign, for both equations to preserve local isostasy. The factor of $\pi / 2$ cancels out, giving the expected gravity anomaly for this subsurface structure:

$$
g=2 G \Delta \rho t\left(\arctan \frac{x}{z_{1}}-\arctan \frac{x}{z_{2}}\right)
$$

Where $z_{1}$ and $z_{2}$ are average depths to the middle of each half-space, representing the crustal and mantle mass anomalies respectively. In this approximation thin layers are still assumed. The result for 'thick' layers is similar but more complicated, expressed by Telford et al. (1990), but the approximation of equation 4.8 is considered adequate to demonstrate the key aspects of how an edge-effect anomaly can explain most of the character we see at the East-West Antarctica transition zone.

By interpreting Bouguer anomalies observed in Profiles 1 and 3 (Figures 4.10 and 4.16) as a combination of two step functions (equation 4.8), a preliminary estimate of 


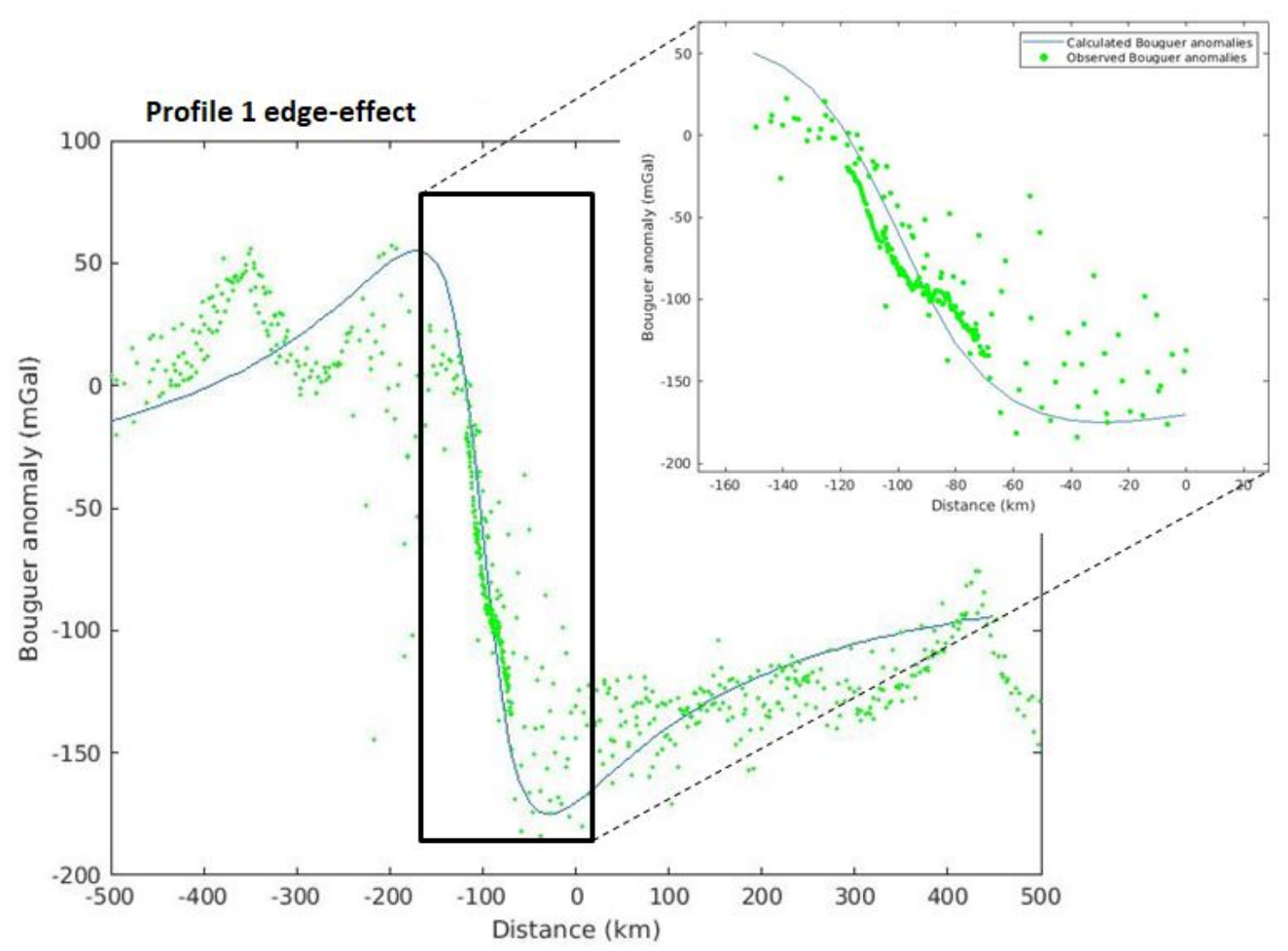

Figure 4.8: Gravity edge effect for two buried thin layers in Profile 1. Observed Bouguer anomalies (in mGal) along Profile 1 from this study and Scheinert et al. (2016) (green circles) are plotted against Bouguer anomalies calculated using equation 4.8 (blue line). The inset map shows a close-up of calculated and observed Bouguer anomalies in the Taylor Valley in this study and that by Scheinert et al. (2016) across the edge-effect. 


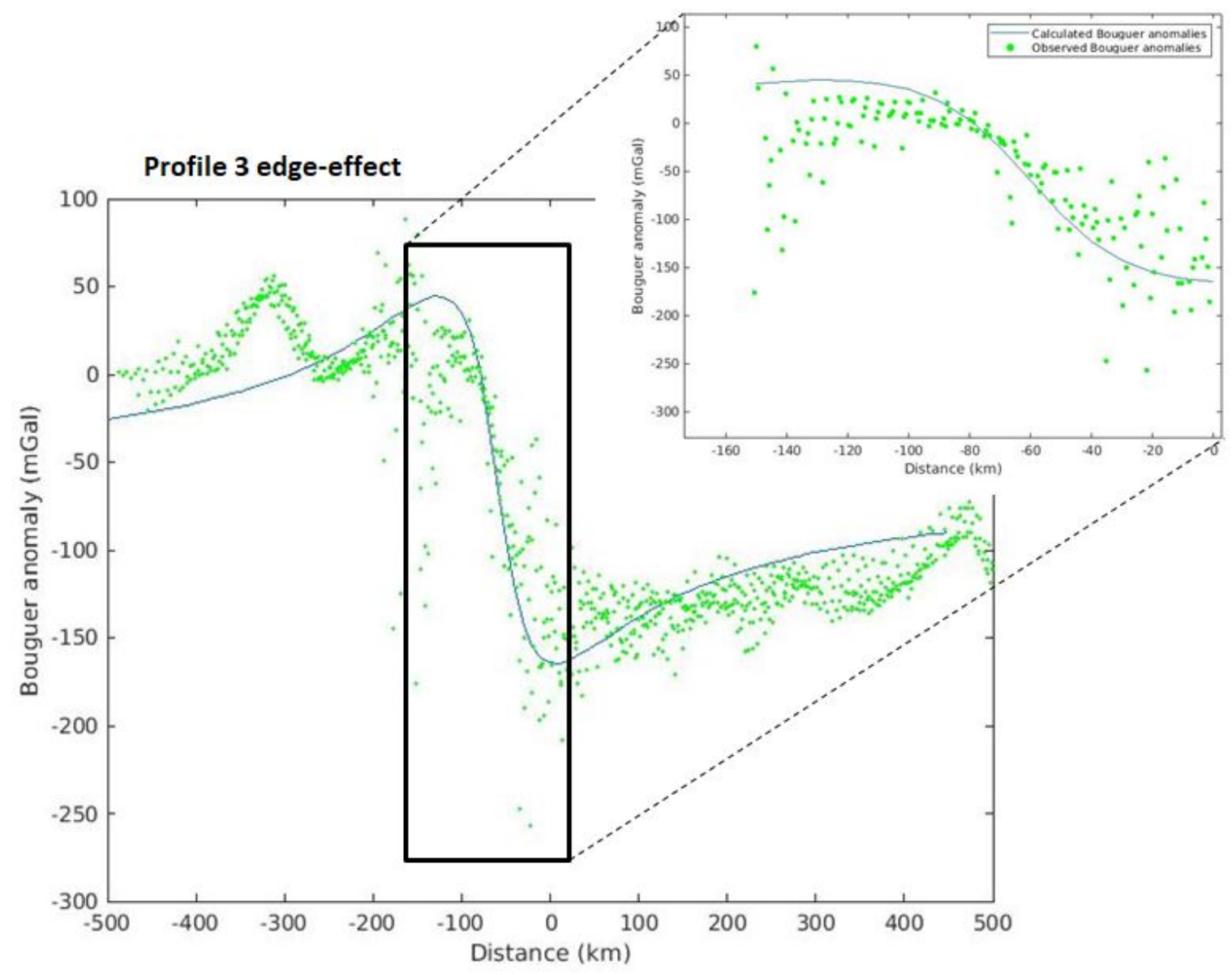

Figure 4.9: Gravity edge effect for two buried thin layers in Profile 3. Observed Bouguer anomalies (in mGal) along Profile 3 from this study and Scheinert et al. (2016) (green circles) are plotted against Bouguer anomalies calculated using equation 4.8 (blue line). The inset map shows a close-up of calculated and observed Bouguer anomalies in the Taylor Valley in this study and that by Scheinert et al. (2016) across the edge-effect. 
the source of observed anomalies can be made. Estimates of crustal and lithospheric mantle thickness are adopted from seismic studies of subsurface structure in the Ross Embayment and Polar Plateau (Shen et al., 2018a; Hansen et al., 2009; Bannister et al., 2003). In Profile 1 (Figure 4.8) a $\mathrm{z}_{1}$ of $35 \mathrm{~km}$ is used, representative of a step in the crust, while $\mathrm{z}_{2}=145 \mathrm{~km}$, representative of a step in the lithospheric mantle. Similarly, in Profile 3 (4.9) $\mathrm{z}_{1}$ is unchanged and $\mathrm{z}_{2}=125 \mathrm{~km}$. Layer thickness and density contrasts applied are as described previously. Note that calculated anomalies are scaled and a DC shift is applied to anomalies such that they fit those observed. This shift is arbitrary, based on the magnitude of the observed Bouguer anomalies and proportional to the Bouguer slab correction if the slab is $\sim 700 \mathrm{~m}$ thick on average within the East Antarctic portion of the profile.

Calculated anomalies fit well to those observed in both Figures 4.8 and 4.9 . We will show later that a single step in density at either the crust or lithosphere is not enough alone to fit observed gravity anomalies. But calculated anomalies fit well to those observed in both Figures 4.10 and 4.11, demonstrating the existence of steps at both depths. Most significantly, calculated anomalies follow the trend and magnitude of land-based gravity measurements observed in this study (see inset images in Figures 4.8 and 4.9 where the edge-effect is measured in high-resolution. This provides a land-based tie and significant gravity constraints for calculated anomalies.

This analysis demonstrates that the source zone of the Bouguer anomalies originates from mass anomalies in both the crust and mantle. The distance between the steepest gradient in Bouguer anomalies and the inflection point can be used as a proxy of the maximum depth to the source layer (equation 4.4), which produces a solution lying within the lithospheric mantle. Furthermore, calculated Bouguer anomalies being steeper than those observed in this study across the edge-effect suggests that a vertical step in the crust and lithospheric mantle between East and West Antarctica is too steep - a shallowed step would improve the fit between anomalies by shallowing the calculated gravity gradient. 


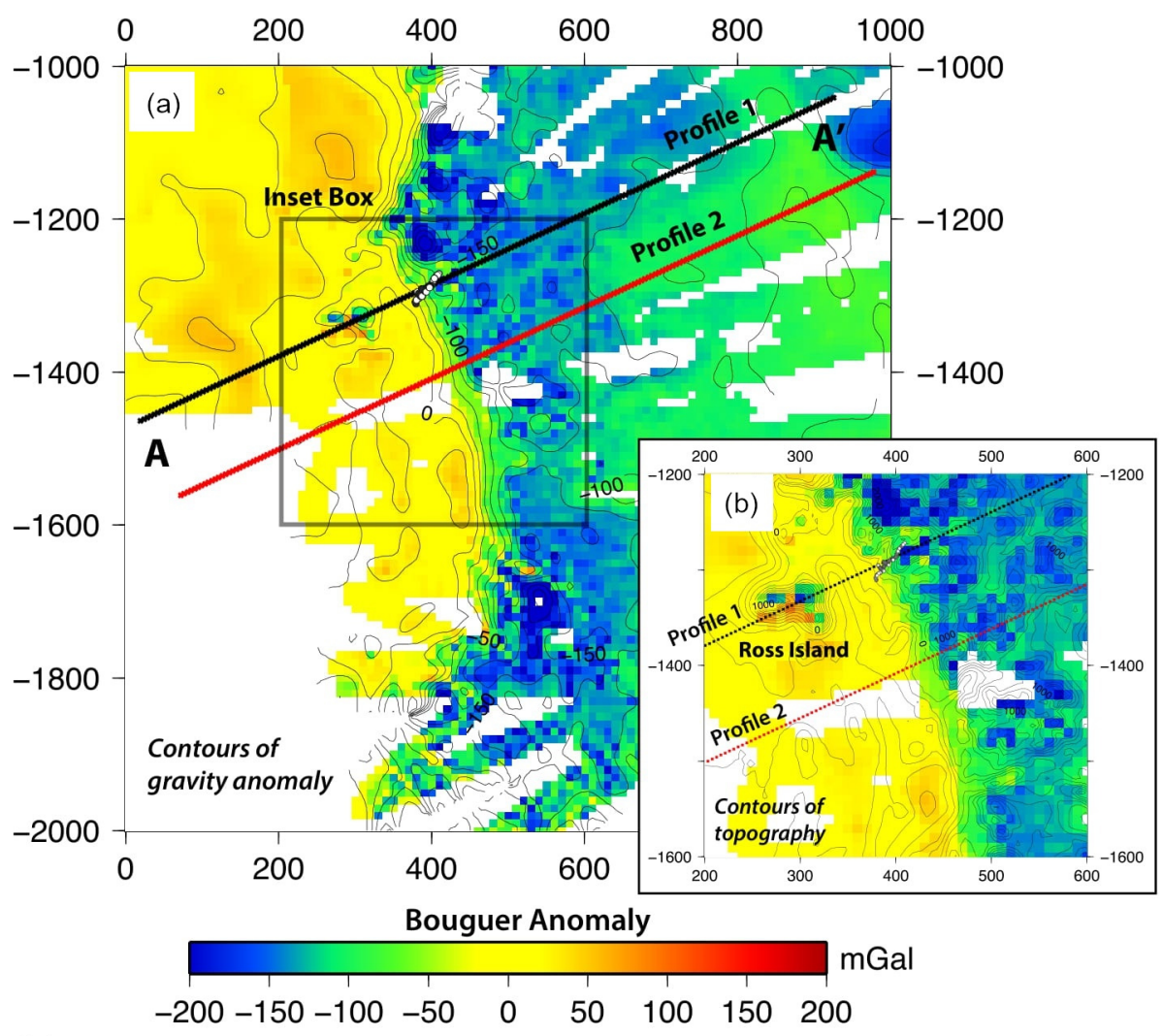

(c)

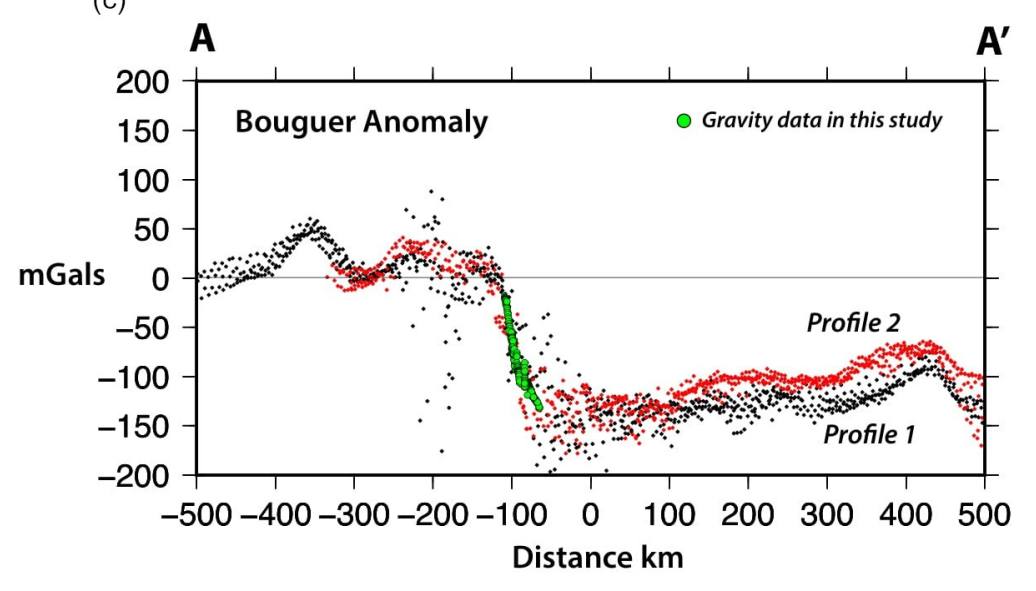

Figure 4.10: Overview map of modelled gravity profiles in southern Victoria Land. (a) Bouguer anomaly map using aero and land-based gravity data from Scheinert et al. (2016). Anomalies are defined by the colour scale. Positions of the two modelled gravity profiles (black and red lines) and gravity data measured in this survey (white circles) are shown. Coordinates are relative to the Antarctic Polar Stereographic projection. (b) Surface topography of the inset box displayed in 1 from the Bedmap2 DEM dataset (Fretwell et al., 2013). (c) Bouguer anomalies along Profiles 1 (black circles) and 2 (red circles). Anomalies are from points on the Bouguer anomaly map at $5 \mathrm{~km}$ spacing's in a swath at $50 \mathrm{~km}$ on either side of each line. Land-based gravity measurements made in this study are overlain (green circles) 


\section{Models with seismic tomography constraints}

\section{Profile 1}

The above section has provided a preliminary analysis into the source of observed Bouguer anomalies measured in the Taylor Valley. To gain further insight into the effects of crustal and lithospheric structures on the observed gravity signal, the regional subsurface is modelled in terms of three layers representing the crust, lithospheric mantle, and asthenospheric mantle. Although these models are very simple, they help to reveal the principal factors that control the regional gravity field, given the regional crustal and lithospheric structure described above.

Profile 1 is oriented parallel to the steepest gradient in Bouguer anomalies (Figure 4.10). To quantify control of the crustal structure on observed Bouguer anomalies along the profile, the model in Figure 4.11 is constructed with a homogeneous mantle density of $3350 \mathrm{~kg} / \mathrm{m}^{3}$ and $20 \mathrm{~km}$ thick step in crustal thickness, similar in scale to estimates made in seismic studies (Shen et al., 2018a; Hansen et al., 2009 Bannister et al., 2003). Calculated anomalies follow the trend of those observed across the Profile and have the same magnitude as those observed in the Taylor Valley in this study. However, the magnitudes of calculated anomalies in the Ross Embayment and Polar Plateau are $\sim 100$ mGal greater than what is observed.

In Model 1A vertical juxtaposition of low-density $\left(3310 \mathrm{~kg} / \mathrm{m}^{3}\right)$ asthenospheric mantle in the Ross Embayment (west) against relatively high density $\left(3350 \mathrm{~kg} / \mathrm{m}^{3}\right)$ lithospheric mantle in the east is modelled in addition to the crustal step (Figure 4.12) to test the control of both the crustal and mantle structure on observed Bouguer anomalies. Resultant calculated anomalies show a dipolar shape, capturing both the trend and magnitude of observed Bouguer anomalies across the Profile. Note, however, local anomalous Bouguer anomalies are observed at a distance of $-200 \mathrm{~km}$ on the profile in the vicinity of Ross Island (Figure 4.12), most likely due to the effects of the volcanic edifice here that may be partially supported by flexure. These anomalies associated with Ross Island are clearly seen in the regional gravity anomalies mapped by Scheinert et al. (2016) (Figure 4.10). They have the effect of increasing the RMS error to $30 \mathrm{mGal}$ in the modelled profile.

Models displayed above (Figures 4.11 and 4.12) are a first approximation of the re- 


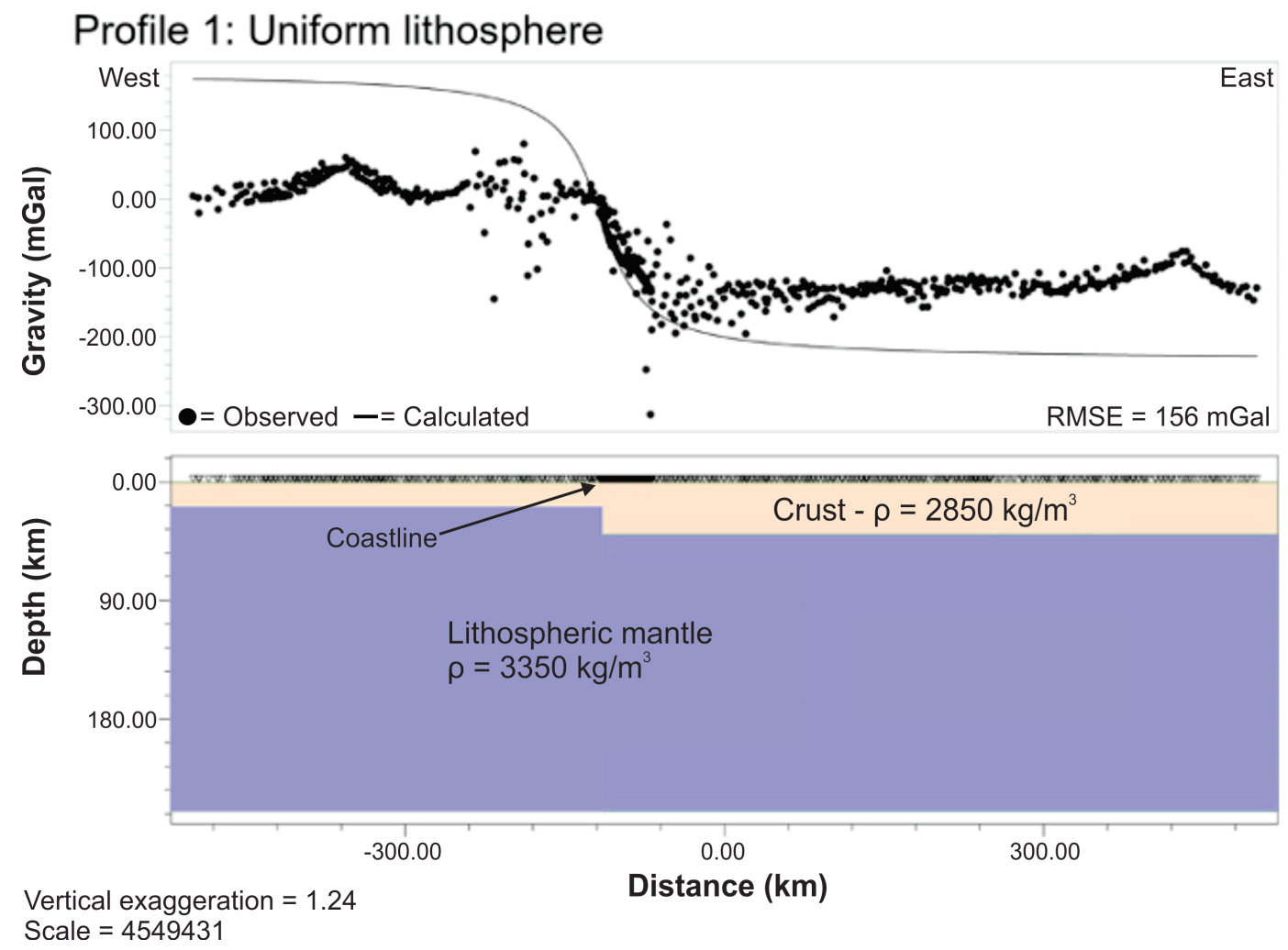

(a)

(b)

Figure 4.11: Gravity model of Profile 1 with a uniform mantle density. (a) Observed (circles) and calculated (black line) Bouguer anomalies in $\mathrm{mGal}$. RMSE $=$ root mean square error of the fit between calculated and observed anomalies in mGal. Observations along Line X at Marble Point are at a distance of $-117 \mathrm{~km}$ and trend eastward. (b) Gravity model of the subsurface below the Taylor Valley, with a uniform lithospheric mantle density of $3350 \mathrm{~kg} / \mathrm{m}^{3}$. The crust is modelled with a vertical step in thickness increasing from 20 to $40 \mathrm{~km}$. Subsurface units are differentiated by colour. $\mathrm{X}$-axis ticks are $60 \mathrm{~km}$ spacings, $\mathrm{y}$-axis ticks are $18 \mathrm{~km}$ spacings. 


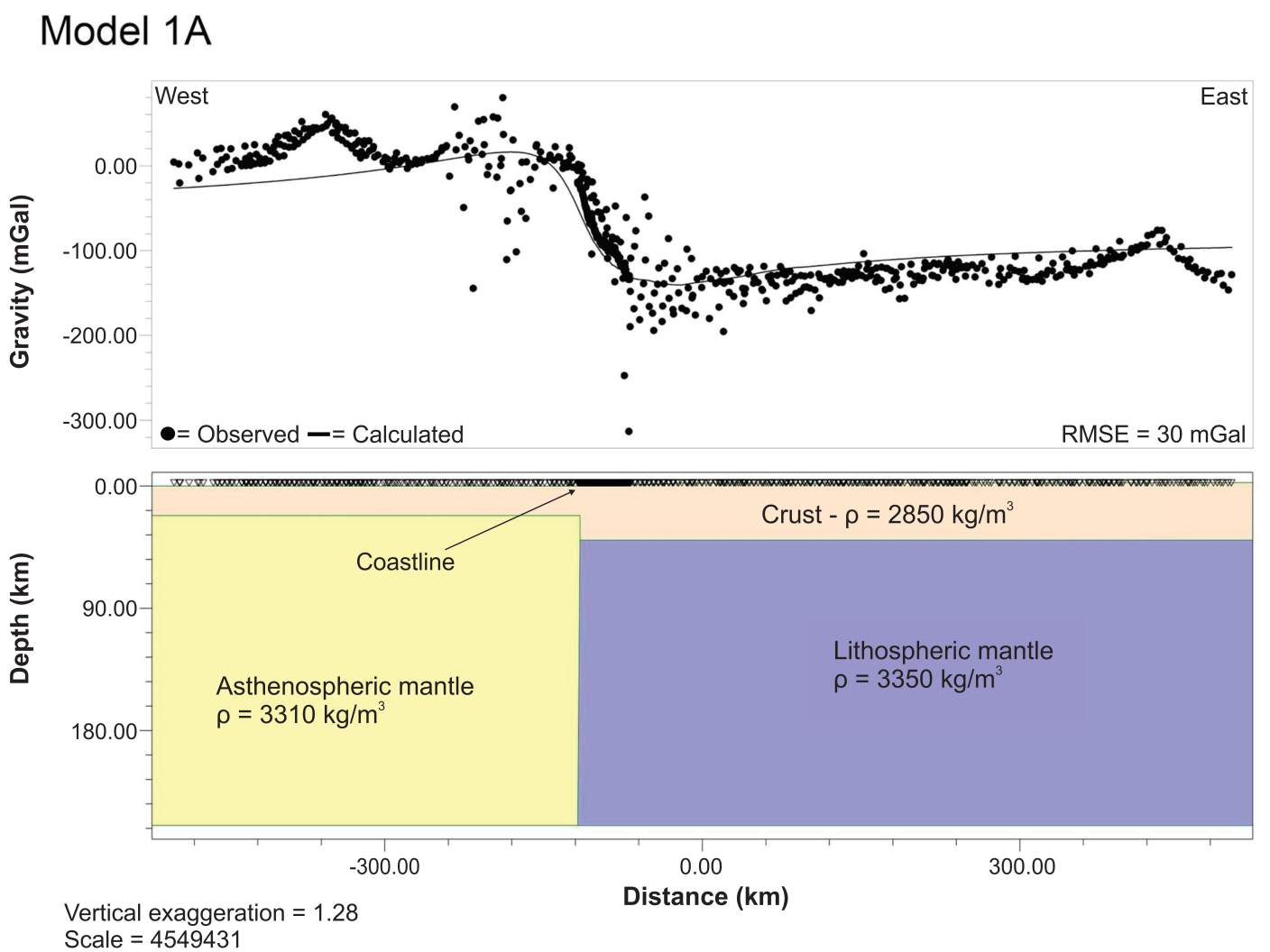

(a)

(b)

Figure 4.12: : Model 1A of Profile 1, showing calculated Bouguer anomalies across the Transantarctic Mountains from both a crustal and mantle source. (a) Observed (circles) and calculated (black line) Bouguer anomalies in mGal. RMSE $=$ root mean square error of the fit between calculated and observed anomalies in mGal. Observations along Line X at Marble Point begin at a distance of $-117 \mathrm{~km}$ and trend eastward. (b) Model of the subsurface below the Taylor Valley. A $20 \mathrm{~km}$ thick step in crustal thickness and $40 \mathrm{~kg} / \mathrm{m}^{3}$ mantle density contrast are modelled. Subsurface units are differentiated by colour. X-axis ticks are $60 \mathrm{~km}$ spacings, $\mathrm{y}$-axis ticks are $18 \mathrm{~km}$ spacings. 


\section{Model 1B}

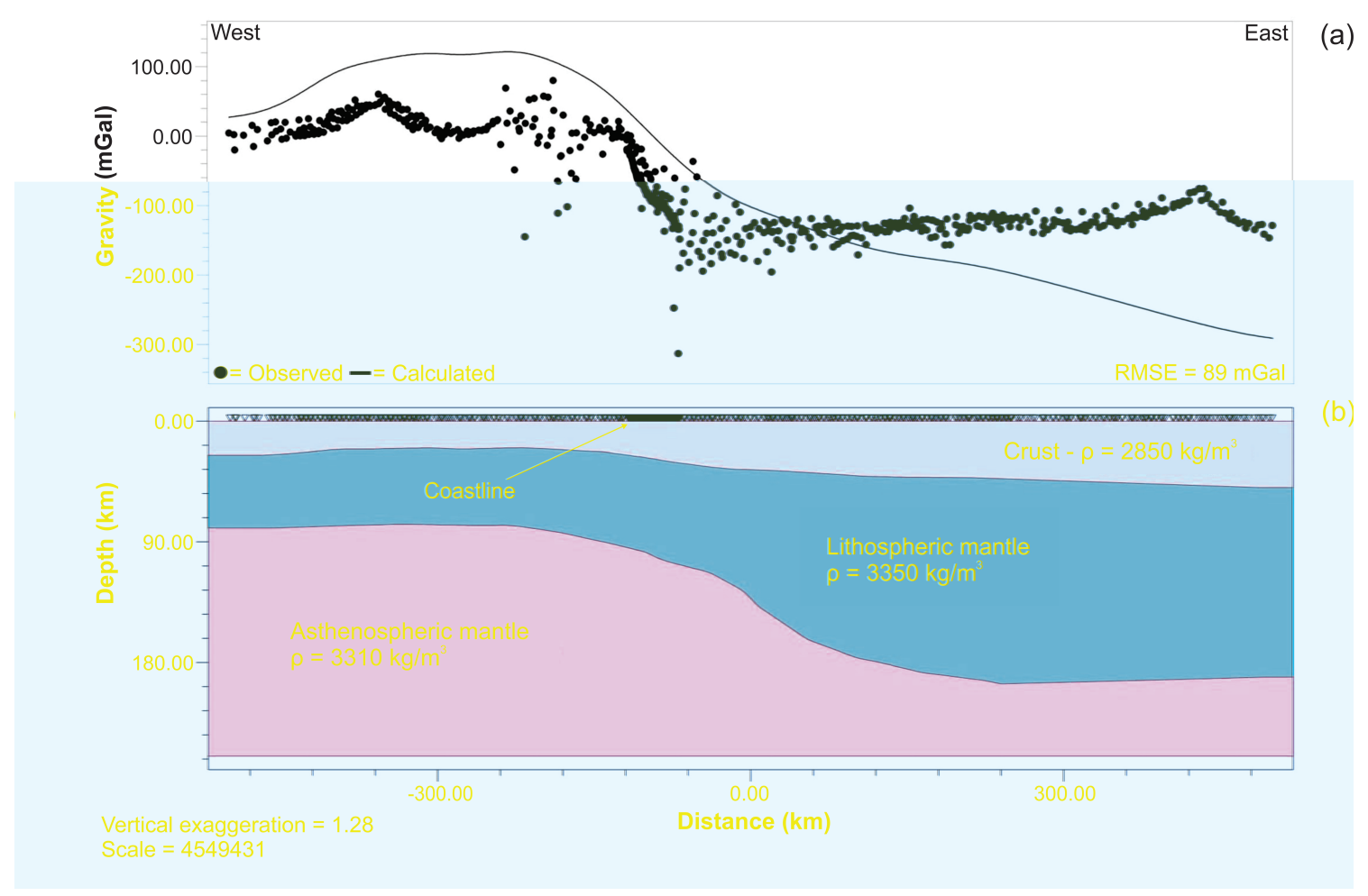

Figure 4.13: Model 1B of Profile 1, showing calculated Bouguer anomalies determined from crustal and lithospheric mantle thicknesses estimated in seismic studies (Priestley et al., 2018, Shen et al., 2018a). (a) Observed (circles) and calculated (black line) Bouguer anomalies in $\mathrm{mGal}$. RMSE $=$ root mean square error of the fit between calculated and observed anomalies in mGal. Observations along Line X at Marble point begin at a distance of $-117 \mathrm{~km}$ and trend eastward. (b) Model of the subsurface below the Taylor Valley. Subsurface units are differentiated by colour. X-axis ticks are $60 \mathrm{~km}$ spacings, y-axis ticks are $18 \mathrm{~km}$ spacings.

gional subsurface structure below Line B and are used to model the effect of varying Moho, lithospheric mantle, and asthenospheric mantle thicknesses and densities on calculated gravity anomalies. They demonstrate the control of the crustal and lithospheric structure on the calculated gravity anomalies. Individually, calculated anomalies from modelling of a step in crustal and lithospheric mantle thickness and are unable to fit the observed Bouguer anomalies across Profile 1 alone, suggesting that both a step in crustal thickness and lithospheric mantle, given their density contrasts, are required to fit the observed Bouguer anomalies (Figure 4.12). This is the same conclusion reached in preliminary analysis of anomalies using the method of Griffiths and King (2013). Note, however, that these models are not formally isostatically balanced - see discussion in Section 5.2 .

Models in Figures 4.11 and 4.12 are not realistic, but are a first attempt. Seismic 


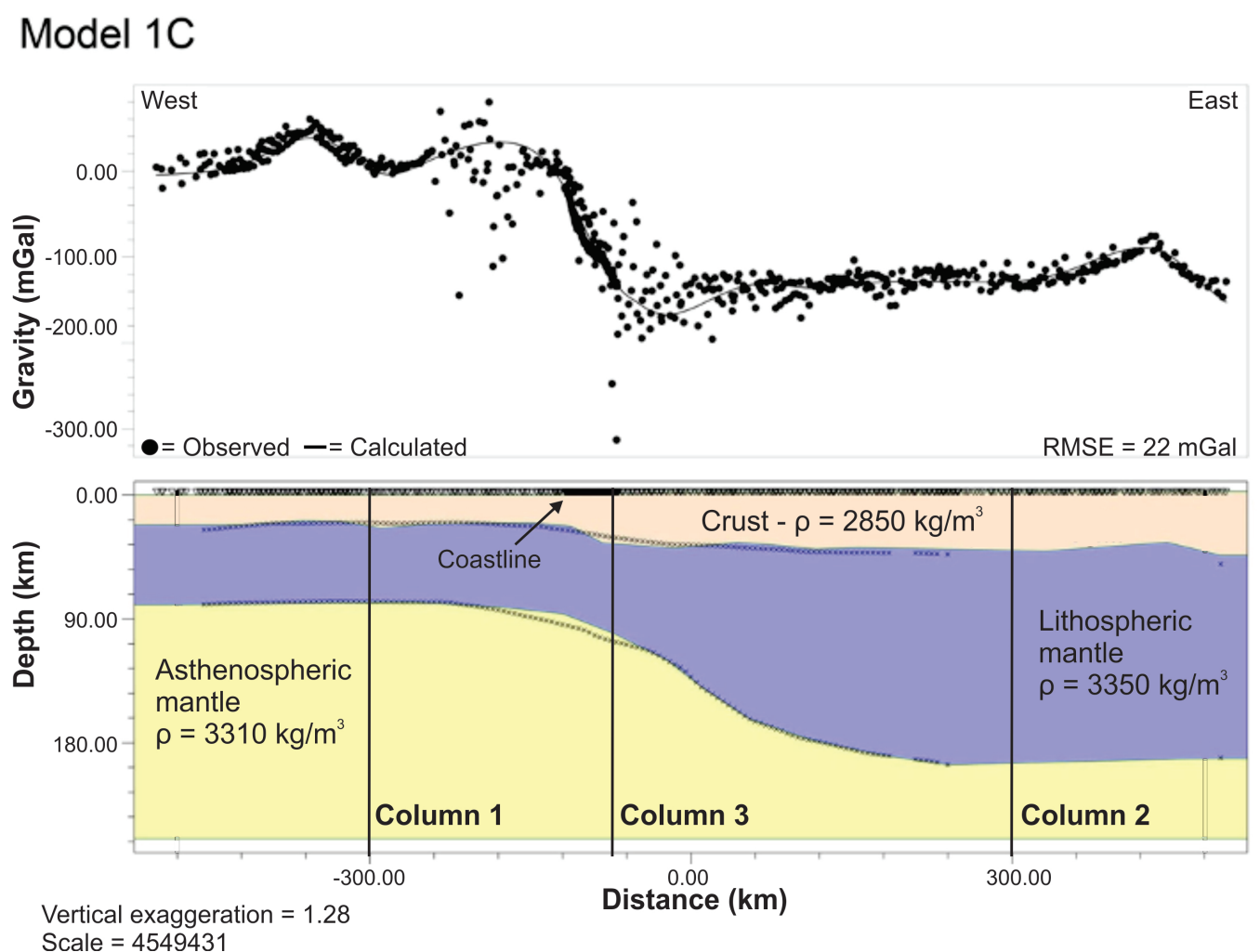

(a)

Figure 4.14: Model 1C of Profile 1. (a) Observed (circles) and calculated (black line) Bouguer anomalies in mGal. RMSE $=$ root mean square error. Observations along Line X at Marble Point begin at a distance of $-117 \mathrm{~km}$ and trend eastward. (b) Model of the subsurface below the Taylor Valley, with an eastward $22.5^{\circ}$ dipping crustal step. Black crosses denote crustal (depth uncertainty $\pm 3 \mathrm{~km}$ ) and lithospheric structure (depth uncertainty $\pm 30 \mathrm{~km}$ ) from Shen et al. (2018a) and Priestley et al. (2018). Subsurface units are differentiated by colour. Vertical black lines represent columns of isostatic balance (see Section 5.2). X-axis ticks are $60 \mathrm{~km}$ spacings, $\mathrm{y}$-axis ticks are $18 \mathrm{~km}$ spacings. 
studies (Priestley et al., 2018; Shen et al., 2018a) and analysis of Bouguer anomalies in Section 4.4.1 have demonstrated that the true crustal and mantle structure is not a vertical step. The following gravity models of Profiles 1, 2, and 3 use as a starting point the published crustal and lithospheric structure beneath the Ross Embayment and Polar Plateau, based on an inversion of surface wave seismic data (Priestley et al., 2018; Shen et al., 2018a).

Estimates of the depth to asthenospheric mantle are from a global model with horizontal resolution of $\sim 250 \mathrm{~km}$ and vertical resolution of $\sim 30 \mathrm{~km}$ to depths of $\sim 300 \mathrm{~km}$ (Priestley et al., 2018). The mantle structure in gravity models is smoothed to account for these relatively large uncertainties, and will not accurately represent local features of scale smaller than the resolution.

Similarly, the relationship between gravity and distance is an inverse square law (equation 3.4), thus the resolution of deeper anomalous mass distributions in the mantle become difficult to model. Therefore, the lithospheric step could be modelled to occur much further beneath the TAM. In the models presented here, departures of lithospheric mantle structure from that determined in seismic studies are kept to a minimum $(<30 \mathrm{~km})$, within uncertainty bounds of the seismic data (Priestley et al., 2018).

Model 1B (Figure 4.13) is constructed using seismic estimates of Moho depth and lithospheric mantle thickness across the TAM front (Priestley et al., 2018; Shen et al., 2018a). The resultant calculated Bouguer anomalies dip towards the Polar Plateau, but do not capture the critical $-1.6 \mathrm{mGal} / \mathrm{km}$ gravity gradient observed in this study across the subsurface transition zone between distances of -130 and $-50 \mathrm{~km}$. This is reflected in the RMS error of $89 \mathrm{mGal}$. The poor fit of calculated and observed Bouguer anomalies in Model 1B is most likely a result of smoothing and the limited resolution of the Moho imaged in the seismic data. These seismic data largely result from tomographic methods, where smoothing is inevitable (Shen et al., 2018a; Brenn et al., 2017). Long-wavelength features are resolved, but local variations in the crust are clearly not captured in seismic-derived estimates of thickness. The simple preliminary models of Profile 1 (Figures 4.11 and 4.12 suggest that a more abrupt change in crustal thickness is required to fit the gravity observations (Figure 4.14.)

To replicate Bouguer anomalies observed in this study along the critical transition zone, 
a relatively abrupt $\sim 12 \mathrm{~km}$ high ramp in crustal thickness, dipping towards the Polar Plateau at about $22.5^{\circ}$, is introduced in Model 1C (Figure 4.14) between distances of $\sim-112$ and $-83 \mathrm{~km}$ on the crustal thickness profile (Shen et al., 2018a). Now, the calculated anomalies resolve the gradient observed in Bouguer anomalies from this study across the TAM front. Small adjustments, within the quoted uncertainty of crustal and lithospheric data, are made to the crustal thickness beneath Ross Island and lithospheric thickness elsewhere to improve the fit. The RMS error of $22 \mathrm{mGal}$ demonstrates a marked improvement in the fit of calculated and observed anomalies from Model 1B (Figure 4.13) where the change in thickness of the crust is more gradual.

\section{Profile 2}

Profile 2 is positioned $\sim 110 \mathrm{~km}$ north of Profile 1 such that the regional gravity field does not contain short-wavelength signals due to local structures such as Ross Island (Figure 4.10). This profile is not constrained by land-based gravity observations collected in this study.

The subsurface structure modelled in Model 2A (Figure 4.15) is similar to that in Model 1C (Figure 4.14), introducing a $\sim 30 \mathrm{~km}$ long, $\sim 12 \mathrm{~km}$ high ramp (dipping $\sim 22^{\circ}$ ) in the Moho from seismic estimates (Shen et al., 2018a). The RMS error of 15 mGal suggests good fit between calculated and observed Bouguer anomalies.

\section{Profile 3}

As part of a related Masters' project on subsurface structure, land-based gravity measurements were collected along the axis of the Wright Valley, extending the existing gravity observations in the valley (Bull, 1960). Profile 3 is positioned between the Taylor and Wright Valleys (Figure 4.16), based on a combination of land-based measurements made in the valleys and existing gravity observations (Scheinert et al., 2016). The origin (zero distance position) of Profile 3 is offset by $\sim 60 \mathrm{~km}$ from Profiles 1 and 2.

$\mathrm{A} \sim 26.5^{\circ}$ eastward dipping ramp in thickness of the Moho is modelled in Model 3A (Figure 4.17, Table 4.1) of Profile 3, increasing the thickness of the crust by $13 \mathrm{~km}$ over a distance of $26 \mathrm{~km}$. Profile 3 intersects Ross Island at a distance of $\sim-150 \mathrm{~km}$ 


\section{Model 2A}

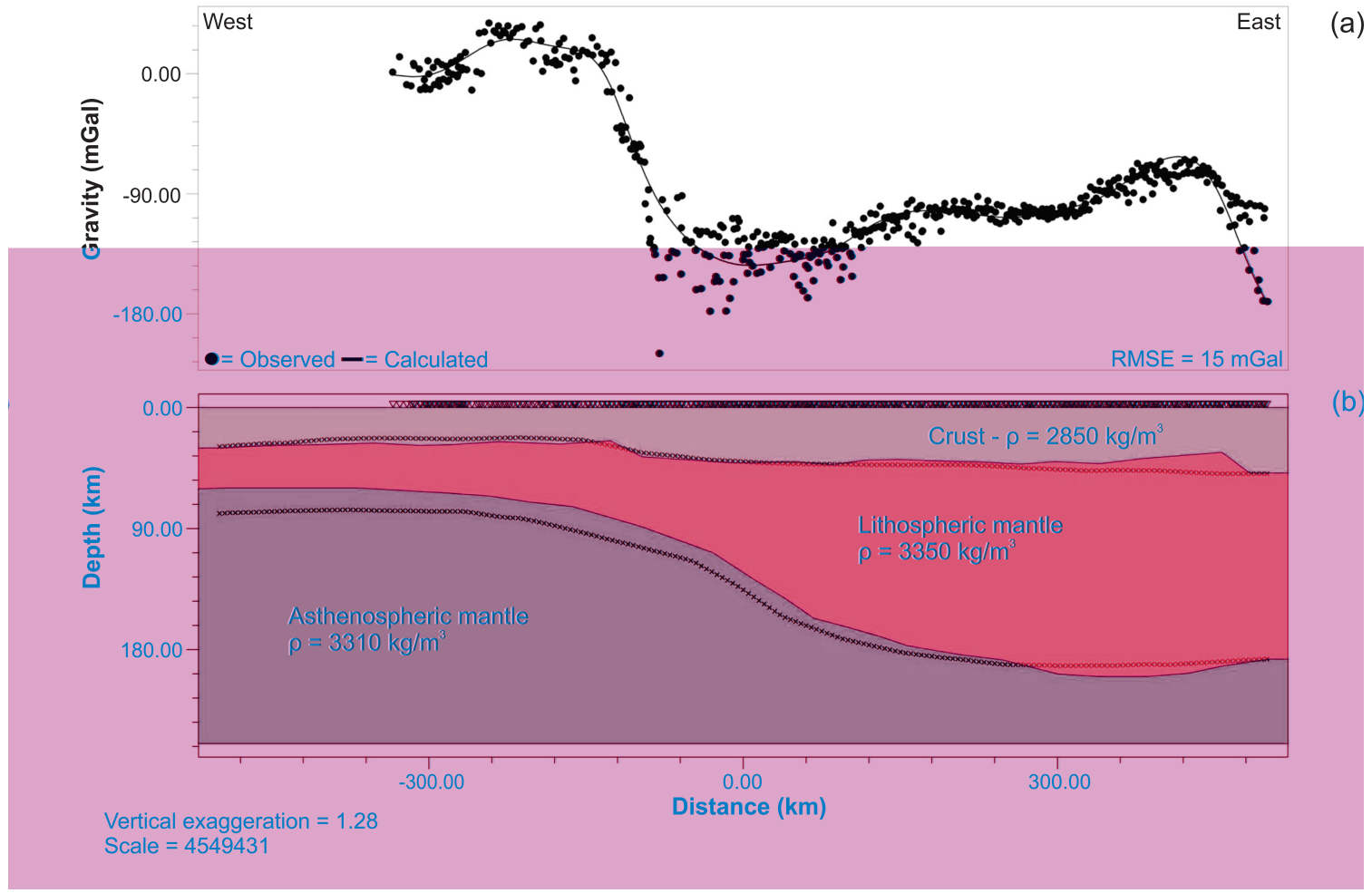

Figure 4.15: Model 2A of Profile 2. (a) Observed (circles) and calculated (black line) Bouguer anomalies in mGal. RMSE $=$ root mean square error of the fit between calculated and observed anomalies in mGal. (b) Model of the subsurface below the Taylor Valley. with an eastward $22^{\circ}$ dipping crustal step. Black crosses denote crustal (depth uncertainty $\pm 3 \mathrm{~km}$ ) and lithospheric structure (depth uncertainty $\pm 30 \mathrm{~km}$ ) from Shen et al. (2018a) and Priestley et al. (2018). Subsurface units are differentiated by colour. X-axis ticks are $60 \mathrm{~km}$ spacings, $\mathrm{y}$-axis ticks are $18 \mathrm{~km}$ spacings. 

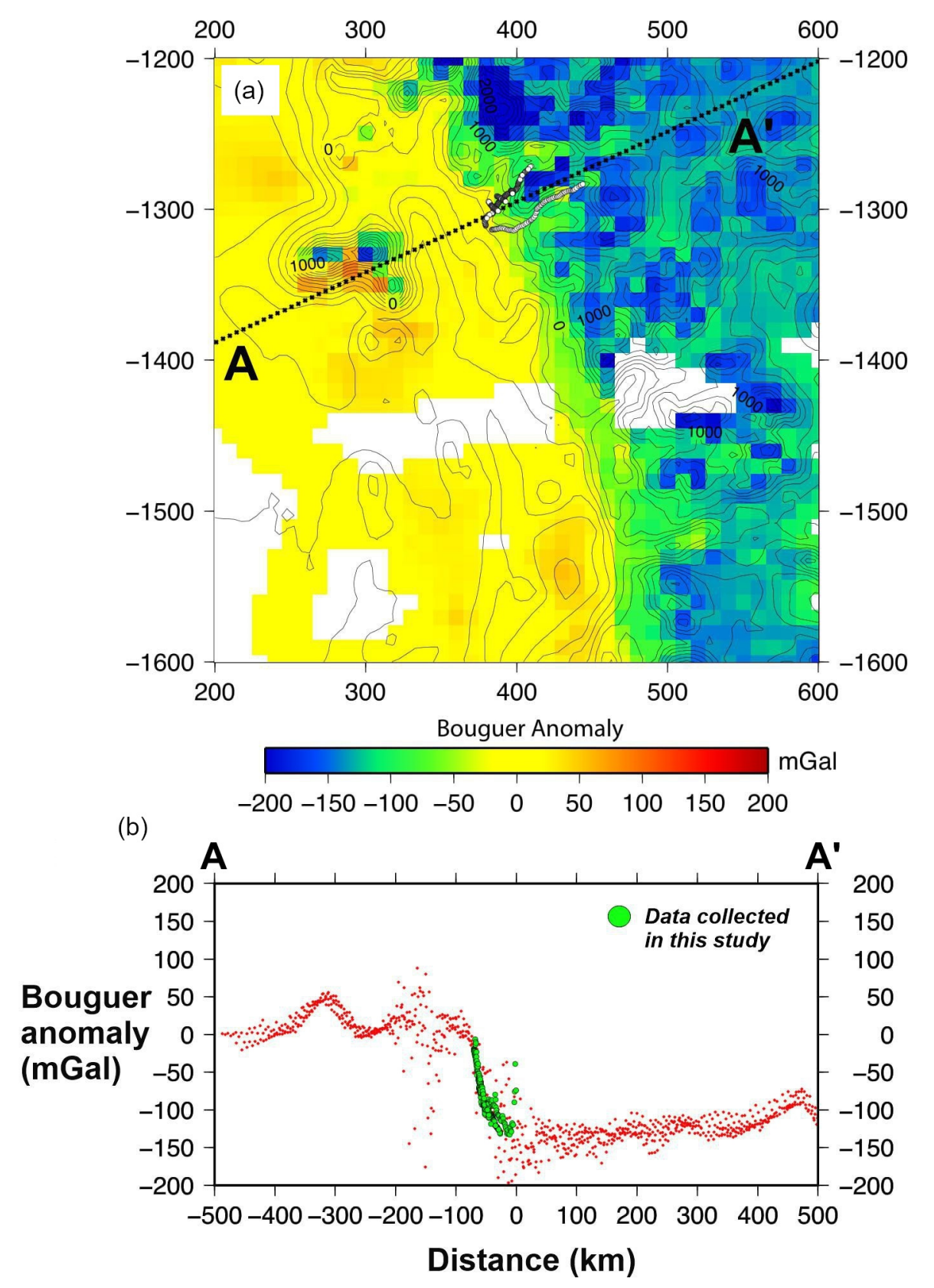

Figure 4.16: 1: Bouguer anomaly map using aero-gravity data from Scheinert et al. (2016). Anomalies are defined by the colour scale. The position of Profile 3 (dashed black line) and gravity data measured in this survey (white circles) are shown. Coordinates are relative to the Antarctic Polar Stereographic projection. 2: Bouguer anomalies along Profile 3 (red circles). Anomalies are from points on the Bouguer anomaly map at $5 \mathrm{~km}$ spacing's in a swath at $50 \mathrm{~km}$ on either side of each line. Land-based gravity measurements made in this study are overlain (green circles). 


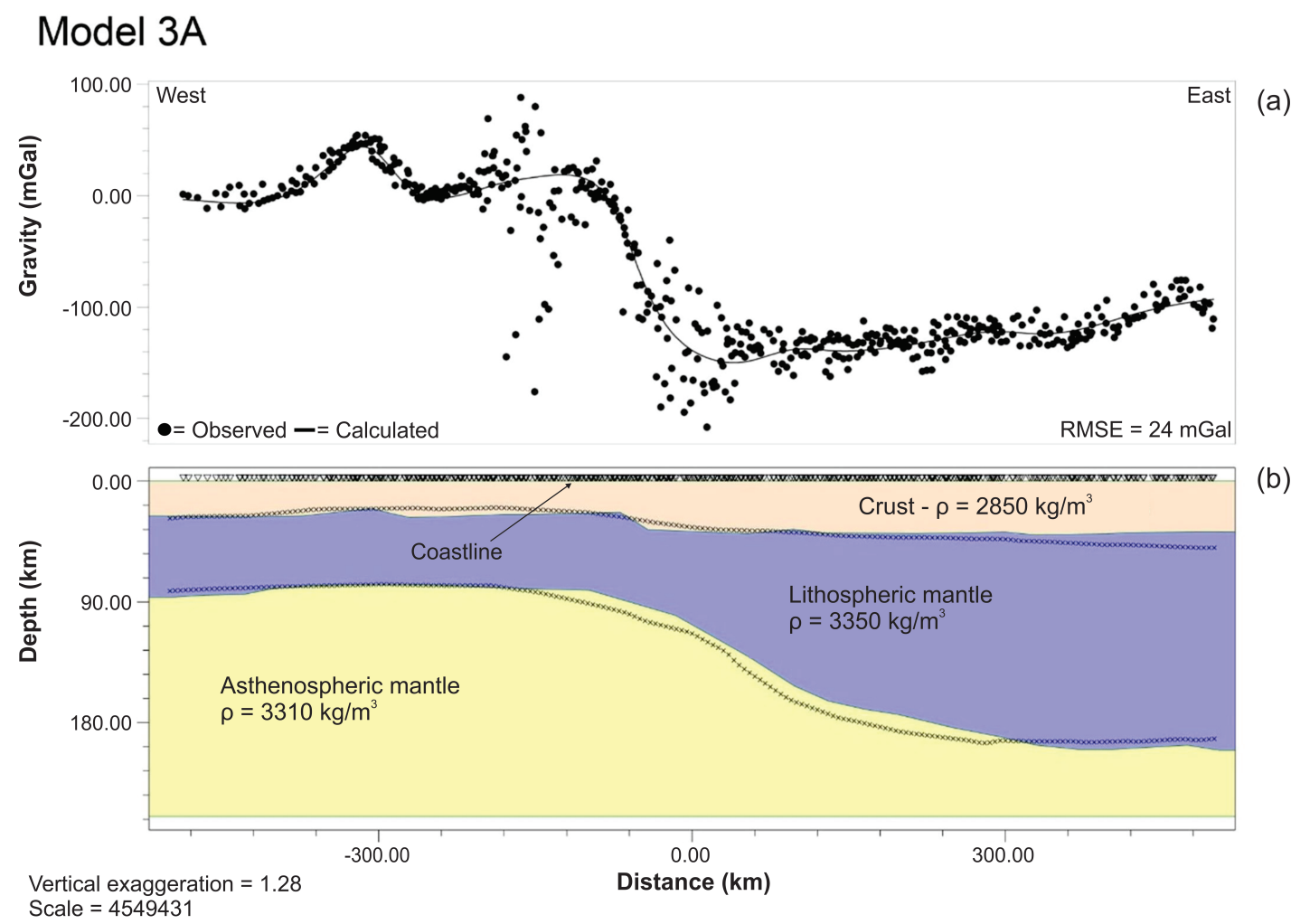

Figure 4.17: Model 3A of Profile 3. (a) Observed (circles) and calculated (black line) Bouguer anomalies in mGal. RMSE $=$ root mean square error of the fit between calculated and observed anomalies in mGal. Measurements made along Line X in the Taylor Valley and land-based observations in the Wright Valley begin at $\sim-57 \mathrm{~km}$ and trend eastward. (b) Model of the subsurface below the Taylor Valley, with an eastward $26.5^{\circ}$ dipping crustal step. Black crosses denote crustal (depth uncertainty $\pm 3 \mathrm{~km}$ ) and lithospheric structure (depth uncertainty $\pm 30 \mathrm{~km}$ ) from Shen et al. (2018a) and Priestley et al. (2018). Subsurface units are differentiated by colour. $\mathrm{X}$-axis ticks are $60 \mathrm{~km}$ spacings, $\mathrm{y}$-axis ticks are $18 \mathrm{~km}$ spacings. 
along the profile, observable in anomalous Bouguer anomalies ranging between -180 and $90 \mathrm{mGal}$. Although the fit of calculated and observed Bouguer anomalies is good visually, this is not reflected in the RMS error of $24 \mathrm{mGal}$, because of the marked anomalies around Ross Island. Significantly, calculated anomalies in Profile 3 capture the trend and magnitude of land-based observed Bouguer anomalies from both the Taylor and Wright Valleys.

\begin{tabular}{cccc}
\hline Profile & Width $(\mathrm{km})$ & Thickness $(\mathrm{km})$ & Dip $\left(^{\circ}\right)$ \\
\hline Model 1C & 29 & 12 & 22.5 \\
Model 2A & 30 & 12 & 22 \\
Model 3A & 26 & 13 & 26.5 \\
Average & 28.3 & 12.3 & 23.6 \\
\hline
\end{tabular}

Table 4.1: Thickness, width and dip of the crustal step from Models 1C (Figure 4.14), 2A (Figure 4.15), and 3A (Figure 4.17) of Profiles 1, 2, and 3 respectively. The bottom row is the average of these parameters from the three models.

\subsection{Moho shape and depth beneath the TAM}

\section{Uncertainty in gravity models and seismic data}

The uncertainty of depths estimated by $\mathrm{P}$-wave receiver functions is positively correlated to depth; regions of thinner crust show smaller average standard deviation, and thus smaller depth uncertainty. Along the Transantarctic Mountain front the standard deviation is relatively high $(4-5 \mathrm{~km})$, reflecting complex lateral Moho and crustal structure (Shen et al., 2018a).

The step in thickness of the Moho in Model 1C (Figure 4.14) has a dip of about 22.5 towards the Polar Plateau. As the position of the step coincides with Line $\mathrm{X}$ where gravity measurements were made in this study, a confidence region of the dip of the step is constructed based on the fit of calculated gravity anomalies to those observed in the Taylor Valley. This region corresponds to an RMSE of $\sim \pm 2 \mathrm{mGal}$ relative to the RMS error of $22 \mathrm{mGal}$ in Model 1C (Figure 4.14).

The crustal step in gravity models is constructed using two 'points' representing the top and bottom of the step. These are shifted horizontally to form the confidence region 

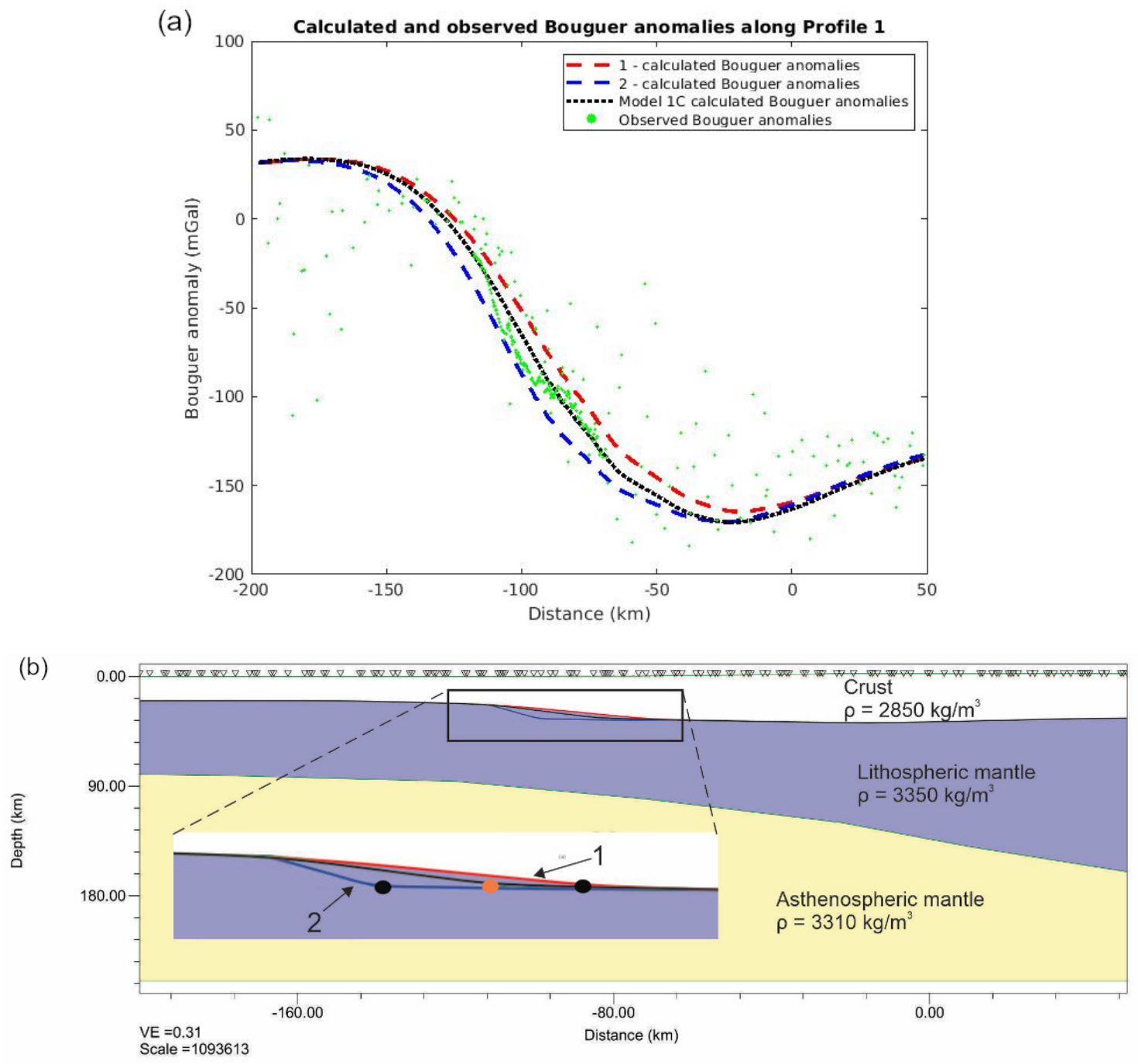

Figure 4.18: Uncertainty analysis of the bottom point forming the crustal step in Model 1C. (a) Calculated Bouguer anomalies along Profile 1 corresponding to the crustal step in Model $1 \mathrm{C}$ (black), a shallowed crustal step, dipping $17.2^{\circ}$ (red; 1 ), and a steepened crustal step, dipping $28.5^{\circ}$ (blue; 2). Observed Bouguer anomalies from aero (Scheinert et al., 2016) and land-based measurements in this study are displayed (green circles). (b) Model 1C, with inset figure showing steepening (blue line; 2) and shallowing (red line; 1) of the modelled crustal step. The original (orange circle) and shifted (black circles) positions of the bottom point of the crustal step are shown. Subsurface units are differentiated by colour.

such that the thickness of the step is a constant. Horizontal shifting of the bottom point forming the crustal step in Model $1 \mathrm{C}$ within the RMSE of the confidence range produces a width of the step between 23 and $40.5 \mathrm{~km}$, equivalent to dips in the range of $17.2-28.5^{\circ}$ (Figure 4.18, Table 4.2).

Similarly, horizontal shifting of the top of the crustal step produces widths of the crustal step between 20 and $48 \mathrm{~km}$. equivalent to a dip between 14.6 - $32^{\circ}$ for a $12.5 \mathrm{~km}$ thick step (Figure 4.19; Table 4.2. 
(a)

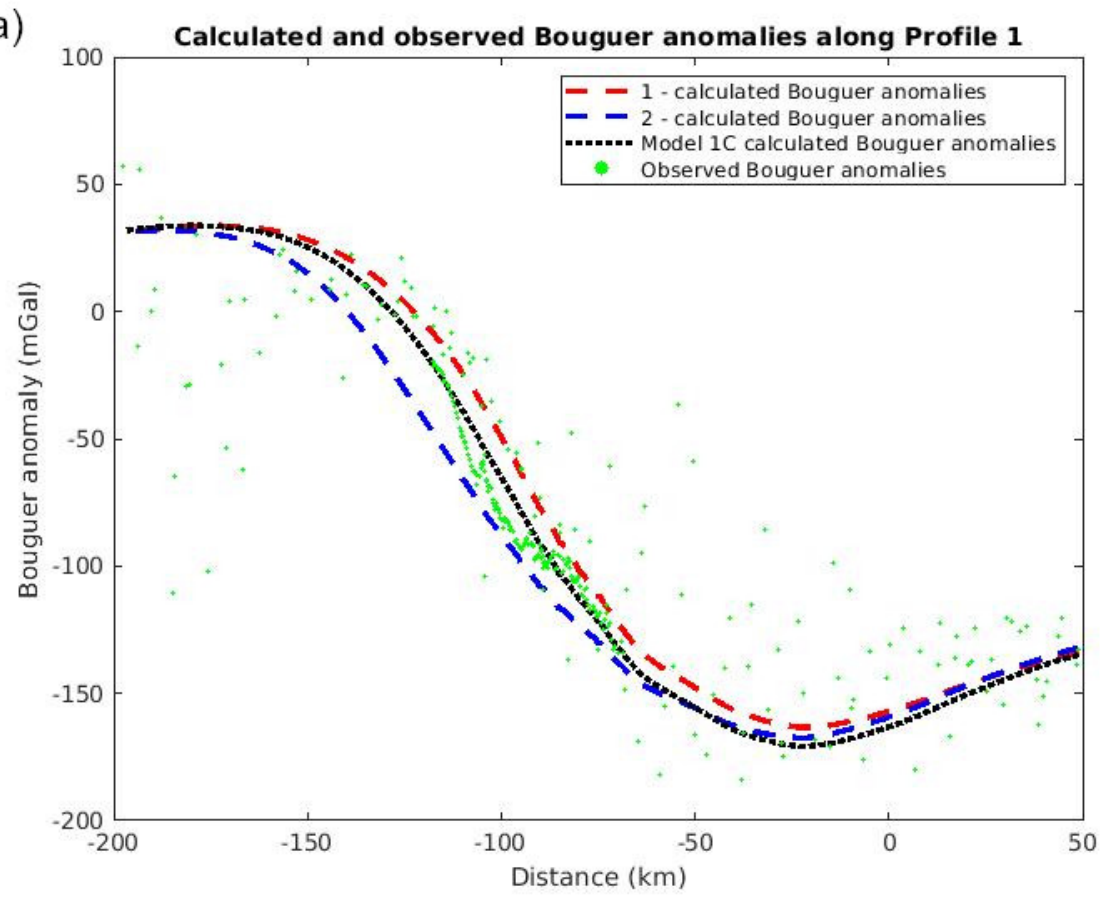

(b)

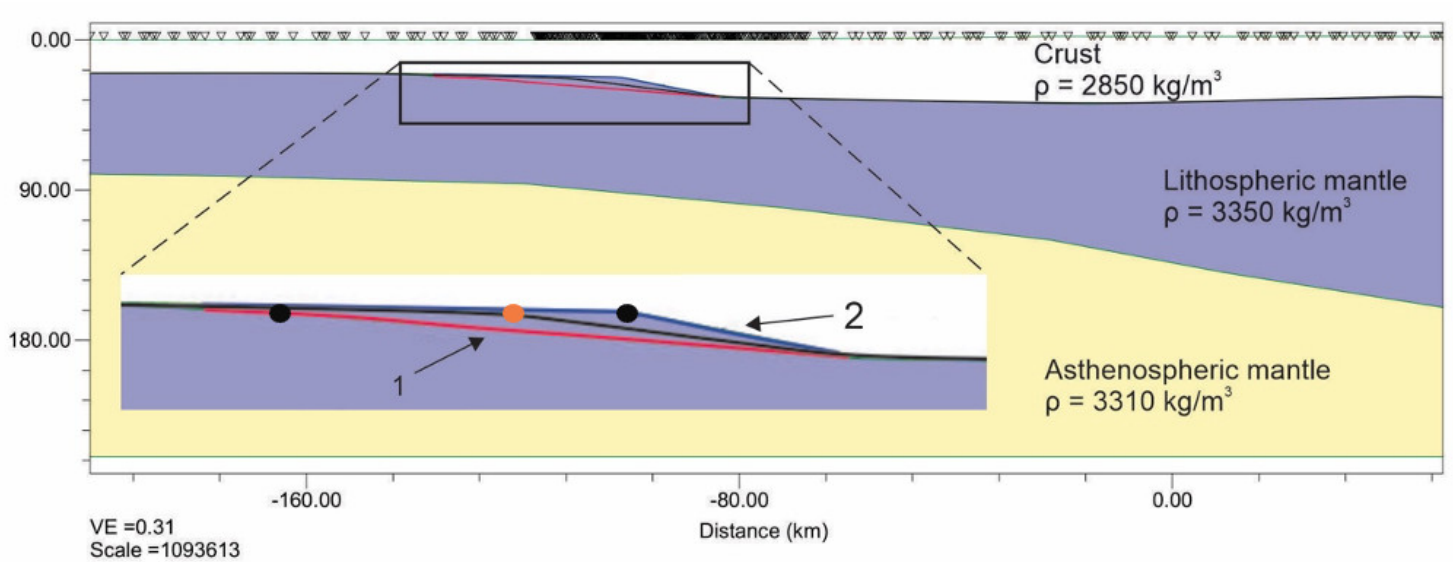

Figure 4.19: Uncertainty analysis of top point forming the crustal step in Model 1C. (a) Calculated Bouguer anomalies along Profile 1 corresponding to the crustal step in Model 1C (black), a shallowed crustal step, dipping $14.6^{\circ}$ (red; 1), and a steepened crustal step, dipping $32^{\circ}$ (blue; 2). Observed Bouguer anomalies from aero (Scheinert et al., 2016) and land-based measurements in this study are displayed (green circles). (b) Model 1C, with inset figure showing steepening (blue line; 2) and shallowing (red line; 1) of the modelled crustal step by moving the top point forming the step. The original (orange circle) and shifted (black circles) positions of the top point of the crustal step are shown. Subsurface units are differentiated by colour. 


\begin{tabular}{cccc}
\hline Model 1C & Width $(\mathrm{km})$ & Thickness $(\mathrm{km})$ & Dip $\left(^{\circ}\right)$ \\
\hline Figure $\mathbf{4 . 1 4}$ & 29 & 12.5 & 24.5 \\
\hline Top Point & & & \\
\hline Steep dip & 20 & 12.5 & 32 \\
Shallow dip & 48 & 12.5 & 14.6 \\
\hline Bottom Point & & & \\
\hline Steep dip & 23 & 12.5 & 28.5 \\
Shallow dip & 40.5 & 12.5 & 17.2 \\
\hline
\end{tabular}

Table 4.2: Confidence region for dip of Moho in Model 1C of Profile 1. Top and bottom point correspond to the points in modelling forming the top and bottom of the step in crustal thickness respectively. Points are shifted horizontally and depths are kept constant. The width, thickness, and dip of the crustal step vary with deviation of the points.

Construction of a confidence region for dip of the crustal step (Table 4.2) demonstrates the importance of new high resolution gravity measurements in constraining this crustal feature. Furthermore, the relatively small range in dip of the crustal step $\left(\sim \pm 7.2^{\circ}\right)$ indicates the crustal step is significant in capturing observed Bouguer anomalies across the TAM front. Convergence of calculated and observed Bouguer anomalies at the edges of the transition zone for all models demonstrates that the crustal step is resolved in the short-wavelength gravity signal. Error bounds in dip of the crustal step means estimates are comparable to dips between 7 and $17^{\circ}$ estimated by Hansen et al. (2009) and Bannister et al. (2003) (Figure 2.15).

Modelled Moho depths differ by up to $7 \mathrm{~km}$ from seismic estimates (Figure 4.17) (Shen et al., 2018a). Limitations in resolution of seismic studies estimating crustal thickness (Shen et al., 2018a; Hansen et al., 2009, Bannister et al., 2003) smooth local-scale $(\sim 5 \mathrm{~km})$ structural features of the subsurface such as the crustal step. This may account for the $7 \mathrm{~km}$ difference in Moho depth modelled in this study. 


\section{Chapter 5}

\section{Discussion}

\subsection{Introduction}

In Chapter 4 models of both the local and regional gravity field have been presented. These models are used to explain variations in the thickness of glacial sediment overlying bedrock, and the regional crustal and upper mantle structure. The marked gradient in Bouguer gravity anomalies in the vicinity of the Transantarctic Mountains can be explained by a step or ramp in crustal thickness of about $12.5 \mathrm{~km}$, associated with a $\sim 100 \mathrm{~km}$ step or ramp in lithospheric thickness, with a thicker crust and mantle lid beneath the interior of East Antarctica compared to the Ross Sea region of West Antarctica. This is essentially a static image of the lithospheric structure. This section will discuss dynamical implications of the lithospheric structure in the context of the principle of isostatic balance and mantle properties such as viscosity.

\subsection{Isostatic balance of gravity models and uplift of the TAM}

The principle of isostatic balance is a key constraint on modelling regional (i.e. on a length scale $>40 \mathrm{~km}$ ) gravity anomalies, and a necessity for a structure to be stable over geological time periods (Lowrie, 1997; Fowler et al., 1990). Isostasy is the equilibrium condition characterized by equal pressure at some level within the mantle. If two vertical columns are taken through a region of isostatic balance, then pressure (the 
line integral of density and thickness) must be the same at the compensation depth for a system to be in equilibrium. In this study the compensation depth is taken as the base of the lithosphere in East Antarctica, because negligible deviatoric stresses can be sustained in the underlying asthenospheric mantle on a time scale greater than $\sim 10^{4}$ years (Walcott, 1970).

Isostatic balance ensures the proposed gravity models are mechanically feasible. Without an isostatic constraint there are an infinite numbers of models that will fit the observed Bouguer anomalies, but most of these will be mechanically infeasible. To ensure isostatic balance of a region, past tectonic processes of the area must first be understood. In southern Victoria Land Cretaceous extension in the Ross Sea thinned the crust and lithosphere, effectively juxtaposing asthenospheric mantle against the thicker East Antarctic craton. Hot, low-density asthenospheric mantle is inferred to have advanced beneath the TAM, producing a buoyancy force capable of supporting $\sim 1.5$ - $2 \mathrm{~km}$ of surface topography and causing large-scale flexure of the region (Shen et al., 2018b; Stern \& ten Brink, 1989).

Stern and ten Brink (1989) further show that the Wilkes Subglacial Basin, that is inboard of the TAM, can be viewed as a flexural 'outer low' coupled to the primary uplift. For a region under flexure the load is compensated by regional, rather than local, displacement of the lithosphere (Watts, 2001). Viewing the Transantarctic Mountains as a flexural load, isostatic balance is achieved at the base of two vertical columns away from this structure, observable in Figure 4.14. This is expressed by summing the product of density and thickness of each layer within each individual column to the compensation depth (Table 5.1).

Seismic estimates of crustal and lithospheric thickness across the TAM front (Priestley et al., 2018; Shen et al., 2018a) demonstrate thinning of lithospheric mantle beneath the Ross Embayment and advance of relatively low-density asthenospheric mantle beneath the TAM. Adopting density contrasts for the crust and mantle estimated in previous gravity models (Pappa et al., 2019; ten Brink et al., 1997), two columns at the extents of Profile 1 are estimated to be close to isostatic balance (Table 5.1) (Lamb et al., 2020).

Pressure at the base of the central column in of Model 1C (Figure 4.14) differs by 


\begin{tabular}{cccc}
\hline West Antarctica & Density $\left(\mathrm{kg} / \mathbf{m}^{\mathbf{3}}\right)$ & Thickness $(\mathrm{km})$ & Pressure $\left(\mathrm{kg} / \mathbf{m}^{\mathbf{2}}\right)$ \\
\hline Water & 1000 & 0.3 & $3.00 \times 10^{5}$ \\
Crust & 2850 & 20 & $5.70 \times 10^{7}$ \\
Lithospheric mantle & 3350 & 57 & $1.91 \times 10^{8}$ \\
Asthenospheric mantle & 3310 & 173 & $5.73 \times 10^{8}$ \\
Total pressure & & & $\mathbf{8 . 2 1 \times 1 0 ^ { 8 }}$
\end{tabular}

\begin{tabular}{cccc}
\hline East Antarctica & & & \\
\hline Ice & 920 & 2.9 & $2.67 \times 10^{6}$ \\
Crust & 2850 & 36 & $1.03 \times 10^{8}$ \\
Lithospheric mantle & 3350 & 164 & $5.49 \times 10^{8}$ \\
Asthenospheric mantle & 3310 & 50 & $1.66 \times 10^{8}$ \\
Total pressure & & & $\mathbf{8 . 2 1 \times 1 0 ^ { 8 }}$ \\
\hline Middle column & & 0 & 0 \\
\hline Ice & 920 & 31 & $8.84 \times 10^{7}$ \\
Crust & 2850 & 86 & $2.88 \times 10^{8}$ \\
Lithospheric mantle & 3350 & 133 & $\mathbf{8 . 1 6 \times 1 0 ^ { 8 }}$ \\
Asthenospheric mantle & 3310 & &
\end{tabular}

Table 5.1: Thicknesses and densities which achieve isostatic balance in three columns, two at the extents of Profile 1 and one located centrally (Figure 4.14). West Antarctica $=$ column 1; East Antarctica $=$ column 2; Middle column $=$ column 3. Densities and thicknesses of the crust, lithospheric mantle, and asthenospheric mantle from seismic (Priestley et al., 2018, Shen et al., 2018a) and gravity (ten Brink et al., 1997) studies are adopted. Pressure (in $\mathrm{kPa}$ ) is the product of thickness and density. Total pressure is the sum of pressure calculated for each layer to a compensation depth of $250 \mathrm{~km}$. The $5.00 \times 10^{6} \mathrm{~kg} / \mathrm{m}^{2}$ pressure difference between East and West Antarctica is due to uncertainty in depth estimates from seismic methods. 
$\sim 5.00 \times 10^{6} \mathrm{~kg} / \mathrm{m}^{2}$ from that in isostatically balanced columns at the extents of the region. This pressure differential is effectively a net positive buoyancy that is distributed over about $80 \mathrm{~km}$ beneath the edge of the TAM. If converted to an equivalent uplift of crustal rocks of density $2850 \mathrm{~kg} / \mathrm{m}^{3}$, it would give:

$$
\text { Surface uplift }=\frac{\text { Pressure }\left(\mathrm{kg} / \mathrm{m}^{2}\right)}{\text { Density }\left(\mathrm{kg} / \mathrm{m}^{3}\right)}=\frac{5 \times 10^{6}}{2.75 \times 10^{3}} \approx 1.7 \mathrm{~km}
$$

The maximum elevation of the TAM is $4500 \mathrm{~m}$, but the average elevation is much less than this because of the effect of deep glacial erosion between the elevated sections. A digital study of uplift and erosion by Stern et al. (2005) shows that for two sections of the central TAM the average elevation, over length scales of $\sim 500 \mathrm{~km}$, is between 1.1 and $1.9 \mathrm{~km}$. This is closely in line with what is estimated from this gravity analysis.

\subsection{Estimates of viscosity}

Understanding post-glacial rebound (PGR) in Antarctica - the process of surface uplift resulting from removal of a 'load' in the past such as ice cover - is critical to solving the problem of what is contributing to eustatic sea level rise today (see Chapter 1).

GNSS sites must be on solid rock to measure PGR, as devices on ice will observe ice ablation or movement. The largest expanses of exposed bedrock on Antarctica are in the TAM and Dry Valleys, thus, these areas are where most GNSS sites monitoring PGR are located (Argus et al., 2014, Figure 5.1). This bias in location of GNSS stations means constraining viscosity of the upper mantle in the Dry Valleys, and in particular, what and where the gradients in upper mantle viscosity might be here, is critical

There are two points to note when viewing the fit between modelled and observed uplift rates (Figure 5.2). Firstly, uncertainty in observed PGR uplift rates is of the same order as the uplift rate $(\sim 1-4 \mathrm{~mm} / \mathrm{yr}$ ) (Argus et al., 2014, Ivins et al., 2013). Secondly, despite the uncertainty in observations of uplift rate, there is a clear trend away of data from perfect correlation $\left(\mathrm{R}^{2}=1\right)$ between modelled and observed rates of uplift (Figure 5.2). Two obvious reasons for this misfit are in the key parameters controlling GIA models: 
(a)

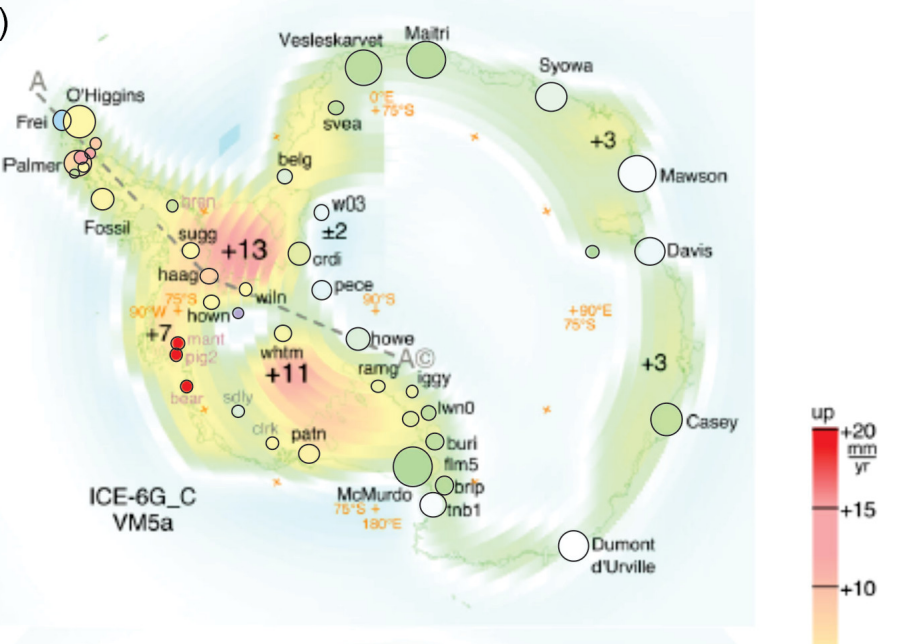

(b)

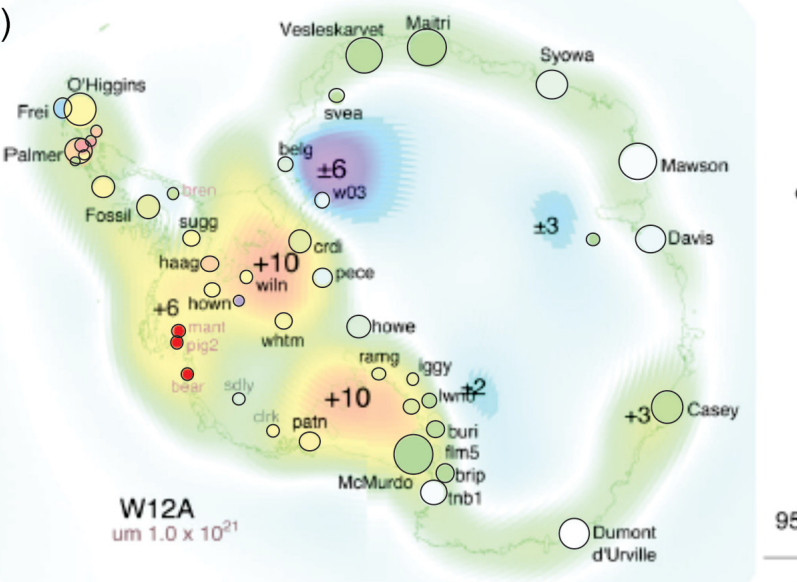

(c)

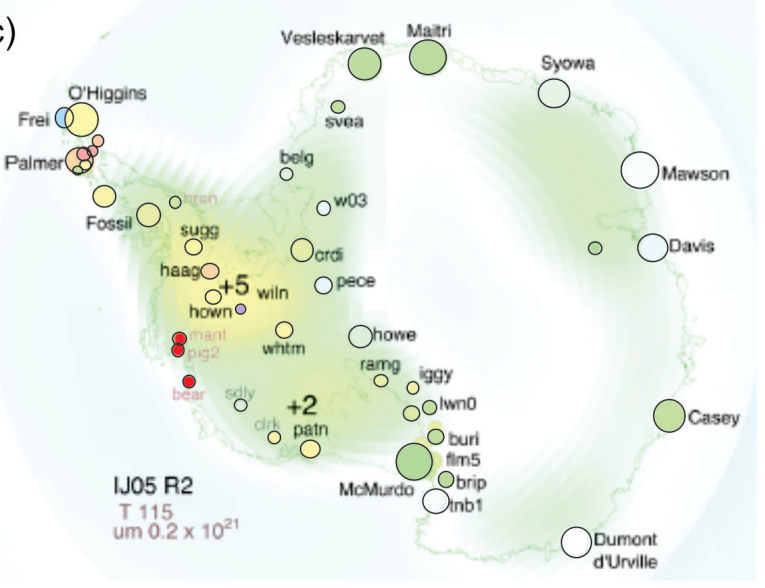

Figure 5.1: Color-scale map of post-glacial rebound model-calculated and GNSS observed uplift rates (in $\mathrm{mm} / \mathrm{yr}$ ). The colour scale corresponds to calculated uplift rate, while colours in circles following the same scale are observed uplift rates at GNSS stations. The names of GNSS stations are displayed on the figure. Larger circles represent more certainty in GNSSderived estimates of uplift. (a) ICE 6G_C GIA model (Argus et al., 2014), (b) W12A GIA model (Whitehouse et al., 2012), and (c) IJ05 R2 GIA model (Ivins et al., 2013). Different modelled uplift rates are a result of differing upper mantle viscosities adopted in GIA models. 


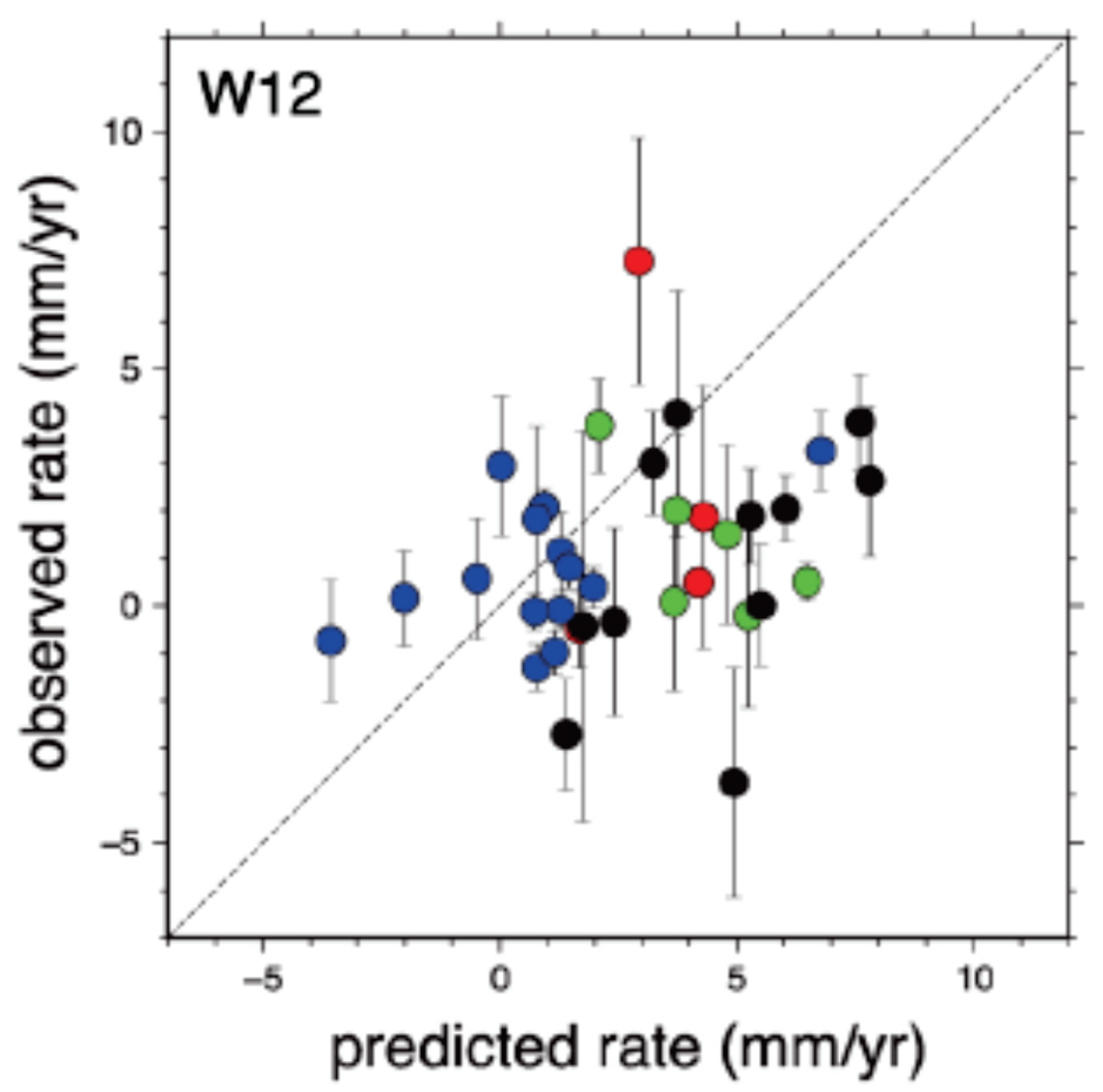

Figure 5.2: Observed (elastic-corrected GNSS) versus predicted (W12 deglacial model) present-day uplift rates (in $\mathrm{mm} / \mathrm{yr}$ ) at 35 GNSS sites in Antarctica from Whitehouse et al. (2012). GNSS site locations follow the code: Ross Sea (red), Antarctic Peninsula (green), East Antarctica (blue), West Antarctica (black). Uncertainty in observed uplift rates are displayed (black error bars). The dashed line represents perfect correlation between observed and predicted uplift rates.

- Uncertainty in the ice loss history adopted for Antarctica i.e. ice loss occurred earlier than was assumed in models

- Viscosity of the upper mantle is less than was assumed in models, such that rebound occurred faster than was calculated and the rebound phase following the LGM is almost complete, with only minor uplift still occurring.

Viscosity is a measure of resistance to flow in the mantle over long timescales; high viscosity causes a slow viscous response to surface load removal. East Antarctica is an old, stable craton with thick lithosphere and high mantle viscosities $\left(\sim 10^{22}-10^{24}\right.$ Pas $)$ (van der Wal et al., 2015; Kaufmann et al., 2005) proposed down to depths of $\sim 200 \mathrm{~km}$, while West Antarctica has thinner lithosphere and lower mantle viscosities as a result of significant extension in the Late Cretaceous (O'Donnell et al., 2017). This has resulted 
in marked lateral variations in viscosity at any particular depth between East and West Antarctica, and as a consequence, there will be different responses to ice sheet removal within each region (Figure 5.2).

The following subsections use two methods to calculate viscosity of the upper mantle and how this varies between East and West Antarctica. The first estimates asthenospheric mantle viscosity using established curves of uplift history for different load geometries, adapted to our study area. The second uses the relationship between density, temperature, and viscosity to estimate the factor of viscosity variation between lithospheric and asthenospheric mantle. These estimates will place some constraints on the variation in viscosity between East and West Antarctica, and aim to resolve the discrepancies between modelled and observed rates of surface uplift.

\subsubsection{Asthenospheric mantle viscosity in the Ross Embayment Uplift of a square-edged trough}

Viscosity of the upper mantle controls the rate of surface uplift following removal of a load. Thus, by assuming an approximate history of surface uplift in a region, estimates can be made of the asthenospheric mantle viscosity within the area.

Cathles (1975) developed equations that approximate the uplift remaining for central regions of a square-edged trough and cylindrical square-edged depression after removal of a two-dimensional load (Figure 5.3). Note that these models and their geometry are referred to purely theoretically and are only used to give an example of possible surface uplift within the study area. The region geometries are not what is important, but rather the example of uplift within the region.

Remaining surface uplift $\left(\mathrm{h} / \mathrm{h}_{0}\right)$ is defined as the ratio between uplift, $\mathrm{h}$, observed at time $t_{H S}$, and uplift, $h_{0}$, at $t_{H S}=$ infinity (i.e. total uplift). The parameter $t^{\prime}{ }_{H S}$ is dimensionless time since removal of the load from the half-space, expressed in equation 5.2 .

$$
t_{H S}^{\prime}=\frac{\rho g \sigma}{2 \eta} t
$$




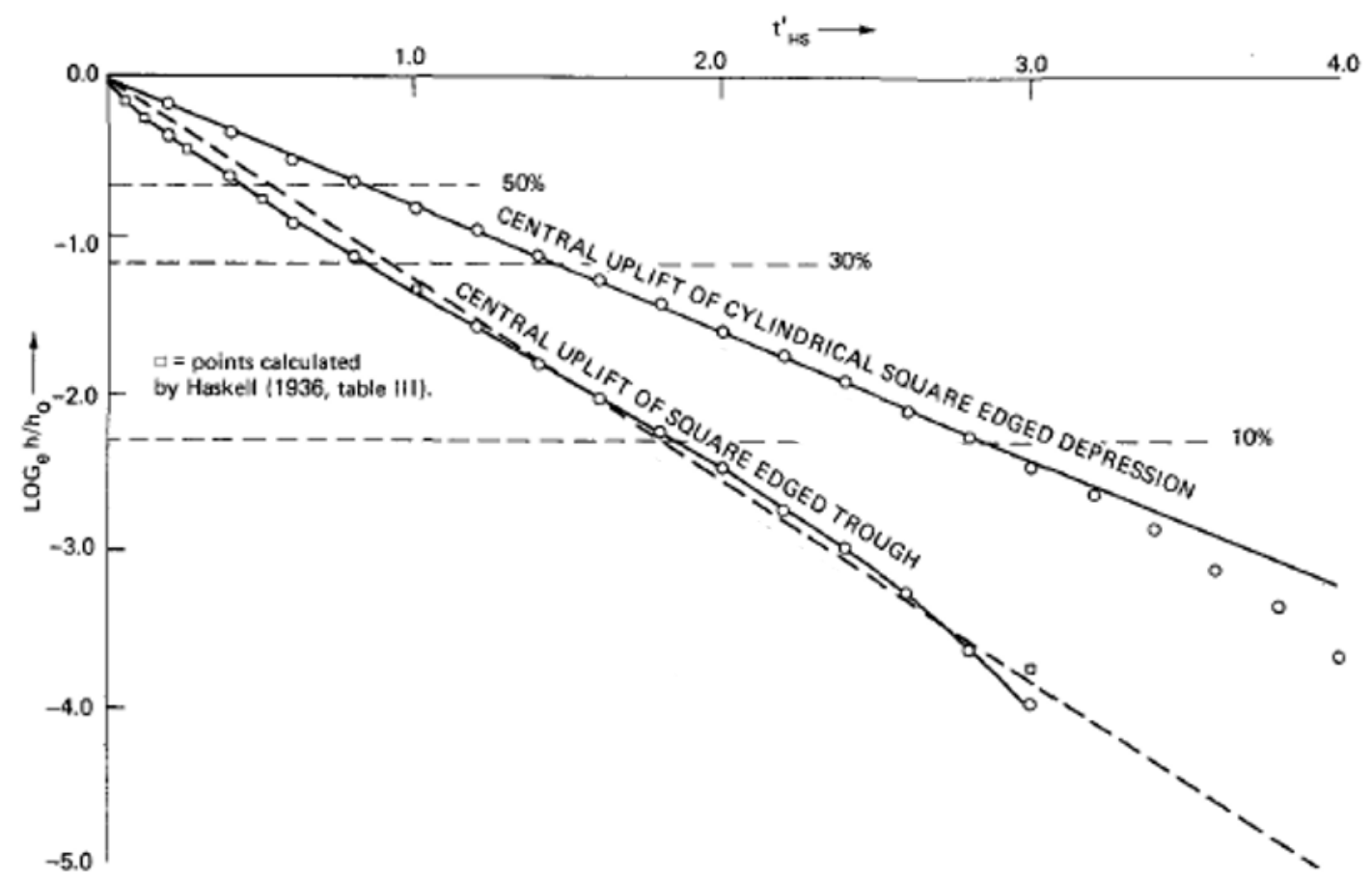

Figure 5.3: The logarithm of normalised uplift remaining for regions of a square-edged trough and cylindrical square-edged depression against dimensionless time, t'Hs. Values calculated numerically by Telford et al. (1990) (black lines) are compared to values calculated analytically by Haskell (1936) (circles). Percentage of uplift remaining relative to the total uplift is plotted (horizontal dashed lines). The bold dashed line represents a constant rate of uplift with time. Figure from Cathles (1975). 
Where $\rho$ is density of the mantle, $\mathrm{g}$ is constant gravitational acceleration at the surface $\left(9.81 \mathrm{~m} / \mathrm{s}^{2}\right), \sigma$ is the half-width of the Gaussian trough, $\eta$ is the viscosity of the halfspace or channel, and $t$ is time since removal of the load. In this study the load is defined as the significant ice cover over the Ross Embayment during the Last Glacial Maximum (LGM). The half-width of the Gaussian trough is, therefore, the half-width of this ice cover at it's maximum extent, assumed as $160 \mathrm{~km}$ (Denton \& Hughes, 2000).

The rate of uplift depends somewhat on load geometry (Figure 5.3). In this study we assume that the model for central uplift of a square-edged trough approximates uplift of the Ross Embayment, and the adjacent TAM, following the Last Glacial Maximum. We can use this relationship (Figure 5.3) to get a first order estimate for the viscosity of the mantle if the area beneath the TAM has already fully rebounded, and there is negligible uplift today. We define full-rebound as when uplift from unloading has recovered so that the surface which was once depressed has returned to its original position before depression. In this case we chose full rebound as $\ln \left(\mathrm{h} / \mathrm{h}_{0}\right)=-4$. That is, rebound is within $2 \%$ of being complete. At this value of $\ln \left(\mathrm{h} / \mathrm{h}_{0}\right), \mathrm{t}^{\prime}{ }_{\mathrm{HS}}=3.1$ (Figure 5.3 .

Comparatively, another estimate of asthenospheric mantle viscosity can be made at $50 \%$ of total uplift, $\ln \left(\mathrm{h} / \mathrm{h}_{0}\right)=\sim-0.7$. This gives a time t' ${ }_{\mathrm{HS}}=0.5$ (Figure 5.3). We here make the assumption that mantle viscosity at complete surface recovery and $50 \%$ recovery are different values. By calculating viscosity at both half ( $\mathrm{t}^{\prime}{ }_{\mathrm{HS}}=0.5$ ), and approximately full-rebound ( $\mathrm{t}_{\mathrm{HS}}=3.1$ ) of the TAM surface, we can see the drop in viscosity of the mantle needed if in fact we are in the situation of $t^{\prime}{ }_{\mathrm{HS}}=3.1$ rather than t' $_{\text {HS }}=0.5$. But before we do this calculation we need to adopt a time when most of the ice retreated.

Constraints on timing of ice retreat during the LGM are broad. King et al. (2020) estimated steady thinning of the Hatherton Glacier, East Antarctica, between 9500 and $2800 \mathrm{yr}$ before present (BP). Therefore, adopting a timing of ice retreat of $7000 \mathrm{yr}$ $\mathrm{BP}$ in the Ross Embayment - an arbitrary estimate within the range estimated by King et al. (2020) - and average mantle density of $3310 \mathrm{~kg} / \mathrm{m}^{3}$, asthenospheric mantle viscosities are calculated for half and full rebound of the TAM surface (Table 5.2 ) by rearranging equation 5.2 . 


\begin{tabular}{cc}
\hline t'$_{\text {HS }}$ & Viscosity (Pa.s) \\
\hline 0.5 & $1.2 \times 10^{21}$ \\
3.1 & $1.9 \times 10^{20}$ \\
\hline
\end{tabular}

Table 5.2: Viscosities of asthenospheric mantle calculated for central uplift of a squareedged trough using equation 5.3 at $50 \%\left(\mathrm{t}^{\prime} \mathrm{HS}=0.5\right)$ and full $\left(\mathrm{t}^{\prime}{ }_{\mathrm{HS}}=3.1\right)$ rebound of the TAM surface. An average mantle density, $\rho$, of $3310 \mathrm{~kg} / \mathrm{m}^{3}$ and time since removal of the load, t, of 7000 yrs BP are assumed.

$$
\eta=\frac{\rho g \sigma}{2 t_{H S}^{\prime}} t
$$

Note that the difference in viscosities calculated using times of 9500 and $2800 \mathrm{yr}$ before present $(\mathrm{BP})$ is negligible, thus assuming an arbitrary estimate within the range is justified.

Asthenospheric mantle viscosity decreases from $1.2 \times 10^{21}$ to $1.9 \times 10^{20}$ Pa.s at $50 \%$ and full surface rebound respectively, a difference of $\sim 16 \%$ (Table 5.2 ).

\section{Uplift of a square-edged, cylindrical depression with a uniform viscous half- space and lithosphere}

The model for central uplift of the square-edged trough in Figure 5.3 is unrealistic as it assumes no lithosphere is present. Cathles (1975) also developed a model for the uplift history of a square-edged, cylindrical depression assuming a uniform viscous half-space and lithosphere with flexural rigidity of $50 \times 10^{23}$ N.m (Figure 5.4). Flexural rigidity is a measure of the resistance to bending of an elastic sheet under a bending force or flexural couple (Walcott, 1970).

The remaining uplift, $\mathrm{h} / \mathrm{h}_{0}$, varies with both dimensionless time, $\mathrm{t}_{\mathrm{HS}}$, and radial distance from the load center. Assuming this model represents the broader TAM - Ross Embayment region, observed uplift rates decrease with distance from the ice load in the Ross Embayment. Thus, the rate of uplift since the LGM is greater across Ross Island, which underwent a greater maximum surface depression, than in the TAM, where total surface depression was less due to relative distances from the load. Between radial distances of 1 and 1.5, a flexural bulge is formed as a response to surface depression nearer to the ice load. Upon removal of the load, the surface uplifts at areas 


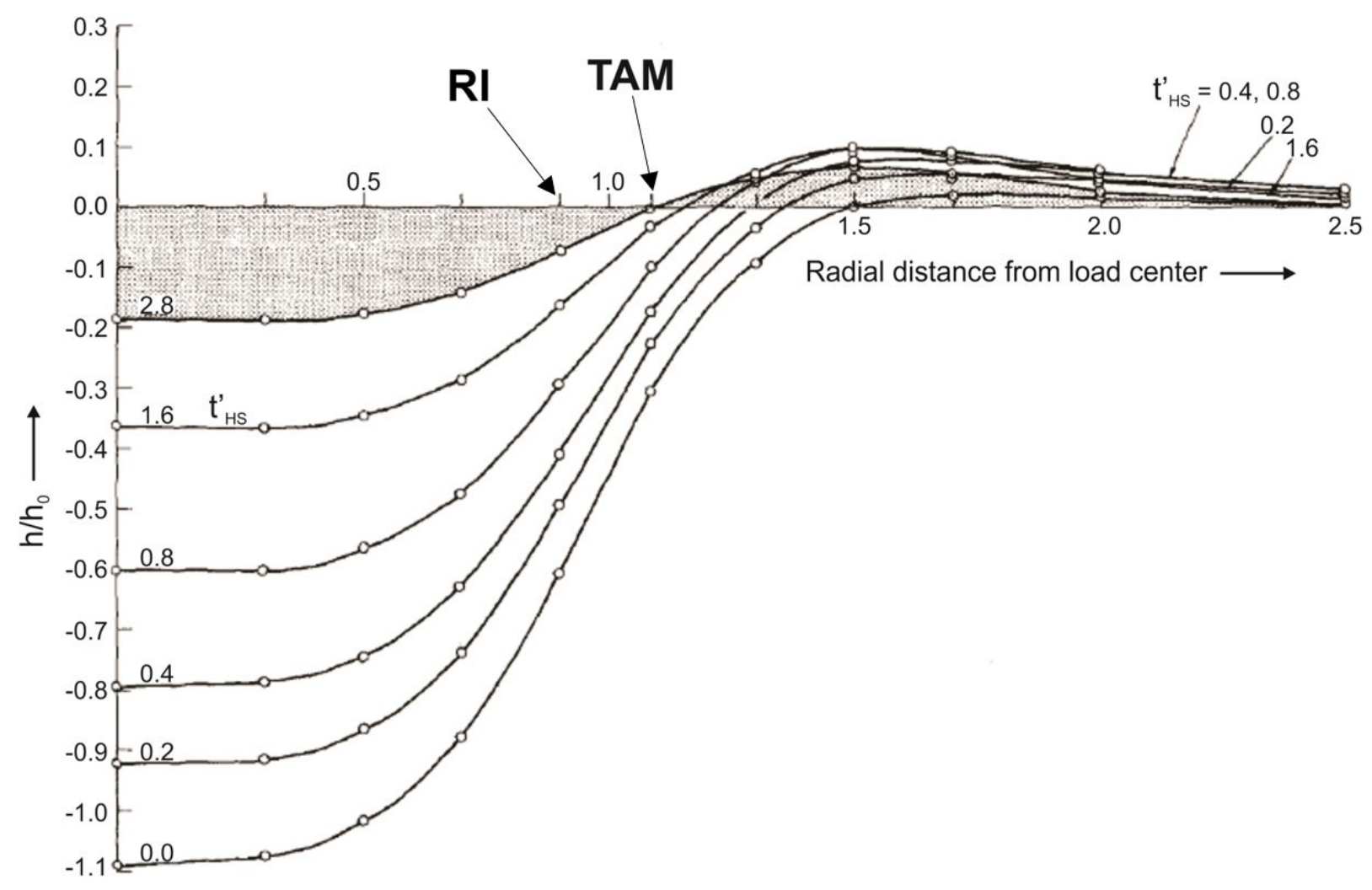

Figure 5.4: Uplift history of a square-edged cylindrical depression assuming a uniform viscous half-space and lithosphere with flexural rigidity of $50 \times 10^{23}$ N.m. Remaining uplift, $\mathrm{h} / \mathrm{h}_{0}$, at different normalised times, t'HS, is plotted against radial distance from the load center (black lines). Shaded areas indicate remaining uplift following t'HS $=2.8$. Open circles highlight uplift remaining at different points in time. Theoretical positions of the Transantarctic Mountains (TAM) and Ross Island (RI) in the model are displayed. Figure from Cathles (1975).

of maximum depression, while subsidence occurs across the flexural bulge. In such a situation, predicted movement in the Dry Valleys region (assumed as lying between radial distances of 1 and 1.5 in Figure 5.4 could be complex, and for some cases, either uplift or subsidence.

From Figure 5.4 we assume full recovery of the TAM surface at t' ${ }_{\text {HS }}=2.8$, and $50 \%$ recovery at $\mathrm{t}_{\mathrm{HS}}=0.4$. Adopting the same parameters of $\sigma$ and $\rho$ applied previously, asthenospheric mantle viscosities are calculated using equation 5.3 (Table 5.3).

Asthenospheric mantle viscosities vary between $1.4 \times 10^{21}$ and $2.1 \times 10^{20}$ Pa.s for t' $\mathrm{HS}=$ 0.4 (50\% recovery) and t' ${ }_{\mathrm{HS}}=2.8$ (full recovery) respectively, on average about $14 \%$ higher than those calculated in models of uplift without a lithosphere (Table 5.2).

The purpose of this analysis for rebound due to simple ice load geometries is not 


\begin{tabular}{cc}
\hline $\mathbf{t}^{\prime}$ HS & Viscosity (Pa.s) \\
\hline 0.4 & $1.4 \times 10^{21}$ \\
2.8 & $2.1 \times 10^{20}$ \\
\hline
\end{tabular}

Table 5.3: Viscosities of asthenospheric mantle calculated using equation 5.3 for uplift of a square-edged cylindrical depression assuming a uniform viscous half-space and lithosphere with flexural rigidity of $50 \times 10^{23}$ N.m at $50 \%$ ( $\mathrm{t}^{\prime} \mathrm{HS}=0.4$ ) and full ( $\mathrm{t}^{\prime} \mathrm{HS}=2.8$ ) rebound of the TAM surface. An average mantle density, $\rho$, of $3310 \mathrm{~kg} / \mathrm{m}^{3}$ and time since removal of the load, t, of 7000 yrs BP are assumed.

the viscosities estimated, but that ice free regions of the TAM may be located in a region such that uplift or subsidence can be expected after ice retreated from the Ross Embayment $\sim 7000$ years ago. Thus, the combination of possible viscosity gradients in the mantle, and being immediately adjacent to the now melted ice advance in the Ross Embayment, make GNSS measurements of uplift in the ice-free regions challenging to interpret.

\subsubsection{Viscosity contrast in the upper mantle}

Although estimates of asthenospheric viscosity have been made above, these values are somewhat arbitrary. What is more important is the contrast in viscosity of the asthenospheric mantle that is under the edge of the TAM, with the previous mantle lithosphere that it is replacing. This upper mantle viscosity contrast is estimated below.

\section{The equation of thermal expansion}

Density and temperature are related by the equation of thermal expansion (equation 5.4) (Stüwe, 2002):

$$
\frac{\Delta \rho}{\rho}=\alpha \Delta T
$$

where the left hand side is the ratio of change in density $(\Delta \rho)$ to the absolute density $(\rho)$, $\alpha$ is the coefficient of thermal expansion taken to be $3 \times 10^{-5} \mathrm{~T}^{-1}$, and $\Delta \mathrm{T}$ is temperature contrast between East and West Antarctica. ten Brink et al. (1993) adopt an absolute density, $\rho$, of $3350 \mathrm{~kg} / \mathrm{m}^{3}$ when modelling advance of low-density asthenospheric mantle below the TAM south of the Nimrod Glacier. The same value is applied here. 
Gravity models in this study adopt a $40 \mathrm{~kg} / \mathrm{m}^{3}$ density contrast between lithospheric and asthenospheric mantle (Section 4.4). Using equation 5.4, a temperature difference between lithospheric and asthenospheric mantle of $\sim 400{ }^{\circ} \mathrm{C}$ is estimated.

Seismic tomographic images of southern Victoria Land (Shen et al., 2018b; Lawrence et al., 2006, Watson et al., 2006) estimate a $200 \mathrm{~km}$ deep $\sim 200-400{ }^{\circ} \mathrm{C}$ temperature difference between asthenospheric mantle of the Ross Embayment and lithospheric mantle beneath the Polar Plateau. The thermal anomaly extends $50-100 \mathrm{~km}$ inland beneath the McMurdo Dry Valleys and portions of the TAM from the Ross Sea (Watson et al., 2006), consistent with modelled advance of asthenospheric mantle beneath the TAM front in this study (Figures 4.14, 4.15, and 4.17).

\section{The Arrhenius relationship}

The Arrhenius Law describes the thermal dependence of viscosity, $\eta$, expressed in equation 5.5 .

$$
\eta=A_{0} \exp \left(\frac{Q}{R T}\right)
$$

Where $A_{0}$ is the pre-exponent constant, $\mathrm{Q}$ is the activation energy, $\mathrm{R}$ is the universal gas constant, and here $\mathrm{T}$ is temperature of the asthenospheric mantle (Stüwe, 2002).

The viscosity contrast between asthenospheric and lithospheric mantle, $\Delta \eta$, is calculated by taking the derivative of equation 5.5 with respect to temperature, $\mathrm{T}$, expressed in equation 5.6 .

$$
\Delta \eta=-\Delta T \frac{Q A_{0}}{R T^{2}} \exp \left(\frac{Q}{R T}\right)
$$

Where $\Delta \mathrm{T}$ is the temperature contrast between lithospheric and asthenospheric mantle.

We can now write the expression for the ratio of the mantle viscosity contrast, $\Delta \eta$, and viscosity, $\eta$, as: 


$$
\frac{\Delta \eta}{\eta}=-\frac{\Delta T Q}{R T^{2}}
$$

Where the factor $\mathrm{A}_{0} \exp (\mathrm{Q} / \mathrm{RT})$ appears in both the numerator and denominator of the expression, and thus cancels.

A typical value for the activation energy, Q, of the dry mantle with dislocation creep is 540x10 $\mathrm{J} / \mathrm{mol}$ (Turcotte \& Schubert, 2002; Karato \& Wu, 1993). Taking the universal gas constant, R, of $8.31 \mathrm{~J} / \mathrm{mol} . \mathrm{K}$, and adopting a mantle undergoing a temperature change from 900 to $1300{ }^{\circ} \mathrm{C}\left(\Delta \mathrm{T}=\sim 400{ }^{\circ} \mathrm{C}\right)$, we have:

$$
\frac{\Delta \eta}{\eta}=-\frac{\left(400 \times 540 \times 10^{3}\right)}{8.31 \times 900^{2}}=-32
$$

In other words, the viscosity contrast would need to decrease by a factor of 32 for the $\sim 1 \%$ density contrast of $40 \mathrm{~kg} / \mathrm{m}$ between the asthenospheric mantle and the mantle lithosphere.

\subsection{Convective removal of the lithosphere}

A variety of geodynamic models have been proposed for uplift of the TAM (Gleadow \& Fitzgerald, 1987; Fitzgerald et al., 1986). Some are conceptual (Studinger et al., 2004) and some analytical (Stern \& ten Brink, 1989). The most recent concept is that of convective removal of mantle lithospheric (Stern et al., 2019; Shen et al., 2018b). Gravity models in this study and previous seismic observations (Shen et al., 2018a; Hansen et al., 2009 Bannister et al., 2003) lack evidence for a crustal root for the mountains. This observation, combined with strong, relatively low-velocity anomalies (Shen et al., 2018a; Brenn et al., 2017), Cenozoic volcanism (Cande et al., 2000), absence of compressional faulting, and extension along the WARS (Lawver \& Gahagan, 1994), provide compelling evidence of a mantle source for the present-day high elevations of the TAM (Stern et al., 2019, Shen et al., 2018b).

Rayleigh-Taylor instabilities created at a lithospheric step will migrate and then contribute to large changes in lithospheric thickness that vary with time (Stern et al., 2013). Such steps exist when a dense layer, such as upper lithospheric mantle, is jux- 
taposed against a lighter layer, such as the hotter asthenospheric mantle (Houseman \& Molnar, 1997) by rifting or strike-slip faulting.

In the Ross Embayment - Polar Plateau region, surface wave data reveal an absence of dense, cratonic lithosphere beneath the Ross Embayment (Shen et al., 2018b). Rather, a low seismic anomaly in uppermost-mantle is observed, extending beneath the TAM and edge of East Antarctica, underlain by relatively high-wave speeds to a depth of $\sim 200 \mathrm{~km}$ (Figure 5.5). Shen et al. (2018b) propose the occurrence of lithospheric mantle foundering in the Ross Embayment and beneath the TAM, where warm, less dense asthenosphere has replaced cold, dense East Antarctic lithosphere at shallow depths. Figure 5.5 is an interpretation of mantle S-wave seismic velocity $\left(\mathrm{v}_{\mathrm{s}}\right)$ perturbations beneath the TAM in southern Victoria Land and Thiel Mountains of the Ellsworth Land region (Shen et al., 2018b). Relatively high $\mathrm{v}_{\mathrm{s}}$ lithospheric mantle in East Antarctica delaminates beneath the TAM and Thiel Mountains, replaced by an upwelling of a low mantle $\mathrm{v}_{\mathrm{s}}$ perturbation from beneath the Ross Ice Shelf and Byrd Subglacial Basin, interpreted as hotter asthenospheric mantle. Advance of this relatively low anomaly mirrors the distribution of high surface elevations.

Lithospheric foundering may initiate in an extensional environment following the formation of a step in the mantle lithosphere (Stern et al., 2013). Shen et al. (2018b) suggest that Cretaceous rifting of the WARS created this step, providing a possible trigger for the delamination of cold, cratonic lithosphere of East Antarctica, and a mechanism for uplift of the Transantarctic Mountains.

Stern et al. (2013) showed within western North Island, New Zealand, that for uppermost lithospheric mantle viscosities on the order of $\sim 5 \times 10^{20}$ Pa.s, thicker mantle lithosphere will drip into the lower density asthenosphere. As part of this deformation, overlying crust will progressively thicken and then thin, creating a 'topographic wave' that migrates with removal of the upper mantle lithosphere. Similarly, Shen et al. (2018b) propose that in a region with lithospheric thicknesses and densities similar to those used in this study (Pappa et al., 2019; Priestley et al., 2018; Shen et al., 2018a; ten Brink et al., 1993), and an upper-mantle viscosity of $\sim 10^{22}$ Pa.s, lithospheric foundering can initiate within 10 - 20 M.y after lithospheric perturbation, running to completion in $\sim 80$ M.y. Thus, if the time lithospheric foundering initiated within the 


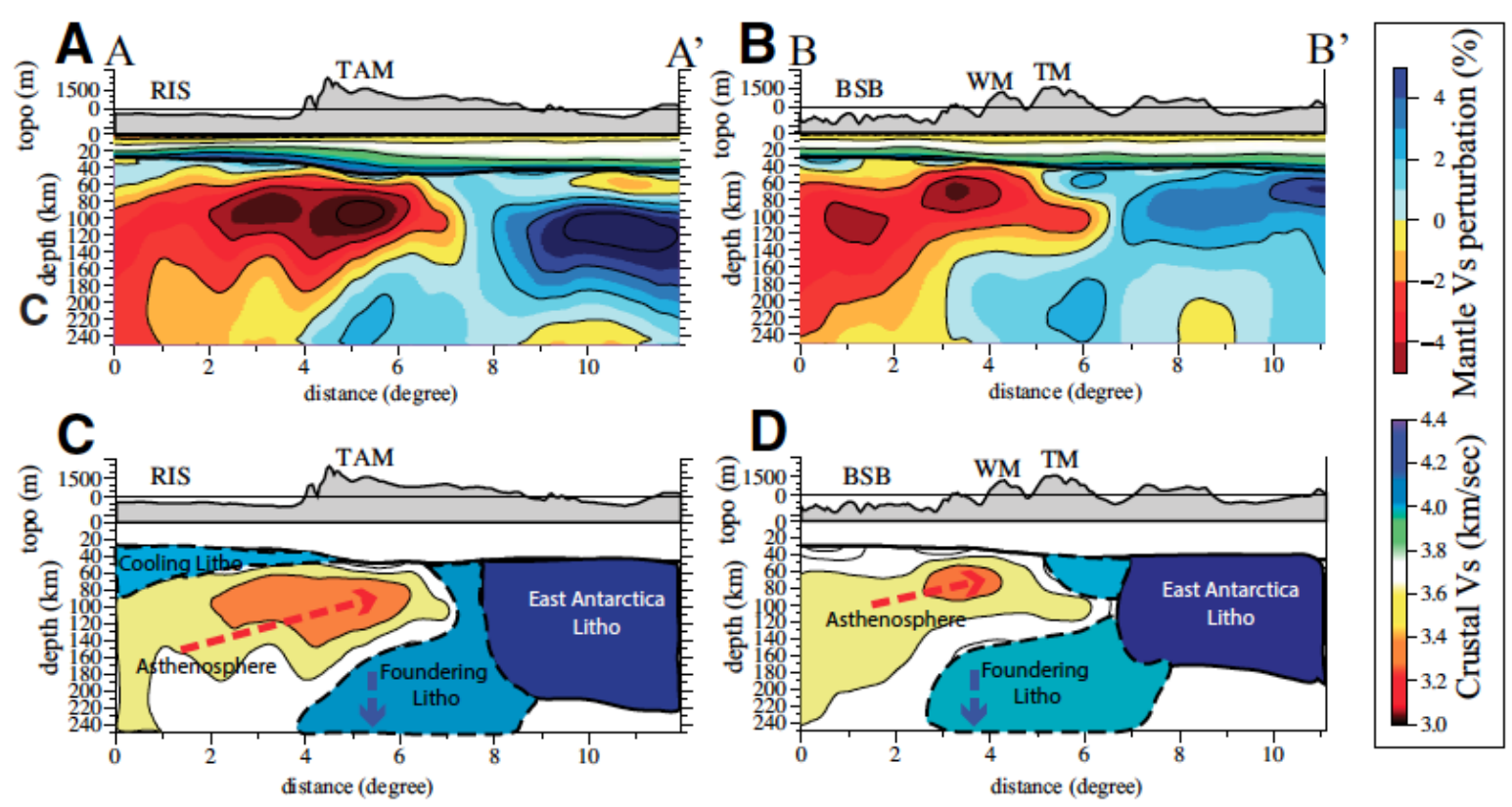

Figure 5.5: A,B: Vertical $\mathrm{v}_{\mathrm{s}}$ cross-sections across the Ross Ice Shelf and TAM (A), and the Byrd Subglacial Basin and Thiel Mountains (B). Crustal $\mathrm{v}_{\mathrm{s}}$ are absolute values (in $\mathrm{km} / \mathrm{s}$ ), while $\mathrm{v}_{\mathrm{s}}$ in the mantle is a percent perturbation relative to averaged one-dimensional $\mathrm{v}_{\mathrm{s}}$ of the regions. Velocities are differentiated by the color scale. Velocities for depths in the upper $20 \mathrm{~km}$ at $\mathrm{A}$ and $\mathrm{B}$, and upper $40 \mathrm{~km}$ at $\mathrm{A}^{\prime}$ and $\mathrm{B}^{\prime}$ represent the crust, while all below are representative of the mantle. C,D: Interpretation of seismic images in A and B, showing foundering of cooler lithospheric mantle and advance of hotter asthenospheric mantle beneath the Mountains. Colours display relative velocities of layers. litho - lithosphere; topo - topography; TAM - Transantarctic Mountains; RIS - Ross Island; TM - Thiel Mountains; WM Whitmore Mountains; and BSB - Byrd Subglacial Basin. Figure from Shen et al. (2018b). 
study region is determined in later studies, an estimate can be made of remaining time until completion of this process, or of when this process completed, based upon mantle viscosities estimated within this study.

\subsection{Study uncertainties and future recommendations}

Gravity surveying is an effective geophysical technique at constraining deep subsurface structures over a regional scale, improving the resolution of crustal features smoothed in regional-scale seismic models (Shen et al., 2018a; Hansen et al., 2009; Lawrence et al., 2006). Uncertainties in the gravity method arise due to its inherent non-uniqueness, limiting conclusions drawn from the use of models alone. Structural features of gravity models are highly variable without constraints from seismic studies (Priestley et al., 2018; Shen et al., 2018a; Hansen et al., 2009, Bannister et al., 2003) and application of the principle of isostatic balance that limits the number of models that are mechanically feasible. The non-uniqueness of gravity models restrict estimates of viscosity and temperature variation across the East-West Antarctic boundary, as different density contrasts fit observed Bouguer anomalies and seismically-derived Moho and lithospheric thicknesses equally well. Nevertheless, the constraints we have from seismic data are robust and the densities adopted here keep with those used elsewhere. Therefore, the models developed are plausible, useful, and certainly a basis for testing by further studies.

Regardless of limitations, measured gravity data displays the regional trend of Bouguer anomalies throughout the Taylor Valley and model structural characteristics of the transition from West to East Antarctica. To progress on results derived in this study, future recommendations include:

- New gravity measurements made along survey lines measured by Hicks and Bennett (1981), improving the resolution and density of gravity measurements in the Taylor Valley. Therefore, uncertainty in gravity models would be reduced and better constraints can be placed on structural features modelled.

- Incorporation of additional geophysical techniques, such as seismic reflection/refraction and aeromagnetic surveying, and physical property measurements (e.g. borehole 
studies) to improve constraints on gravity models, reducing non-uniqueness of solutions.

- Additional gravity observations (and models) made throughout the Transantarctic Mountains, comparing and constraining properties of the East-West Antarctic transition across the continent.

- Incorporation of Bouguer anomaly observations and Moho and LAB depths from this study into regional-scale gravity and depth models respectively, providing high-resolution data within the Taylor Valley.

Implications of this research are in studies of glacial isostatic adjustment as new viscosity estimates from this study constrain the lithospheric and asthenospheric mantle structure beneath the TAM front. Structural characteristics of the advance of asthenospheric mantle beneath the TAM have been modelled, constraining the position of the mantle transition zone within the region. The position of this boundary, beneath the Polar Plateau and in to regions of year-round ice cover, limit the resolution of gravity observations directly above the boundary due to corrections associated with measurements made on ice.

Predicted surface movement in the Dry Valleys following removal of ice after the LGM the Ross Embayment may be complex, either uplift or subsidence, depending on the position of a continuous GNSS station relative to the ice load present during the Last Glacial Maximum. Thus, GPS sites in this region may observe differing signals with location. Better constraints on the surface uplift (or subsidence) history in the TAM will improve constraints on GIA models, and when combined with viscosities calculated in this study, possibly contribute to reducing misfit between predicted and observed uplift rates. One solution to this issue is a closer array of GPS stations across icefree regions of the Taylor Valley, which may help to decipher the history of surface topography variations. 


\section{Chapter 6}

\section{Conclusions}

Collection of 119 new gravity measurements in the Taylor Valley, and amalgamation with existing land and aero gravity observations, has made it possible to model the transition zone between East and West Antarctic upper mantle. Key findings of this study are summarised below:

- An eastward gradient of -1.6 mGal $/ \mathrm{km}$ in observed Bouguer anomalies within ice-free regions of the Taylor Valley.

- Thickening of the Moho from $23 \pm 5 \mathrm{~km}$ beneath the Ross Sea to $35 \pm 5 \mathrm{~km}$ in the Polar Plateau (dipping at $24.5 \pm 7.2^{\circ}$ ) respectively. Additionally, $\sim 100 \mathrm{~km}$ thicker lithospheric mantle in the Polar Plateau $(\sim 200 \pm 30 \mathrm{~km})$ than beneath the Ross Embayment ( $90 \pm 30 \mathrm{~km})$.

- Estimates of asthenospheric mantle viscosity in the Ross Embayment varying between $1.4 \times 10^{21}$ Pa.s at $50 \%$ of surface uplift and $2.1 \times 10^{20}$ at full surface recovery following removal of the ice load after the LGM ( 7000 yrs BP). Overall, GPS uplift rates in the ice free areas of the TAM will need to be interpreted with care given that they lie beneath a region of changing mantle viscosity and next to the edge of now melted ice advance during the Last Glacial Maximum.

- An estimated temperature contrast of $\sim 400{ }^{\circ} \mathrm{C}$ between lithospheric and asthenospheric mantle, equivalent to a viscosity that decreases by a factor of about 30 . 


\section{Appendix A}

\section{Appendix}

\section{A.1. GNSS and DEM elevation differences}

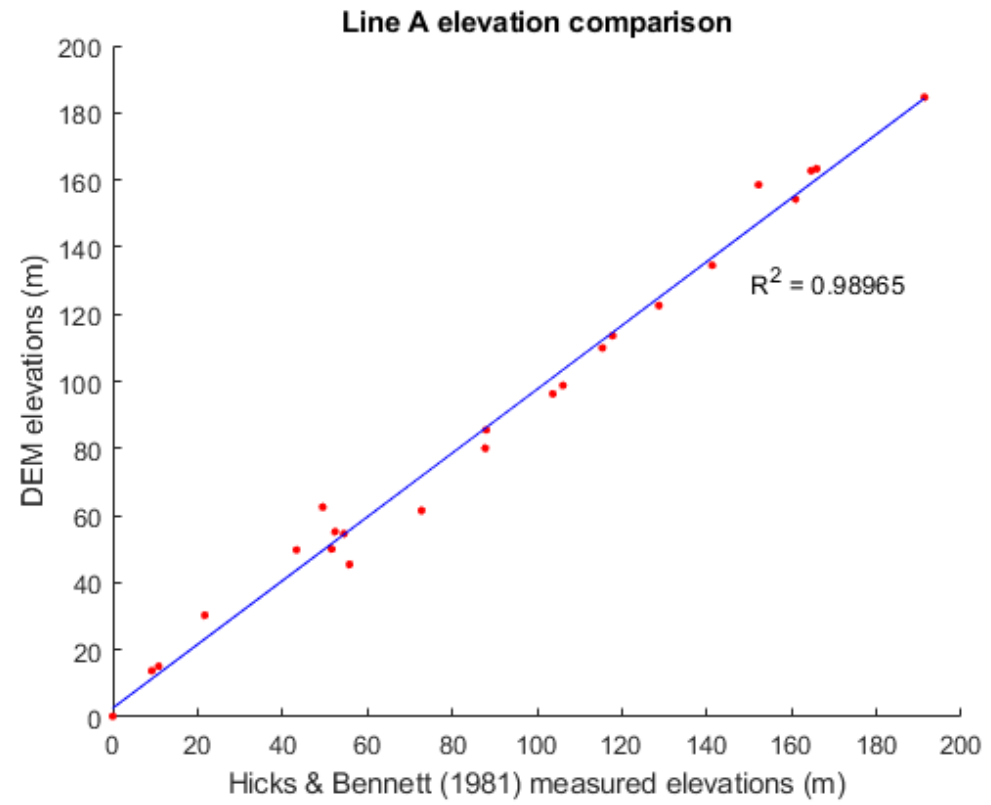

Figure A.1: Comparison of elevations estimated by the $2 \mathrm{~m}$ resolution digital elevation model (Howat et al., 2019) and those estimated by Hicks and Bennett (1981) at gravity observations (red circles) along Survey Line A. The blue line is the position along which observations have perfect correlation $\left(\mathrm{R}^{2}=1\right)$. 


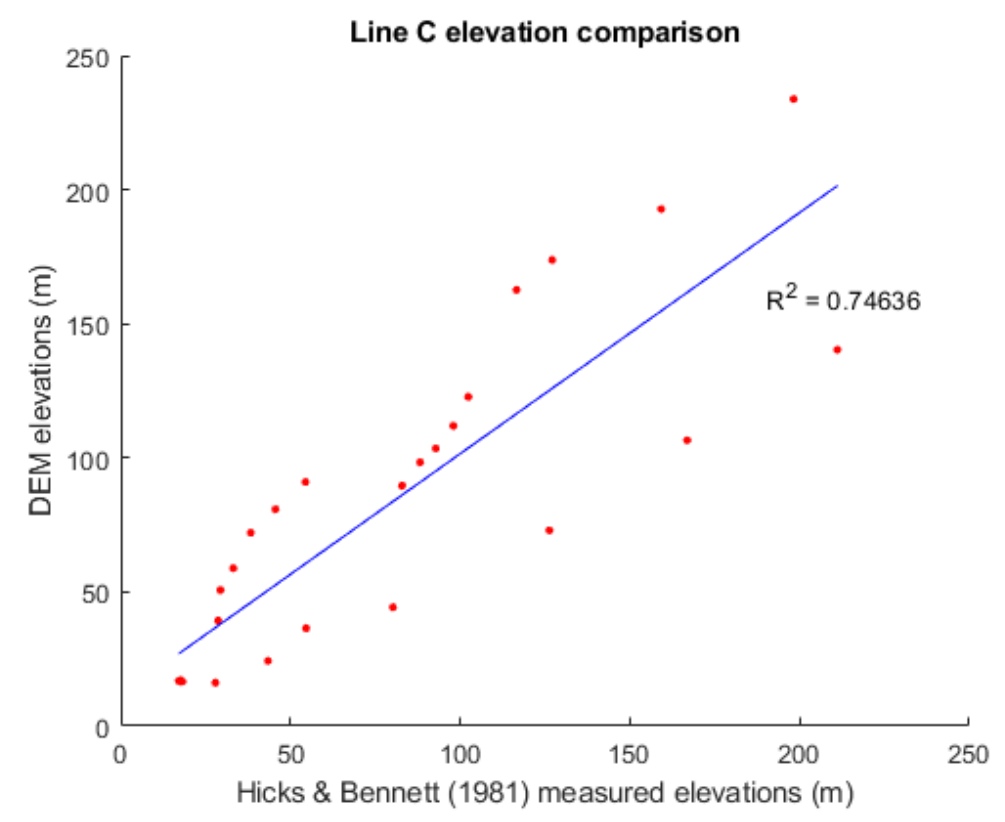

Figure A.2: Comparison of elevations estimated by the $2 \mathrm{~m}$ resolution digital elevation model (Howat et al., 2019) and those estimated by Hicks and Bennett (1981) at gravity observations (red circles) along Survey Line C. The blue line is the position along which observations have perfect correlation $\left(\mathrm{R}^{2}=1\right)$.

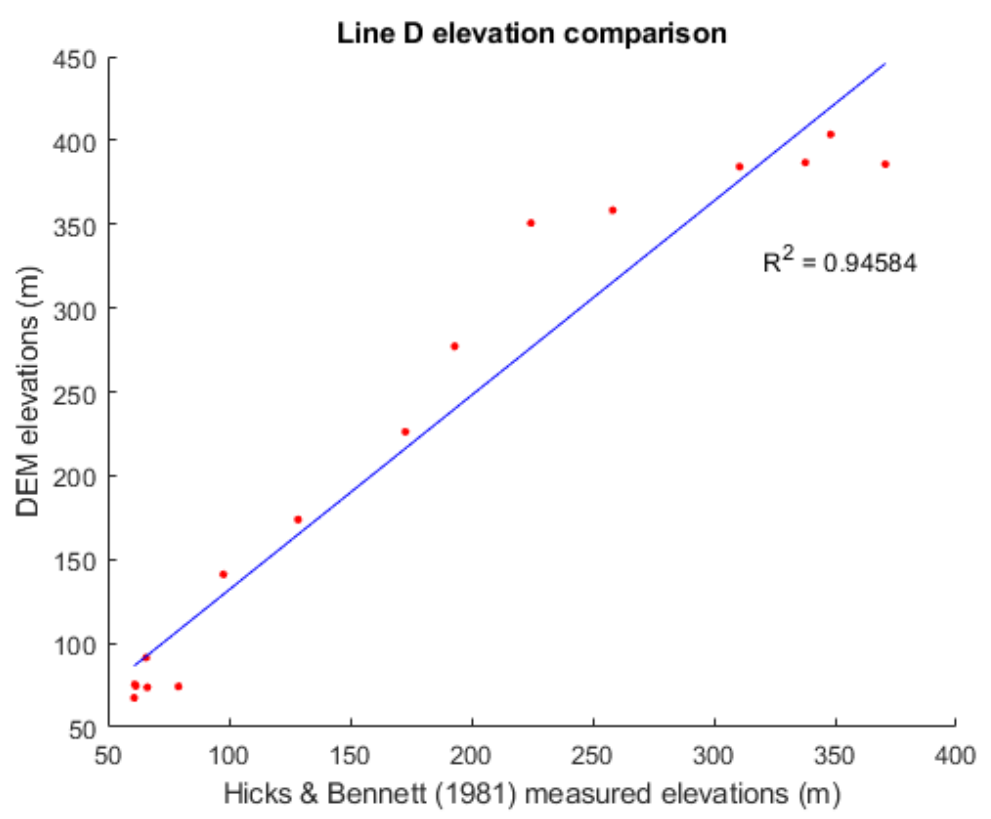

Figure A.3: Comparison of elevations estimated by the $2 \mathrm{~m}$ resolution digital elevation model (Howat et al., 2019) and those estimated by Hicks and Bennett (1981) at gravity observations (red circles) along Survey Line D. The blue line is the position along which observations have perfect correlation $\left(\mathrm{R}^{2}=1\right)$. 


\section{A.2. Observed gravity anomalies}

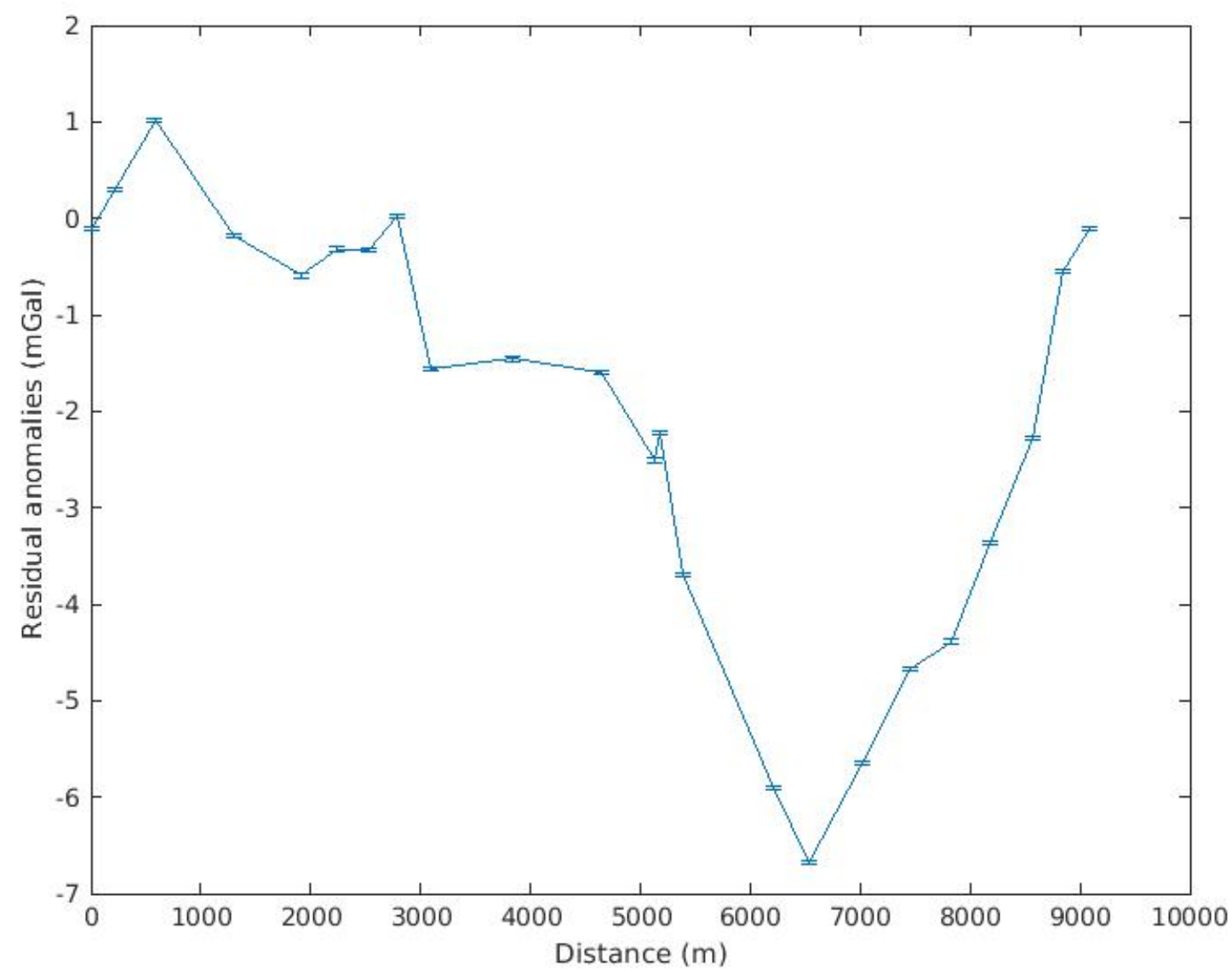

Figure A.4: Residual anomalies (blue line) measured along Line Y (in mGal). Uncertainty in each measurement is plotted (horizontal lines). 


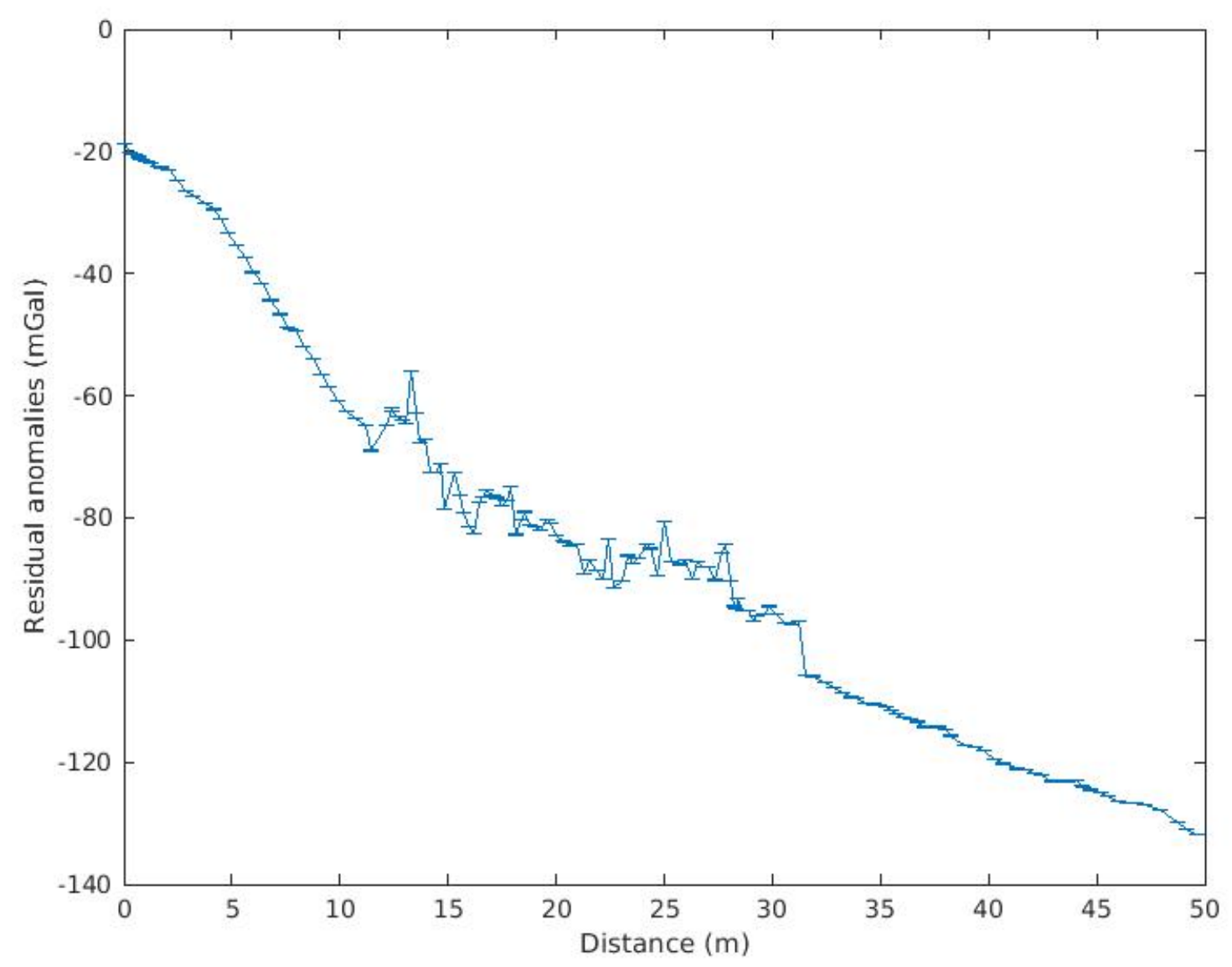

Figure A.5: Bouguer anomalies (blue line) measured along Line X (in mGal). Uncertainty in each measurement is plotted (horizontal lines). 
A.3. Gravity data 


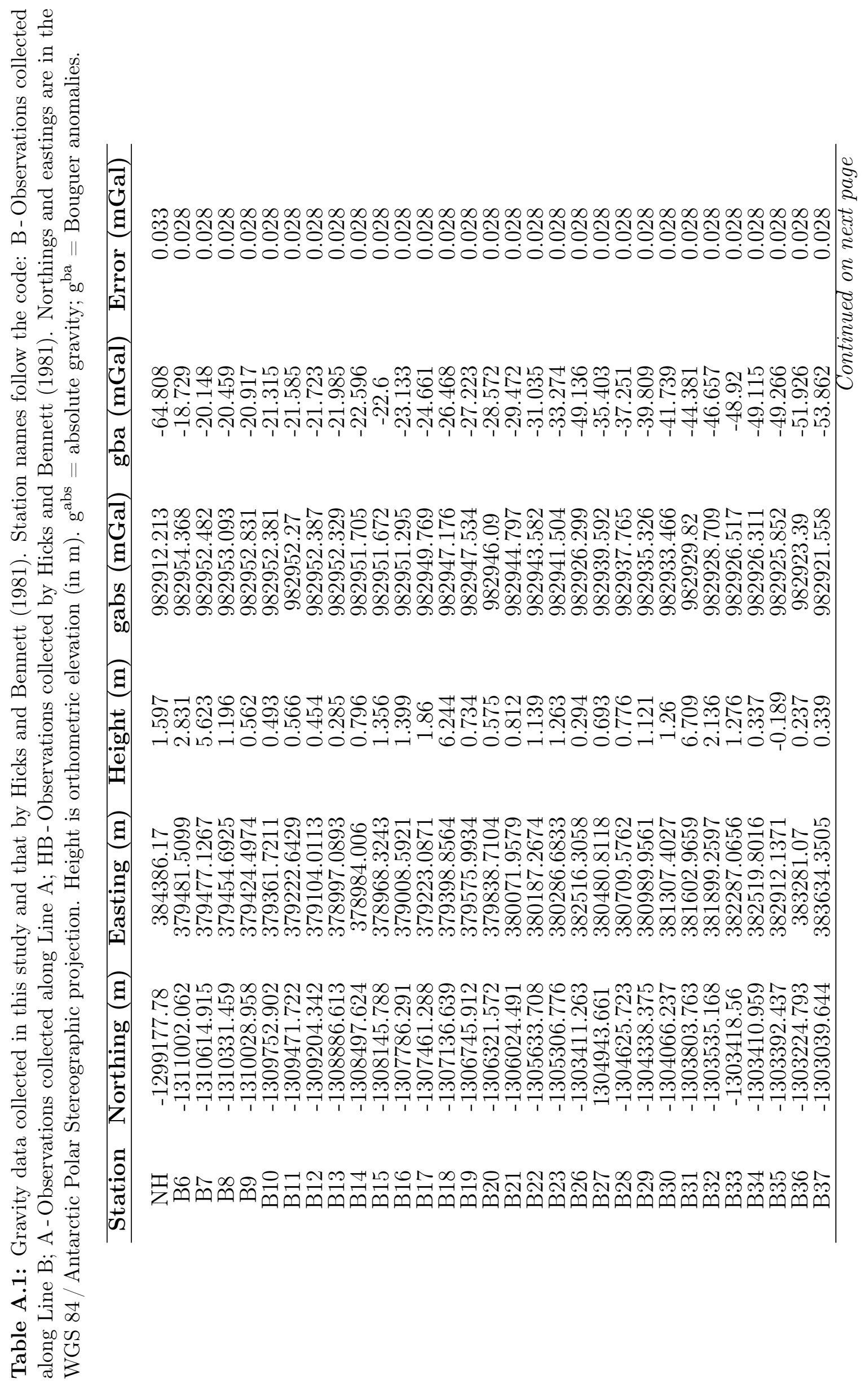




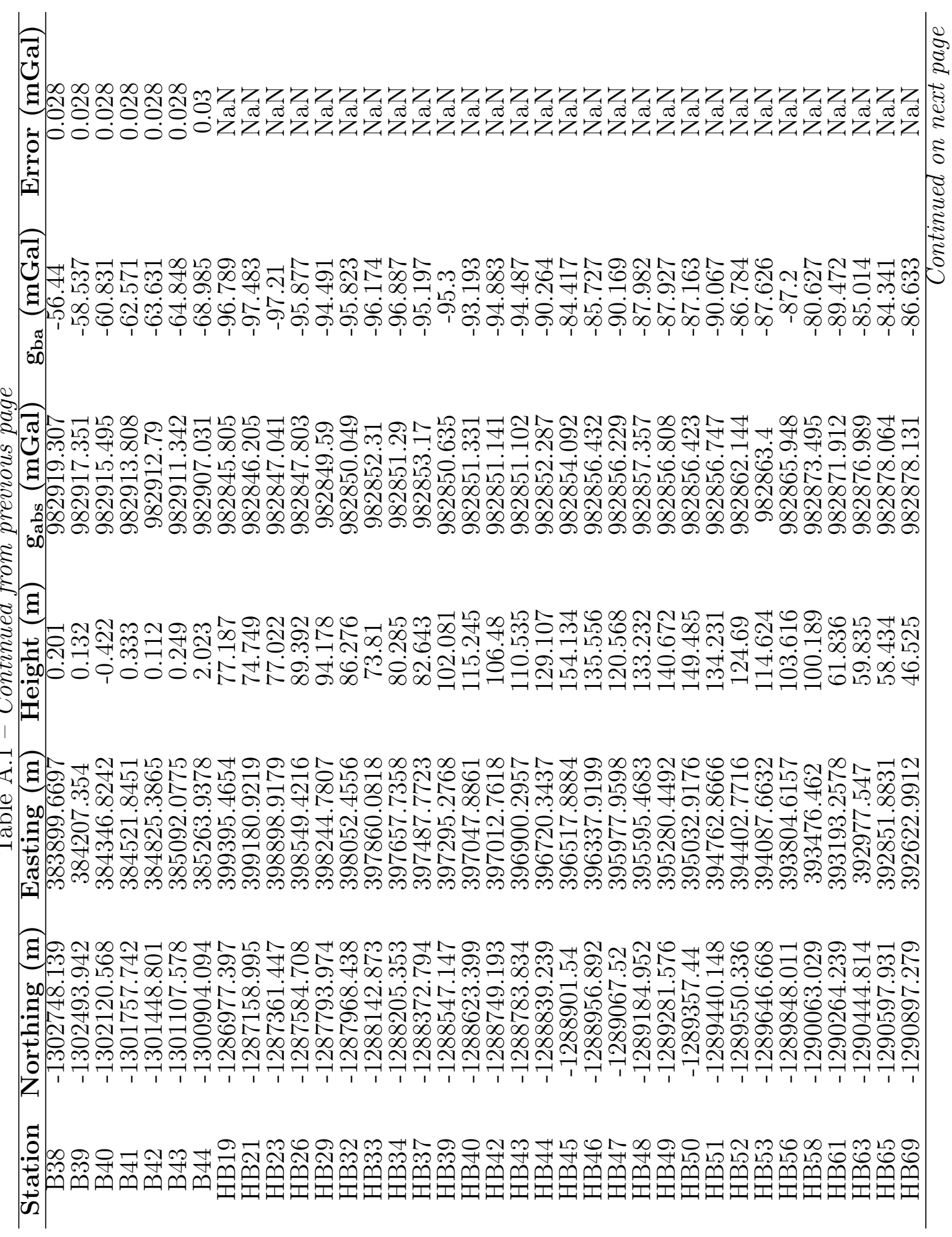




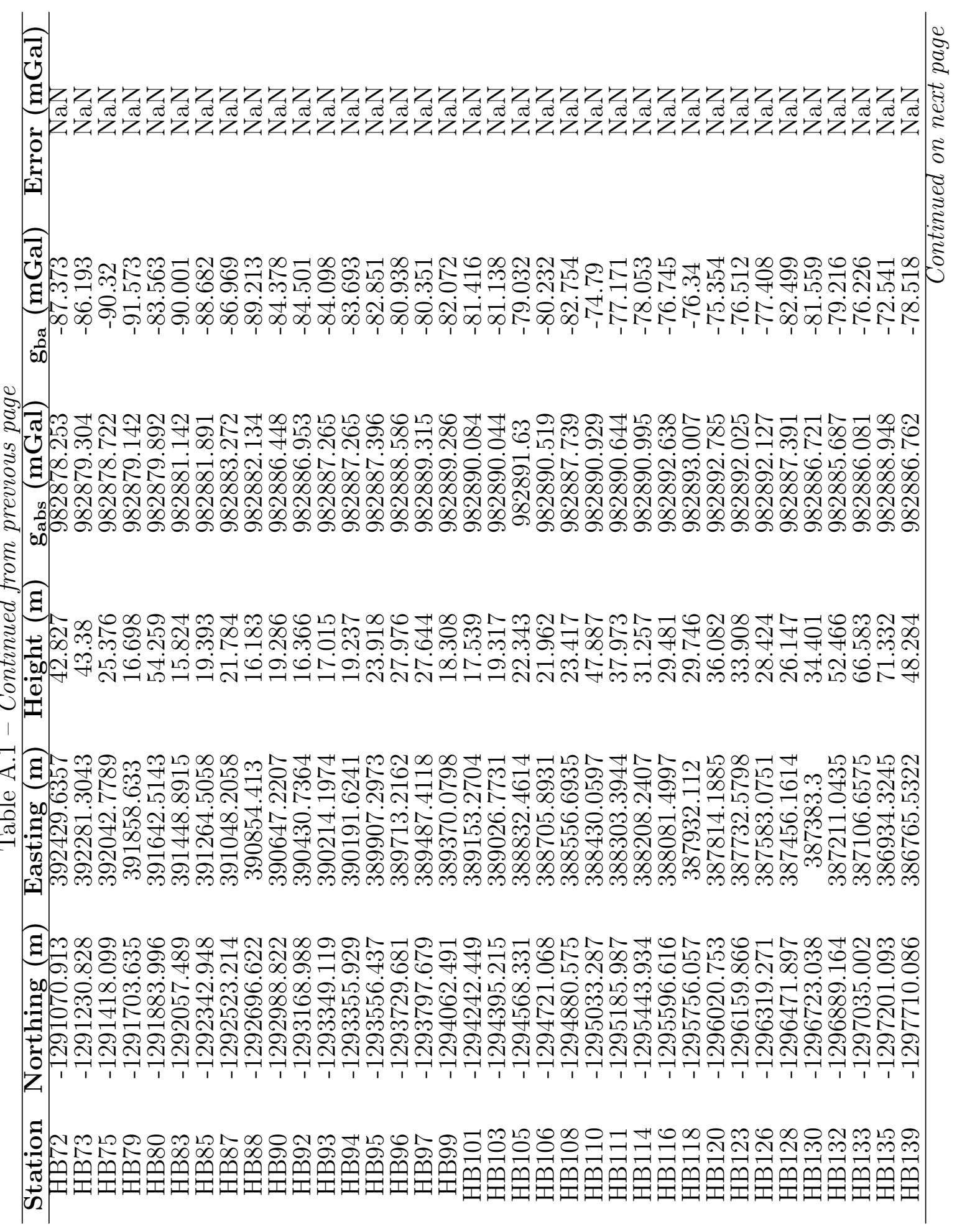




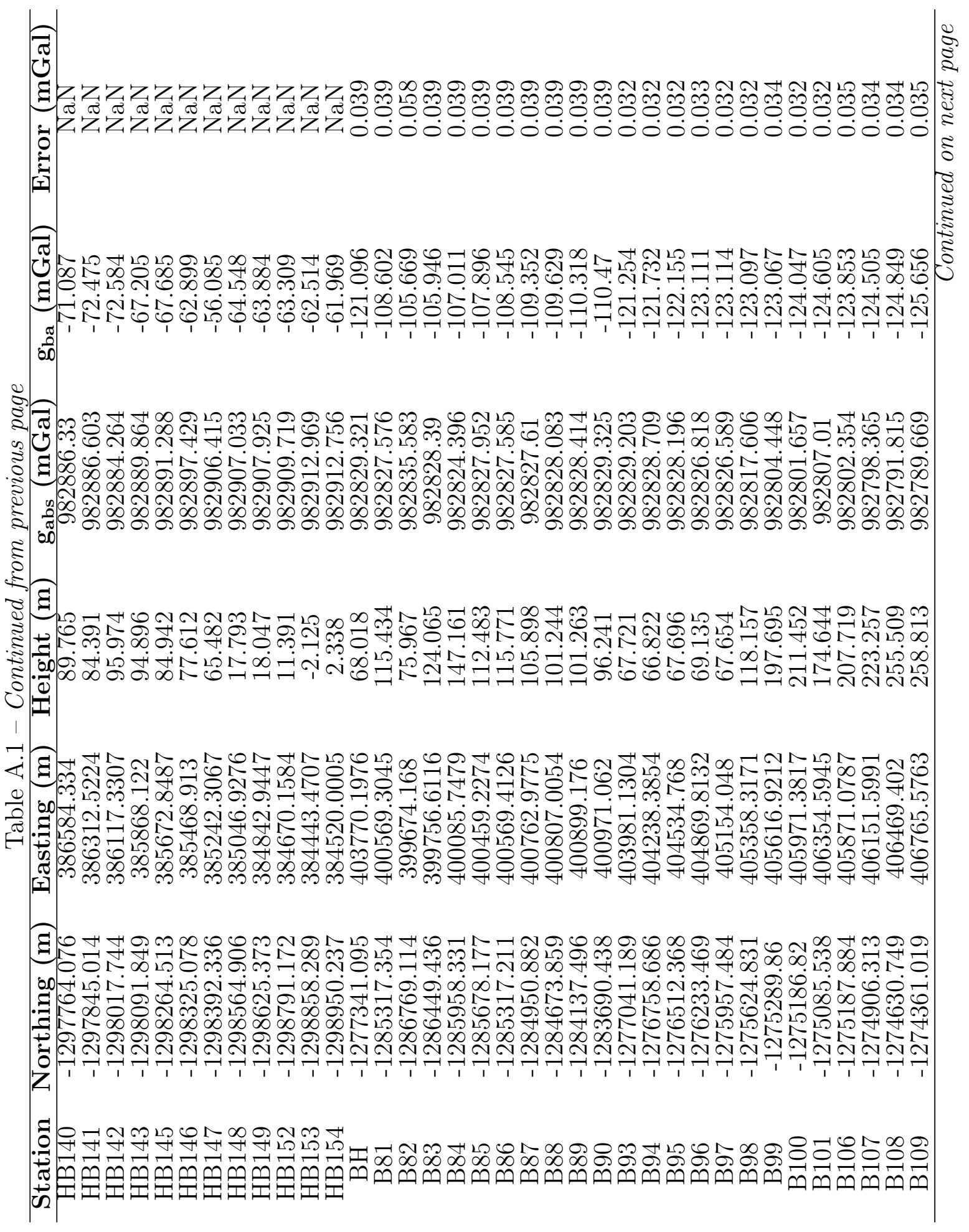




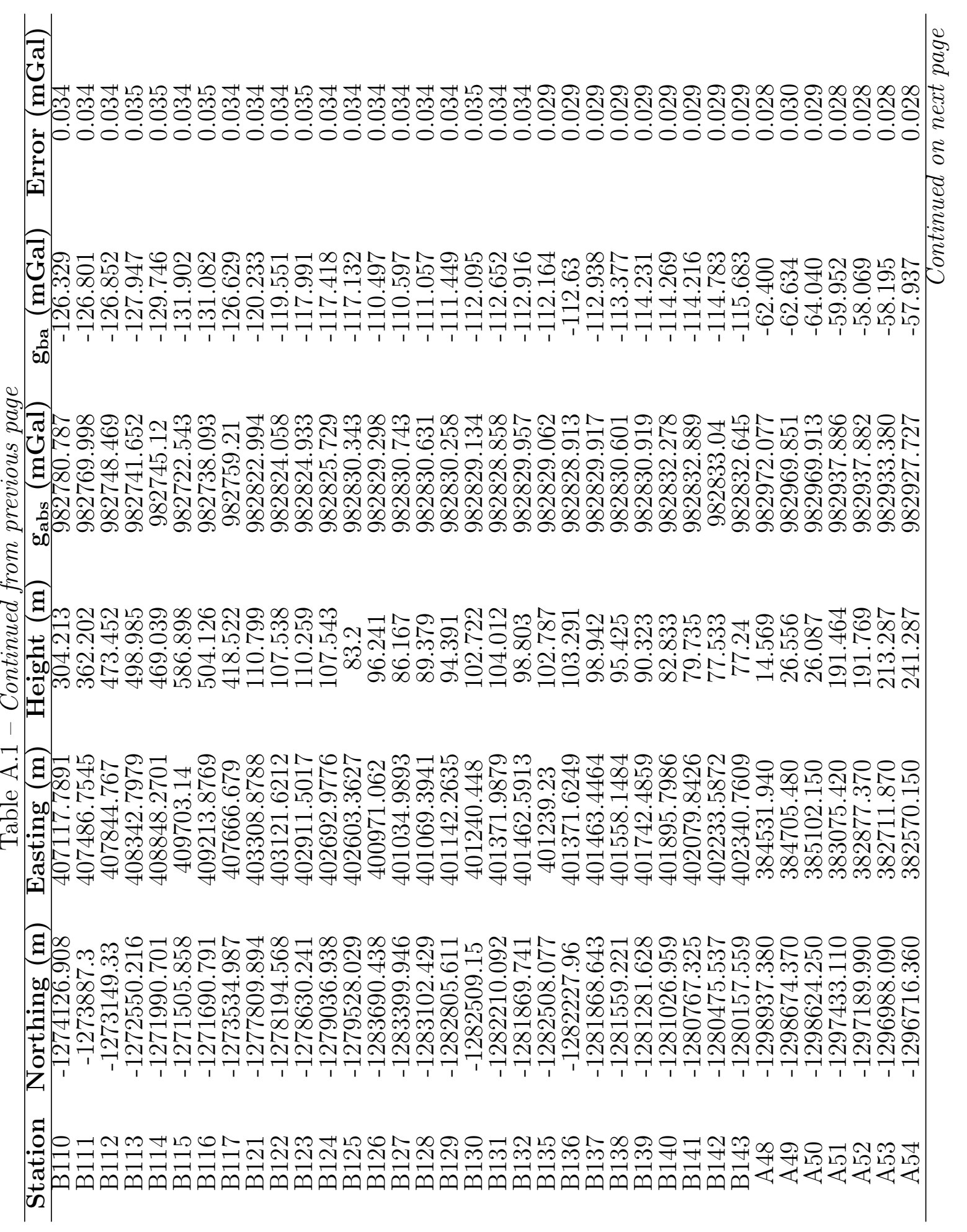




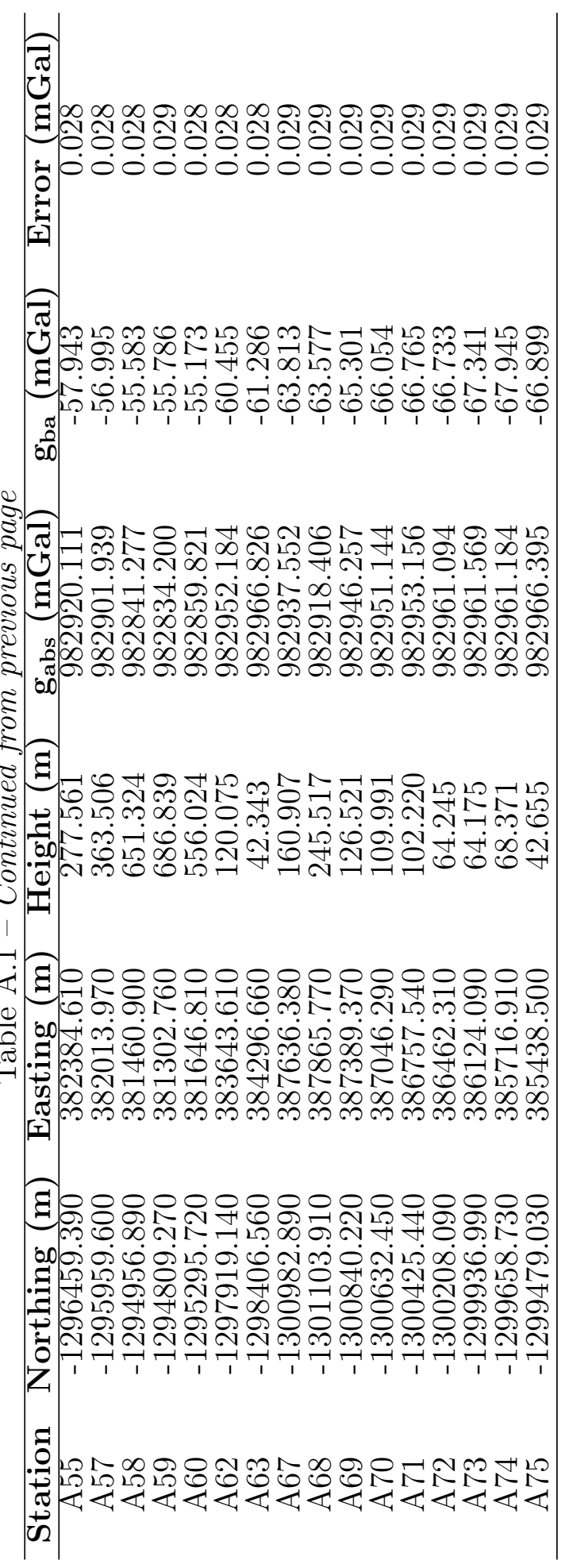




\section{Bibliography}

Allibone, A., Forsyth, P., Sewell, R., Turnbull, I., \& Bradshaw, M. (1991). Geology of the Thundergut area, southern Victoria Land, Antarctica, 1: 50000. New Zealand Geological Survey Miscellaneous Geological Map, 21.

Angino, E., Turner, M., \& Zeller, E. (1962). Reconnaissance geology of lower Taylor Valley, Victoria Land, Antarctica. Geological Society of America Bulletin, $73(12), 1553-1561$.

Argus, D. F., Peltier, W., Drummond, R., \& Moore, A. W. (2014). The antarctica component of postglacial rebound model ICE-6G_C (VM5a) based on GPS positioning, exposure age dating of ice thicknesses, and relative sea level histories. Geophysical Journal International, 198(1), 537-563.

Armstrong, R. L., Hamilton, W., \& Denton, G. H. (1968). Glaciation in Taylor Valley, Antarctica, older than 2.7 million years. Science, 159(3811), 187-189.

Bannister, S., Yu, J., Leitner, B., \& Kennett, B. (2003). Variations in crustal structure across the transition from West to East Antarctica, Southern Victoria Land. Geophysical Journal International, 155(3), 870-880.

Barrett, P. Et al. (1976). Initial Report of DVDP 15, western McMurdo Sound, Antarctica.

Barrett, P., \& Froggatt, P. (1978). Densities, porosities, and seismic velocities of some rocks from Victoria Land, Antarctica. New Zealand journal of geology and geophysics, $21(2), 175-187$.

Bart, P., Anderson, J., Trincardi, F., \& Shipp, S. (2000). Seismic data from the Northern basin, Ross Sea, record extreme expansions of the East Antarctic Ice Sheet during the late Neogene. Marine Geology, 166(1-4), 31-50. 
Bockheim, J. G., Prentice, M., \& McLeod, M. (2008). Distribution of glacial deposits, soils, and permafrost in Taylor Valley, Antarctica. Arctic, Antarctic, and Alpine Research, 40(2), 279-286.

Brenn, G. R., Hansen, S. E., \& Park, Y. (2017). Variable thermal loading and flexural uplift along the Transantarctic Mountains,Antarctica. Geology, 45(5), 463-466.

Bromley, A. M. (1985). Weather observations, Wright Valley, Antarctica. New Zealand Meteorological Service.

Brook, E. J., Kurz, M. D., Ackert Jr, R. P., Denton, G. H., Brown, E. T., Raisbeck, G. M., \& Yiou, F. (1993). Chronology of Taylor Glacier advances in Arena Valley, Antarctica, using in situ cosmogenic 3he and 10be. Quaternary Research, $39(1), 11-23$.

Bull, C. (1960). Gravity observations in the Wright Valley area, Victoria Land, Antarctica. New Zealand journal of geology and geophysics, 3(4), 543-552.

Burger, H. R., Sheehan, A. F., \& Jones, C. H. (2006). Introduction to applied geophysics: Exploring the shallow subsurface. WW Norton.

Calkin, P. E. (1964). Geomorphology and glacial geology of the Victoria Valley system, southern Victoria Land, Antarctica. Research Foundation; Institute of Polar Studies, The Ohio State University.

Calkin, P. E. (1974). Subglagial Geomorphology Surrounding the Ice-Free Valleys of Southern Victoria Land, Antarctica. Journal of Glaciology, 13(69), 415-429.

Cande, S. C., Stock, J. M., Müller, R. D., \& Ishihara, T. (2000). Cenozoic motion between east and west Antarctica. Nature, 404(6774), 145-150.

Cathles, L. M. (1975). Viscosity of the Earth's Mantle. Princeton University Press.

Chapman-Smith, M. (1975). Geology of DVDP holes 12 and 14. Antarctic Journal of the United States, 10(4), 170-172.

Chetwin, E. (1998). Active Faulting and Subsurface Structure in the Mackenzie Basin: An Investigation Using Gravity and Seismic.

Chinn, T. (1993). Physical hydrology of the dry valley lakes. Physical and biogeochemical processes in Antarctic lakes, 59, 1-51.

Cole, J., Kyle, P., \& Neall, V. (1971). Contributions to Quaternary geology of Cape Crozier, White Island and Hut Point Peninsula, McMurdo Sound Region, Antarctica. New Zealand Journal of Geology and Geophysics, 14(3), 528-546. 
Connor, C., \& Connor, L. (2017). Gravity 5: Instruments and gravity processing. Retrieved March 10, 2020, from http://www.cas.usf.edu/ cconnor/pot_fields_ lectures/Lecture5-gravity.pdf

Conovitz, P. A., McKnight, D. M., MacDonald, L. H., \& Fountain, A. G. (1998). Fryxell Basin, Antarctica (Vol. 72). Wiley Online Library.

Cook, Y. (2007). Precambrian rift-related magmatism and sedimentation, south Victoria Land, Antarctica. Antarctic Science, 19(4), 471-484.

Cooper, A., Trey, H., Pellis, G., Cochrane, G., Egloff, F., \& Busetti, M. (1997). Crustal structure of the Southern Central Trough, Western Ross Sea.

Cox, S. C. (1993). Inter-related plutonism and deformation in South Victoria Land, Antarctica. Geological magazine, 130(1), 1-14.

Cox, S. C., Turnbull, I., Isaac, M., Townsend, D. B., \& Lyttle, B. S. (2012). Geology of Southern Victoria Land, Antarctica.

David, T. W. E., Priestley, R. E., Taylor, T. G., \& Goddard, E. (1914). Glaciology, physiography, stratigraphy, and tectonic geology of South Victoria Land. William Heinemann.

DeConto, R. M., \& Pollard, D. (2016). Contribution of Antarctica to past and future sea-level rise. Nature, 531 (7596), 591-597.

Denton, G. H., Bockheim, J. G., Wilson, S. C., \& Stuiver, M. (1989). Late Wisconsin and early Holocene glacial history, inner Ross embayment, Antarctica. Quaternary Research, 31 (2), 151-182.

Denton, G. H., \& Hughes, T. J. (2000). Reconstruction of the Ross ice drainage system, Antarctica, at the last glacial maximum. Geografiska Annaler: Series A, Physical Geography, 82(2-3), 143-166.

Elliot, D. H. (1975). Tectonics of Antarctica: A review. American Journal of Science, 275, 45-106.

Elliot, D. H. (2013). The geological and tectonic evolution of the Transantarctic Mountains: A review. Geological Society, London, Special Publications, 381(1), 7-35.

Elliot, D. H., Fleming, T. H., Kyle, P. R., \& Foland, K. A. (1999). Long-distance transport of magmas in the Jurassic Ferrar large igneous province, Antarctica. Earth and Planetary Science Letters, 167(1-2), 89-104. 
Elliot, D., \& Fleming, T. (2008). Physical volcanology and geological relationships of the Jurassic Ferrar large igneous province, Antarctica. Journal of Volcanology and Geothermal Research, 172(1-2), 20-37.

Elston, D., Bressler, S., \& Robinson, P. (1981). Magnetostratigraphy and sedimentology of late Cenozoic glaciogenic deposits, eastern Taylor Valley. Antarctic Journal of the US, 16(5), 39-41.

Elston, D., Rieck, H., \& Robinson, P. (1985). Dry Valleys/McMurdo Sound magnetostratigraphy and sedimentology project: A progess report. Antarctic Journal of the US, 20(5), 15-17.

Encarnación, J., Fleming, T. H., Elliot, D. H., \& Eales, H. V. (1996). Synchronous emplacement of Ferrar and Karoo dolerites and the early breakup of Gondwana. Geology, $24(6), 535-538$.

Environmental Systems Research Institute. (2013). Mean Sea Level, GPS, and the Geoid. Retrieved March 12, 2020, from https://www.esri.com/news/arcuser/ 0703/geoid1of3.html

Evison, F., Ingham, C., Orr, a., RH, \& Le Fort, J. (1960). Thickness of the Earth's crust in Antarctica and the surrounding oceans. Geophysical Journal International, 3(3), 289-306.

Evison, F., Ingham, C., \& Orr, R. (1959). Thickness of the earth's crust in Antarctica. Nature, 183(4657), 306-308.

Ferrar, H. T. (1907). Report on the field geology of the region explored during the "Discovery" Antarctic Expedition 1901-4. National Antarctic Exped, 1 (Geology), 1100.

Finotello, M., Nyblade, A., Julia, J., Wiens, D., \& Anandakrishnan, S. (2011). Crustal Vp-Vs ratios and thickness for Ross Island and the Transantarctic Mountain front, Antarctica. Geophysical Journal International, 185(1), 85-92.

Fitzgerald, P. (2002). Tectonics and landscape evolution of the Antarctic plate since the breakup of Gondwana, with an emphasis on the West Antarctic Rift System and the Transantarctic Mountains. Royal Society of New Zealand Bulletin, 35, 453-469. 
Fitzgerald, P. G., Sandiford, M., Barrett, P. J., \& Gleadow, A. J. (1986). Asymmetric extension associated with uplift and subsidence in the Transantarctic Mountains and Ross Embayment. Earth and Planetary Science Letters, 81(1), 67-78.

Fitzgerald, P. G., Stump, E., Yoshida, Y., Kaminuma, K., \& Shiraishi, K. (1992). Early Cretaceous uplift of the southern Sentinel Range, Ellsworth Mountains. West Antarctica. Recent Progress in Antarctic Earth Science: edited by Y. Yoshida et al, 331-340.

Fitzgerald, P. (1995). Cretaceous and Cenozoic exhumation of the Transantarctic Mountains: Evidence from the Kukri Hills of southern Victoria Land compared to fission track data from gneiss at DSDP site 270, In Seventh international symposium on antarctic earth sciences. siena, italy.

Fleming, T., Heimann, A., Foland, K., \& Elliot, D. (1997). 40Ar/39Ar geochronology of Ferrar Dolerite sills from the Transantarctic Mountains, Antarctica: Implications for the age and origin of the Ferrar magmatic province. Geological Society of America Bulletin, $109(5), 533-546$.

Forsyth, P. (1996). Comment on "Constraining the Devonian to Triassic Evolution of the Ross Sea Sector" by KJ Woolfe and PJ Barrett (1995). Terra Antartica, 3, $55-56$.

Fountain, A. G., Lyons, W. B., Burkins, M. B., Dana, G. L., Doran, P. T., Lewis, K. J., McKnight, D. M., Moorhead, D. L., Parsons, A. N., Priscu, J. C., Et al. (1999). Physical controls on the Taylor Valley ecosystem, antarctica. Bioscience, $49(12), 961-971$.

Fowler, C. M. R., Fowler, C. M. R., \& Fowler, M. (1990). The Solid Earth: An Introduction to Global Geophysics. Cambridge University Press.

Fretwell, P., Pritchard, H. D., Vaughan, D. G., Bamber, J. L., Barrand, N. E., Bell, R., Bianchi, C., Bingham, R., Blankenship, D. D., Casassa, G., Et al. (2013). Bedmap2: Improved ice bed, surface and thickness datasets for Antarctica. The Cryosphere, 7(1), 375-393.

Geomatrix Earth Science Ltd. (2020). Cg-6 Autograv Data Sheet. https://www. geomatrix.co.uk/land-products/gravity/cg6/ (accessed: 28.01.2020)

Gleadow, A., \& Fitzgerald, P. (1987). Uplift history and structure of the Transantarctic Mountains: New evidence from fission track dating of basement apatites in the 
Dry Valleys area, southern Victoria Land. Earth and planetary science letters, 82(1-2), 1-14.

Griffiths, D. H., \& King, R. F. (2013). Applied geophysics for geologists and engineers: The elements of geophysical prospecting. Elsevier.

Grindley, G. (1963). The Geology of the Queen Alexandra Range, Beardmore Glacier, Ross dependency, Antarctica; with notes on the correlation of Gondwana sequences. New Zealand journal of geology and geophysics, 6(3), 307-347.

Gunn, B. M., \& Warren, G. (1962). Geology of Victoria Land between the Mawson and Mulock Glaciers, Antarctica. Trans-Antarctic Expedition Committee.

Hall, B. L., Denton, G. H., Lux, D. R., \& Bockheim, J. G. (1993). Late Tertiary Antarctic paleoclimate and ice-sheet dynamics inferred from surficial deposits in Wright Valley. Geografiska Annaler: Series A, Physical Geography, 75(4), 239-267.

Hammer, S. (1939). Terrain corrections for gravimeter stations. Geophysics, 4(3), 184194.

Hansen, S. E., Graw, J. H., Kenyon, L. M., Nyblade, A. A., Wiens, D. A., Aster, R. C., Huerta, A. D., Anandakrishnan, S., \& Wilson, T. (2014). Imaging the Antarctic mantle using adaptively parameterized P-wave tomography: Evidence for heterogeneous structure beneath West Antarctica. Earth and Planetary Science Letters, 408, 66-78.

Hansen, S. E., Julia, J., Nyblade, A. A., Pyle, M. L., Wiens, D. A., \& Anandakrishnan, S. (2009). Using s wave receiver functions to estimate crustal structure beneath ice sheets: An application to the Transantarctic Mountains and East Antarctic craton. Geochemistry, Geophysics, Geosystems, 10(8).

Hansen, S. E., Reusch, A. M., Parker, T., Bloomquist, D. K., Carpenter, P., Graw, J. H., \& Brenn, G. R. (2015). The Transantarctic Mountains Northern Network (TAMNNET): Deployment and performance of a seismic array in Antarctica. Seismological Research Letters, 86(6), 1636-1644.

Haskell, N. (1936). The motion of a viscous fluid under a surface load. Part II. Physics, $7(2), 56-61$. 
Haskell, T., Kennett, J., Prebble, W., Smith, G., \& Willis, I. (1965). The geology of the middle and lower Taylor Valley of south Victoria Land, Antarctica. Trans. Roy. Soc. NZ, 2(12), 169-186.

Henrys, S. A., Wilson, T., Fielding, C. R., Hall, J., \& Naish, T. (2008). Tectonic history of mid-Miocene to present southern Victoria Land Basin, inferred from seismic stratigraphy in McMurdo Sound, Antarctica.

Hicks, S., \& Bennett, D. (1981). Gravity models of the lower Taylor Valley, Antarctica. New Zealand journal of Geology and Geophysics, 24(4), 555-562.

Houseman, G. A., \& Molnar, P. (1997). Gravitational (Rayleigh-Taylor) instability of a layer with non-linear viscosity and convective thinning of continental lithosphere. Geophysical Journal International, 128(1), 125-150.

Howat, I. M., Porter, C., Smith, B. E., Noh, M.-J., \& Morin, P. (2019). The Reference Elevation Model of Antarctica. Cryosphere, 13(2).

Isaac, M. J., Forsyth, P., \& Bradley, G. (1996). Geology of the Olympus Range Area, Southern Victoria Land, Antarctica 1: 50 000. The Institute.

Isacks, B., Oliver, J., \& Sykes, L. R. (1968). Seismology and the new global tectonics. Journal of Geophysical Research, 73(18), 5855-5899.

Ivins, E. R., James, T. S., Wahr, J., O. Schrama, E. J., Landerer, F. W., \& Simon, K. M. (2013). Antarctic contribution to sea level rise observed by GRACE with improved GIA correction. Journal of Geophysical Research: Solid Earth, 118(6), $3126-3141$.

Julià, J., Herrmann, R. B., Ammon, C. J., \& Akinci, A. (2004). Evaluation of deep sediment velocity structure in the New Madrid Seismic Zone. Bulletin of the Seismological Society of America, 94(1), 334-340.

Kane, M. (1962). A comprehensive system of terrain corrections using a digital computer. Geophysics, 27(4), 455-462.

Karato, S.-i., \& Wu, P. (1993). Rheology of the upper mantle: A synthesis. Science, 260(5109), 771-778.

Kaufmann, G., Wu, P., \& Ivins, E. R. (2005). Lateral viscosity variations beneath Antarctica and their implications on regional rebound motions and seismotectonics. Journal of Geodynamics, 39(2), 165-181. 
Keary, P., \& Brooks, M. (1992). An introduction to exploration geophysics. Blackwell series, London.

King, C., Hall, B., Hillebrand, T., \& Stone, J. (2020). Delayed maximum and recession of an east antarctic outlet glacier. Geology, 48(6), 630-634.

LaFehr, T. (1991). Standardization in gravity reduction. Geophysics, 56 (8), 1170-1178.

Lamb, S., Moore, J. D., Perez-Gussinye, M., \& Stern, T. (2020). Global Whole Lithosphere Isostasy: Implications for Surface Elevations, Structure, Strength, and Densities of the Continental Lithosphere. Geochemistry, Geophysics, Geosystems, 21(10), e2020GC009150.

Lawrence, J. F., Wiens, D. A., Nyblade, A. A., Anandakrishnan, S., Shore, P. J., \& Voigt, D. (2006). Crust and upper mantle structure of the Transantarctic Mountains and surrounding regions from receiver functions, surface waves, and gravity: Implications for uplift models. Geochemistry, Geophysics, Geosystems, $7(10)$.

Lawver, L., \& Gahagan, L. (1994). Constraints on timing of extension in the Ross Sea region. Terra Antartica, 1(3), 545-552.

LeMasurier, W. E., Thomson, J. W., Baker, P., Kyle, P., Rowley, P., Smellie, J., \& Verwoerd, W. (1990). Volcanoes of the Antarctic Plate and Southern Ocean (Vol. 48). American Geophysical Union.

Lewis, A., Marchant, D., Ashworth, A., Hemming, S., \& Machlus, M. (2007). Major middle Miocene global climate change: Evidence from East Antarctica and the Transantarctic Mountains. Geological Society of America Bulletin, 119(11-12), 1449-1461.

Li, X., \& Götze, H.-J. (2001). Ellipsoid, geoid, gravity, geodesy, and geophysics. Geophysics, 66(6), 1660-1668.

Lillie, R. J. (1999). Whole Earth Geophysics. An Introductory Textbook for Geologists. Lowrie, W. (1997). Fundamentals of geophysics. Cambridge University Press.

MacElroy, C., \& Rose, G. (1987). Geology of Beacon Heights: Southern Victoria Land, Antarctica. Science Information Publ. Centre, DSIR.

Marchant, D. R., Denton, G. H., BOCKheIM, J. G., WILSON, S. C., \& KERR, A. R. (1994). Quaternary changes in level of the upper Taylor Glacier, Antarc- 
tica: Implications for paleoclimate and East Antarctic Ice Sheet dynamics. Boreas, 23(1), 29-43.

McGinnis, L., \& Mudrey Jr, M. (1975). Summary of drilling activities December 1974 - February 1975. Dry Valley Drilling Project (1975). Bulletin No. 5, 11-15.

McGinnis, L. (1979). Initial report on a refraction seismic study in western McMurdo Sound. Unpublished.

McGinnis, L. (1980). Seismic refraction studies in western McMurdo Sound. Antarctic Journal of the US, 15(5), 11.

McGinnis, L., Bowen, R., Erickson, J., Allred, B., \& Kreamer, J. (1985). East-West Antarctic boundary in McMurdo Sound. Tectonophysics, 114(1-4), 341-356.

McKelvey, B. (1981). The lithologic logs of DVDP cores 10 and 11, eastern Taylor Valley.

McKelvey, B., Webb, P., \& Kohn, B. (1977). Stratigraphy of the Taylor and lower Victoria Groups (Beacon Supergroup) between the Mackay Glacier and Boomerang Range, Antarctica. New Zealand journal of geology and geophysics, 20(5), 813863.

Montaj, G. O. (2004). Gm-sys version 7.0 gravity and magnetic modeling software user guide. beaverton: Northwest geophysical associates. Geosoft Incorporated.

Moritz, H. (1980). Geodetic reference system 1980. Bulletin géodésique, 54(3), 395-405.

Mudrey Jr, M. (1974). Summary of drilling activities December 1973 - February 1974. Dry Valley Drilling Project. Bulletin No. 3, 9-12.

Nagy, D. (1978). Direct gravity formula for the geodetic reference system 1967. Bulletin géodésique, 52(2), 159-164.

Nagy, D. (1966). The prism method for terrain corrections using digital computers. Pure and applied geophysics, 63(1), 31-39.

Näränen, J., \& Amos, M. (2019). Absolute Gravity Measurement Campaign at Ross Island, Antarctica, 14-27 November 2018.

Natural Resources Canada. (2012). Precise point positioning. Retrieved April 14, 2020, from https:// www . nrcan .gc .ca/maps - tools - publications / tools / geodeticreference-systems-tools/tools-applications/10925\#ppp 
NovAtel Inc. (2015). Precise point positioning (ppp). Retrieved April 14, 2020, from https : / / www . novatel . com / an - introduction - to - gnss / chapter - 5 - resolving errors/precise-point-positioning-ppp/

Obryk, M., Doran, P., \& Priscu, J. (2014). The permanent ice cover of Lake Bonney, ntarctica: The influence of thickness and sediment distribution on photosynthetically available radiation and chlorophyll-a distribution in the underlying water column. Journal of Geophysical Research: Biogeosciences, 119(9), 1879-1891.

O’Donnell, J., Selway, K., Nyblade, A. A., Brazier, R., Wiens, D., Anandakrishnan, S., Aster, R., Huerta, A. D., Wilson, T., \& Winberry, J. P. (2017). The uppermost mantle seismic velocity and viscosity structure of central West Antarctica. Earth and Planetary Science Letters, 472, 38-49.

Pappa, F., Ebbing, J., Ferraccioli, F., \& van der Wal, W. (2019). Modeling satellite gravity gradient data to derive density, temperature, and viscosity structure of the Antarctic lithosphere. Journal of Geophysical Research: Solid Earth, 124(11), 12053-12076.

Pederson, D., G, M., \& C, E. (1981). Aeromagnetic survey of Ross Island, McMurdo Sound, and the Dry Valleys.

Péwé, T. L. (1958a). Pleistocene glacial chronology of the McMurdo Sound region, Antarctica, In Symposium on antarctic research, new zealand national committee for the igy, wellington.

Péwé, T. L. (1958b). Quaternary glacial geology of the McMurdo Sound region, Antarcticaa progress report. IGY Glaciological Rept, 1, 1-4.

Péwé, T. L. (1960). Multiple glaciation in the McMurdo Sound region, Antarctica: A progress report. The Journal of Geology, 68(5), 498-514.

Plume, R. (1978). A revision of the existing stratigraphy of the New Mountain Sandstone (Beacon Supergroup), south Victoria Land, Antarctica. New Zealand journal of geology and geophysics, 21 (2), 167-173.

Priestley, K., \& McKenzie, D. (2013). The relationship between shear wave velocity, temperature, attenuation and viscosity in the shallow part of the mantle. Earth and Planetary Science Letters, 381, 78-91. 
Priestley, K., McKenzie, D., \& Ho, T. (2018). A Lithosphere-Asthenosphere Boundary - a Global Model Derived from Multimode Surface-Wave Tomography and Petrology. Lithospheric discontinuities, 111-123.

Ritzwoller, M. H., Shapiro, N. M., Levshin, A. L., \& Leahy, G. M. (2001). Crustal and upper mantle structure beneath Antarctica and surrounding oceans. Journal of Geophysical Research: Solid Earth, 106(B12), 30645-30670.

Robinson, E. S. (1964). Correlation of magnetic anomalies with bedrock geology in the McMurdo Sound area, Antarctica. Journal of Geophysical Research, 69(20), 4319-4326.

Roy, S. K. (2010). Fundamentals of surveying. PHI Learning Pvt. Ltd.

Scheinert, M., Ferraccioli, F., Schwabe, J., Bell, R., Studinger, M., Damaske, D., Jokat, W., Aleshkova, N., Jordan, T., Leitchenkov, G., Et al. (2016). New Antarctic gravity anomaly grid for enhanced geodetic and geophysical studies in Antarctica. Geophysical Research Letters, 43(2), 600-610.

Shen, W., \& Ritzwoller, M. H. (2016). Crustal and uppermost mantle structure beneath the United States. Journal of Geophysical Research: Solid Earth, 121 (6), 43064342 .

Shen, W., Wiens, D. A., Anandakrishnan, S., Aster, R. C., Gerstoft, P., Bromirski, P. D., Hansen, S. E., Dalziel, I. W., Heeszel, D. S., Huerta, A. D., Et al. (2018a). The crust and upper mantle structure of central and West Antarctica from Bayesian inversion of Rayleigh wave and receiver functions. Journal of Geophysical Research: Solid Earth, 123(9), 7824-7849.

Shen, W., Wiens, D. A., Stern, T., Anandakrishnan, S., Aster, R. C., Dalziel, I., Hansen, S., Heeszel, D. S., Huerta, A., Nyblade, A., Et al. (2018b). Seismic evidence for lithospheric foundering beneath the southern Transantarctic Mountains, Antarctica. Geology, 46(1), 71-74.

Sissons, B. (1980). Sea ice gravity survey. Victoria University of Wellington Wellington.

Smith, P. M. (1981). The role of the Dry Valley Drilling Project in Antarctic and international science policy. Dry Valley Drilling Project, 33, 1-5.

Smithson, S. B. (1972). Gravity interpretation in the Trans-Antarctic Mountains near McMurdo Sound, Antarctica. Geological Society of America Bulletin, 83(11), 3437-3442. 
Stern, T. A., \& ten Brink, U. S. (1989). Flexural uplift of the Transantarctic Mountains. Journal of Geophysical Research: Solid Earth, 94(B8), 10315-10330.

Stern, T. (1979). Regional and residual gravity fields, central North Island, New Zealand. New Zealand journal of geology and geophysics, 22(4), 479-485.

Stern, T., Baxter, A., \& Barrett, P. (2005). Isostatic rebound due to glacial erosion within the Transantarctic Mountains. Geology, 33(3), 221-224.

Stern, T. A., Lamb, S. H., Moore, J. D. P., Shen, W., \& Yates, A. (2019). Convective Removal of Lithosphere and Uplift of the Transantarctic Mountains, In Agu fall meeting abstracts.

Stern, T., Houseman, G., Salmon, M., \& Evans, L. (2013). Instability of a lithospheric step beneath western North Island, New Zealand. Geology, 41(4), 423-426.

Stern, T. A. (1978). Gravity survey of the Taylor Glacier, Victoria Land, Antarctica.

Studinger, M., Bell, R. E., Buck, W. R., Karner, G. D., \& Blankenship, D. D. (2004). Sub-ice geology inland of the Transantarctic Mountains in light of new aerogeophysical data. Earth and Planetary Science Letters, 220(3-4), 391-408.

Stüwe, K. (2002). Geodynamics of the lithosphere. An introduction. Springer.

Summerfield, M., Sugden, D., Denton, G., Marchant, D., Cockburn, H., \& Stuart, F. (1999). Cosmogenic isotope data support previous evidence of extremely low rates of denudation in the Dry Valleys region, southern Victoria Land, Antarctica. Geological Society, London, Special Publications, 162(1), 255-267.

Swanger, K. M., Marchant, D. R., Kowalewski, D. E., \& Head III, J. W. (2010). Viscous flow lobes in central Taylor Valley, Antarctica: Origin as remnant buried glacial ice. Geomorphology, 120(3-4), 174-185.

Talalay, P. G., \& Pyne, A. R. (2017). Geological drilling in McMurdo Dry Valleys and McMurdo Sound, Antarctica: Historical development. Cold Regions Science and Technology, 141, 131-162.

Talwani, M., Worzel, J. L., \& Landisman, M. (1959). Rapid gravity computations for two-dimensional bodies with application to the Mendocino submarine fracture zone. Journal of geophysical research, 64 (1), 49-59.

Taylor, T. G. (1922). The physiography of the McMurdo Sound and Granite Harbour region. Printed; published by Harrison; sons, ltd. 
Telford, W., Geldart, L., Sheriff, R. E., \& Sheriff, R. (1990). Applied geophysics. Cambridge university press.

ten Brink, U. S., Bannister, S., Beaudoin, B., \& Stern, T. (1993). Geophysical investigations of the tectonic boundary between East and West Antarctica. Science, $261(5117), 45-50$.

ten Brink, U. S., Hackney, R. I., Bannister, S., Stern, T. A., \& Makovsky, Y. (1997). Uplift of the Transantarctic Mountains and the bedrock beneath the East Antarctic ice sheet. Journal of Geophysical Research: Solid Earth, 102(B12), 27603-27621.

Torii, T. (1981). A review of the Dry Valley drilling project, 1971-76. Polar record, $20(129), 533-541$.

Treves, S., \& McKelvey, B. (1974). Drilling in Antarctica, September-December 1974 (tech. rep.). Technical Report. Dry Valley Drilling Project Bulletin 5, 5-8.

Turcotte, D. L., \& Schubert, G. (2002). Geodynamics. Cambridge university press.

van der Wal, W., Whitehouse, P. L., \& Schrama, E. J. (2015). Effect of GIA models with 3D composite mantle viscosity on GRACE mass balance estimates for Antarctica. Earth and Planetary Science Letters, 414, 134-143.

Walcott, R. (1970). Flexural rigidity, thickness, and viscosity of the lithosphere. Journal of Geophysical Research, $75(20), 3941-3954$.

Watson, T., Nyblade, A., Wiens, D. A., Anandakrishnan, S., Benoit, M., Shore, P. J., Voigt, D., \& VanDecar, J. (2006). P and S velocity structure of the upper mantle beneath the Transantarctic Mountains, East Antarctic craton, and Ross Sea from travel time tomography. Geochemistry, Geophysics, Geosystems, 7(7).

Watts, A. B. (2001). Isostasy and Flexure of the Lithosphere. Cambridge University Press.

Whitehead, N. (2010). Montaj Gravity Terrain Correction. Geosoft Incorporated.

Whitehouse, P. L., Bentley, M. J., Milne, G. A., King, M. A., \& Thomas, I. D. (2012). A new glacial isostatic adjustment model for Antarctica: Calibrated and tested using observations of relative sea-level change and present-day uplift rates. Geophysical Journal International, 190(3), 1464-1482.

Whitehouse, P. L., Gomez, N., King, M. A., \& Wiens, D. A. (2019). Solid Earth change and the evolution of the Antarctic Ice Sheet. Nature communications, 10(1), 114. 
Wilch, T. I., Denton, G. H., Lux, D. R., \& McIntosh, W. C. (1993). Limited Pliocene glacier extent and surface uplift in middle Taylor Valley, Antarctica. Geografiska Annaler: Series A, Physical Geography, 75(4), 331-351.

Wilson, G. S. (2000). Glacial Geology and Origin of Fossiliferous-Erratic-Bearing Moraines, Southern Mcmurdo Sound, Antarctica-an Alternative Ice Sheet Hypothesis. Paleobiology and Paleoenvironments of Eocene Rocks: McMurdo Sound, East Antarctica, 76, 19-37.

Winberry, J. P., \& Anandakrishnan, S. (2004). Crustal structure of the West Antarctic rift system and Marie Byrd Land hotspot. Geology, 32(11), 977-980.

Wrenn, J., \& Webb, P. (1982). Physiographic analysis and interpretation of the Ferrar Glacier-Victoria Valley area, Antarctica. Antarctic geoscience, 1091-1099.

Wright, C., \& Priestley, R. E. (1922). Glaciology: British Terra Nova Antarctic Expedition, 1910-1913. Harrison.

Zelt, B., \& Ellis, R. (1999). Receiver-function studies in the Trans-Hudson orogen, Saskatchewan. Canadian Journal of Earth Sciences, 36(4), 585-603.

Zumberge, J., Heflin, M., Jefferson, D., Watkins, M., \& Webb, F. (1997). Precise point positioning for the efficient and robust analysis of GPS data from large networks. Journal of geophysical research: solid earth, 102(B3), 5005-5017. 
